\title{
The Snakes of the Subfamily Dipsadinae
}

BY

\author{
JAMES A. PETERS
}

Published in co-operation with

BROWN UNIVERSITY, PROVIDENCE, RHODE ISLAND
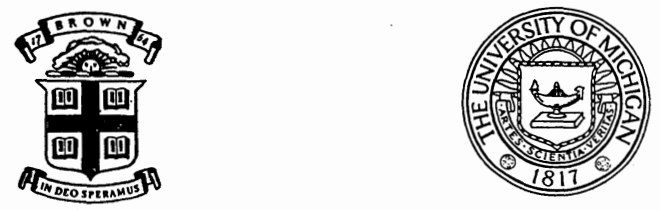

ANN ARBOR

MUSEUM OF ZOOLOGY, UNIVERSITY OF MICHIGAN MAY 25,1960 


\section{MISCELLANEOUS PUBLICATIONS MUSEUM OF ZOOLOGY, UNIVERSITY OF MICHIGAN}

The publications of the Museum of Zoology, University of Michigan, consist of two series-the Occasional Papers and the Miscellaneous Publications. Both series were founded by Dr. Bryant Walker, Mr. Bradshaw H. Swales, and Dr. W. W. Newcomb.

The Occasional Papers, publication of which was begun in 1913, serve as a medium for original studies based principally upon the collections in the Museum. They are issued separately. When a sufficient number of pages has been printed to make a volume, a title page, table of contents, and an index are supplied to libraries and individuals on the mailing list for the series.

The Miscellaneous Publications, which include papers on field and museum techniques, monographic studies, and other contributions not within the scope of the Occasional Papers, are published separately. It is not intended that they be grouped into volumes. Each number has a title page and, when necessary, a table of contents.

A complete list of publications on Birds, Fishes, Insects, Mammals, Mollusks, and Reptiles and Amphibians is available. Address inquiries to the Director, Museum of Zoology, Ann Arbor, Michigan.

\section{List of Miscellaneous Publications on Reptiles and Amphibians}

No. 8. The amphibians and reptiles of the Sierra Nevada de Santa Marta, Colombia. By AleXander G. Ruthven. (1922) 69 pp., 12 pls., 2 figs., 1 map... $\$ 1.00$

No. 29. A contribution to a knowledge of the herpetology of a portion of the Savanna Region of Central Petén, Guatemala. By L. C. StuART. (1935)

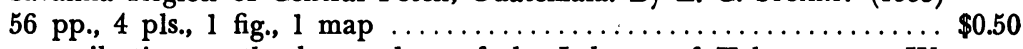

No. 47. A contribution to the herpetology of the Isthmus of Tehuantepec. IV. An annotated list of the amphibians and reptiles collected on the Pacific slope during the summer of 1936. By NoRman Hartweg AND

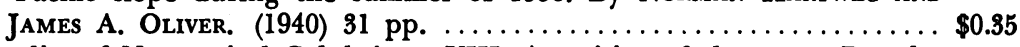

No. 49. Studies of Neotropical Colubrinae. VIII. A revision of the genus Dryadophis Stuart, 1939. By L. C. StuART. (1941) 106 pp., 4 pls., 13 figs.,

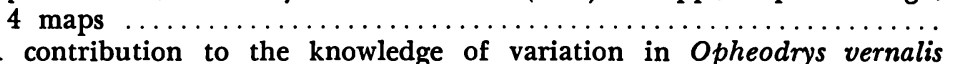

No. 50. A contribution to the knowledge of variation in Opheodrys vernalis
(Harlan), with the description of a new subspecies. By ARNOLD B. GROB

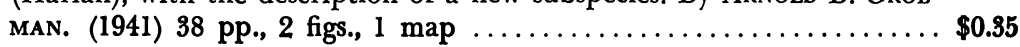

No. 56. Taxonomic and geographic comments on Guatemalan salamanders of the genus Oedipus. By L. C. StuART. (1943) 33 pp., 2 pls., 1 map .... $\$ 0.35$

No. 61. Home range, homing behavior, and migration in turtles. By FRED R. CaGle. (1944) 34 pp., 2 pls., 4 figs., 1 map .................. $\$ 0.35$

No. 69. The amphibians and reptiles of Alta Verapaz, Guatemala. By L. C. Stuart. (1948) 109 pp., 10 figs., 1 map . . .................. $\$ 1.50$

No. 76. Studies of the black swamp snake, Seminatrix pygaea (Cope), with descriptions of two new subspecies. By Herndon G. Dowling. (1950) 38 pp., 6 figs., 1 map $\ldots \ldots \ldots \ldots \ldots \ldots \ldots \ldots \ldots \ldots \ldots \ldots \ldots \ldots \ldots$ lizards of the genus Anolis: By L. C.

No. 91. A brief review of the Guatemalan lizards of the genus Anolis: By L. C.
Stuart. (1955) $31 \mathrm{pp} . \ldots \ldots \ldots \ldots \ldots \ldots \ldots \ldots \ldots \ldots \ldots \ldots \ldots$
No. 94. The anatomy of the head of Ctenosaura pectinata (Iguanidae). By Thomas M. Oelrich. (1956) 122 pp., 59 figs. .................. $\$ 1.85$

No. 96. The frogs of the hylid genus Phrynohyas Fitzinger, 1843. By WiLliam E. Duellman. (1956) 47 pp., 6 pls., 10 figs., 4 maps .............. $\$ 0.70$

No. 97. Variation and relative growth in the plastral scutes of the turtle Kinosternon integrum Leconte. By James E. MosimanN. (1956) 43 pp., 1 pl.,

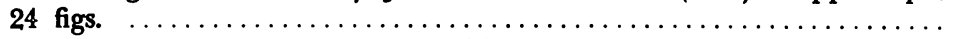

No. 101. A biogeography of reptiles and amphibians in the Gomez Farfas Region, Tamaulipas, México. By Paul S. Martin. (1958) 102 pp., 7 pls., 7 figs.,

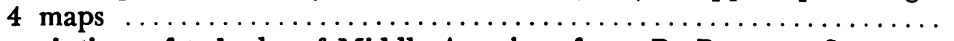

No. 110. Descriptions of tadpoles of Middle American frogs. By Priscilla Starretr.

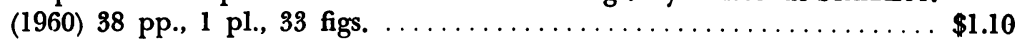

No. 111. A systematic study of the lizards of the deppei group (Genus Cnemidophorus) in México and Guatemala. By William E. Duellman and John Wellman. (1960) 80 pp., 1 pl., 16 figs. .................. $\$ 1.75$

No. 112. A Revision of the Ecuadorian Snakes of the Colubrid Genus Atractus. By JAY M. SAvage. (1960) 86 pp., 11 figs. ........................ $\$ 2.00$

No. 114. The Snakes of the Subfamily Dipsadinae. By James A. Petrrs. (1960) 228 pp., 8 plates, 11 figs., 12 maps. 



\title{
The Snakes of the Subfamily Dipsadinae
}

\author{
$B Y$ \\ JAMES A. PETERS \\ Published in co-operation with \\ BROWN UNIVERSITY, PROVIDENCE, RHODE ISLAND
}
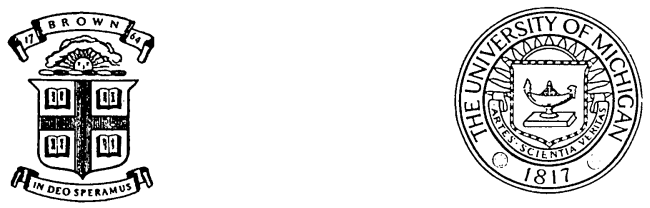

ANN ARBOR

MUSEUM OF ZOOLOGY, UNIVERSITY OF MICHIGAN MAY 25, 1960 
PRINTED IN THE UNITED STATES OF AMERICA 


\section{CONTENTS}

INTRODUCTION $\ldots \ldots \ldots \ldots \ldots \ldots \ldots \ldots \ldots \ldots \ldots \ldots \ldots \ldots \ldots$

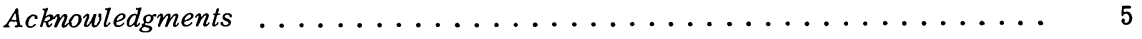

MATERIALS AND METHODS $\ldots \ldots \ldots \ldots \ldots \ldots \ldots \ldots \ldots \ldots \ldots$

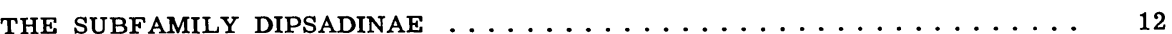

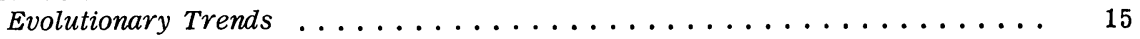

Key to the Genera ........................... 19

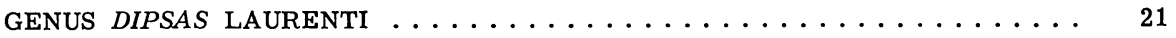

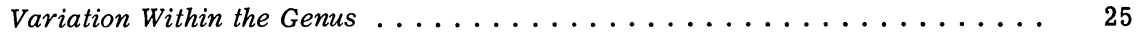

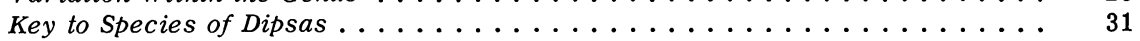

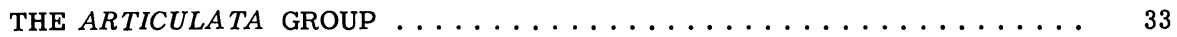

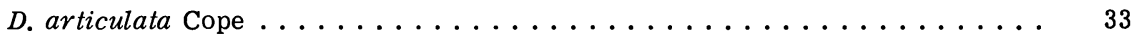

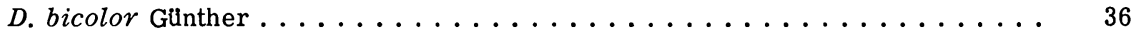

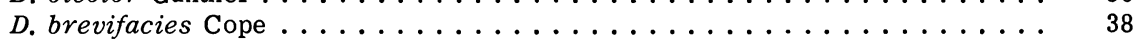

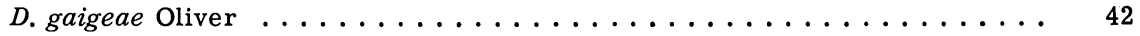

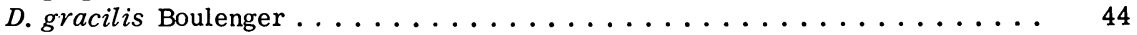

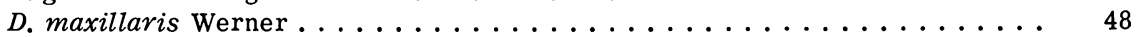

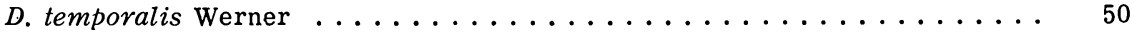

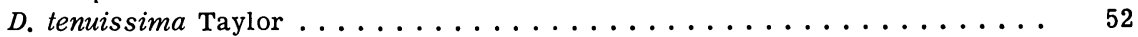

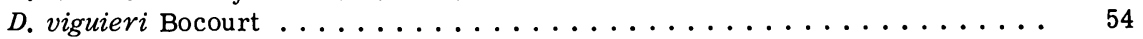

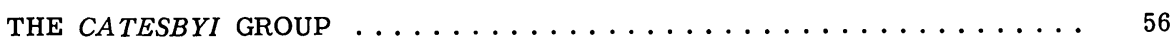

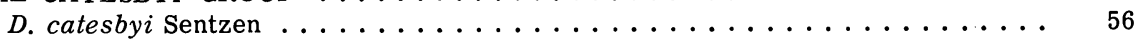

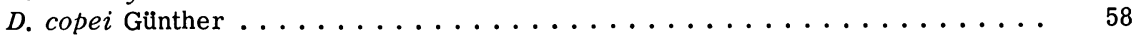

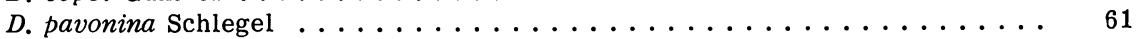

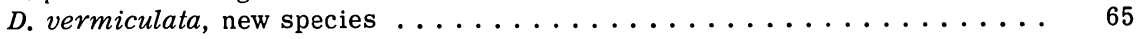

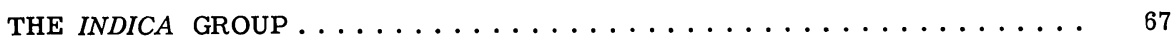

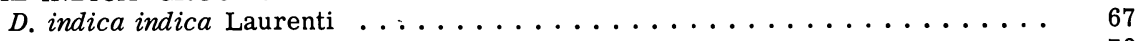

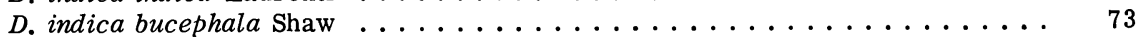

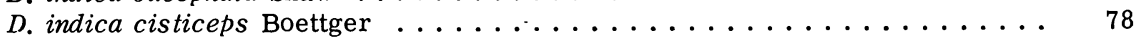

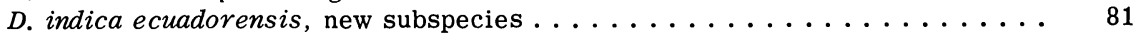

D. neivai Amaral ........................... 85

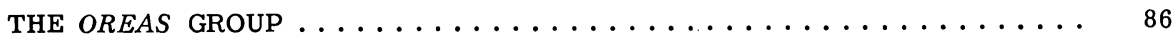

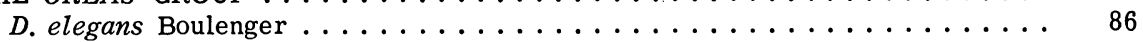

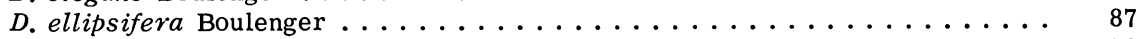

D. oreas Cope ............................ 92

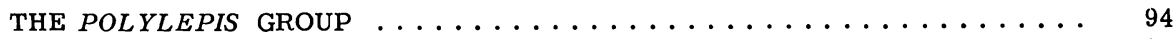

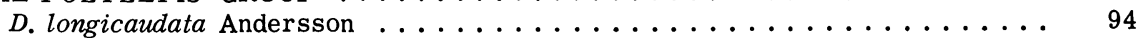

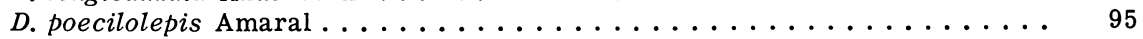

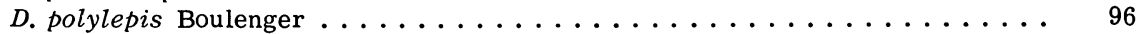

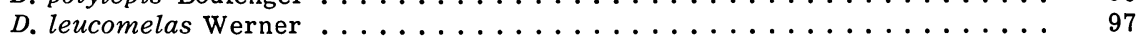

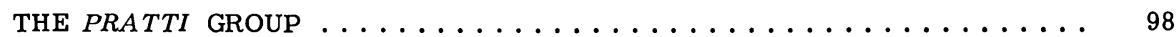

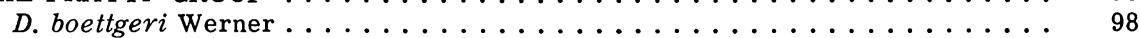

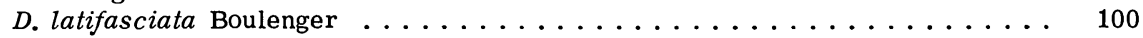

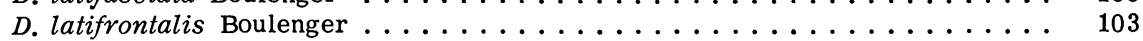

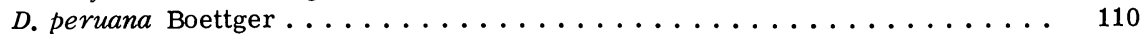

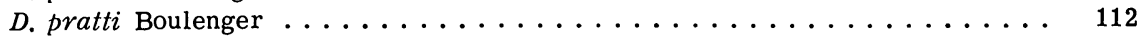

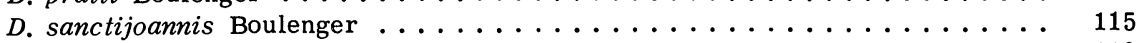

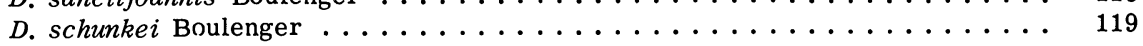


D. albifrons Sauvage $\ldots \ldots \ldots \ldots \ldots$

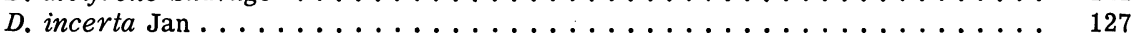

D. variegata variegata Duméril, Bibron and Duméril . . . . . . . . . . . 132

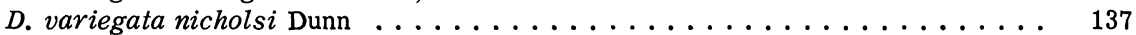

D. variegata trinitatis Parker . . . . . . . . . . . . . . . . . 139

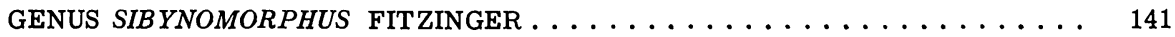

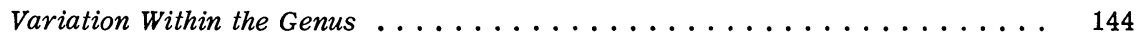

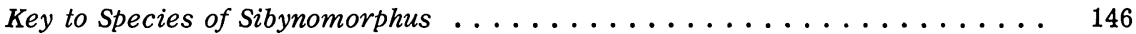

S. inaequifasciatus Duméril, Bibron, and Duméril . . . . . . . . . . . . 146

S. mikani mikani Schlegel . . . . . . . . . . . . . . . . . . . . 148

S. mikani neuwiedi von thering . . . . . . . . . . . . . . . . . . . . 154

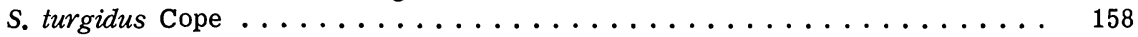

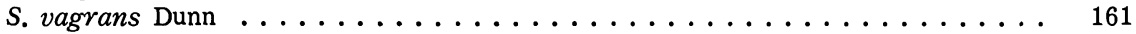

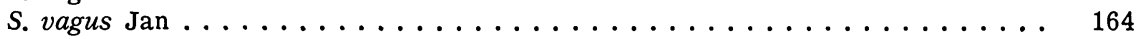

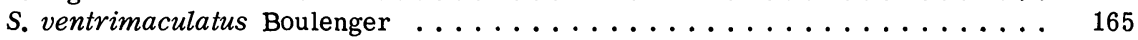

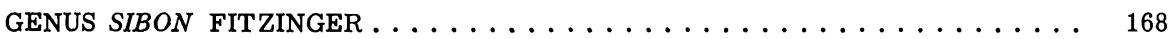

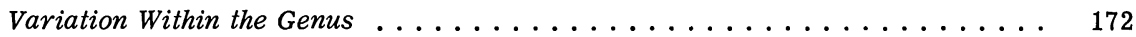

Key to Species of Sibon . . . . . . . . . . . . . . . . . . 175

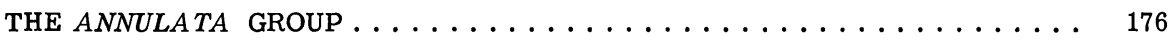

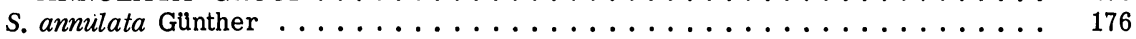

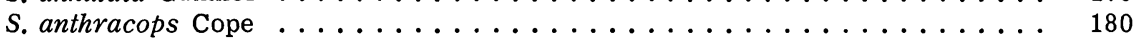

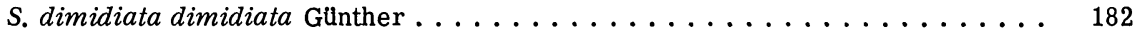

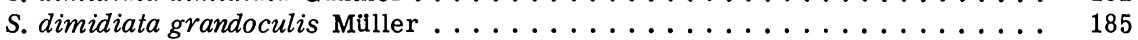

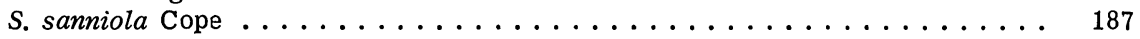

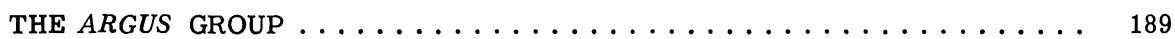

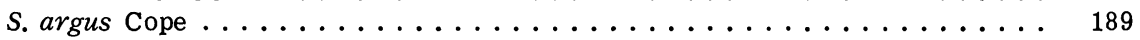

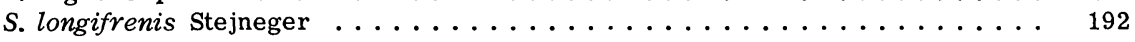

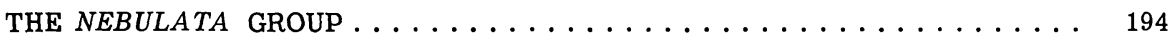

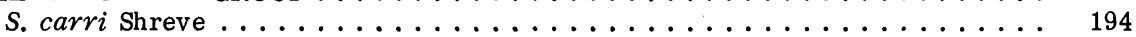

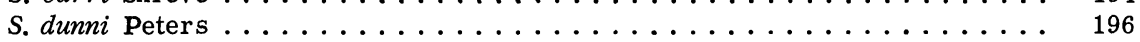

S. nebulata Linnaeus . . . . . . . . . . . . . . . . . . . 197

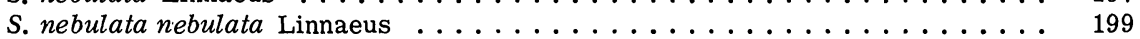

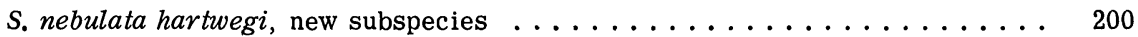

S. nebulata leucomelas Boulenger....................... 202

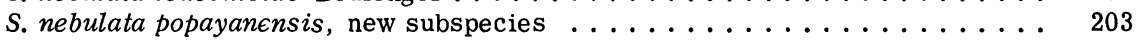

Variation Within the Species Sibon nebulata . . . . . . . . . . . . 205

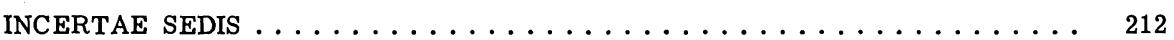

Leptognathus andrei Sauvage . . . . . . . . . . . . . . . 212

Leptognathus brevis Duméril, Bibron, and Duméril . . . . . . . . . . 213

Dipsas infrenalis Rosén . . . . . . . . . . . . . . . . . . . 214

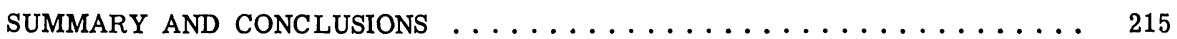

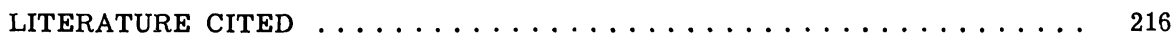




\section{ILLUSTRATIONS}

\section{PLATES}

(Plates I-VIII follow p. 224)

Plate
I. Color pattern in articulata group
II. Color pattern in catesbyi group
III. Color pattern in indica group
IV. Color pattern in oreas group
V. Dipsas peruana, lateral view of head; color pattern in variegata group
VI. Color pattern in Sibynomorphus

VII. -VIII. Color pattern ir nebulata group

\section{FIGURES IN THE TEXT}

1. Dorsum of head in Sibon nebulata ..................

2. Types of division of ventral scales in Dipsadinae ............

3. Sibon dimidiata, S. nebulata, and Dipsas latifrontalis . . . . . . . . . . .

4. Sibon dimidiata, s. nebulata, and Dipsas latifrontalis . . . . . . . . . .

5. Variation in loreal and preocular region in Dipsas brevifacies .......

6. Correlation between sex and point of reduction of dorsal scale rows

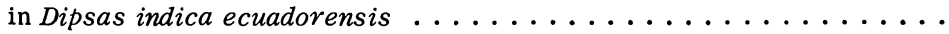

7. Sexual dimorphism in number of subcaudals and point of reduction of caudodorsal scale rows from 6 to 4 in Sibon sanniola. . . . . . . . . . 190

8. Variation in number of ventral scales in Sibon nebulata . . . . . . . . . . . 207

9. Variation in number of ventral scales in Central American population of Sibon nebulata .................... 208

10. Variation in number of subcaudal scales in females of Sibon nebulata . . . 209

11. Variation in number of subcaudal scales in males of Sibon nebulata . . . . 209

MAPS

Map

1. Geographic distribution of Middle American species of the

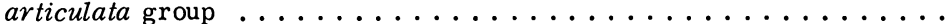

2. Geographic distribution of South American species of the

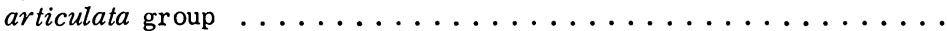

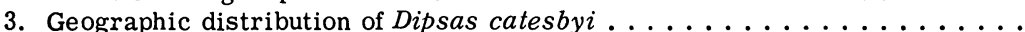

4. Geographic distribution of the catesbyi group .............

5. Geographic distribution of the indica group ...............

6. Geographic distribution of the oreas group except Dipsas elegans ......

7. Geographic distribution of the pratti group ..............

8. Geographic distribution of the southeastern Brazilian species of the variegata group ....................... 122

9. Geographic distribution of Dipsas variegata . . . . . . . . . . . . . 132

10. Geographic distribution of Sibynomorphus species for which localities are known ........................... 143

11. Geographic distribution of the annulata and argus groups of Sibon . . . . 177

12. Geographic distribution of subspecies of Sibon nebulata . . . . . . . . . 198 



\section{THE SNAKES OF THE SUBFAMILY DIPSADINAE*}

\section{INTRODUCTION}

ONE of the many facts made clear in the burgeoning literature of ecology and evolution is that accurate and detailed studies of a fauna cannot be made until all segments of it have been thoroughly investigated taxonomically. This was brought home to me most effectively several years ago when I began an analysis of the herpetofauna of Ecuador. It became obvious that many of the generic and familial groups involved were so poorly known that any work on the region must be preceded by a series of hard scrubbings on some of taxonomy's dirtiest dishes. The study presented here is the first of several that are projected.

I have included all taxa within the Dipsadinae that have been described for Central and South America; I have also inquired into their relationships to amblycephalid species of Asia. The number of revisions of relationships and realignments of species has been considerable, but is a direct consequence of the length of time since the group was studied as a unit. There has been no summary of the species, with descriptions, since Boulenger published his catalogue in 1896. The species described are about twice the number of forms I recognize, and the descriptions are widely scattered, many in little known publications. They have been written in Latin, French, German, Portuguese, Spanish, and English. The literature is widely dispersed and has never been synthesized.

Many of the original descriptions are entirely inadequate and, as a result, several species still remain in the category of incertae sedis. Of 90 species for which data concerning the types are available, 67 (75 percent) were described from a single specimen. For many of them, additional specimens have now been obtained, and further information concerning them can be provided. Many species names were based upon variations that are individual, sexual, or ontogenetic; these have been synonymized for the first time in this study. The number of names that could be utilized so far exceeded the actual number of species, that I have found it necessary to "coin" only five; two for new species and three for new subspecies.

\section{AC KNOWLEDGMENTS}

It is impossible to begin a revisionary study of this type without first enlisting the co-operation of the many curators and caretakers of herpetological study collections throughout the world. I would like to extend my

*A revised version of a dissertation submitted in partial fulfillment of the requirements for the degree of Doctor of Philosophy at the University of Michigan, 1952 .

Accepted for publication, June 13, 1958. 
most sincere thanks to the following persons, who either examined or permitted me to examine material in their care (with the abbreviations used in reference to their specimens in this study): Charles M. Bogert and Mrs. Max Hecht, American Museum of Natural History (AMNH); the late Emmett R. Dunn (ERD) and Robert Sutcliffe, Academy of Natural Sciences of Philadelphia (ANSP); Heinz Wermuth, Berlin Museum; H. W. Parker and J. C. Battersby, British Museum (Natural History) (BMNH); J. R. Slevin, California Academy of Sciences (CAS); M. Graham Netting, Neil Richmond and Grace Orton, Carnegie Museum (CM); the late Karl P. Schmidt, Clifford Pope, and Robert Inger, Chicago Natural History Museum (CNHM); Gustavo Orcés-V., Escuela Polytecnica Nacional, Quito, Ecuador (EPN); Harold Trapido (HT); Edward H. Taylor, University of Kansas Natural History Museum (KMNH); Jánis Roze, Museo de Biología, Universidad Central de Venezuela (MBUCV); Antenor de Carvalho, Museo Nacional do Brasil (MNB); Paulo Vanzolini, Museo Paulista, São Paulo (MP); Lawrence M. Klauber (LMK); Jean Guibé, Museum d'Histoire Naturelle, Paris; Arthur Loveridge and Benjamin Shreve, Museum of Comparative Zoology, Harvard (MCZ); Instituto Polytecnico de México (IPM); James A. Oliver and William Beebe, New York Zoological Society (NYZS); Raymond Paynter, Peabody Museum, Yale (PM); Robert Mertens, Senckenberg Museum (SMF); George S. Myers and Jay Savage, Stanford University (SU); Hobart M. Smith, University of Illinois Museum of Natural History (UIMNH); and Doris M. Cochran, United States National Museum (USNM). Specimens from my collection are abbreviated JAP.

Most of this study was made at the University of Michigan Museum of Zoology (UMMZ), under the direction of Norman Hartweg; it has been completed in the Department of Biology at Brown University, under the chairmanship of J. Walter Wilson. Thanks are due to both of them for the degree of freedom with which I was permitted to do my work. Lawrence C. Stuart and the late Emmett R. Dunn gave freely of their time and furnished herpetological information to assist me. Joseph R. Bailey helped me greatly by obtaining the permission to borrow the collections of the National Museum of Brazil.

All of the line drawings and much of the photography except those of variations in Dipsas brevifacies were done by William Brudon, staff artist of the Museum of Zoology. My indebtedness to him cannot be exaggerated. Other photography was done by William Duellman, Eugene Bell, and myself. I made liberal use of the facilities of the Bureau of Statistical Services at the University of Michigan, and of the Tabulating Office of Brown University, and wish to thank the authorities in charge.

\section{MATERIALS AND METHODS}

With the exception of certain types and material in collections not open for loan, I have examined all preserved specimens in the United States. I have also received (on loan) collections from several institutions and individuals in South America and Europe. In all, I have seen some $1200 \mathrm{spec}-$ imens that I consider to belong to the Dipsadinae. While I have observed 
and collected living snakes of several of the species, the material has, for the most part, been preserved in alcohol. Hence, the color descriptions are based on dead specimens, but whenever possible, information concerning the color in life has been added under each species heading. Skulls were removed from those specimens for which there was ample material. In some snakes only the maxillo-pterygo-palatine arch on one side of the head was removed.

Oliver's (1948:166) definition and use of the terms "normally" and "usually," as he applied them "to describe conditions that exist in 75 per cent or more of a population," have been adopted for the present study. In descriptions of individual species I have included all characters that are "usual" in this sense but without mention of variation. Discussions of variation follow the descriptions.

In the synonymy of each species I have cited only the original description, the names of forms that I consider synonymous with it, and the different combinations under which the species and its synonyms have been mentioned. Each citation is by author, date, and page.

Methods of measuring and counting the various characters are explained below. Dorsal head scale terminology is in accord with accepted practices. Measurements of head scales (see Fig. 1) were made with vernier calipers under a dissecting microscope as follows: (1) Greatest depth and width of rostral; (2) width of prefrontals and internasals, at the widest point, which is usually at the outer ends of their posterior sutures; (3) length of prefrontals and internasals, along their mutual sutures and, therefore, not always an expression of their greatest length; (4) length of frontal, along middorsal line, from anteriormost to posteriormost tip; (5) width of frontal, at the widest point, which is always at the anterior end and is actually the length of the anterior margin; (6) and the greatest length of parietal, regardless of shape. Most of these measurements, often used by earlier workers with dipsadine snakes and prominent in their descriptions, are quite variable, and for the most part represent only modest expressions of the relationships between the scales and the shortening of the head. I found them of little use except as supplemental to descriptions of species that had been based upon more distinctive characters.

Sex was determined by dissection. There are no completely reliable external sex indicators in these snakes, even though sexual dimorphism is pronounced in certain characters.

Because the scales on the side of the head have been subject to a greater degree of change than those of the dorsum, they require a more detailed discussion. The nasal is not at all uniform in its appearance, and the various degrees of division are distinguished. If a suture passes through the nasal opening and separates the scale into two parts the nasal is regarded as "divided"; if the suture is completely absent it is considered "entire" or "single." Quite often only the upper or lower half of the suture is present, with the scale complete on the opposite side of the nostril. This condition is referred to as "semidivided" nasal. The character of the nasal seems to have a degree of specific affinity, although in some species all three types of division occur.

If there is only a single scale between the nasal and the orbit, it is 


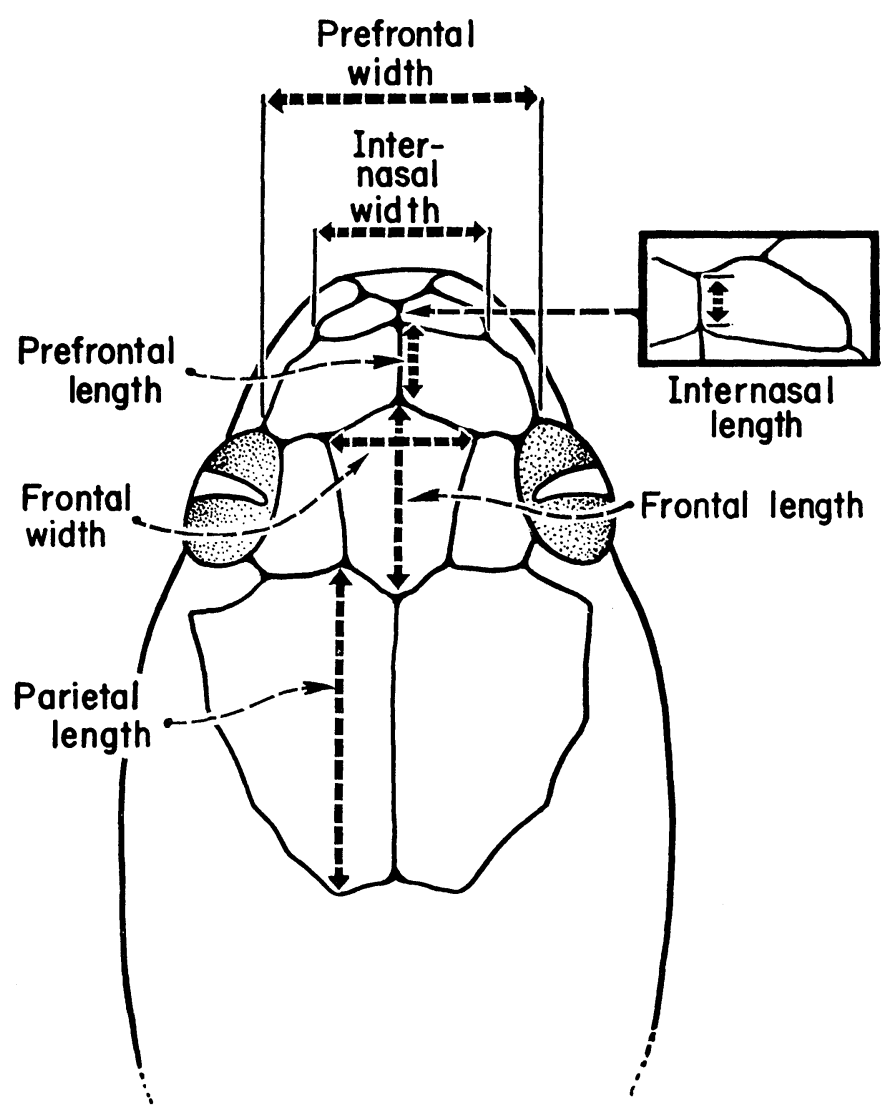

Fig. 1. Diagram of dor sum of head in Sibon nebulata (UMMZ 87612) showing method of measuring scales.

referred to throughout this study as a loreal. Such has been the practice among most students of dipsadine snakes, although a few workers have persisted in calling it a preocular. This single scale may be considered to represent a fused preocular and loreal, but I believe that the preocular has actually been lost, for when both preoculars and the loreal are present, the loreal is obviously the larger scale, and dominates the snout region.

The suboculars are of two types. The first is the presubocular and is in the anterior corner of the orbit, under either the loreal or a preocular. 
Now, a presubocular is any scale between the upper labials and the loreal in the species with the loreal entering the orbit. In species with the loreal excluded from the orbit by preocular scales, however, proper designation of the lowermost scale is sometimes difficult. On the one hand, any scale in the preocular row that is entirely below a line drawn along the lower margin of the loreal is called a "subocular;" on the other hand, any scale that extends above that line is called a "preocular," regardless of the depth to which it may descend into the labial row. The above is the first type of subocular. The second type, the postsubocular, is directly below the postoculars, and appears to be either part of the postocular row or to be split off the upper end of a labial (which seems to be true of the presubocular also). Again, if the entire scale is below the posterior edge of the orbit, it is called a subocular. In my species discussions both preoculars and postoculars are called "suboculars."

The temporal region is of sufficient taxonomic importance to warrant a detailed analysis of its variations. I include in the count of the temporals only those scales that actually lie between the upper labials and the parietals. Other scales in the temporal region are considered to be posttemporals. There may be as many as three rows of temporal scales; these are considered as primary, secondary, and tertiary temporals. The presence or absence of tertiary temporals is of considerable taxonomic and phylogenetic significance. There is often a tiny scale inserted at one of the junctions of sutures in the temporal region. This scale is found most frequently between the postoculars, the primary temporals, and the upper labials, and is of some taxonomic significance in the species Dipsas indica. Similar scales are often inserted elsewhere in the temporal rows. The temporals themselves are subject to fusion and division, both horizontally and vertically. "Fractionation" is the term that I have applied to vertical division of a single scale, in recognition of the symbols used to indicate that such is the case. For example, if the secondary temporals are given as $1 / 2$, it signifies that the upper scale is of normal size, whereas the lower scale has been divided vertically into two scales.

Labial counts were made according to standard practices. The lower labials were counted to the posterior margin of the last upper labial whenever need for arbitrary selection existed.

The small, unpaired scale following the mental plate in some of the species of Sibon is called a "postmental" in this study. Gloyd (1940:14), who encountered a similar problem in terminology, called the small scale a "submental," paired scales in the postmental region "divided first infralabials," and a small scale following these divided infralabials an "intergenial." Although his interpretation of the paired scales as having arisen by division off the ends of the first labials is probably correct, and has been used to explain the similar phenomenon in species of Dipsas and Sibon, they are considered paired chin shields in this study. I do not use term intergenial; it has no parallel in the dipsadine snakes.

The scale reductions for both dorsal rows and caudodorsals are expressed in the latest refinement of the formula proposed by Dowling (1951a). I have introduced a slight simplification in the tabulation of variation in the point of reduction of the caudodorsals. Since the reduction from 6 to 4 
scales and from 4 to 2 is quite uniform in the scale rows involved, it is possible to express the range of subcaudals marking the point of reduction by listing the extremes, without regard to side. For example, the caudodorsal reduction formula for males of the species Dipsas albifrons is:

$$
\underline{6} 2+3(10-24) \underline{4} 1+2(58-78) \underline{2}(82-92)
$$

This means that the reduction from 6 to 4 rows occurs by fusion of the second and third scale rows at points between the 10th and 24th subcaudals, regardless of side.

The degree of enlargement of the vertebral row of scales varies from species to species within the subfamily, and may vary in a single individual, depending on the number of dorsal scale rows present. The literature is replete with references to the degree of enlargement, which has been called "scarce", "moderate", "strong", or "broad", usually with no indication as to what these terms meant to the individual author. I have attempted to stabilize my usage in the following manner. "Not enlarged" indicates that the scales of the vertebral row are the same size as the other dorsal scales; "scarcely enlarged", that the vertebrals are slightly wider than the dorsals; "moderately enlarged", a range from vertebrals that are obviously larger than the dorsals to vertebrals that are not quite as broad as long; "broadly enlarged", that vertebrals are approximately twice as broad as long; and "strongly enlarged" that vertebrals are obviously more than twice as broad as long.

I have employed the system of counting ventral scales suggested by Dowling $(1951 b)$, in spite of the fact that the actual situation existing in the throat region is not strictly comparable to that in the colubrid snakes he examined. The ventrals in the dipsadine snakes are either immediately in contact with the paired chin shields or narrowly separated from them by unpaired gulars, and there are never regular rows of scales such as depicted in Dowling's figure (1951b). The usefulness of the method is not obviated by this discrepancy, however, and it does provide a consistent method. In general, it has resulted in my counts running slightly lower than those of other authors, since the unpaired gulars were incorporated in the ventral count by most earlier workers. For this reason, any ventral count taken from literature that I have not been able to verify is enclosed in parentheses.

The ventrals are frequently divided, and there are six different types of division that can take place (Fig. 2). Type 1 is an actual insertion of a half ventral between the ends of two normal ventral scales, and usually involves a slight narrowing and indentation of the anteriormost of the latter. Type 2 is a simple division of a single ventral, so that it resembles the normal condition in the subcaudal scales. Type 3 involves a bifurcation of the end of a single ventral, with the suture running almost to the midline, and the ventral is usually broader where double. Type 4 is similar to Type 1, but the extra scale is confined to the midventral line, and does not connect with a dorsal scale row. Type 5 is similar to Type 3, but adds a complete suture between the bifurcated end and the normal portion, and the two completely isolated scales are not larger than the single one adjoining them. Type 6 

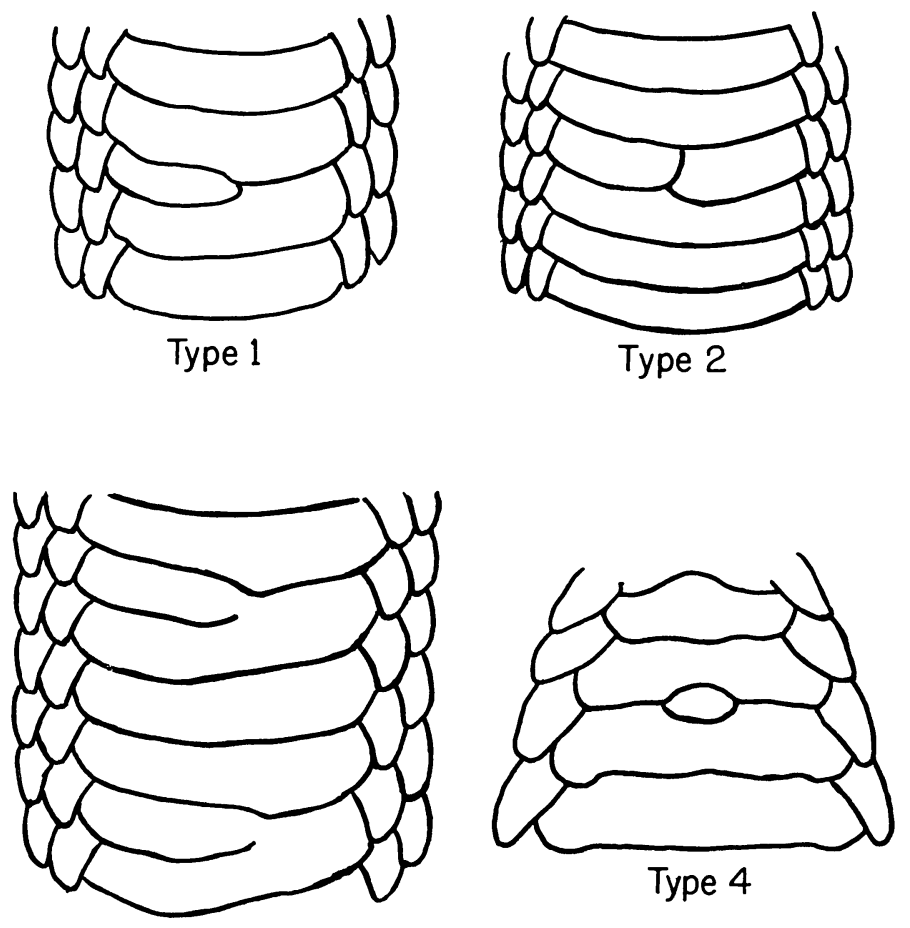

Type 3
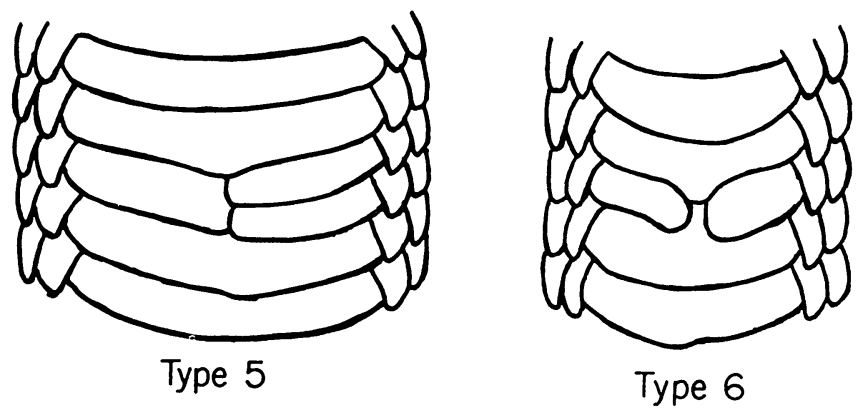

Fig. 2. Types of division of ventral scales in Dipsadinae. 
is similar to Type 2, but there is no overlap between the inner ends of the two half scales, and the ventral anterior to them often extends part way into the gap between them. It seems likely that Type 6 results from two scales of Type 1 occurring opposite one another.

\section{THE SUBFAMILY DIPSADINAE}

Cephalophes Fitzinger (part), 1843: 27. Subfamilial headings, called "Gen." by Fitzinger, for this group are "Dipsadomorphus" and "Dipsas."

Ophidiens Aglyphodontes, Leptognathiens Duméril, 1853: 68.

Dipsadidae Günther (part), 1858: 162.

Dipsadinae Cope (part), 1860: 264.

Leptognathinae Cope, 1886:484. Included in the family Colubridae.

Colubridae, Cope, (part), $1887 \mathrm{~b}: 66$. Cope included no subfamily designations in this paper.

Amblycephalidae, Boulenger (part), 1890: 414; Mahendra, 1938: 350 et seq.

Xenodontinae Cope (part), 1893: 481. Included in the family Xenodontidae.

Colubridae Aglyphae Günther (part), 1885-1902(1893): 87.

Colubrinae, Boulenger (part), 1893: 177 et seq.; Smith and Taylor (part), 1945: 29. Included in the family Colubridae.

Dipsadinae Amaral (part, non Cope), 1923: 95; Schmidt, 1950: 83.

Ophiinae Dunn (part), 1928: 20.

NOMENCLATURAL HISTORY. - Schlegel (1837) combined most of the arboreal snakes into his single genus Dipsas; this was the first attempt to set this group off as a separate entity. Since his arrangement is based almost entirely on external morphology, it runs afoul of the extreme parallelism exhibited by snakes modified for tree climbing.

Fitzinger's family Cephalophes is an extremely large and cumbersome grouping, and he made some of the same mistakes that Schlegel did. This arrangement in his so-called "Gen." grouping, which appears to be equivalent to a subfamily, shows that he had grasped many of the anatomical distinctions between the arboreal forms: under "Dipsadomorphus" he included genera that are for the most part fairly closely related; however, under "Dipsas" he placed Dipsas indica (as bucephala) but gave it the generic name "Pholidolaemus."

Duméril (1853), although he misapplied nearly all the generic names now used in this subfamily, did recognize the existence of a distinct grouping of aglyphous snakes, which he called the "Leptognathiens." It included almost all the forms now considered to be dipsadines, on the generic level at least. The name for his family is based upon the generic name Leptognathus, which was later discovered to be preoccupied by a genus of fishes and, therefore, not available for the family or subfamily.

Günther misused the generic name Dipsas and ignored the existence of the name Sibon. But he recognized the existence of a larger unit, which he termed the "Dipsadidae." All of the snakes he called Leptognathus remain in the subfamily today. None of the snakes he called Dipsas belongs to the subfamily, however, nor do most of the genera he included, such as Leptodeira, Thamnodynastes, Dipsadomorphus, Rhinobothryum, and others.

Cope (1860) based his Dipsadinae primarily on Günther's family discussed above, with a few alterations. The genera he included were Boiga, 
Imantodes, Tripanurgus, Dipsas, and Sibon. This is one of the few occasions when Cope used the generic name Dipsas in the sense that Laurenti intended in his original description of the genus, and he included three species still in the subfamily today (as "Sibon nebulatus, Dipsas pavonina and "Dipsas" brevis [see section "Incertae sedis"]). He' used Sibon for the snakes now known as Leptodeira, however, and none of the other genera fits into the modern conception of the subfamily. When he revised the family Colubridae in 1886, however, he had stopped following Laurenti in his application of the name Dipsas, and had substituted Leptognathus for it; thus, his subfamily designation became Leptognathinae. Later (1893:481), Cope discarded this subfamily and included the genera Leptognathus and Mesopeltis in his Xenodontinae, which at that time he considered to be the only subfamily of the Xenodontidae. He again revised this arrangement (1895:201 et seq.), when he re-established the Leptognathinae as distinct from the Xenodontinae, and as a member of the Colubridae. This arrangement, chiefly based upon the character of the hemipenis, is the first in which all the genera (Petalognathus, Leptognathus, and Mesopeltis) assigned to the subfamily remain members of it. Petalognathus and Mesopeltis are now considered to be synonyms of Sibon.

In the interim, Boulenger (1890) had combined all snakes with nondivergent pterygoids in the Amblycephalidae, which Günther (1864:324) had originally described as a unit composed of Old World species. Boulenger included "Dipsadomorus" and Leptognathus as tropical American representatives and Amblycephalus and Haplopeltura as Asian genera. Later $(1896 a: 438$ et seq.) he included the same genera, but with the name "Dipsadomorus" replaced by the correct name, Dipsas, and added a new genus, Pseudopareas. The genus Sibon, which he called Petalognathus, was included in the Colubrinae, of the family Colubridae.

Amaral (1923:95) described the genus Heterorhachis. He believed it to bridge the gap between the Amblycephalidae and Colubridae of Boulenger, and reduced the former to the status of subfamily of the Colubridae, using the name Dipsadinae for it in recognition of Laurenti's earlier generic name. In this subfamily he included Dipsas, Amblycephalus, Sibynomorphus, Aplopeltura, Pseudopareas, and Heterorhachis.

In the present study, the Dipsadinae is considered to be entirely Neotropical, and this requires that Amblycephalus and Aplopeltura be removed from Amaral's list and replaced in the Asiatic family Amblycephalidae. Pseudopareas is combined with Sibynomorphus, which is restricted to forms found south of the Amazon basin in Brazil. Dipsas is somewhat less inclusive than is generally regarded by those who combined Sibynomorphus and Dipsas, following Parker (1926), but is more inclusive than the genus as set up by Amaral (1929), since most of the species from northern South America that he put in Sibynomorphus have been transferred to Dipsas. About half of the Central American species of Dipsadinae, those considered by most authors to be Dipsas or Sibynomorphus, I have transferred to Sibon, which also belongs to the Dipsadinae.

REMARKS. - The snakes belonging to this subfamily have long been recognized as a group, characterized in its greatest degree of specialization by extremely short, parallel pterygoid bones, strongly compressed 
body, broad, flattened head with protruding eyes and elliptical pupils, and complete absence of the mental groove. These specializations are accompanied by many other changes in external and internal morphology, and provide in many forms an easy tool for identification of the members of the group. In spite of these well-known facts, there has always been a great amount of difficulty encountered by taxonomists in assigning species and defining the group. It would appear at first glance that the difficulties arise from improper application of generic names, with a resultant disproportionate amount of shifting about of forms, but this is not so. Because the species names included in this unit have, for the most part, remained the same throughout all the generic and familial shuffling that has taken place, it indicates that systematists have recognized affinities and units as such, even though they have not all handled them in the same fashion.

The basis behind the consistent difficulties, one that has tormented not only workers concerned with the dipsadine snakes, but with all the Colubridae, is the persistence of intermediate forms. Because some species resembling intermediate stages in the development of the highly specialized, monophagous, arboreal forms such as Dipsas indica continue to survive, the sequence of events in dipsadine evolution can be followed fairly closely. The subfamily provides an interesting study for the evolutionist, but the situation within it forces the taxonomist to select a point of separation between its members and closely related colubrids. Amaral (1923:95) believed that his new genus Heterorhachis was of peculiar interest, because, as he said, "it shows characteristics belonging to both families Colubridae and Amblycephalidae. It agrees with the Colubridae in having rather long and slightly diverging pterygoids, and with the so-called Amblycephalidae in having hypophyses present only anteriorly and no mental groove. It may suggest the suppression of the family Amblycephalidae, the different genera of which should be included in a new subfamily of the Colubridae." Amaral attached too much significance to the "long and slightly diverging pterygoids" of his specimen. All of the species that are considered to belong to the genus Sibon in this study possess long and divergent pterygoids similar to those of Sibon nebulata. In all of them the degree of divergence is certainly equal to that of nebulata, but in none is there the articulation between the pterygoid and the quadrate found in that species. They all have a fairly strong cartilaginous connection, however, and it is apparent that the situation in nebulata precedes that of the species in which the pterygoid connection becomes lost. The connection in nebulata is not as strong, nor is the angle of divergence as great, as that in most colubrid snakes. With the exception of nebulata, all of the species that I consider to be members of the genus Sibon were placed in the Dipsadinae and in the genus Sibynomorphus by Amaral (1929), without comment on their pterygoid condition. It seems likely that he had no opportunity to examine them, for they are certainly more "colubrid" than is his genus Heterorhachis. The mental groove is retained by most of them, to a certain degree, and the scales of the first pair of chin shields retain a crescentic shape, as in Sibon nebulata.

The genus Sibynomorphus, as understood here, has nondivergent pterygoids, but does not have the compressed body exhibited by members of the Sibon group. Also, the mental groove is absent and the vertebral row is 
usually moderately enlarged. The genus Dipsas shows a sequence of variation, but for the most part the species fulfill the classic definition for dipsadines, that is, nondivergent pterygoids, absence of a mental groove, compressed body, large distinct head, and enlarged vertebral row of scales correlated with lower number of scale rows. Species still exist with a higher number of scale rows correlated with narrow vertebral scales. There is also a sequence in the loss of teeth on the pterygoid, for some species of Dipsas have teeth over the greater part of the bone while others lack them.

\section{EVOLUTIONARY TRENDS}

The directions taken by the evolutionary processes within this subfamily, as expressed in the morphology of its species, are quite clear cut. There have been two principal trends within the group: the first toward a more efficient food-getting mechanism and the second toward, primarily, a more efficient arboreal existence. Practically every change in character that has been used by previous authors as demonstration of relationships between species on the American continent and between those of Neotropical and Oriental genera is strongly adaptive. Each can be correlated with significant changes in habits or habitat and as such conceivably occurs in unrelated forms of similar habits or habitat.

I. The first principal trend in the changes that have taken place in the dentition and the dentigerous bones in the snakes of this subfamily have all been directed toward a more efficient mechanism for feeding on molluscans. The slimy condition of these food animals in their naked state is such that their predators must be able to maintain a very secure grip on them during the entire eating process. I have never found any food other than slugs and de-shelled snails, with snails definitely in the minority, in the stomach contents of any of these snakes, regardless of species. Beebe (1946:24-25) found land snails, soft-bodied wood roaches, and ants in the stomachs of dipsadine snakes. Development of monophagy is perhaps one of the best nonmorphological indications of extreme specialization.

Changes in morphology which have accompanied this development of monophagy are (1) the turning inward of the maxillary bone, (2) the freeing of the posterior end of the pterygoid, (3) the loss of teeth on the pterygoid, (4) the development of a hingelike joint on the dentary, and (5) several changes in musculature of the temporal and chin region. The first of these, the turning inward of the maxilla, forming a shelf under the eye, and the directing of the maxillary teeth inward toward the center of the mouth, seems to be an adaptation for firmly grasping the prey, particularly the kind of prey that is not a great deal larger than the normal gape of the predator. In snakes that feed on rats, mice, and birds, all of which may be several times larger in diameter than their snake predators, the teeth are in a vertical plane, with the tips directed backward, and in such a position they provide a double grip when the lower jaw is disengaged at the symphysis and the distance between upper and lower jaws is great. In this iype of snake, the lower and upper jaws work forward over the prey in unison by 
sides, and the snake "walks" its mouth over its food. When the prey is small, as with slugs, it is quite possible that symphysial disengagement of the lower jaw may not often be necessary. Hence, the diagonal inward direction of the maxillary teeth becomes very advantageous in maintaining a grip, since there is no expansion over the prey to provide a holding mechanism in itself.

The second, the freeing of the posterior pterygoid, that is, the loss of the junction of the pterygoid with the quadrate-mandible joint, is a characteristic of all species except nebulata in this subfamily. It can, perhaps, also be explained by the necessity for continuous maintenance of a firm grip. When the pterygoid is connected with the lower jaw through the quadrate, the action of the two in unison (as described above for nondipsadine colubrid snakes) appears to be compulsory. In fact, such bilateral unison of jaw movements may account for the persistence of the character of attachment in snakes in general. If the end of the pterygoid is detached from the quadrate, separate and isolated movements by any single component of the toothed structures (that is, the maxillopterygoids and the dentaries) becomes possible. Thus, it would be definitely advantageous to slug-eating snakes to be able to move a single component at a time while maintaining a triangular grasp with the other three.

The third, the loss of teeth on the pterygoid bone is directly correlated with the shortening of the bone itself. In the species of Sibon that retain a definite angle in the pterygoid, with the posterior tip extending toward the quadrate, the teeth are always present, and extend from the anterior end of the bone to the point of divergence. Tooth counts run as high as 24 in these species. In the members of Dipsas that have kept a moderately long pterygoid but show no divergence, the teeth do not extend all the way to the posterior end and there are fewer of them. In members of the variegata group the number of teeth is reduced, with incerta the only form having more than ten. In those of the indica group the pterygoid is rather short, does not extend beyond the posterior margin of the brain case, and has no teeth on it. Possibly, loss of attachment to the quadrate made teeth upon the posterior part of the pterygoid a liability as far as swallowing is concerned, a liability compensated for by the gain in ability to manipulate the maxillae and lower jaws independently.

The fourth, the development of an apparent hinge on the mandible which provides the dentary with independent movement. This was noted by Dunn (1952:356), who commented as follows: "It appears to me that there is a functional hinge between the anterior (dentary-splenial) part of the lower jaw and the posterior (compound bone) part. It is unfortunate that no one has seen this hinge in operation. If the tip of each mandible could operate independently of the hind half there might be some functional correlation with loss of the mental groove, and loss of the pterygoid-mandible connection." Mertens (1952a) summarized the literature on snail-eating snakes. He saw a juvenile Dipsas albifrons seize the body of a snail close to the shell, and extract it easily, by chewing movements of the jaws, in only one or two minutes. Mertens did not discuss the actual mechanics of jaw movements or of tooth position.

Whether or not a functional hinge actually exists, certainly the anterior 
elements are weakly attached to the posterior, and stripping of tissues from the margins of the bone often results in lifting the posterior edge of the dentary completely away from the "compound bone." There does not seem to be this freedom in the species indica, however, which is the most highly specialized member of the genus Dipsas in all other respects, but I have observed the hinge in the pratti, oreas, catesbyi, and articulata groups. In latifrontalis, a member of the pratti group, the dentary not only appears to be hinged to a certain extent, but there is also a distinct curvature in the posterior end of the mandible. This curvature is even more strongly emphasized in ellipsifera, a member of the oreas group. Indeed, in that species, the curvature is so great that lines drawn parallel to the ends form close to a $90^{\circ}$ angle. It is probable that this curvature is related to the free movement of the dentary. Unfortunately, skulls of all species were not available to determine the extent of its development throughout the genera concerned.

The fifth, the modifications in jaw musculature that have taken place in conjunction with the other changes have been discussed by Haas (1931). He pointed out that in both Leptognathus (=Dipsas) and Petalognathus (=Sibon) there is a peculiar elongation of the adductor mandibulae which he called the M. adductor externus superficialis. He found that this elongation inserts on the dentary bone (rather than on the rear part of the mandible). Although this is similar to the situation in Amblycephalus, it should be noted that the origin of the muscle in both Dipsas and Sibon is postorbital, whereas in Amblycephalus it has migrated to a preorbital position. A somewhat similar condition exists in Sibynophis and Xenopeltis (Haas, 1938: 77 ), both of which are considered to be quite distinct phylogenetically from any of the above mentioned genera. Dunn (1952:356) discussed the probable function of this muscle and its correlation with the hinged-jaw development, and he suggested that the muscle be known as the "abductor dentalis" in reference to its function.

In addition to the one discussed above, I have noticed in several species the presence of a muscle which passes from the posterior ventral margin of the mandible diagonally across the chin to the tip of the opposite dentary. It forms a chiasma with its counterpart on the other side, and inserts on the tip of the dentary. It appears to be identical with that called the $M$. intermandibularis by Lubosch (1933:618). Lubosch represented it as extremely short in his drawing of the situation in the colubrid genus Dryophis, but in the dipsadines I examined it is quite long and appears to function as an "adductor dentalis," in opposition to the "abductor dentalis" of Dunn.

Loss of the mental groove, which is complete in the snakes of the genus Dipsas and partial in those of Sibon, is probably directly correlated with the changes in the morphology and anatomy of the head discussed above, although possibly it is an indirect consequence of the shortening of the head, with a resultant crowding of the scales on the lower jaw. Gans (1952:233) discussed the functional significance of the disappearance of the mental groove in Dasypeltis. In that genus, at least, the loss of the mental groove provides a rigid structural unit that facilitates the ingestion of eggs, and Gans theorized that the unit can be pushed forward under the egg through intrinsic pressures, thus permitting the snake to swallow the egg without 
external surfaces to push against. Gans also suggested that the loss of the mental groove in earthworm- and slug-eating snakes is an adaptation providing for a reduction in gape. It seems plausible, however, that reduction in gape is only part of the advantage gained for it is likely that the loss of the mental groove adds rigidity in Dipsas just as it does in Dasypeltis.

This rigidity perhaps compensates in part for the increased mobility of all the toothed bones.

II. The second principal trend in the evolutionary history of the snakes of this subfamily is toward an arboreal existence. Modifications for this purpose have been focused in over-all body shape and proportions, with a few scale changes of importance. Some of these adaptations are: (1) compression of the body, (2) elongation of the body and tail, (3) abrupt narrowing of the body back of the head, (4) ability to direct the eyes downward, and (5) widening of the vertebral scale row.

First, the compression of the body is least noticeable in the members of the genus Sibynomorphus which, although they show most of the dipsadine characters indicating malacophagy, generally lack the lateral flattening so typical of the members of Sibon and Dipsas. Seemingly, they do not lead as totally an arboreal existence as do others of the subfamily. Since practically nothing is known concerning their habits, they cannot be discussed profitably at this time. In all other dipsadines, the body is strongly compressed laterally, so that in cross section it appears ovate or even oblong. The structural importance of compression is discussed below in conjunction with the development of the widened vertebral row, since there appears to be a strong correlation between the two characters.

Second, the elongation of the body and tail seems to be a fairly obvious modification for life in trees. It has occurred in several distinct groups of snakes, many of which were grouped by Schlegel (1837) into a single genus, called Dipsas, based on that character. This is perhaps the most clear-cut example of parallelism in a highly adaptive character to be found in snakes today.

Third, the abrupt narrowing of the body immediately posterior to the head serves to give members of this group the appearance of being very broad-headed snakes, which they actually are not. The narrowing is most abrupt in the snakes of the genus Dipsas. In Sibon, it is more gradual, and in Sibynomorphus the head is only moderately distinct from the neck.

Fourth, the eye protrudes to a considerable degree in most species and the lip line below the eye is vertical. Such protrusion appears to be of adaptive value in these arboreal forms, in that it permits looking directly downward without rotation of the head. The maximum development of this ability seems to have been in the indica and articulata groups. The articulata group has a slightly narrower snout to accompany this situation, while in the indica group the snout is shortened.

Fifth and most important of the changes that took place in the evolution of arboreal habits in this group was the widening of the vertebral scale row. In the species with the greatest number of scale rows, such as polylepis, the vertebral row is not enlarged at all. It is often scarcely to moderately enlarged in the forms with 15 scale rows, but it reaches its maximum width in species with 13 rows, which often reduce to 11 posteriorly. The widest 
vertebral row is found in the subspecies of Dipsas indica, again indicating that these are the representatives of the most specialized species in the genus. An interpretation of the importance of the wide vertebrals is based upon the constructional precept that the maximum stress on a supporting column is placed on its dorsal and ventral edges. As a consequence, any widening of these two edges results in an increase in the column's resistance to bending, and a similar relief from stress results from flattening of the sides of the column.

While I have no record of published observations concerning movement from branch to branch of dipsadine snakes, similar movements have been observed in Oxybelis, another arboreal genus with widened vertebrals. Norman Hartweg, who has watched these snakes, has told me that they start from one branch and proceed in a straighi line, with the body held rigid, directly to the next branch. Apparently up to half or more of the body can be extended in this fashion without its bending or falling over. The advantage of the compression of the body combined with the widening of the vertebral row now becomes apparent. The ventrals form a wide ventral edge, the widened vertebrals function to increase the width of the dorsal edge of the body, and the compression of the body is emphasized by tightening of the costal muscles. All contribute to the increase of resistance to bending. This gives the snake the greatest degree of rigidity possible, and permits passage between widely separated limbs in the trees.

As has been pointed out elsewhere, one of the greatest obstructions to a satisfactory analysis of the snakes of this group is that species with nearly every combination of the above characters can be found. Dipsas indica is the only species that possesses all of them. The entire genus Sibynomorphus lacks the major compression of the body and most of the accompanying modifications. The genus Sibon possesses all of the arboreal adaptations, on the other hand, but it has not incorporated all of the changes involved in the freedom of the dentigerous bones. In several species of the genus Dipsas there is little or no widening of the vertebral row, but all have compressed bodies. It seems to be apparent that the lines of evolution have not followed a single path, but started together, and diverged into the various distinct units of the subfamily.

\section{KEY TO THE GENERA}

1. Body more or less compressed, vertebral scale row usually enlarged, head sharply distinct from neck, eye prominent and clearly visible from below . . . . . . . Body cylindrical or only slightly compressed, vertebral scale row not or only slightly enlarged, head only slightly wider than neck, eye moderate, does not protrude over lip line to become visible from below (Pl. VIe)....... Sibynomorphus

2. Labial beneath primary temporal greatly enlarged, higher than other labials, contacts postocular, primary and secondary temporal (Fig. $3 a-b$ ), one posterior lower labial greatly enlarged, extends beyond labial row to contact one of posterior pair of chin shields, mental groove present, although occasionally poorly defined, each scale of first pair of chin shields crescent-shaped, longer than broad (Fig. $4 a-b$ ), not more than a single pair of lower labials in contact behind mental, often none .... Sibon 
No greatly enlarged upper labials, no single labial higher than rest and in contact with postocular, primary and secondary temporals (Fig. $3 c$ ), no enlarged lower labials, mental groove absent, each scale of first pair of chin shields rectangular (Fig. $4 c$ ), often two or more pairs of lower labials in contact behind mental. Dipsas
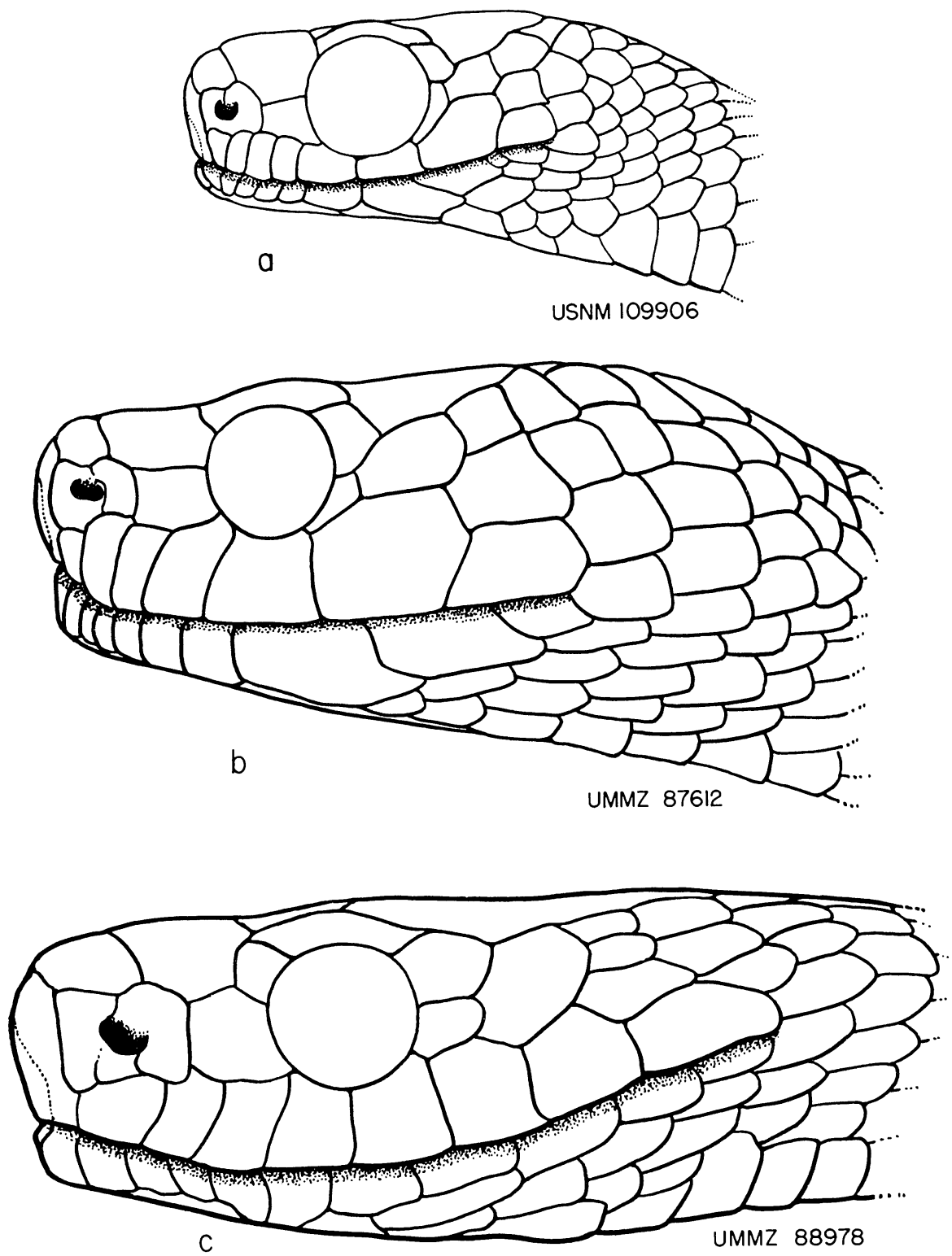

Fig. 3. a: Sibon dimidiala. b: S. nebulala. $a$ Dipsas lalifronlalis. 


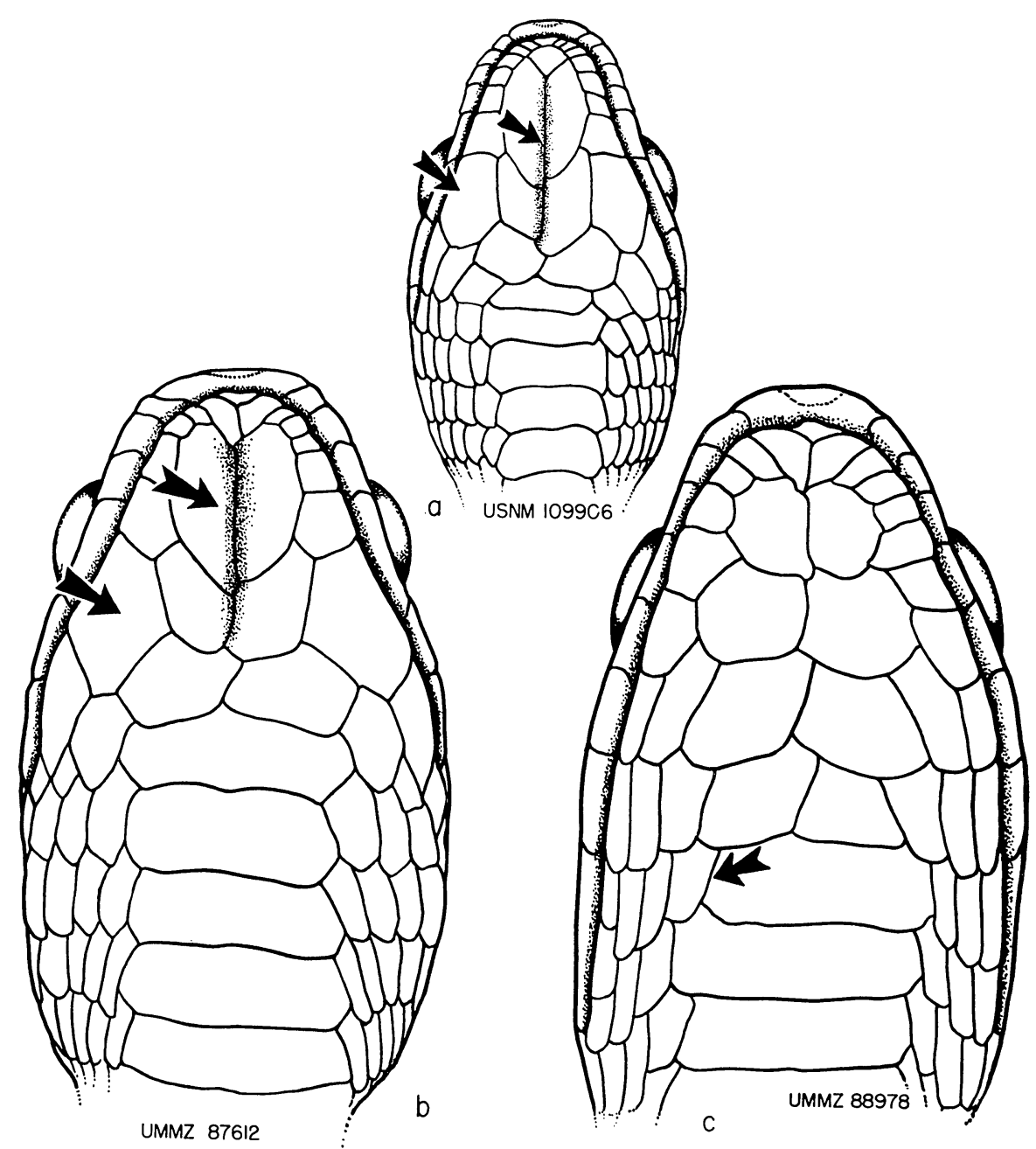

Fig. 4. a: Sibon dimidiata. b: S. nebulata. c: Dipsas latifrontalis. Arrows on $a$ and $b$ point to mental grove, crescentic chin shield, and enlarged lower labial. On arrow indicates small unpaired gular; first ventral follows this scale.

\section{GENUS DIPSAS LAURENTI}

Dipsas Laurenti, 1768: 89. Genotype: indica Laurenti.

Bungarus Oppel (part), 1810: 391. Genotype: none designated, Coluber cenchoa first listed species, genus preoccupied by Bungarus Daudin 1803.

Dipsadomorus Duméril, 1853: 467. Genotype: indicus Laurenti (a new name for this species to replace Dipsas, which he used for a composite group of opisthoglyph snakes). Leptognathus Duméril, 1853: 467. Genotype: Dipsas pavonina (Schlegel) as first species listed. Preoccupied by Leptognathus Swainson, 1839, a genus of fishes. 
Stremmatognathus Duméril, 1853: 468. Genotype: Coluber catesbyi Sentzen, 1796. Pholidolaemus Fitzinger, 1843: 27. Genotype: Dipsas bucephala Boie, 1827 (=Dipsas indica bucephala Shaw).

Neopareas Günther, 1895 (1885-1902): 178. Genotype: Neopareas bicolor Günther. Heterorhachis Amaral, 1923: 94. Genotype: Heterorhachis poecilolepis Amaral. Neoparias Taylor, 1951: 66. In errore for Neopareas Günther.

DESCRIPTION OF GENUS. - Dorsum of head with full complement of colubrid head scales, that is, internasals, prefrontals, frontal, supraoculars, and parietals; nasal may lie in undivided scale, in semidivided scale, or between two scales; loreal always present, often enters orbit; preoculars none, 1 or 2; suboculars variable; postoculars usually 2 , occasionally 3 ; temporals very irregular; upper labials 7 to 11 ; anterior labials usually crowded together and higher than long, labials posterior to eye often longer than high; no single labial in contact with postoculars, primary and secondary temporals (Fig. $3 c$ ). Lower labials narrow, crowded, usually more than 10 , at least one pair in contact behind the mental in all species (except temporalis), of ten 2 or 3 pairs in contact; no single labial greatly enlarged and extending beyond labial row so as to touch posterior chin shields; mental groove lacking entirely, paired chin shields all squarish, irregular.

Body strongly compressed; head distinct from neck, short, blunt, and extremely prominent; eye large with vertical pupil, usually protruding; tail elongate, slim. Dorsal scale rows smooth, without apical pits, may be slightly oblique, varying from 11 to 19 , with reductions, when present, quite irregular (except in two subspecies of Dipsas indica); vertebral row only slightly widened in those with high scale-row counts, strongly widened in those with the lowest; caudodorsals reduce abruptly immediately behind anus to 6 rows, and gradually thereafter to 2 , which is number at tip, points of reduction variable. Ventrals rounded, occasionally split or divided into two parts; anal single; subcaudals in two rows, with occasional fusion.

Color pattern of two kinds, one of broad, complete annuli about the body, usually of extremely contrasting colors, and one of dorsal blotches extending to tips of ventrals or slightly onto ventrals, not fused across belly, often with irregular edges and nonparallel sides, with interspaces often heavily spotted and mottled; some species with ontogenetic color changes.

Hemipenis short, capitate, sulcus spermaticus bifurcate, tip slightly bilobed; proximal portion spinose, with several enlarged and prominent basal spines, distal portion calyculate, with long papillae; collar at border between spinose and calyculate portions rather prominent, producing capitate appearance.

Maxillary with toothed edge directed inward, teeth subequal or increasing slightly in length toward rear; ectopterygoid $\mathrm{Y}$-shaped at anterior end; palatine short, weak, toothed for entire length; pterygoid toothed or not, free from quadrate, not or only slightly divergent toward the quadratomandibular joint, posterior end lies loose in roof of mouth. Mandible with teeth decreasing in length posteriorly; dentary-splenial joined to compound bone by a hingelike joint (in some of the species, at least). Hypapophyses absent on posterior vertebrae.

RANGE. - Southern Brazil, northern Argentina, Paraguay, Bolivia, and Perú north through entire remainder of South America, all of Central 
America, and México as far north as Veracruz on the Atlantic slope and Colima on the Pacific, excluding the highlands of northern Central America and México.

NOMENCLATURAL HISTORY. - The first person to assign the name "Dipsas" to a specific kind of snake, subsequent to the establishment of the binomial system of nomenclature, was Laurenti in 1768. The source of his information concerning the species was Seba's work (1734), and it is fairly certain that Laurenti examined no specimens himself. D. indica was then the only known species and Laurenti followed Seba in considering it to be from Ceylon. A complete discussion of the validity of applying this generic and specific name to a South American form will be found under the remarks section of the description of Dipsas indica indica Laurenti.

The next use of the name was by Lacépède (1789), who discussed a species that he called "Coluber dipsas." The situation seems to be analogous to his usage of the name "Coluber boiga" for Coluber ahaetulla Linnaeus, where "boiga" is actually a vernacular name for the species. It is possible that Lacépède did not intend his usage be considered an application of the binomial system. At all events, the description and the illustration of the species indicate that he did not have a specimen of any of the presently recognized forms at hand, for he refers to the "blue" color of the snake, a color that does not appear in any of the species I have studied.

Shaw (1802) described the bull-headed snake, which he called Coluber bucephalus, also basing his description upon the figures presented by Seba. Fortunately, he and Laurenti used two different figures of the same species, and both of the specific names are applicable to subspecies within indica. Shaw perpetuated Lacépède's use of the name dipsas, referring to it as a "blue snake," but he gave the locality as Surinam.

Gray $(1825: 208)$ placed the genus Dipsas in the family Colubridae, and was the first author to use the name other than monotypically. He included in it three species, two of which are now considered to be subspecies of indica; the other is Dipsas catesbyi.

Fitzinger (1826), recognized Laurenti's genus and listed (p. 59) eight species as members of it, but not indica. He considered the genus fairly closely related to Xiphosoma, Boiga, Dendrophis, and Sibon.

Schlegel (1837) greatly expanded the genus to include all arboreal species with compressed bodies and vertical pupils, regardless of provenance. Schlegel's extremely composite genus has long since been broken up into many components. Of the 25 species, only three are still considered to belong to the genus (catesbyi, pavonina, and bucephala). His classification was based upon highly adaptive characters that arise independently, e.g., compressed body and vertical pupil. Schlegel did discuss the species indica but under the name bucephala, and he indicated that it came from Sumatra. He stated that he had examined two specimens, but (according to the text) his information concerning the provenance of the species was not derived from them but from "les recherches de Sir Stamford Raffles."

Andre Duméril (1853) was the first to divorce the name Dipsas from the snakes to which it had been originally applied. He placed the species that I consider to belong to the genus Dipsas in a family called the "Leptognathiens." The generic name Dipsas was used in the Schlegelian sense, 
with the species bucephala (or indica) omitted. This breach of taxonomic etiquette, that is, the omission of the genotype from the genus concerned is left unexplained by the author. The genus is included among the "Opisthoglyphes." The posterior maxillary teeth are not grooved, of course, in indica, and not a single one of the species included in Dipsas by Duméril is still considered to be a member of that genus.

Günther (1858) included 12 species in the genus Dipsas, none of which are currently recognized as belonging to the genus. He followed Boie, Schlegel and others in the application of the name, and did not cite Laurenti as its original author, but Laurenti's name and the species indica appear under the generic name Leptognathus as being from Sumatra. Günther briefly described a specimen in the British Museum collections, saying nothing that would not apply very well to the South American species. He persisted in this usage of the name in the Biologia Centrali-Americana, and there definitely stated that Boie (1827) is the authority for the name in this sense. The section of the "Biologia" in which this usage by Günther was published was issued in 1895, just a year before Boulenger, also working at the British Museum, fixed the name Dipsas in its present sense.

Cope's first contribution toward determining the status of the genus Dipsas appeared in 1860. He reviewed the various applications of the name, and wrote that "in order to avoid further confusion we have employed it for that to which it was first applied," in the sense, that is, of Laurenti. He considered indica Laurenti to be the typical species and said that, since Günther's arrangement of the species into genera was more natural than others, he would follow it in his work, merely substituting Dipsas for Leptognathus and Boiga for Dipsas, as used by Günther. This is for the most part the arrangement followed later by Boulenger in his "Catalogues," but, oddly enough, Cope himself did not continue to use it, for he later (1887b) followed the practise of applying the name Dipsas to opisthoglyphous snakes. Since that paper was concerned only with Central America and México, all of the species Cope included are members of the genus now known as Imantodes. He did not indicate his conception of the limits of the genus. The species indica was not mentioned since it does not enter the region discussed. A few years later, Cope (1893) published his new classification of the nonvenomous snakes, based upon hemipenial characters. The genus Dipsas, again with no mention of included species, was placed in the Colubridae, a family characterized as having an undivided sulcus spermaticus. This is not true of Dipsas indica and indicates that Cope was continuing the use of the name in the sense of Boie, Schlegel, and Günther. This view was perpetuated (1895) in his "Classification of the Ophidia." In this work Cope credited Laurenti as author of the name Dipsas and the genus serves as the type of the subfamily Dipsadinae and the family Dipsadidae, in the monotypic superfamily Glyphodonta, again referring to the grooved teeth on the rear of the maxillary. The species now considered to belong to Dipsas he included in the subfamily Leptognathinae and the family Colubridae; again, the position of the species indica was not indicated.

Boulenger (1896a) returned the genus to monotypic status, the single species being bucephala Shaw, the name which he apparently preferred to indica Laurenti, since the latter was based upon a mistake as to provenance. 
He considered this genus, Leptognathus, and Pseudopareas as American representatives of the family Amblycephalidae. Leptognathus and Dipsas were separated on the basis of presence or absence of pterygoid teeth. This return to usage in the sense of Laurenti has since been followed by most herpetologists.

Werner (1922) reviewed the species of "Amblycephalidae" and included two species beside indica in the genus Dipsas, infrenalis Rosen and albifrons Sauvage. Amaral (1923) used the genus as type of a new subfamily of the Colubridae, which he called the Dipsadinae. Parker (1926) pointed out that the distinction between Dipsas and Sibynomorphus (which had been substituted for Leptognathus as used by Boulenger) was based on a character that is variable even within a single species, and he combined them under the name Dipsas. Amaral (1929, et seq.) did not accept this combination, but other herpetologists have followed Parker (Prado, 1940a; Smith and Taylor, 1945).

I have also followed Parker in this study, but with certain modifications. Most of the species listed in Amaral (1929) as belonging to Sibynomorphus and all those that Parker used in his comparison of Dipsas and Sibynomorphus are here considered to belong to Dipsas. Since the genotype of Sibynomorphus is the species mikani, however, it has been necessary to use that name for the genus formerly called Pseudopareas, to which mikani has been transferred. In addition, several of the species which previously contributed to the hodge-podge of forms called Dipsas in Central America and México have been transferred to the genus Sibon, where they constitute a more orderly grouping.

\section{VARIATION WITHIN THE GENUS}

In contrast to the genera Sibon and Sibynomorphus, which are composed of fairly closely knit, unified groups of species, the genus Dipsas is a widespread, diversified complex, with seven fairly distinct subgenera or species groups. The differences between the groups are most marked in their coloration, but there are numerous distinctions in scutellation as well. These will be pointed out below.

Division, extra suturing, or fusion takes place in nearly every head scale in this genus. The internasals are occasionally fused to each other, and may also fuse with the prefrontals. The prefrontals aremore often fused to each other, and are more variable, than any other of the dorsal head scales. The fusion of prefrontals has been noticed in the following groups: catesbyi, indica, pratti, and oreas. The nasal may be entire, semidivided, or completely divided, and of ten all three conditions obtain within a single species. Most species have a division of some type, however, either wholly or in part. The loreal enters the eye in all species except sanctijoannis, catesbyi, copei, tornieri, and some individuals of brevifacies. The last species, of those examined, displays the greatest amount of breakup in the loreal region (Fig. 5), which involves not only the loreal but also the preoculars, suboculars, and certain of the upper labials. From the standpoint of the generic diagnosis, the most aberrant species of Sibon is 
sanniola, the only representative of that genus on the Yucatan Peninsula, as is Dipsas brevifacies. Both are peripheral forms, and apparently are a considerable distance from the center of distribution for their respective genera. Since the Yucatán Peninsula was flooded for the most part during the Pliocene and Pleistocene, it is likely that both of these species are of fairly recent origin, and are quite possibly still in a state of evolutionary flux.

The preocular is present as a single scale, above the loreal, in all except the catesbyi group, the variegata group, in which it is typically absent, although occasionally present, and the articulata group, in which it is quite variable from species to species, and even within species, such as brevifacies. In the latter species, the preoculars vary from none to three. In the catesbyi group there are often two and, in the species catesbyi, sometimes three preoculars. The loreal is excluded from the eye occasionally in most of the species belonging to the catesbyi group, and almost invariably in the species catesbyi. The presence of suboculars is not the normal situation in any species except sanctijoannis and viguieri. There are two types of subocular scales, one below the preocular row or the loreal and one below the postoculars. The first is anterior to the labials entering the eye, the second is posterior. Both types occur sporadically within this genus, but the first is the more common. Suboculars occur as variants in the species of the articulata group, but they are not typical of any one species. The postoculars are usually two, but divisions that produce three are not uncommon, and three is usual in bicolor and brevifacies, both in the articulata group. Fusion of the two postoculars into a single scale, fusion of the upper postocular with the supraocular, and fusion of the lower postocular with one of the upper labials have all been observed in this genus, but all are rather rare.

The variation from specimen to specimen in the scales of the temporal region (Fig. 3) is perhaps greater than that exhibited by any other scale or group of scales in this genus. It seems likely that it is a direct result of the shortening and rounding of the head, with a considerable amount of this shortening taking place on the posterior half of the head. The presence or absence of the tertiary temporals seems to be of significance in the phylogeny of these snakes, since they appear to be crowded off the temporal row, and form the first row of posttemporals in the species groups of catesbyi and indica, both of which contain the more highly specialized members of the genus. This shortening of the head is accompanied by an actual shortening of the gape of the mouth, so that the last labial lies below the secondary temporals, and there is no room for the tertiary temporals. Tertiaries are present in all the remaining groups of species. The rest of the temporal region, including the primary and secondary rows, also is subject to the pressures exerted by the shortening of the head, with fusion and division of all sorts extremely common. Fusion has taken place both horizontally and vertically, so that enlarged scales running from the postoculars to the end of the tertiary row, as well as single scales from parietal to labials, have been observed. It is possible that the loss of the tertiary row in indica and others has been due to fusion of that row with the others. The primary and secondary rows in those species that lack tertiary rows are 
not elongate, but on the contrary are small and crowded. No species of the genus Sibon possesses tertiary temporals, and the region is extremely stable and uniform at a single primary and two secondary temporals, the same combination that has either been arrived at or closely approached by the more specialized species groups in Dipsas, such as catesbyi and indica. Fragmentation or fractionation of temporals is quite common in the species of Dipsas, however, but is unusual in Sibon. Fragmentation involves the splitting off of extremely small scales, which are usually wedged into a suture corner between the postoculars and the temporals or between two temporal rows. The amount of fragmentation, or its presence and absence, is of considerable importance within the species group indica, in which there is some correlation with geographic variation and with the various subspecies defined within indica. Fragmentation seems to be much more common in the more specialized subspecies of the species, which are found in the Andean region of South America. Fractionation (vertical splitting of one of the normal scales in the temporal rows) has not been observed in every species, but I suspect takes place in all. Every species, of which I have examined more than five specimens, includes specimens with vertically divided temporals.

Herpetologists working with other colubrid genera have pointed out that variations in upper labial counts are usually due to fusions and/or divisions of labials anterior to the eye. Stuart $(1941: 16)$ said “... loss of labials in Dryadophis is always anterior to the orbit..." Oliver $(1948: 187)$ stated that for the genus Leptophis “... it is apparent that the difference in number of these plates (in reference to upper labials) involves the area anterior to the eye rather than that behind the eye." Ruthven $(1908: 31)$ pointed out that reductions in the number of labials in the gartersnakes took place both anterior and posterior to the eye, however, and suggested that shortening of the head in that group of snakes took place toward the eye, from both ends. He did not think that any fusion has taken place in the labials that enter the orbit, and it is true that two labials enter the orbit in nearly every species of Thamnophis. In the genus Dipsas the number of labials that enter the orbit is variable, a situation that appears to be unique among genera for which the character has been examined in this respect. It can be demonstrated for the dipsadine snakes that reductions from the maximum number of upper labials takes place anterior to, posterior to, and under the eye, all within the same species. This seems to be directly correlated with the fact that the shortening of the head in the genus Dipsas is much more pronounced than that of any other recently studied genus, such as Leptophis or Dryadophis. The immediate ancestor in the Colubridae of the dipsadine snakes almost certainly did not have a shortened head, and it seems likely that all of the shortening has taken place along with the evolution of the subfamily itself. The range of upper labials within the genus is from 6 to 11 , and has been observed within the single species catesbyi, but this is an exceptional situation for any snake species. The extreme variability in the actual number makes correlation with phylogeny, after the fashion of Ruthven (1908) in his work with the gartersnakes, virtually impossible. It is apparent, however, that fusion has not been the method of compensation for the shortening of the head in this genus, since the more specialized forms 
retain high labial counts. The subspecies indica indica, although one of the most specialized forms of the group, retains a normal labial count of 9 . The shortening of the head has rather resulted in compression of labials, with the resultant cramped appearance of those anterior to the eye. Fusion obviously does take place between labials, but it is as an individual variation, and not as a specific character, for the most part. That fusion actually takes place among the labials that enter the orbit can easily be demonstrated. In Dipsas indica indica there are normally three labials entering the orbit; 32 percent have only 2, however, and 2 percent have 4 (see Table $\mathrm{V})$. It seems probable that individuals with only 8 labials, and only 2 in the orbit are indicators of a fusion of labials in the eye, since 9 is the normal number, with 3 of them entering the orbit. It is true, in most of the species at least, that the number of reductions posterior to the eye are in the minority. The labials in that area tend to elongate or shorten in themselves, without fusion between 2 scales.

Variation in the lower labials is similar to that in the upper ones. In all species an apparent crowding together of the anterior labials takes place, and this is particularly prominent in members of the indica group. The first half dozen labials on the tip of the jaw are very narrow, and the number of labial pairs in contact behind the mental is increased to 3 . The range in total number of lower labials within the genus is from 9 to 16 , but most species have more than 10 . The lowest counts occur in the articulata group, and particularly in the species maxillaris and gaigeae, both of which are peripheral in México. Within this species group there seems to be a trend toward reduction in the number of labials toward the north, and also toward the periphery of the range of the genus. The number of labials in median contact with one another behind the mental seems to be correlated with the degree of specialization of the species, for the more specialized the species, the more likely it is that the labial pairs in contact will be multiple (except in the catesbyi group). The groups in which some members have two or more labial pairs in contact behind the mental are: pratti, oreas, indica, variegata, and to a degree, articulata. In the articulata group, there are as many with only a single pair in contact as there are with two, and in addition, one species, temporalis, duplicates the condition in Sibon annulatus, in which there are no pairs of lower labials in contact; a very tiny pair of chin shields is present, however, in the postmental region.

The number of pairs of chin shields is fairly consistently 3 throughout the genus, but members of the articulata group show a strong tendency to have only 2 , and one of its members, bicolor, is the only species in the genus which lacks any pairs at all. Because of this, bicolor has been considered to belong to a separate genus (Günther, 1895:178; Taylor, 1951:66). The condition is, however, a logical consequence of the adaptive changes that take place in this region and does not appear to be any more indicative of generic differentiation than the change from 3 to 2 , which is usually the result of fusion across the midline. The mental groove is absent in all members of the genus, so its apparent loss in bicolor as a result of the fusion is not particularly significant. The chin shields are regularly 4 in the members of the oreas group.

The scales of the dorsum of the body are important in several respects 
insofar as the phylogeny of the group is concerned. This will be discussed in detail elsewhere, but it is apropos here to point out the variations that take place within the species groups.

Little is known about those species with more than 15 dorsal scale rows. Boulenger described polylepis as having 19 scale rows, with no enlargement of the vertebral row. I do not know whether this species has a tertiary temporal row or not. Amaral based his genus Heterorhachis on the extreme heterogeneity of dorsal scale-row counts that he observed in the species poecilolepis. The scale rows vary from 15 to 19 , with a broadly enlarged vertebral row when 15 are present, and a very slight enlargement when there are 19. All of the variation in the scales takes place in the vertebral row, and, as in all dipsadine species, the vertebral row widens at the expense of the paravertebrals. The pratti, articulata, oreas and variegata groups are almost entirely made up of species with 15 scale rows; the only exception is gaigeae, a peripheral form from Colima, México, which has only 13. Oddly enough, the vertebral row is not enlarged in this species. The scale rows are 13 in the catesbyi and indica groups, again with a single exception, copei, with 15 . It is in these groups, and most pronouncedly in the indica group, that the widest vertebral row development takes place. Reductions from the normal number for the species are not uncommon, particularly on the posterior part of the body, and have been observed in every species group. The reduction is most of ten far posterior, just a short distance anterior to the anus, and is correlated with the narrowing of the body in that region. There is always a sharp reduction in number of rows at the anus, of course, and the rows on the tail are not more than 6 from the level of the 5 th or 6 th subcaudal posteriorly. It seems likely that typical reduction in dipsadines is due to the start of the caudal reductions on the extremity of the body, and it does not possess any great significance. It has long been the custom to make the posteriormost count of dorsal scales at least a head length anterior to the anus, in order to eliminate the effects of this caudal constriction. If this practice had been strictly followed in this study, however, it seems likely that some interesting information might have been obscured, and I have instead counted all dorsals from the parietals to the tip of the tail. Perhaps the most remarkable variation in dorsal reductions takes place in the subspecies of indica. In eleven specimens of $i$. cisticeps, eight have a minimum of 13 rows anterior to the anus, the other three have 11. In the subspecies $i$. bucephala only two individuals out of fourteen have any reductions whatsoever, while four have an increase in dorsal count due to the splitting off of a row from the vertebrals. On the other hand, the other two subspecies of indica are characterized by their dorsal reductions. In $i$. indica, 43 of 45 specimens not only show a reduction from 13 to 11, but have it far anterior to the anus, so that the scale rows are 11 over a large part of the body. In the subspecies ecuadorensis only two individuals, of 31 examined, do not have a reduction to 11 rows. There is a slight indication of sexual dimorphism in this subspecies for this character; in females the reduction is usually located more posteriorly.

The range in total ventrals for the genus is from 153 (in ellipsifera) to 218 (in copei). The ranges for the individual groups are, for the most part, only slightly smaller, as for example, in the articulata group, with the range 
162-214, or in the variegata group, with 160-202. Divided ventrals occur in every group, but have not been observed in every species. Type 1 (Fig. 2 ) is the most frequent, and occurs most often on the last ventral anterior to the anus.

The total range for the genus in subcaudal scales is from 60 in both ellipsifera and pratti to 140 in copei. There is a high degree of sexual dimorphism in many of the species for this character, with the males consistently having the higher counts. The caudodorsals also exhibit sexual dimorphism, with the males having the more posterior reduction. This is presumably correlated with the presence of the hemipenis and its retractor muscles in the base of the tail. The females have a short anal gland, generally not reaching any farther back into the tail than to the level of the 5 th or 6th caudal. The reduction in female caudodorsals, from 6 to 4 rows, is usually slightly behind the posterior end of this gland. Typically, the reduction is extremely abrupt at the level of the anus and immediately behind it, from the 15 or 13 scale rows on the body to 6 on the tail. After the 6row condition is reached the rate of reduction is much more gradual, with reductions from 6 to 4 and from 4 to 2 . These are normally bilateral, but occasional individuals from species to species have fusions across the vertebral row. These are discussed as individual variations under the separate species headings.

The principal character used in separating the various species groups is color pattern. There are no striped or unicolor species in the genus, although in the pratti group, with ontogenetic color change, there is a tendency toward complete darkening in the very old adults, which sometimes approaches a unicolor pattern.

In the articulata group, the body is ringed with broad bands, the color of which contrasts strongly with that of the much narrower interspaces (Pl. I). The bands are complete across the belly, although occasionally they alternate along the midline, and in two species fail to meet if opposed. Color, when present in the interspaces, is arranged in distinct spots, usually grouped together. The head is unicolor, usually the same hue as the broad body bands.

The members of the catesbyi group have ovate, dark-brown or black blotches that are often narrow at the middorsal line and at the edges of the ventrals, and usually extend onto the ventrals but do not meet across midventral line, except anteriorly (Pl. II). The interspace color is not strongly contrasting with that of the blotches, but is reddish-brown, and is often quite dark posteriorly. The dorsum of the head is often unicolor, with a white bar across the snout, but is sometimes spotted and variegated. The dorsal scale rows, with one exception, are 13.

The general pattern in the indica group is one of dark triangular or lozenge-shaped blotches, with the wider edge at the ventrals (Pl. II). The interspaces are a lighter brown than the blotches, and usually contain a yellow spot at the junction of the ventrals and first dorsal row, between the ends of the blotches. Another yellow spot is centered on the first scale row of each dorsal blotch. The dorsum of the head varies in pattern from unicolor with a regular group of spots on the posterior dorsal head scales to extremely variegated and mottled - all within the subspecies of the single species indica. 
The species of the variegata group typically have a light pattern, usually of tans and light browns ( $\mathrm{Pl} . \mathrm{V} c, d$, and $e$ ). The blotches are narrow, usually higher than long, and not as wide as the interspaces over the greater part of the body. The interspaces are seldom unicolor, but usually have streaks, spots, and stippling throughout.

In species of the oreas group the blotches are wider than the interspaces, with little contrast in color between them. (Pl. IV $a$ ). The centers of the blotches are considerably lightened, which often gives the species an appearance of having paired ellipses on the sides, looking like this: ( ). The interspaces are rather heavily streaked and spotted with dark colors.

In the pratti group ontogenetic color change seems to be the rule (Pl. IV $b-f ; \mathrm{Pl} . \mathrm{V} a-b)$. The young are often strikingly similar to snakes of the articulata group, with fairly strong contrast between blotches and interspaces, although usually the blotches are not continuous across the belly but end on the edges of the ventrals. As the individuals mature, there is an invasion of the interspaces by darker color, until, in large adults, there is little left of the original interspace color, and there is no distinction between blotch and interspace. However, the blotches have a light border of white or yellow that persists throughout ontogeny. Since the blotches are wider than the interspaces, the final appearance is an almost unicolor animal with thin, paired, white or yellowish lines from vertebral row to ventrals.

As for the polylepis group, little can be said concerning the color pattern until additional information is available. Amaral, in his original description (1923) did not describe the pattern of the species poecilolepis, but in his figure of the head and neck of the species (1926b: Pl. 2) the first two blotches are visible, and it appears that the pattern is similar to that of Dipsas indica, that is, triangulate, with the wide edge ventrally. The description of the color of the type of polylepis given by Boulenger (1912:423) is unlike that of any form that I know of in the genus, and the type will have to be re-examined in the light of the present arrangement to discern its relationships.

\section{KEY TO SPECIES OF Dipsas ${ }^{1}$}

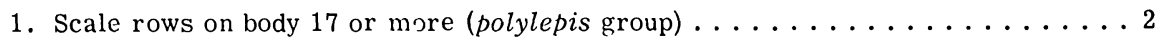

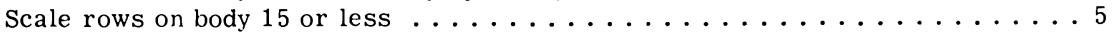

2. Scale rows a consistent number from head to anus.............. Scale rows extremely variable over entire body........... poecilolepis

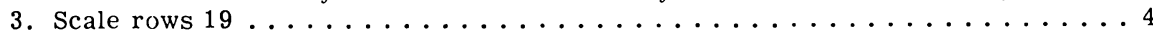

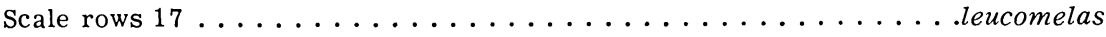

4. Loreal in eye, 9 upper labials, 3 pairs of chin shields, black with whitish cross

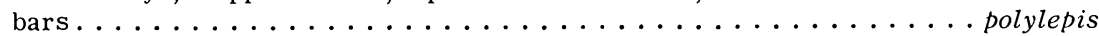
Loreal not in eye, eight upper labials, two pairs of chin shields, broad brown cross

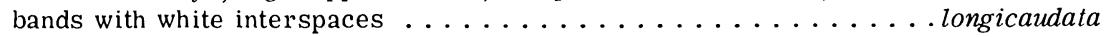

5. Dorsal pattern of broad, dark-brown or black bands that are much wider than interspaces, and are complete (except in temporalis and viguieri) across venter over length of body; interspaces pink or red in life, yellow in preservative (Pl. I-

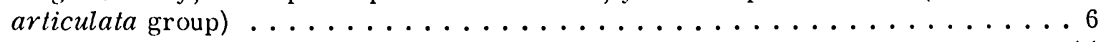
Dorsal pattern not as above ................... 14

${ }^{1}$ Since the species considered Incertae Sedis (p. ) are insufficiently characterized in their original descriptions, it has been impossible to include them in this key. 
6. Scales in 15 rows over greater part of body $\ldots \ldots \ldots \ldots \ldots \ldots \ldots \ldots$ Scales in 13 rows over greater part of body $\ldots \ldots \ldots \ldots \ldots \ldots$ gaigeae

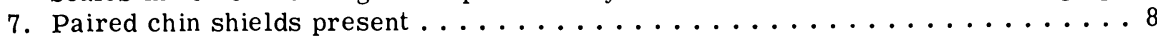
All chin shields posterior to labials in contact single . . . . . . . bicolor

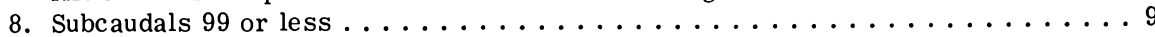

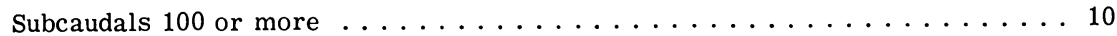

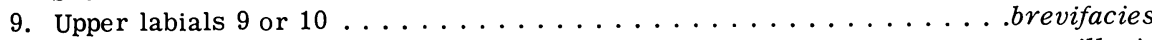

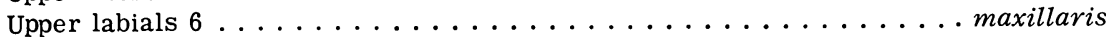

10. At least one pair of labials in contact behind mental .............11 Mertal in contact with paired chin shields .............. temporalis

11. No preocular; usually 2 postoculars; posterior interspaces not or lightly

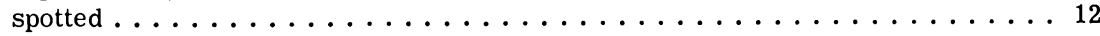
One preocular; usually 3 postoculars; posterior interspaces heavily streaked

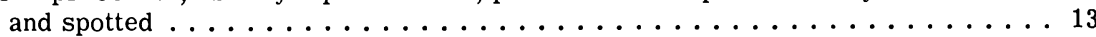

12. Bands on posterior part of body twice as wide as interspaces. . . . . . . gracilis Bands on posterior part of body approximately equal to interspaces . . . . articulata

13. Dorsum of head unicolor dark brown; upper labials $8 \ldots \ldots \ldots \ldots$. . . tenuissima Dorsum of head spotted with white; upper labials 9 or $10 \ldots \ldots \ldots \ldots$. . . viguieri

14. Dorsal pattern of rounded, dark-brown or black blotches or saddles on sides,

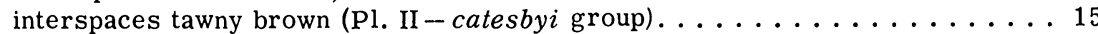

- Dorsal pattern not as above ..................... 18

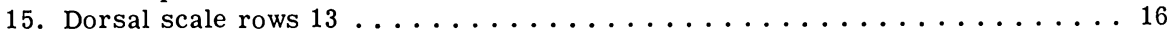
Dorsal scale rows $15 \ldots \ldots \ldots \ldots \ldots \ldots \ldots \ldots \ldots$

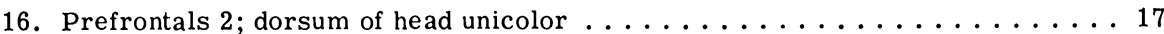
Prefrontals usually fused; dorsum of head variegated and streaked with white

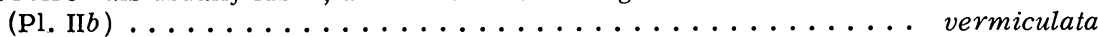

17. Blotches narrower at vertebral row than laterally; loreal does not enter eye

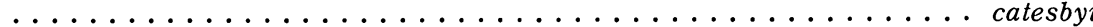
Blotches saddle-shaped, wider at vertebral row than laterally; loreal enters

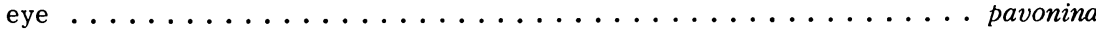

18. Dorsal blotches triangular or lozenge-shaped, usually widest at ventrals, with yellow spot between corners of blotches at ventrals (Pl. III - indica group) . . . 19 Dorsal pattern not as above ...................... 23

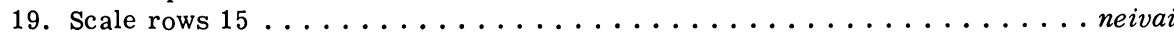

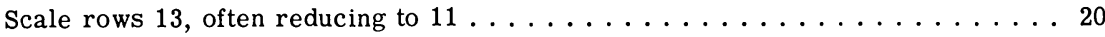

20. Dorsum of head unicolor light brown, or with 3 or 4 dark brown spots on posterior head shields (frontal, parietals, and occipitals) . . . . . . . . . 21 Dorsum of head darker brown, strongly variegated with black and yellow or

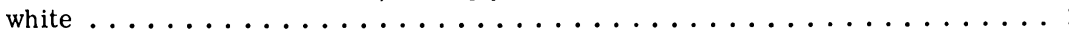

21. Spots on posterior head plates absent or small, occupying less than one quarter

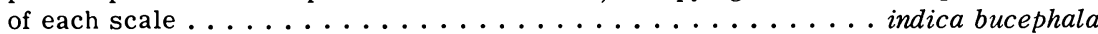
Spots on posterior head plates large, occupying almost entire area of each

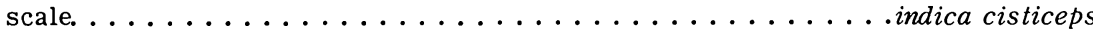

22. Occipital region not streaked, may be spotted, first dorsal blotch broadly fused along middorsal line ..................... indica indica Occipital region longitudinally streaked, first dorsal blotch separated by light line at vertebrals ................... indica ecuadorensis

23. Dorsal ground color of light browns and tans, with narrow blotches that are higher than wide, and much narrower than interspaces (at least posteriorly), interspaces streaked, spotted, or stippled throughout (Pl. V $c-e-$ variegata group) $\ldots \ldots .24$

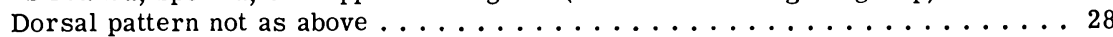

24. Two or more pairs of labials in contact behind mental . . . . . . . . . . 25 A single pair of labials in contact behind mental . . . . . . . . . . incerta

25. Dorsum of head unicolor light tan or with poorly defined darker spots on

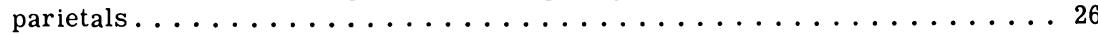
Dorsum of head with dark-brown spot clearly defined on parietal and occipital region, sutures of head scales outlined in brown $\ldots \ldots \ldots \ldots \ldots \ldots \ldots$

26. Small brown spot present on tips of ventrals and first scale rows, alternating with dorsal blotches. ................. variegata trinitatis Spots in interspaces absent or poorly defined, never prominent . . . . . albifrons 
27. Dark-brown spots on head unite on frontals to form U-shaped mark, posterior tips of "U" often fused to first dorsal blotch . . . . . . . . variegata nicholsi Dark-brown spots on head not fused on frontal, do not extend to first dorsal

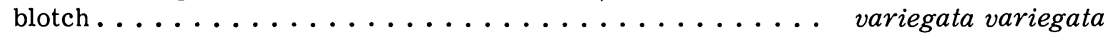

28. Dorsal blotches wider than interspaces, little contrast between them, centers of blotches often considerably lightened, so that blotch resembles paired ellipses

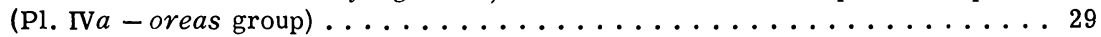
Color not as above (Pl. IV $b-f ; \mathrm{Pl} . \mathrm{V} a-b-$ pratti group) $\ldots \ldots \ldots \ldots \ldots \ldots \ldots$

29. Dorsal blotches extend onto ventrals .................. 30

Dorsal blotches end on first or second scale rows . . . . . . . . . . elegans

30. Centers of dorsal blotches very light, so that blotch resembles paired ellipses, on all individuals ( $\mathrm{Pl}$. IV $a$ ); chin heavily spotted; venter with two parallel dark streaks; ventrals often less than 170 , subcaudals less than 80 (see statement of

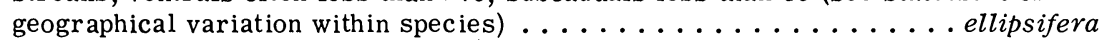

Centers of dorsal blotches lightened only in adults, not in juveniles, and never so light that the blotch resembles paired ellipses; chin not or sparsely spotted; venter with large rectangular blotches between ends of neighboring dorsal blotches; ventrals more than 175 ; subcaudals more than $79 \ldots \ldots \ldots$. . . oreas

31. Loreal enters orbit; no suboculars . . . . . . . . . . . . . . . . . 32 Loreal does not enter orbit: suboculars present. . . . . . . . . sanctijoamis

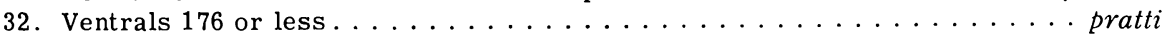
Ventrals 177 or more ....................... 33

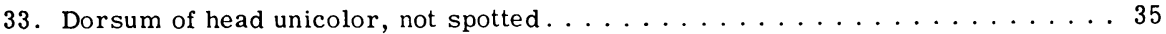

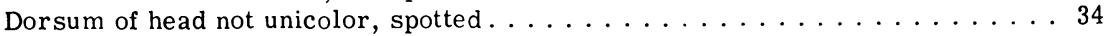

34. Dorsum of head reddish-brown with black spotting ............ boettgeri

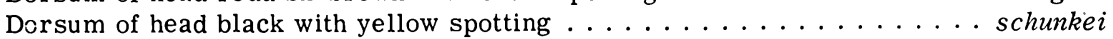

35. First few dorsal blotches fused ventrally; usually 2 pairs of labials in contact

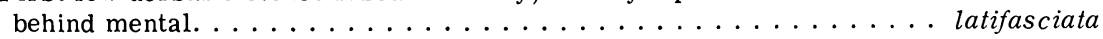
All dorsal blotches fail to meet on venter; usually less than 2 pairs of labials

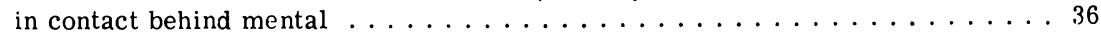

36. Anterior body blotches twice as wide as lighter interblotch area. . . . . latifrontalis Anterior body blotches approximately the same width as light interblotch areas

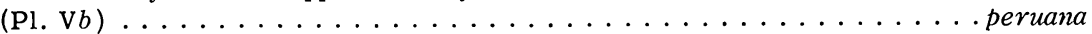

\section{THE ARTICULATA GROUP}

\section{Dipsas articulata Cope}

D. [ipsas] brevis (non Duméril, Bibron, and Duméril), Cope, 1860: 266.

Leptognathus articulata Cope, 1868: 135.

S. [ibynomorphus] articulata, Barbour and Dunn, 1921: 158.

Dipsas articulata, Parker, 1926: 206 (by inf.); Dunn, 1942: 7.

HOLOTYPE. - ANSP 10113, male, from Veraguas, Panamá, collected by R. W. Mitchell (see Remarks below).

RANGE. - Costa Rica and Panamá, apparently on both Atlantic and Pacific slopes (Map 1).

DESCRIPTION. - Rostral broader than deep, visible from above; internasals slightly shorter than prefrontals; frontal approximately as wide as long, considerably shorter than parietal; nasal divided or not; loreal enters eye; preoculars none or 1 ; postoculars 2 ; suboculars none or 1 ; primary temporals 2; secondary temporals 3; tertiary temporals 4; upper labials 9 or 10,4 th, 5 th, and 6 th entering orbit; lower labials 11 or 12 , first pair in contact behind mental, 5 pairs in contact with first pair of chin shields; no lower labial enlarged; 2 pairs of chin shields. 


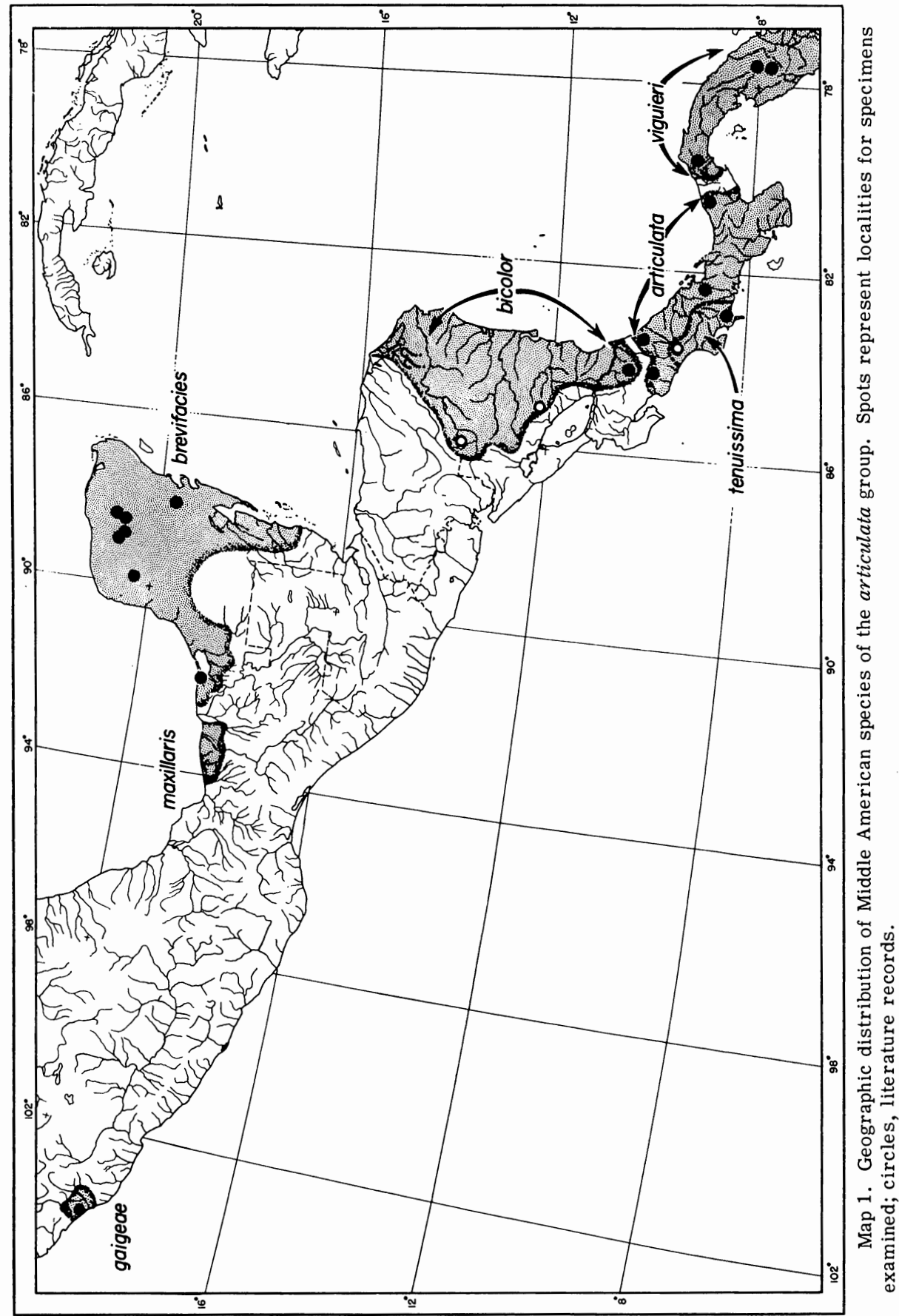


Ventrals 198-214 in males, 196-210 in females; anal entire; subcaudals 120-135 in males, $108-113$ in females; dorsal scale rows 15 , vertebral row scarcely to moderately enlarged; caudodorsals:

\author{
Males: $62+3(25-28) 41+2(87-98) 2(120-135)$ \\ Females: $\underline{6} 2+3(12-1 \overline{9}) \underline{4} 1+2(55-7 \overline{7}) \underline{2}(108-113)$
}

Maxillary teeth 18-21 (4 individuals); palatine teeth 10-13(3); pterygoid teeth 5-7(4); dentary teeth 19(1).

Body length, male (holotype) $483 \mathrm{~mm}$., female $460 \mathrm{~mm}$., no juveniles observed; tail length, male (holotype) $229 \mathrm{~mm}$., female $205 \mathrm{~mm}$.

Dorsal ground color cream or yellow-white, with 14 to 18 reddishbrown to dark chocolate-brown bands on body, not narrowed on sides, considerably wider than interspaces anteriorly, equal to interspaces posteriorly; interspaces usually unicolor, occasionally with more or less prominent brownish spotting. Venter as on dorsum, bands slightly narrowed at ventrals; interspaces occasionally with irregular brown spotting. Tail color and pattern as on body, with 8 to 12 bands.

Head above for most part color of dorsal bands, ending in point behind parietals, leaving white nuchal collar which extends forward on temporals to postoculars, and includes most of brown-spotted upper labials. Supraoculars, prefrontals, internasals all lightly speckled with white. Chin white with brown spotting on labials and anterior chin shields.

INDIVIDUAL VARIATION. - Three specimens have 10-10 upper labials, the 4 th, 5 th, and 6 th entering the orbit. Two have $9-9$, in one of these the 4 th, 5 th, and 6 th enter the orbit on one side, and the 4 th and 5 th on the other. The $3 \mathrm{~d}, 4$ th, and 5 th enter the orbit in the other specimen. There is no variation in postoculars; one specimen has a single preocular on both sides, a second has a single subocular on both sides, and a third (AMNH 3946) has a single preocular on the right side, no preocular on the left, and a subocular on each side. There are occasional fusions, both horizontal and vertical, between temporal scales, and in one specimen a tiny scale is split off the anterior edge of the lower primary temporal. The only irregularities in primary and secondary temporals are 1 primary on the left and 2 secondaries on the right in one specimen, and 2 secondaries on the left in another. All are obviously larger scales than the other temporals, and are the result of fusion. The lower labials are very variable; one has 1011, a second 11-11, a third 11-12, and a fourth 12-12.

Divided ventrals occur in two of the specimens seen; the holotype has the last ventral divided as in Type 1, and ANSP 22380 has the last ventral divided as in Type 3 . The caudal reduction is entirely regular in all the individuals seen.

The only striking variation in color is that of AMNH 3946, which has a considerable amount of pigment in the light interspaces, both above and below. All the other specimens seen, including the type, are either unicolor or very lightly spotted in the posterior interspaces only.

REMARKS. - When Cope $(1860: 266)$ discussed the type of this species under the name Dipsas brevis, he stated that it came from Cocuyas de Veragua, Grenada. When he described it (1868) as Leptognathus articulata, 
he gave its origin as "Veraguas, Costa Rica." Since the area known as "Granada" or "Nuevo Granada" at no time included what is now known as Costa Rica, and since the province of Veraguas is actually in Panamá, I have made this minor emendation in the citation of type locality.

\section{SPECIMENS EXAMINED. -}

No data (AMNH 3946). COSTA RICA: San Jose (AMNH 17370), La Castilla, lower Revantazon River (ANSP 22380). PANAMA: La Loma (MCZ 19346), Veraguas (ANSP 10113, type).

\section{Dipsas bicolor Günther}

Neopareas bicolor Günther, 1895: 178.

Leptognathus bicolor, Boulenger, $1896 a$ : 460.

S. [ibynomorphus] bicolor, Barbour and Dunn, 1921: 158.

Dipsas bicolor, Parker, 1926: 206 (by inf.).

Neoparias [sic] bicolor, Taylor, 1951: 66 .

Neopareas tricolor Brattstrom and Howell, 1954: 120.

HOLOTYPE. - BMNH 94.10.1.39, male, from Chontales mine, Nicaragua, collected by R. A. Rix.

RANGE. - Pacific slopes of southern Nicaragua and northern Costa Rica (Map 1).

DESCRIPTION. - Rostral broader than deep, visible from above; internasals more than half length of prefrontals, which do not enter orbit; frontal as long as broad, very slightly shorter than parietal; nasal entire or semidivided; loreal enters orbit; preocular 1; postoculars 3; suboculars none; primary temporals 1 or 2 ; secondary temporals 2 or 3 ; tertiary temporals 3 or 4 ; upper labials 10,4 th, 5 th, 6 th, and 7 th entering orbit, none greatly enlarged. Lower labials 10 or 11, first pair in contact and partly fused with one another behind mental, 5 in contact with first unpaired chin shield; 3 large, unpaired chin shields.

Ventrals 195-199 in males, 188 in female; anal entire; subcaudals 129 (male), 111 (female). Dorsal scale rows 15; vertebral row not to scarcely enlarged; caudodorsals (for MCZ 15262 only):

$$
\text { Male: } \underline{6} 2+3(15) \underline{4} 1+2(67-71) \underline{2}(103+)
$$
(1).

Maxillary teeth 20 ( 1 individual); palatine teeth 9 (1); pterygoid teeth 5

Body length of single male $368 \mathrm{~mm}$, tail incomplete. Body length of female type of tricolor $319 \mathrm{~mm}$., tail length $163 \mathrm{~mm}$. (Brattstrom and Howell, 1954:121).

Dorsal ground color white, with 14-17 reddish-brown to black bands on body, (12)-14 on tail, very slightly narrowed on sides; interspaces unicolor or extre mely lightly stippled with brown, reddish in life; bands approximately equal in length throughout body, about twice width of interspaces. Venter white, interspaces very rarely with small brown spots, dorsal bands complete across midline, edges even, no alternation.

Dorsum and sides of head solidly brown from snout to parietals; primary temporals, last labial in orbit, secondary and tertiary temporals and occipitals white. Anterior half of lower jaw unicolor brown to about level of 6th or 7th labials, posterior half uniformly white. 
INDIVIDUAL VARIATION. - I have seen only one specimen, but have compared it with the descriptions of Boulenger and Günther, as well as the latter's figure of the type, and with the description of Neopareas tricolor. Data from their publications were incorporated into the description above as well as included in the variations described below.

The type of bicolor has 4 postoculars on the right side, that of tricolor has 2 postoculars on one side, as well as 2 preoculars, with the loreal excluded from the orbit. The temporal region is typically dipsadine in its irregularities. In the type, judging from Günther's plate, the formula is 2-2-3, with the upper primary and upper secondary fused into a single scale on both sides. In MCZ 15262 the entire primary and secondary rows appear to be fused on the right into 1 large scale followed by 2 enlarged tertiaries, and on the left 2 small primaries are followed by a very large secondary resulting from vertical fusion in that row. The temporal formula for the type of tricolor is not given. The upper labials are 10 on five sides and 11 on the sixth. Labials $4,5,6$, and 7 enter the orbit on five sides, and 3, 4, 5 , and 6 on the left side in the type of bicolor, which has 10.

Boulenger stated that the first lower labials of the type are only partly fused; Gunther said that the fusion is complete. In MCZ 15262 there is only partial fusion, and in the type of tricolor there is a small scale between the ends of the 2 labials. In the type of bicolor the 3 large unpaired chin shields are followed by paired scales, 2 on the right and 1 on the left, which Boulenger called a pair. In MCZ 15262 there is a small scale split off from the posterior right corner of the second unpaired chin shield. There are no paired gulars in the type of tricolor. From the plate of the type of $b i$ color it appears that the third unpaired chin shield is fused with the 6th labial on the right.

Boulenger and Gunther both stated that in the type the color of the bands in the type is black. On one of the specimens they are reddish-brown, but this difference is probably due to fading in preservative.

REMARKS. - Boulenger synonymized the genus Neopareas with Leptognathus one year after it had been described, and it remained in the synonymy of that genus throughout its various changes in name until Taylor revived it (1951:66). His statement that "striking character of the chin shields in Neoparias [sic] readily separate the two genera [Dipsas and Neopareas]" is true as far as Costa Rican species are concerned. Its relatives in Dipsas, however, approach it quite closely, as for example, D. viguieri. This Panamanian representative of the genus normally has only two pairs of chin shields, with the paired one immediately followed by unpaired, broad gulars, as in bicolor. One of six specimens of viguieri seen has only a single pair of chin shields, however, and another has a single shield on one side paired with two on the other. It has been observed elsewhere that the trend throughout the genus Dipsas has been toward loss of individual scales on the chin through fusion, and bicolor is obviously only one fusion farther along than the specimen of viguieri mentioned above with only a single pair. On the other hand, the similarities between bicolor, viguieri, and articulata are impressive in their numbers, and include such characters as color pattern, head-scale arrangement, body and tail scutellation, and vertebral-row size. Obfuscation of relationships is the result when a monotypic genus is 
established on the basis of an extreme variation of a single character known to be quite variable within any single species. In this particular case, the strong affinities of bicolor, with its sympatric species, would be buried under the connotations of full generic status, especially for those who feel that generic level definitions should be based upon characters other than those that are variable within a genus on the species or even subspecies level.

Brattstrom and Howell (1954:121) described a new species, Neopareas tricolor, which they diagnosed as follows: "A Neopareas differing from $N$. bicolor in having red interspaces in the white body bands; fourth to seventh supralabials entering orbit; first infralabials separated medially by a small scale, the submental." As shown above, the supralabial character is typical for specimens of bicolor, and the type of bicolor has this diagnostic character on one side. The color of fresh specimens of bicolor is not known, but there is a strong possibility that the interspaces are red, because other members of this species group have red interspaces in life that disappear upon preservation. The extremely light stipplings of brown in preserved specimens of bicolor are quite likely the remnants of reddish areas in life. As for the third character mentioned in the diagnosis, the late E. R. Dunn informed me (in litt.) that the type of bicolor, which he had examined, has the first pair of lower labials separated by an azygous postmental, which would correspond to the "submental" of Brattstrom and Howell. Dunn saw two other specimens of bicolor, one in Hamburg and one in Vienna, and found the first pair of lower labials in contact in both. The type of tricolor is unique in having 2 preoculars, with the loreal excluded from the orbit, but again this is a common variant in the genus Dipsas. In view of the fact that the species is based on variations that occur commonly within single populations and on a color character that is expected to occur in fresh material of the original species, bicolor, I believe that it is not justifiable to perpetuate both names.

SPECIMENS EXAMINED. -

COSTA RICA: Sarapiqui (MCZ 15262).

ADDITIONAL RECORDS. -

COSTA RICA: San Jose (Hamburg Museum 5503). NICARAGUA (Vienna, no number): Chontales Mine (BMNH 94.10.1.39, type of bicolor), Jalapa, Nueva Segovia (Dept. Zool. Univ. Calif. at Los Angeles 6160, type of tricolor).

\section{Dipsas brevifacies Cope}

Tropidodipsas brevifacies Cope, 1866 a: 127.

Leptognathus brevifacies, Cope, 1868: 108.

Dipsadomorus fasciatus Bocourt, 1884: 135.

Leptognathus torquatus Cope, 1885: 172.

L. [eptognathus] brevifasies (sic), Cope, 1899: 14 .

Cochliophagus brevifacies (by inf.), Berg, 1901: 291.

Sibynomorphus brevifacies, Amaral, 1926a: 9 (by inf.); Amaral, 1929: 196.

Sibon brevifacies, H. M. Smith, 1943: 470.

Dipsas brevifacies, Parker, 1926: 206 (by inf.); Smith and Taylor, 1945: 51.

HOLOTYPE. - USNM 24886, male, from Yucatán.

RANGE. - The Yucatán Peninsula to British Honduras on the east and to Carmen Island on the west (Map 1). 
DESCRIPTION. - Rostral broader than deep, barely visible from above; internasals three-fourths the length of prefrontals; frontal as long as or slightly shorter than broad; nasal divided; loreal enters orbit; preoculars none, 1, 2 or 3 (loreal and preocular region extremely variable, see below); postoculars 3 ; suboculars none or 1 ; primary temporals 2 , secondary temporals 3 , tertiary temporals 4 ; upper labials 9 , 4th and 5 th entering orbit. Lower labials 9 to 13, the first 2 pairs in contact behind mental, 4 labials in contact with first chin shield; no lower labial enlarged; 2 pairs of chin shields.

Ventrals $167-176$ in males, $166-174$ in females; anal entire; subcaudals 83-100 in males, 69-87 in females. Dorsal scale rows 15 from 5th to 7 th ventral to anus; vertebral row not to scarcely enlarged; caudodorsals:

Males: $6 \underline{2} 2+3(19-31) \underline{4} 1+2(51-82) \underline{2}(83-100)$

Females: $\underline{6} 2+3(11-2 \overline{4}) \underline{4} 1+2(48-6 \overline{9}) \underline{2}(69-87)$

Maxillary teeth 17-19 (9 individuals); palatine teeth 11-16 (7); pterygoid teeth 3-6 (9).

Body length, male $373 \mathrm{~mm}$., female $357 \mathrm{~mm}$. , minimum $131 \mathrm{~mm}$.; tail length, male $155 \mathrm{~mm}$., female $123 \mathrm{~mm}$., minimum $42 \mathrm{~mm}$.

Dorsal ground color cream to white, occasionally with pink cast, with, in males, 12-16 complete dark-brown to black rings on body, 6-11 on tail, in females, 10-14 on body, 5-8 on tail; which are longer anteriorly (15 to 20 scale rows) than posteriorly (8-12 scale rows), and shorter ventrally than dorsally by one or two scales; eight interspaces, 2 to 5 scale rows wide at vertebral row, wider ventrally when black ring is narrowed; both rings and interspaces unicolor, without lighter centers or spotting and stippling ( $\mathrm{Pl}$. I $a$ ). Belly as in dorsum; dorsal bands meet uniformly on midventral line on body, may be irregular on tail, with edges widely separated.

Head unicolor black from tip of snout to posterior edge of parietals and to primary or secondary temporal rows; followed by a nuchal collar which is cream-colored as are the rest of interspaces. Chin black to end of paired chin shields or to first unpaired gulars, edges usually confluent with the black of head.

Juvenile pattern as in adult.

Schmidt and Andrews (1936:175) stated that "In life the light body-bands were bittersweet pink alternating with black, with a flame scarlet neckband."

INDIVIDUAL VARIATION (Table I). - The preocular and loreal region is more variable than that of any other species examined (Fig. 5). Extra scales are inserted in various places, or are split off from labials. The loreal is often reduced in size, split in two, or is enlarged and enters the orbit. In 18 specimens out of 25 there are one or more extra scales in the loreal region. In those without such extra scales, the $2 \mathrm{~d}$ upper labial is usually elongate and in broad contact with the loreal, and it appears that the extra scale when present has split off from the end of this labial. The situation may vary from side to side in a single animal, and practically all combinations can be found. In a single specimen (CNHM 36395) there is a complete ring of ocular scales on the left side, made up of 2 preoculars, 


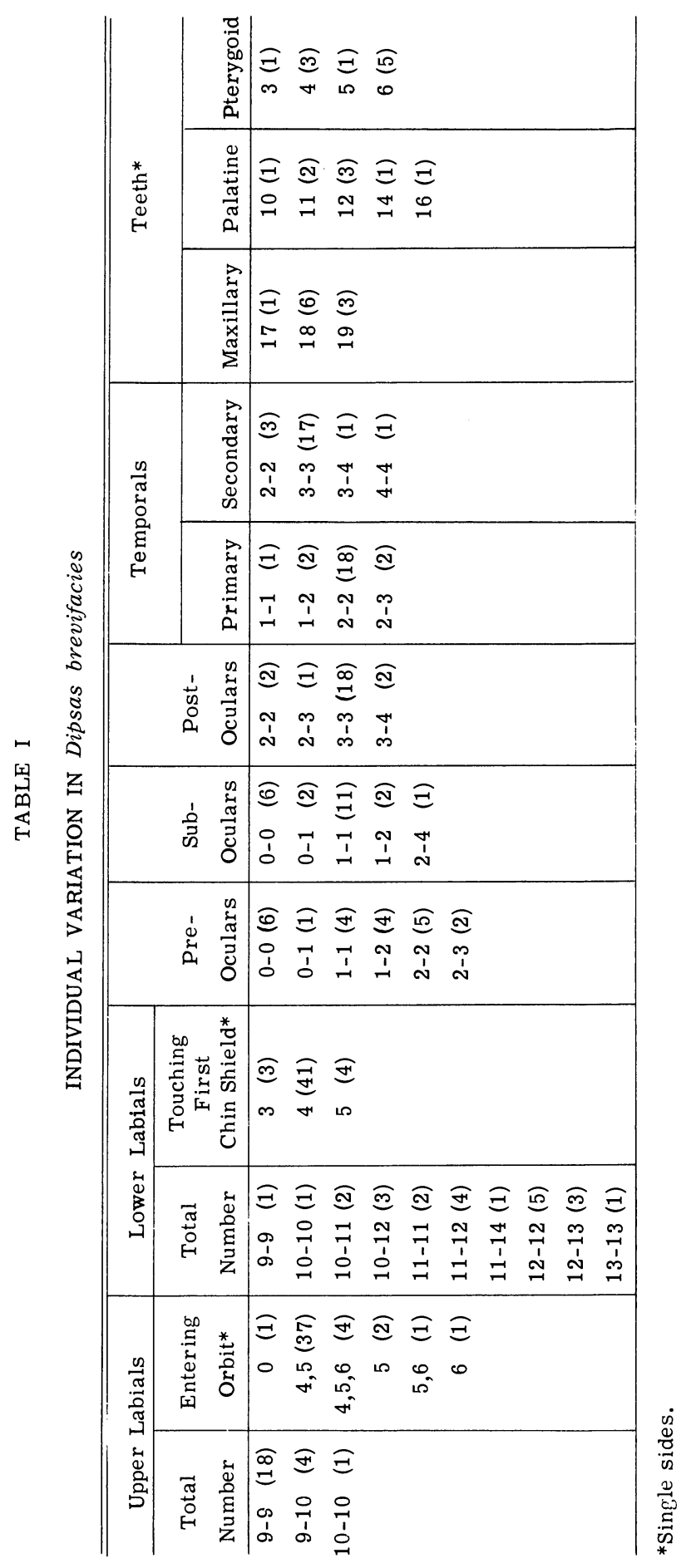




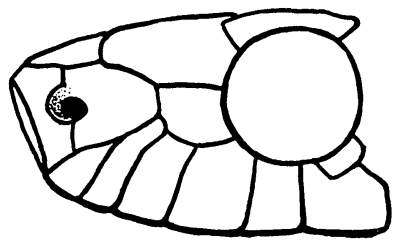

CNHM 20634

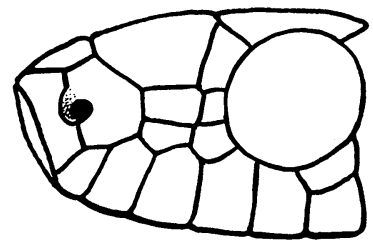

CNHM 36397

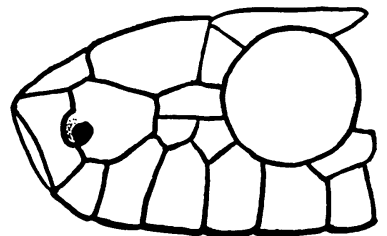

CNHM 36403

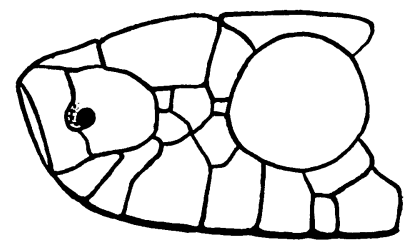

UMMZ 73030

Fig. 5. Variation in loreal and preocular region in Dipsas brevifacies.

4 suboculars, and 3 postoculars; on the right side the ring is not quite complete, with only 2 suboculars present. In addition, this specimen has the extra scale below the loreal on both sides, and the upper end of the 6th labial on the left is split off horizontally. The prefrontal enters the orbit on nine specimens, seven of which lack preoculars. When a preocular is present it is the upper one, and it excludes the prefrontal from the orbit in all except two specimens. The temporal region is typically dipsadine in its range of variation, with occasional serial fusion and with vertical splitting of individual scales.

In three specimens the first 2 pairs of chin shields are followed by a single broad shield, then another irregular pair. In a single specimen the first pair of lower labials is separated by the mental and the second pair is in full contact.

Three specimens show deviations in dorsal scutellation; the reduction. from 16 to 15 occurs at the 10th ventral in one and at the 19 th in the other. The third specimen (CNHM 36405) is quite unusual, and shows the following formula: 
(4) $\underline{15} \frac{\mathrm{V}+7(148)}{14}+\mathrm{V}(153) \underline{15} \overline{\mathrm{V}+7(155)} \underline{14} \overline{\mathrm{V}-7(156)} \underline{15} \overline{\mathrm{V}+7(158)} \underline{14}$

$\underline{14} 7+7(162) \underline{13}$ 7-7(163) 14 (169)

This reduction begins far posteriorly, and as usual with species in this group, involves only the vertebral and paravertebral rows.

One individual possesses a divided ventral (Type 1), and another has single caudals.

REMARKS. - The type of Dipsadomorus fasciatus Bocourt has several of the individual variations mentioned above, and, in addition, possesses one which has not been duplicated, that is, 4 pairs of chin shields, a situation which is, perhaps, equivalent to that described in which two pairs are followed by an undivided shield and then another pair. It has a complete ocular ring on the left side; on the right the 4th and 5th labials enter the orbit. The ventral count of 162 is close enough to the known range to be expected. Leptognathus torquatus Cope was published as a substitute name for Bocourt's species, which was preoccupied in Cope's classification by Leptognathus fasciata Gunther (=Tropidodipsas fasciata Günther).

I examined the type of brevifacies, and found several points of minor disagreement with Cope's original description. Cope gave the ventralscale count as 171 and the subcaudal-scale count as 86 , but my counts for the two are 174 and 87 . He gave the lower labials as 11 ; I found them to be 12 on the left side and estimated 10 on the right. The right side is the mutilated one mentioned by Cope and my count of 10 is approximate. Cope counted 10 yellow annuli on the body (thus inferring 11 black ones), but I counted 12 black annuli. The type is now somewhat faded, with the bands a light chocolate-brown rather than a glossy black, as they were when Cope described the type. The body of the type is $181 \mathrm{~mm}$. long, the tail $63 \mathrm{~mm}$.

Stuart $(1935: 23)$ placed brevifacies among the forms endemic to the arid region of the Yucatán Peninsula north of a line from Cape Catoche to Champoton, and suggested that the species originated there. Added material has extended the range considerably beyond the limits of that region, and makes questionable the position of this species on his list of forms originating in situ. Andrews (1937:356) perpetuated the notion of endemism to Yucatán, but based his acceptance of the idea upon inadequate material. Apparent endemics of a limited biotic area are quite often artifacts of insufficient collections.

\section{SPECIMENS EXAMINED. -}

BRITISH HONDURAS (CNHM 4234). MEXICO: Campeche; Ciudad del Carmen (UMMZ 83541). Yucatán (USNM 6562(2), USNM 24886, holotype): Chichén-Itzá (CNHM 20634, 3639799, 36402, 36405-06, 36408; UMMZ 73030), Citipech [=Cilpach] (ANSP 10129), Kantunil (CNHM 36400, 36403), Libre Union (CNHM 36401), Uxmal (PM uncataloged), Yokdzonot (CNHM 36395-96, 36404, 36407). Quintana Roo; Felipe Carrillo Puerto (UMMZ 113556-57).

\section{Dipsas gaigeae Oliver}

Sibynomorphus gaigeae Oliver, 1937: 22.

Dipsas gaigeae, Smith and Taylor, 1945: 51. 
HOLOTYPE. - UMMZ 80221, male, from Paso del Río, Colima, México, collected by James A. Oliver, July 26, 1935 (Pl. Id).

RANGE. - Known only from the type locality (Map 1).

DESCRIPTION. - Rostral broader than deep, visible from above; internasal three-fourths length of prefrontal; frontal only slightly longer than broad, almost as long as parietal; nasal divided; loreal enters orbit; preocular lacking on left side, one on right side, prefrontal enters orbit below preocular, which does not contact frontal; postoculars 2; suboculars none; primary temporals 2; secondary temporals 3 ; tertiary temporals 4 ; upper labials 7 on left, 8 on right, 3d and 4th and 5th entering orbit, no enlarged upper labials. Lower labials 8 on left, 7 on, right, one pair in contact behind mental, 5 on the left and 4 on the right in contact with first chin shield; 2 pairs of chin shields; 3 unpaired gulars between chin shields and first ventral.

Ventrals 162; anal entire; subcaudals 71. Dorsal scale row formula:

$$
\text { (4) } 17 \frac{1+2(5)}{1-2(5)} \underline{15} \frac{1+2(8)}{1+2(8)} \underline{13}(162)
$$

Vertebral row not enlarged, paravertebrals as large as or larger than vertebrals; caudodorsal scale row formula:

$$
6 \frac{2+3(22)}{2+3(23)} \underline{4} \frac{1+2(57)}{1+2(59)} \underline{2}
$$

Maxillary teeth 10 ; pterygoid apparently toothless.

Body length of type $214 \mathrm{~mm}$.; tail length $67 \mathrm{~mm}$.

Dorsal ground color white with 11 wide black rings on body, 4 on tail, wider anteriorly on body than posteriorly, slightly narrowed on sides and strongly narrowed on venter; light interspaces 4 to $51 / 2$ scales wide at vertebral row, wider ventrally, a black spot on tip of dorsal scales in interspaces $(\mathrm{Pl}$. I $d)$. Belly as in dorsum, with no spotting or stippling in interspaces.

Snout and labials white; a dark-brown mask runs from upper edge of $3 \mathrm{~d}$ and 4th labials on both sides, includes postoculars, posterior half of loreal, supraoculars, frontal, posterior third of prefrontals and anterior third of parietals; remainder of head and chin white.

Oliver $(1937: 23)$ stated that in life "the anterior portion of ... the upper dorsal scales... has a light reddish color which on the lower dorsal scales gives way to the white on the second or third row on either side."

INDIVIDUAL VARIATION. - Since the type is still the only specimen in collections, I have included its bilateral asymmetries in the description given above.

REMARKS. - The single recorded occurrence of this species so far from its nearest congeners (at the Isthmus of Tehuantepec) is perhaps primarily due to a defection of collecting activity in the intervening areas. Sibon nebulata is now known from an area in the western end of Michoacán that is not more than 35 miles from the type locality of Dipsas gaigeae, and 
its collection there supplements the already strong evidence pointing toward the existence of geographically equivalent ranges in Middle America for the two genera.

\section{SPECIMENS EXAMINED.-}

MEXICO: Colima; Paso del Rio (UMMZ 80221, type).

\section{Dipsas gracilis Boulenger}

Leptognathus gracilis Boulenger, 1902: 57.

Leptognathus hammondii Boulenger, 1920: 110.

S. [ibynomorphus] gracilis, Amaral, 1923: 93.

Sibynomorphus macrostomus Amaral, 1925: 9.

Sibynomorphus hammondi, Amaral, 1929: 197.

COTYPES. - BMNH; two males, from San Javier, Ecuador.

RANGE. - Northwestern Ecuador (Map 2).

DESCRIPTION. - Rostral broader than deep, not visible from above;

internasals half as long as prefrontals; frontal as long as or slightly longer than broad, shorter than parietals; nasal divided or not; loreal enters orbit; preoculars none; postoculars 2 or 3 ; suboculars none or 1 ; primary temporals 1 or 2 ; secondary temporals 2 or 3 ; tertiary temporals 4; upper labials 9 or $10,3 \mathrm{~d}, 4$ th, 5 th, and 6 th entering orbit in various combinations (see below). Lower labials 10-12, a single pair in contact behind mental, 4 or 5 pairs in contact with 1st pair of chin shields; 2 pairs of chin shields.

Ventrals 197-208 in males, 185-210 in females; anal entire; subcaudals 117-129 in males, 99-121 in females. Dorsal scales 15 on most of body after reduction in abrupt succession from 19 to 17 immediately behind head; vertebral row scarcely to moderately enlarged; caudodorsals:

$$
\begin{aligned}
& \text { Males: } 6 \underline{6} 2+3(17-26) \underline{4} 1+2(59-84) 2(118-120) \\
& \text { Females: } \underline{6} 2+3(10-1 \overline{9}) \underline{4} 1+2(55-8 \overline{0}) \underline{2}(99-115)
\end{aligned}
$$

Body length, male $528 \mathrm{~mm}$., female $528 \mathrm{~mm}$. , minimum $171 \mathrm{~mm}$.; tail length, male $236 \mathrm{~mm}$., female $213 \mathrm{~mm}$., minimum $63 \mathrm{~mm}$.

Dorsal ground color cream-white to very light brown, with 13-23 regular blackish-brown bands on body, equal in width dorsally and laterally on. anterior part of body, may be slightly widened on sides toward ventrals, somewhat narrowed at and on ventrals, anteriorly two to three times width of interspaces, posteriorly twice or slightly less; interspaces, at least posteriorly, with brown spots high on sides and on bands continuous across belly, slightly constricted, edges somewhat irregular, occasional small rectangular spots on interspaces, near midline (Pl. I $b-c)$. Tail as body, with 8-12 bands, slightly more brown spotting in interspaces.

Dorsum of head with dark-brown blotch vermiculated, often very faintly, with white; blotch extends from snout through eyes and includes all dorsal head scales through parietals and anterior part of vertebral row of scales; temporals, and other occipitals for the most part yellowish-white, with scattered brown spots, labials brown with white spots anteriorly, white with brown spots posteriorly. Chin white, anterior tip dark brown, including mental, labials in contact, first chin shields; color may or may not include other labials. 


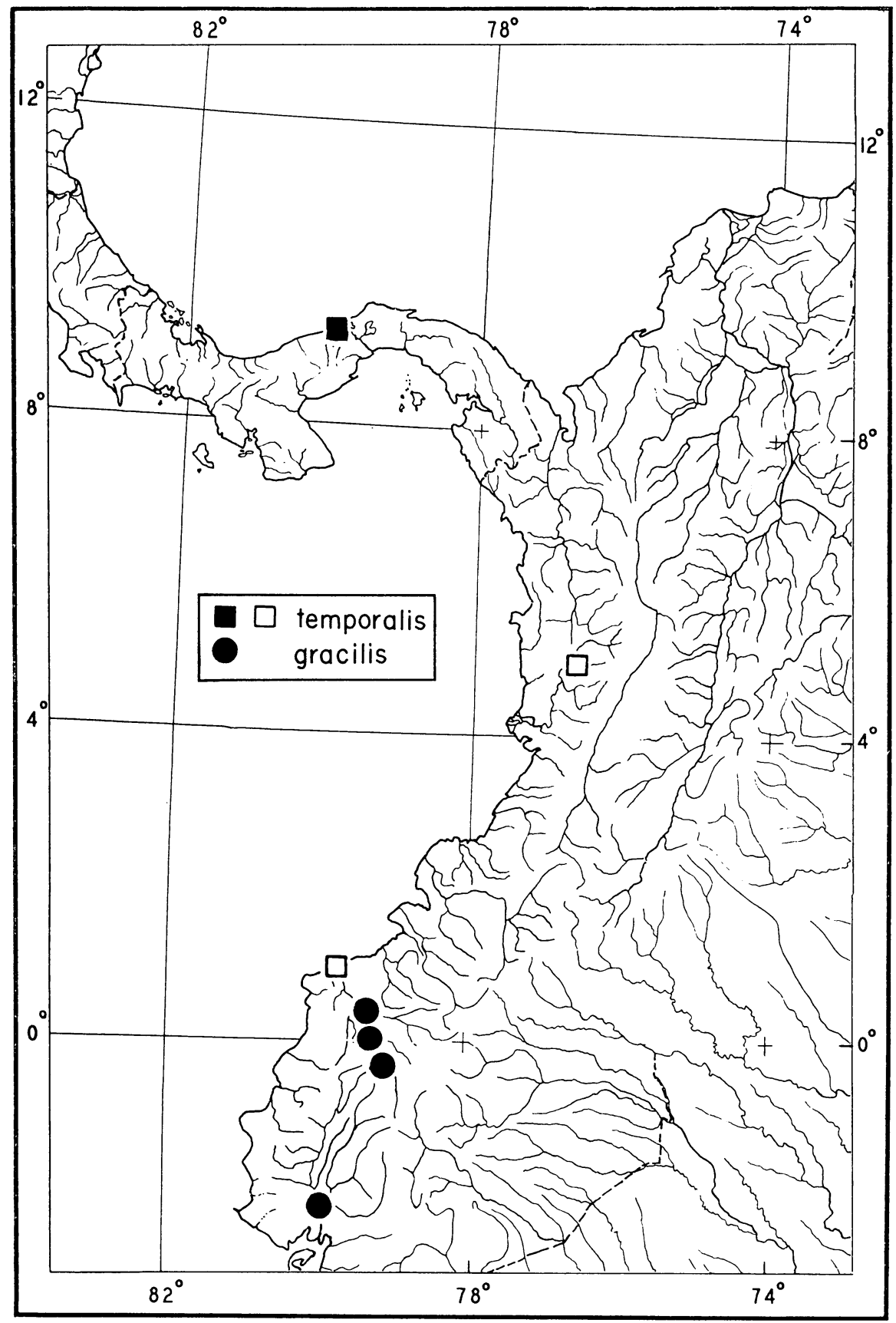

Map 2. Geographic distribution of South American species of the articulata group. Solid symbols represent localities for specimens examined; hollow, literature records. 
INDIVIDUAL VARIATION. -- The upper labials are 8-8 in the type of hammondi, with the 6th very large; 9-9 in three specimens, two of which are the cotypes of gracilis; $9-10$ in four, 10-10 in two, and 10-11 in the type of macrostomus. According to Boulenger, labials 2, 3, and 4 enter the orbit on one side of the head in the type of hammondi, but only 3 and 4 on the other. Two other specimens have 3, 4, and 5 entering the orbit. There are five sides with 4 and 5 in the orbit; nine with 4,5 , and 6 ; one with 5 and 6 ; and the type of macrostomus has 4,5 , and 6 on one side; and $4,5,6$, and 7 on the other. In all except one individual there are 4 labials behind the last one in the orbit, so practically all the variation mentioned has taken place anterior to that scale. The exception, EPN 751, has 9 labials on the left side, with 4,5 , and 6 in the orbit, and thus has only 3 posterior to the last in the orbit. In all except six of the 22 sides there are 3 labials in the orbit; in five there are only 2 , and on one side of the type of macrostomus there are 4 . The loreal is in the orbit in all specimens. One individual, EPN 98, has a preocular on both sides. Suboculars are present in five specimens. The postoculars are 2-2 in seven individuals, 3-3 in three, and 3-4 in one. The primary temporals are 1-1 in four, 1-2 in two, and 2-2 in six. The secondary temporals are 1-2 in one, 2-2 in five, 2-3 in three, and $3-3$ in three. Boulenger $(1902: 97 ; 1920: 110)$ said the nasal is divided in all of his types, but this may be only a semidivision, for reexamination of some of his specimens of other species has shown that he did not make a clear distinction. Of the specimens seen, it is not divided in two, semidivided in five, divided in one, and too badly crushed for determination in the ninth. There is a tiny scale split off the lower anterior corner of the single primary temporal on the left side of the type of macrostomus, and three other specimens show this extra scale in the same place.

The lower labials for the specimens examined are 10-10 in one, 10-11 in one, 11-12 in three, 12-12 in two, 13-13 in one, and 12-14 in one (the type of macrostomus). All specimens have a single labial pair in contact behind the mental. In the nine specimens in which the number of labials in contact with the first chin shield is known, it is 4-4 in two, 5-5 in four, and 4-5 in three. The paired chin shields are 2 in all specimens (although Amaral said 3 in his original description of macrostomus). Re-examination of the type of macrostomus revealed a cut across the middle of the first unpaired gular following the paired chin shields. When its edges are in contact, the cut resembles a suture. The sutures on the first two pairs can be easily found, but there is no such suture on the next chin shield. Three specimens show partial fusion of the chin shield pairs, all with a loss of the posterior portion of the suture. Two of them have both pairs partially fused; the third has only the second pair fused, but more than half of the suture is missing.

The dorsal scale rows are 15 over the major part of the body, but five specimens show vertebral reductions to either 14 or 13 rows. In these the reduction is less than 5 ventrals anterior to the anus. It is possible that the "more enlarged vertebral scales on the posterior part of the body" that Boulenger mentioned in his type description of hammondi are the result of such a reduction. The caudal reductions are uniform, and there is no variation from the formula given in the description. No divided ventrals or fused caudals were observed. 
In the specimen from the British Museum (Natural History), catalogued as gracilis, and presumably compared with the types, the bands are broad and their sides slope more than in the other two seen, and there is a correspondingly low number of total bands, 13. The type of hammondi has only 15; the cotypes of gracilis have 22 and 24, similar to AMNH 28729, with 22, and the type of macrostomus, with 23 on the left due to the doubling of the ninth blotch, and 22 on the right.

REMARKS. - When Boulenger described hammondi, he compared it with gracilis. The type locality for hammondi was given as "Guatea, western Ecuador" and the collector or Mr. G. Hammond. I have been unable to locate Guatea in Ecuador, but there is a small town named Gualea in western Ecuador, that may be the place referred to. The altitude of the type locality was given by Boulenger as 2900 feet, while Gualea lies between the 1000- and 1500-foot contours. I have also been unable to find any other references to collections made by $\mathrm{Mr}$. Hammond, and have not been able to check the orthography of the locality. It seems likely, however, that both the type localities concerned are fairly near one another. Boulenger remarked that hammondi differs from gracilis "in the labial and te mporal scutellation and in the more enlarged vertebral scales on the posterior part of the body." Boulenger mentioned that the type of hammondi has the "sixth (labial) very large," which indicates a fusion of the 6 th and 7 th labials. Since he mentioned also that the $2 \mathrm{~d}$ labial enters the orbit on one side of the head, it is very likely that at least one fusion has taken place anterior to the orbit between two of the crowded anterior labials. Two fusions would account for the low number of labials in the type. As for the temporals, while the $1+2$ count on the type of hammondi is duplicated by JAP 1886, EPN 96, and BMNH 1928.7.19.1 on one side of the head in each individual, JAP 1886 has the temporal count of the cotypes of gracilis, 2-2, on the other side. AMNH 28729 has the $1+2$ temporal count on both sides of the head. The unreliability of temporal-scale counts for dipsadine species became obvious during this study, and the same might be said for the counts of labials. Since these are the characters that impressed Boulenger the most, I cannot place as much faith in the validity of his species as he did, and accordingly synonymize the two.

Amaral distinguished his species macrostomus from both gracilis and hammondi by its having "a higher number of temporals, upper labials and chin shields, a lower number of subcaudals, and many more light rings on the body." While it is true that the type of macrostomus has more labials (11) on one side of the head than any other specimen known, the other side of it has only 10, and is not different from six other individuals seen. On the side with 11 labials, the 4th, 5th, 6th, and 7th enter the orbit. The type is the only specimen in which more than 3 labials enter the orbit, and it appears that an extra scale has been crowded onto the labial row, probably through splitting, under the eye. It has only 3 labials in the orbit on the right side, the normal number for the species gracilis. The third pair of chin shields referred to by Amaral is not present. The number of subcaudals does not seem to be beyond the normal range of intrasexua! variation; while it is low, it is true that the type is a female, whereas the types of gracilis are both males. Actually, the count for the type of hammondi, 
said to be a female, is rather high as compared to the males known. It has more subcaudals than any of the three males examined. One of the male cotypes of gracilis has more, with 129.

With one exception, the locality records for Dipsas gracilis indicate that its range is entirely within the dense, humid tropical forest of the northwestern provinces of Ecuador, duplicating that of Leptophis ahaetulla bocourti (Boulenger), as given by Oliver (1948:223). Since this Leptophis is also known from Gorgona Island, off the coast of Colombia, where the forest conditions are similar to those of the Esmeraldas region of Ecuador, gracilis may also be present there. The exception mentioned above is EPN 751, recorded originally as collected "cerca de Guayaquil." Since Guayaquil lies in an entirely different climatic area than does that of the northwest provinces, the locality might be doubted. The specimen, however, is certainly a valid member of this species.

The characters separating this species and $D$. viguieri are comparatively weak ones, and the close relationship between the two is obvious. Their respective ranges are separated by that of $D$. temporalis, a species easily recognized by the absence of any contact of labial pairs behind the mental. In addition to the characters mentioned in the key, which give a fairly clear-cut contrast between the two species, $D$. gracilis usually lacks the preocular and the subocular, has 3 labials entering the orbit, and has 2 postoculars more often than 3 ; viguieri usually has a preocular and a subocular, only 2 labials enter the orbit, and 3 postoculars occur more often than 2. Members of each species can be found that have characters more frequently associated with the other, however, and this makes those characters most unsatisfactory for key purposes. Even in the key characters given, there is overlap, for a viguieri with lightly spotted interspaces closely resembles some of the more heavily spotted gracilis. The most consistent characteristic is the comparative widths of the dorsal blotches and the interspaces.

SPECIMENS EXAMINED.-

ECUADOR: locality unknown (USNM 14047, type of macrostomus), Guayaquil (EPN 751), Hacienda Equinox, $30 \mathrm{~km}$. NNW of Santo Domingo de los Colorados (JAP 1886, 1928tail only, 2558), Pachijal (EPN 96), Pambelar (BMNH 1928.7.19.1), Santo Domingo de los Colorados (AMNH 28729; EPN 97-98).

ADDITIONAL RECORDS. -

ECUADOR: San Javier (BMNH, cotypes of gracilis), "Guatea" (BMNH, type of hammondi).

\section{Dipsas maxillaris Werner}

Leptognathus maxillaris Werner, 1909a: 279.

Sibynomorphus elegans (part), Amaral, 1929: 196.

Dipsas maxillaris, Smith and Taylor, 1945: 51 .

HOLOTYPE. - Institut Royal de Science Naturelle de Belgique No. 3042, female, from Tabasco, México.

RANGE. - Known only from the type locality (Map 1).

DESCRIPTION (from published data and figure). - Rostral as deep as 
broad, visible from above; internasal half length of prefrontal, which does not enter orbit; frontal longer than broad, shorter than parietals; nasal divided; loreal enters orbit; preocular 1; postoculars 2; suboculars none; primary temporals 2 ; secondary temporals 2 or 3 ; tertiary temporals 3 ; upper labials $6,3 \mathrm{~d}$ and 4 th in orbit, 5 th appears somewhat enlarged and in contact with postocular, primary and secondary temporals. Lower labials 8 on left, 9 on right, 1st labial on left in contact behind mental with first 2 labials on right, 5 labials on left, 4 on right in contact with 1st pair of chin shields; no greatly enlarged lower labials; 4 pairs of chin shields.

Ventrals 180; anal entire; subcaudals 84 . Dorsal scale rows 15 , vertebral scale row moderately enlarged; caudodorsals not known.

Body length of type $335 \mathrm{~mm}$; tail length, $70 \mathrm{~mm}$.

Dorsal ground color yellowish with coffee-brown cross bands, 40 on body and 21 on tail, which are broader than interspaces. Belly with large brown spots.

Dorsum of head to level of parietals brown, with irregular lighter markings; snout with dark, anchor-shaped mark on a grayish ground color, "anchor-hooks" run from eye to eye across middle of prefrontals, a median triangular process lies on internasals, and shaft of “anchor" lies on frontal; upper labials light with scattered brown spots; temporal region brown. Chin apparently light with brown spotting (not mentioned as distinct from “Unterseite").

REMARKS. - Although Werner says that the name he gave this species was originated by Jan, it is obvious that Jan can be author "in name only," and that the description is entirely Werner's.

Amaral synonymized this species with Dipsas elegans $(1929: 196)$ on the basis of comparison of the type descriptions and on geography, but it seems likely that his action was unjustified. Laurent $(1949: 15)$ redescribed the type of maxillaris in the light of Amaral's synonymy. He pointed out a fact that Werner failed to mention concerning the labials in contact behind the mental. That is, although Werner says 2 labials enter this contact, Laurent found this to be true on one side only, since on the left side the 1st labial occupies the entire zone of contact. Laurent stressed that even if the 2 labials in the contact on the right is an anomaly, there are other characters which separate the two species: (1) the presence in maxillaris of 6 labials with the $3 \mathrm{~d}$ and 4 th entering the orbit, as opposed to 8 in elegans with the 4 th and 5 th in the orbit and (2) differences in color and pattern.

It is true that the distinctions that Laurent mentioned exist, but the similarities are impressive, and the type localities are not separated from each other by great distance. The practically identical counts for ventrals, subcaudals, and, particularly, for body and tail blotches are suggestive of a close affinity between the species. These two species are the only members of the genus Dipsas in Middle America that have such high blotch counts. The characters used to separate them are for the most part known to be variable in other species of the genus. Deviations equal to those between the type specimens are known to exist within a single species. The problem cannot be completely solved without additional material from the lower areas of the Isthmus of Tehuantepec and the Atlantic coast of México. 
AVAILABLE RECORDS. - (Mus. Roy. d'Hist. Nat. Belg. 3042, type).

\section{Dipsas temporalis Werner}

Leptognathus temporalis Werner, $1909 \mathrm{~b}$ : 241.

Leptognathus spurrelli Boulenger, 1913a: 1036.

Sibynomorphus spurrelli, Amaral, 1926a: 9 (by inf.); Amaral, 1929: 199.

Sibon sibon (part), Amaral, 1929: 194.

Sibon temporalis, Dunn and Bailey, 1939: 9.

HOLOTYPE. - Hamburg Naturhistorischen Museum, from Esmeraldas, Ecuador, collected by Captain E. Krause.

RANGE. - Known from two localities on the Pacific coast of South America, in Ecuador and Colombia, and one locality on Atlantic coast of Central America, in Panamá (Map 2).

DESCRIPTION. - Rostral some what broader than deep, not visible from above; internasals one-third length of prefrontals; frontal as long as broad, much shorter than parietals; nasal divided; loreal enters orbit; preocular 1 , in contact with frontal; postoculars 2, may be separated from each other by primary temporal which enters the orbit; suboculars none; primary temporals 2 or 3 ; secondary temporals 3 ; tertiary temporals 3 or 4 ; upper labials 7 or 8 , 4th and 5th entering orbit, no enlarged upper labials. Lower labials 11 to 13 , no pairs in contact with each other behind mental; 4 or 5 pairs in contact with 1 st large pair of chin shields (actually $2 \mathrm{~d}$ pair); 4 or 5 pairs of chin shields.

Ventrals 206-208; anal entire; subcaudals 125-132. Dorsal scale rows 15 , vertebral row moderately to broadly enlarged; caudodorsals unknown.

Maxillary teeth 26 ( 1 individual); palatine teeth 9 (1); pterygoid teeth 25 (1).

Body length, male $445 \mathrm{~mm}$; ; tail length, male $235 \mathrm{~mm}$. (holotype of spurrelli). Werner $(1909: 283)$ gave the total length of the type of temporalis as $520 \mathrm{~mm}$., with a tail length of $67 \mathrm{~mm}$. Since he stated elsewhere "Schwanz lang," it seems likely that the latter measurement is in error.

Dorsal ground color light reddish-brown, with 23 (1) broad, dark-brown bands that are two to three times as long as interspaces, somewhat narrowed on sides, where they may be edged by small white spots; interspaces darkest at vertebral line, lighten on sides to yellowish on first scale row. Venter yellowish, bands strongly narrowed, equal in length to interspaces; ends of bands on anterior part of body may or may not meet on midventer, if not, they approach closely, more widely interrupted posteriorly; interspaces with irregular brown stippling which may form longitudinal streaks. Tail above with inđistinct dark bands, below dark brown with scattered white spots on at least anterior two-fifths.

Top of head dark reddish-brown, unicolor, lightening slightly towards labials, which occasionally have black spots on sutures; chin yellowishwhite with irregular dark brown spots, some of which form parallel lines along edges of chin shields and gulars.

INDIVIDUAL VARIATION. - Unless Boulenger's text is correct and his figure (1913a: Pl. 108, Fig. 3) inaccurate, the upper labials are 7 in all known specimens. According to his text 8 labials are present, but the 
figure shows 7 . In all the 4 th and 5 th labials enter the orbit. The only variation in the ocular region is in the postoculars; there are 3 on the left side (right side undeterminable) in MCZ 50214, the specimen from Panamá. The upper and lower postocular are separated by a primary temporal in both the type of temporalis and the type of spurrelli, but this does not appear to be true of the Panamanian specimen. The primary temporals are 2 in two individuals, the type of spurrelli has 3 . In the type of temporalis there seems to be an abnormally large scale in the primary temporal row; it is probably the result of fusion between both the upper primaries and at least one secondary. All published descriptions, plates, and specimens are in agreement that the secondary temporals are 3, although they appear very irregular in the type of temporalis.

The lower labials are accurately known only for the single specimen examined, which has 11-13. The plate of the type of spurrelli shows 1010; the plate of the type of temporalis appears to show 11-11. In both of types 4 labial pairs are in contact with the first enlarged chin shield pair; in MCZ 50214 there are 4 labials on the right and 3 on the left in contact with the 1st chin shield. In both types there are 4 paired chin shields on the right and 5 on the left; in MCZ 50214 there are 4 on both sides, with an azygous scale between the $3 \mathrm{~d}$ and 4 th pairs on the left, which are in broad contact behind it.

Dorsal-scale row variations are unknown in this species, as the one specimen available to me consists only of the head and neck; I have not seen the types.

There seems to be little change from specimen to specimen in color pattern. Boulenger did not record the presence of longitudinal lines on the venter, which are vague in MCZ 50214, but they are apparently quite prominent on the type of temporalis. The single specimen I examined is practically identical with the type of spurrelli as figured by Boulenger, insofar as dorsal pattern and coloration is concerned.

REMARKS. - Dunn and Bailey (1939:9) were the first to note the discrepancies between Boulenger's description and figure, and they suggested at that time that the two species discussed above be considered synonymous. In view of the strong similarities between the two forms, it is difficult to understand now why Boulenger saw fit to describe his specimen as a new species. Although he stated that spurrelli is "closely allied to ... L. temporalis Werner, from Ecuador" he did not elaborate upon similarities or point out differences. It might be added that Dunn and Bailey reversed the situation as it appears in the original description, for they commented: "Boulenger says his specimen had no preocular and seven upper labials. His figure shows an upper preocular and eight upper labials..." Actually, Boulenger said his specimen had 8 upper labials, but the figure shows only 7. Regardless of which situation exists (and I am inclined to believe the figure), a single difference between two dipsadine snakes is insufficient grounds for added species names, particularly when that difference is a matter of labial count.

This species is found in Chapman's $(1917: 106)$ “Colombian-Pacific Fauna" life area, which is characterized by exceptionally heavy rainfall and luxuriant forest growth. The type of temporalis comes from 
approximately the southern limit of this faunal area, which according to Chapman, ends at the divide between the Esmeraldas and Guayaquil drainage systems. The northern limit of the area is stated to include "Eastern Panama, south of the mountains facing the Caribbean and west to the Tuyra River region." Presumably, this includes the Panama Canal region, which is the locality represented by the MCZ specimen.

This species is geographically intermediate between $D$. viguieri and $D$. gracilis, but is not intermediate between them with respect to characteristics. In fact, the latter two species are quite similar in many characters, while temporalis is distinct from either in the same characters. If the ranges of viguieri and gracilis were contiguous there would be reason to consider them only subspecifically distinct. D. temporalis does not fit into such a subspecies chain, however, and apparently shares part of its range with viguieri. Both species are known from the Panama Canal Zone, and perhaps also overlap in eastern Panamá, although it is possible that temporalis occurs on the Atlantic slope only. All specimens of viguieri known from eastern Panamá are from the Pacific slope.

SPECIMENS EXAMINED.-

PANAMÁ: Pequeni-Chagres.Ridge between headwaters of Río Limpio and Las Tres Hermanas Quebrada (MCZ 50214).

ADDITIONAL RECORDS. -

COLOMBIA: Chocó; Condoto, Peña Lisa (BMNH, type of spurrelli). ECUADOR: Esmeraldas; Esmeraldas (Hamburg Mus., type of temporalis).

\section{Dipsas tenuissima Taylor}

Dipsas tenuissima Taylor, 1954: 771.

HOLOTYPE. - KMNH 31961, sex not known, from approximately 15 kilometers WSW of San Isidro del General, Costa Rica, on Dominical Road, in swamp, collected by Edward H. Taylor, on July 10, 1952.

RANGE. - Known from type locality and Puerto Armuelles, Panamá (Map 1).

DESCRIPTION. - Rostral twice as broad as deep, scarcely visible from above; internasals shorter than prefrontals; frontal minutely longer than broad, shorter than parietals; nasal entire or semidivided; loreal enters orbit; preocular 1; postoculars 3 ; subocular 1 ; primary temporals 2; secondary temporals 3 ; tertiary temporals 3 ; upper labials 8 , 4th and 5th entering orbit; no enlarged upper labials. Lower labials 9 or 10, one pair in contact behind mental, four in contact with first chin shields; 2 pairs of chin shields.

Ventrals 225; anal entire; subcaudals 128. Dorsal scale rows 15; vertebral row enlarged; caudodorsal reduction unknown.

Maxillary teeth 20-24 (2 individuals).

Body length $390 \mathrm{~mm}$., tail length $165 \mathrm{~mm}$.

Dorsum with broad, dark, chocolate-brown bands anteriorly which are considerably wider than interspaces, posterior blotches much smaller and approximately equal in width to interspaces; interspaces unicolor anteriorly, heavily spotted and streaked with blotch color posteriorly; vague 
streaks connect dorsal blotches on vertebral line on all parts of body. Dorsum of head unicolor dark brown, with outer edges of parietals, all temporals quite heavily spotted with lighter color; upper labials dark for most part, some stippling with light color, which is most prominent on posterior labials. Anterior half of chin dark, posterior half of chin and throat light with scattered stippling and spotting.

INDIVIDUAL VARIATION. - The single specimen I have seen, which is a head and neck only differs in several points from the type description. The nasal is semidivided in the type; it is entire on ANSP 24255. There are 3 primary temporals on the left side of the head on the second specimen, and the uppermost is divided vertically into two smaller scales. The lower labials are 10 rather than 9 as in the type, and there are 5 on the left and 6 on the right in contact with the first chin shields. The number of chin shields is irregular, with 3 on the right paired with 4 on the left side.

It is impossible, of course, to determine the full dorsal reduction in ANSP 24255, but a reduction to 13 rows occurs quite close to the head, This would indicate that the scale-row count over the body might well have been 13 , and if so, is quite different from the type. The counts for the anterior part of the snake are:

$$
\underline{16} 8+8(5) \underline{15} \stackrel{-3(15)}{14} \overline{-6(20)} \underline{13} \frac{+4(25 \text { only) }}{+4(23)} \underline{14} \overline{-4(26)} \underline{13}(26-n)
$$

REMARKS. - The description given here is taken directly from Taylor's paper, with additional data from the second available specimen. Since Taylor did not describe the color of his type, the color-pattern description is taken from his figures and from the incomplete specimen from Panamá.

Taylor's specimen comes from the Pacific slope of Costa Rica, near the Panamanian border, and the ANSP head is from just across the border in Panamá. Both show a marked similarity to Dipsas viguieri Bocourt, the Pacific slope representative of the genus in eastern Panamá. The resemblance is so great that it seems likely that additional material will demonstrate the relationship to be at most a subspecific one.

D. tenuissima differs from viguieri and articulata, its nearest relatives, in having only 8 upper labials, in the occurrence of a preocular, in the somewhat higher ventral count, and in details of coloration. Additional material from western Panamá and Costa Rica is necessary to demonstrate the constancy of these differences. All of characters have been observed to be quite variable in other dipsadine species, however, and it is most unlikely that individuals showing viguieri characteristics will not be found in Costa Rica.

The second specimen assigned to this species was discussed in detail by Dunn (1942:7) who placed it in Dipsas anthracops Cope, a species that I consider to belong to the genus Sibon. In part, the characters itemized by Dunn by which this specimen differs from others of anthracops are those used here to differentiate the genera Dipsas and Sibon. Taylor's specimen helps clear up the generic affinity problem, since it appears to be a Dipsas in all respects.

The name Dipsas tenuissima is a secondary homonym, by virtue of the 
use of that name by Cope $(1887 b: 68)$ for a specimen of Imantodes tenuis sima, from Yucatán. This was during the period when Cope was using the name Dipsas for opisthoglyphous snakes, and the usage has never been perpetuated. It is, of course, of no consequence in its current use by Taylor.

SPECIMENS EXAMINED. -

PANAMA: Puerto Armuelles (ANSP 24255).

ADDITIONAL RECORD. -

COSTA RICA: $15 \mathrm{~km}$. WSW of San Isidro del General (holotype).

\section{Dipsas viguieri Bocourt}

Leptognathus viguieri Bocourt, 1884, 136.

Sibynomorphus viguieri, Amaral, 1926a: 9 (by inf.): Amaral, 1929: 200.

Dipsas viguieri, Parker, 1926: 206 (by inf.); Dunn, 1942: 7.

Sibon viguieri, Dunn and Bailey, 1939: 9.

HOLOTYPE. - Museum d'Histoire Naturelle de Paris, Type no. 6203, male, from the Isthmus of Darien, Panamá, collected by Dr. Viguier.

RANGE. - Pacific coast of Panamá (Map 1).

DESCRIPTION. - Rostral considerably broader than deep, visible from above; internasals about three-fourths length of prefrontals; frontal wider than long, slightly shorter than parietals; nasal divided; loreal enters orbit; preoculars none; postoculars 3; subocular 1; primary temporals 2 or 3 ; secondary temporals 3 ; tertiary temporals 4 ; upper labials 9 or 10, 4th and 5 th or 5 th and 6 th entering orbit. Lower labials 9 to 11, first pair in contact behind mental, 4 or 5 pairs in contact with first pair of chin shields; no greatly enlarged lower labials; 2 pairs of chin shields.

Ventrals 201-203 in males, 190-192 in females; anal entire; subcaudals 114-127 in males, 102-113 in females. Dorsal scale rows 15 , vertebral row scarcely to moderately enlarged; caudodorsals:

Males: $62+3(18-23) 41+2(75-85) 2(114-127)$

Females: $\underline{6} 2+3(12-1 \overline{7}) \underline{4} 1+2(61-7 \overline{6}) \underline{2}(102-113)$

Maxillary teeth 20-21 (2 individuals); palatine teeth 9-12 (2); pterygoid teeth 4-7 (2).

Body length, male $439 \mathrm{~mm}$., no adult females examined, minimum 155 mm.; tail length $198 \mathrm{~mm}$., minimum $68 \mathrm{~mm}$.

Dorsal ground color yellowish-white, with reddish tinge, with 16-20 reddish-brown bands on body in females, 19-22 in males; anterior interspaces usually unicolor, posterior interspaces with horizontal bar of same color as band on adjacent edges of paravertebral and 6th scale rows, which may be broad enough to include all of 6 th row and part of 5th, secondary bar or scattered dappling below it; dorsal bands slightly narrowed at vertebral row and at junction of first scale row and ventrals, often with small light spot centered in band at first scale row, shorter posteriorly than anteriorly but never as short as interspaces.

Belly color as on dorsum; interspaces stippled, spotted, or blotched; dorsal bands complete anteriorly, fail to meet on midline posteriorly. 
Tail as in body with $10-15$ bands in females, $14-17$ in males, much wider than interspaces and all complete across ventral surface.

Dorsum of head with irregular reddish-brown patch spotted with white extending from labial to labial below eyes and from prefrontals to posterior edge of parietals; does not include temporals, nasals or internasals, which are light cream or white with brown spotting; upper labials white with sutures of ten brown. Chin and neck white with scattered brown spots and flecks.

INDIVIDUAL VARIATION (Table II). - Four of six individuals have 9-9 upper labials, the fifth has $9-10$, and the sixth has 10 on the only determinable side. Where the labials are 9 , the 4 th and 5 th enter the orbit; where 10 , the 5th and 6th. A single exception has 9-9 labials, with 4, 5, and 6 entering the orbit on both sides. Three specimens have 3-3 postoculars, two have 2-3, and one has 2-2. The subocular is lacking on the left side of one individual. The temporals are extremely irregular, with much fusion and splitting, and the same is true of the lower labials. Three individuals have 2 pairs of chin shields; one has 2 on the left side and the posterior one on the right split to make 3; one has only 1 on the left with the normal 2 on the right; and the sixth has only a single pair. Four labials come in contact with the first chin shield on 7 of twelve sides, while 5 labials do so the other 5 .

The dorsal scales are usually 15, but in two specimens there is a reduction to 13 a row or two anterior to the anal level. A single individual shows a Type 1 division on the last ventral. The vertebral row often varies from scarcely to moderately enlarged in the same individual, with a gradual increase from anterior to posterior. The caudal reductions are the same in all individuals as to row fusion, with normal variation in point of fusion.

TABLE II

INDIVIDUAL VARIATION IN Dipsas viguieri

\begin{tabular}{|c|c|c|c|c|c|}
\hline \multirow[b]{2}{*}{ Specimen } & \multicolumn{2}{|c|}{ Temporals* } & \multirow{2}{*}{$\begin{array}{l}\text { Lower } \\
\text { Labials }\end{array}$} & \multirow{2}{*}{$\begin{array}{c}\text { Body } \\
\text { Blotches }\end{array}$} & \multirow{2}{*}{$\begin{array}{c}\text { Tail } \\
\text { Blotches }\end{array}$} \\
\hline & Left & Right & & & \\
\hline Males & & & & & \\
\hline AMNH 36200 & $3-3$ & $\sqrt[3]{2}$ & 8-9 & 22 & 17 \\
\hline MCZ 34376 & $2-3$ & $2-4$ & $10-9$ & 22 & 15 \\
\hline MCZ 34377 & $\frac{1}{2}-3$ & $3-3$ & $9-10$ & 19 & 14 \\
\hline Females & & & & & \\
\hline ANSP 23912 & $2-3$ & $2-3$ & $11-13$ & 16 & 10 \\
\hline MCZ 37150 & $2 \smile 3$ & $2-3$ & $10-10$ & 20 & 14 \\
\hline USNM 50112 & $2-3$ & $2-3$ & $11-11$ & 20 & 15 \\
\hline
\end{tabular}

*Figures given for the temporals refer to primary and secondary temporals, in that order, for each side of the head, and a Indicates that a horizontal fusion between a scale or scales from both rows has taken place. 
REMARKS. - When Mocquart (1908:888) re-examined the type of this species, he noted that the yellow color of the interspaces and the ${ }^{\alpha}$ jaune orange" of the temporal and nuchal region had become white in alcohol. He repeated from Bocourt's description that the top of the head was "brun violace," but I have not seen any specimens which have a purplish cast on the head scales.

SPECIMENS EXAMINED.-

PANAMA: Agua Clara, Chagres River (ANSP 23912), Cana (USNM 50112), Chagres River (MCZ 34376-77), Darien (AMNH 36200), Fork of Pihuila-Tucuti Branch of Rio Tuira (MC̣Z 37150).

\section{THE CATESBYI GROUP}

Dipsas catesbyi Sentzen

Coluber catesbeji, Sentzen, 1796: 66 .

Dipsas catesbyi, Boie, 1827: 560 .

Stremmatognathus catesbyi, Duméril, Bibron, and Duméril, 1854: 522.

Leptognathus catesbyi, Günther, 1858: 180.

Leptognathus catisbyi (sic), Peters, 1871: 402.

Cochliophagus Catesbyi, Berg, 1901: 291.

Sibynomorphus catesbeji, Barbour and Noble, 1920: 620.

Sibynomorphus catesbyi, Amaral, 1926c: 27.

Sibynomorphus catesbyei, Amaral, 1929: 196.

?Sibynomorphus macedoi Prado and Hoge, 1947: 180.

HOLOTYPE. - Present location unknown.

RANGE. - Amazonas region of South America, from Andean slopes of Bolivia, Peru, Ecuador, and Colombia to coast of Venezuela and British Guiana, and through northern half of Brazil (Map 3).

DESCRIPTION. - Rostral much broader than deep, scarcely visible from above; internasals one-third to two-thirds length of prefrontals, which do not enter orbit; frontal width and length approximately equal, often slightly broader than long, only slightly shorter than parietals; nasal not divided; loreal not entering orbit; preoculars 2; postoculars 1 or 2; suboculars none; primary temporals 1 or 2; secondary temporals 2; tertiary temporals 2; upper labials 8 or 9 , 4th and 5th or 5 th and 6 th in eye; none enlarged. Lower labials 8 to 11 , none or 1 pair of labials in contact behind mental, 4 or 5 pairs in contact with first pair of chin shields; 3 or 4 pairs of chin shields.

Ventrals 164-202 in males, 167-189 in females; anal entire; subcaudals 86-118 in males, 77-102 in females. Dorsal scale rows 13 from level of third or fourth ventral to anus, vertebral row moderately to broadly enlarged.

Maxillary teeth 15-18; palatine teeth 8-11; pterygoid teeth 14-18.

Maximum body length male $542 \mathrm{~mm}$., female $585 \mathrm{~mm}$., minimum 122 mm.; tail length male $235 \mathrm{~mm}$., female $235 \mathrm{~mm}$., minimum $48 \mathrm{~mm}$.

Dorsal ground color light brown to reddish-brown, with 14-40 dark brown to black blotches on body, first blotches elongate, squared, twice length of remaining ones which are rounded above and below; prominent 


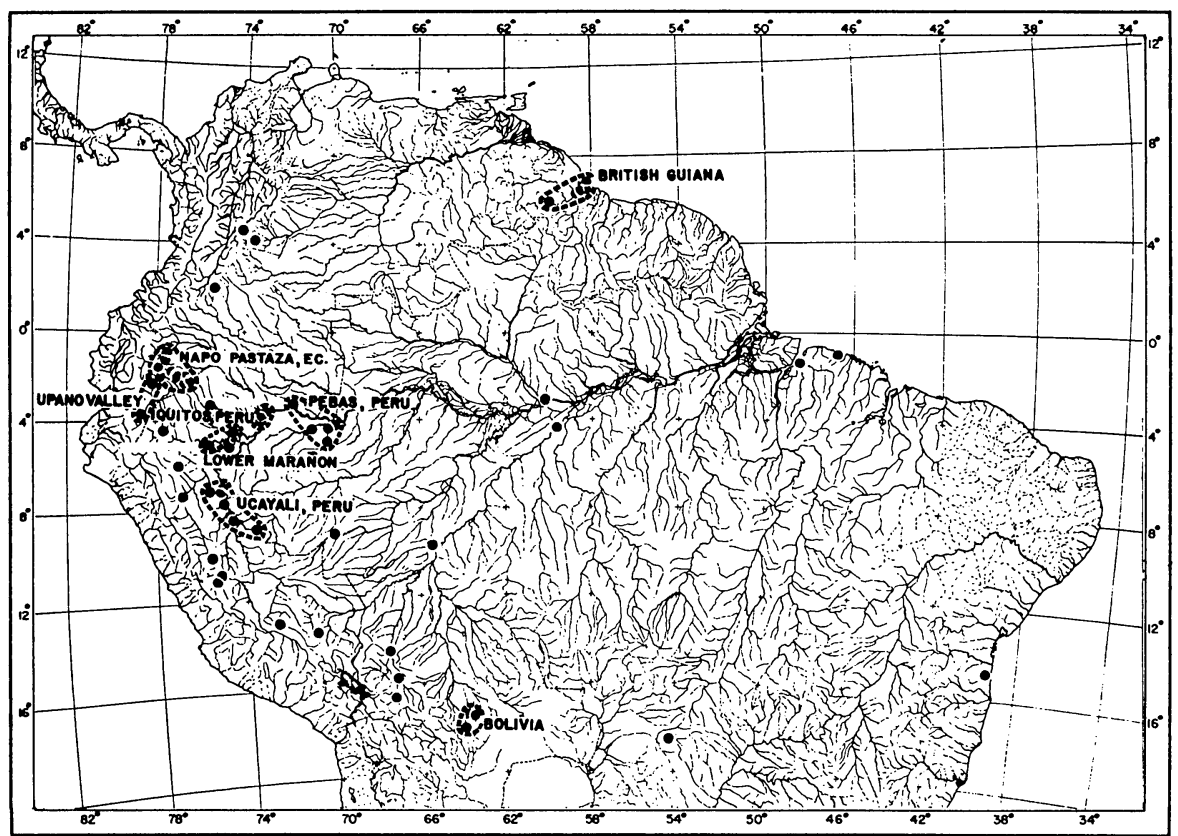

Map 3. Geographic distribution of Dipsas catesbyi. Names and dashed circles refer to the population sampies used in analysis of variation in the species (Peters, 1956).

white border on each blotch; blotches in some contact when opposing, even far posteriorly, but usually alternating over most of body; interspaces unicolor, lack spotting or stippling (Pl. II $a$ ). Venter light cream, with dorsal blotches meeting or closely approximated and no spots between them anteriorly, ends of blotches widely separated posteriorly, with large, rectangular spots between neighboring blotches. Tail as in body, with 7-20 dorsal blotches, when countable.

Dorsum of head unicolor dark brown to black, with whitish collar on occipitals and nape of neck that comes forward over posterior labials and temporals; white stripe across snout from labial to labial, through loreals and along anterior edge of prefrontals. Dorsal markings fairly continuous or occasionally broken up across chin, nuchal collar broader ventrally, extending anteriorly on chin shields; snout stripe runs across first chin shields.

REMARKS. - I have provisionally synonymized Sibynomorphus macedoi Prado and Hoge with $D$. catesbyi, an action which may be rescinded when the type of the former has been re-examined. I was fortunate enough to have a series of excellent photographs of the type, which were prepared by A. R. Hoge and sent to me by Robert Mertens. The entire color pattern, as shown in these pictures, of the full body and of the head, as well as practically all of the scutellation of the type, can be duplicated by specimens of catesbyi. The only striking difference is in dorsal scale rows, which were given as 15-15-11 for the type of macedoi, but are 13 over 
practically all of the body in catesbyi. Variations in scale-row counts, though unusual for dipsadine species, are present. Of approximately 480 specimens of catesbyi examined for this study, 32 have increases to 15 scale rows on some part of the body. Also, 23 specimens show posterior reductions to either 12 or 11 scale rows, a situation which resembles $m a$ cedoi. More rare are specimens that combine increases to 15 with reductions to 11 . I have seen only 7 specimens ( 1 from British Guiana, 1 from Bolivia, 2 from Ecuador, and 3 from Peru) that have multiple fusions and additions of scale rows. Infrequent though they may be, specimens have been found from all parts of the range of catesbyi that duplicate all of the macedo $i$ characteristics and I have, accordingly, synonymized the name with catesbyi. I feel that a complete dorsal scale-row count is a vital part of this decision, however, and until it is made, I withhold final judgment.

A complete analysis of the variations observed within Dipsas catesbyi was published elsewhere (Peters, 1956). Owing to the excellent opportunity provided (by the Bassler collections in the American Museum of Natural History) to analyse extent and kind of variation within a single species, it was deemed desirable to issue the report as a separate unit. The published study has, however, provided the basis for many of the actions taken here. If the same variations found to be frequent within single populations and uniform samples of catesbyi were used as the basis for separation of two other dipsadine species, however, particularly if a species were based on only one or two specimens, then the validity of the two would be open to question. Many of the synonymies in this paper follow from this extrapolation. A detailed list of the specimens examined is given in the separate study.

\section{Dipsas copei Günther}

Leptognathus Copei Günther, 1872: 30.

Leptognathus pavonina (Part), Boulenger, 1896a: 450.

Leptognathus copii, Boulenger, 1920: 111.

Dipsas copii, Parker, 1935: 527.

HOLOTYPE. - BMNH, male, "probably from Surinam," from collection of Dr. van Lidth de Jeude.

RANGE. - Guianas (Map 4).

DESCRIPTION. - Rostral slightly wider than high, visible from above; internasals less than one-third length of prefrontals, which do not enter orbit; frontal slightly longer than wide, shorter than parietals; nasal semidivided; loreal does not enter orbit; preoculars 2; postoculars 2; suboculars none; primary temporal 1 ; secondary temporals 2 or 3 ; tertiary temporals none; upper labials 10 or 11 , 4th through 7th may enter orbit. Lower labials 10,11 or 12 , first pair in contact behind mental, 4 pairs in contact with first pair of chin shields; 3 pairs of chin shields.

Ventrals 218 in single male (count from type description), 211 in single female; anal entire; subcaudals circa 140 in male, 124+ in female (tail incomplete). Dorsal scales 15 (see note below on individual variation); vertebral row moderately enlarged; caudodorsals (for BMNH 1920.1.13.2): 


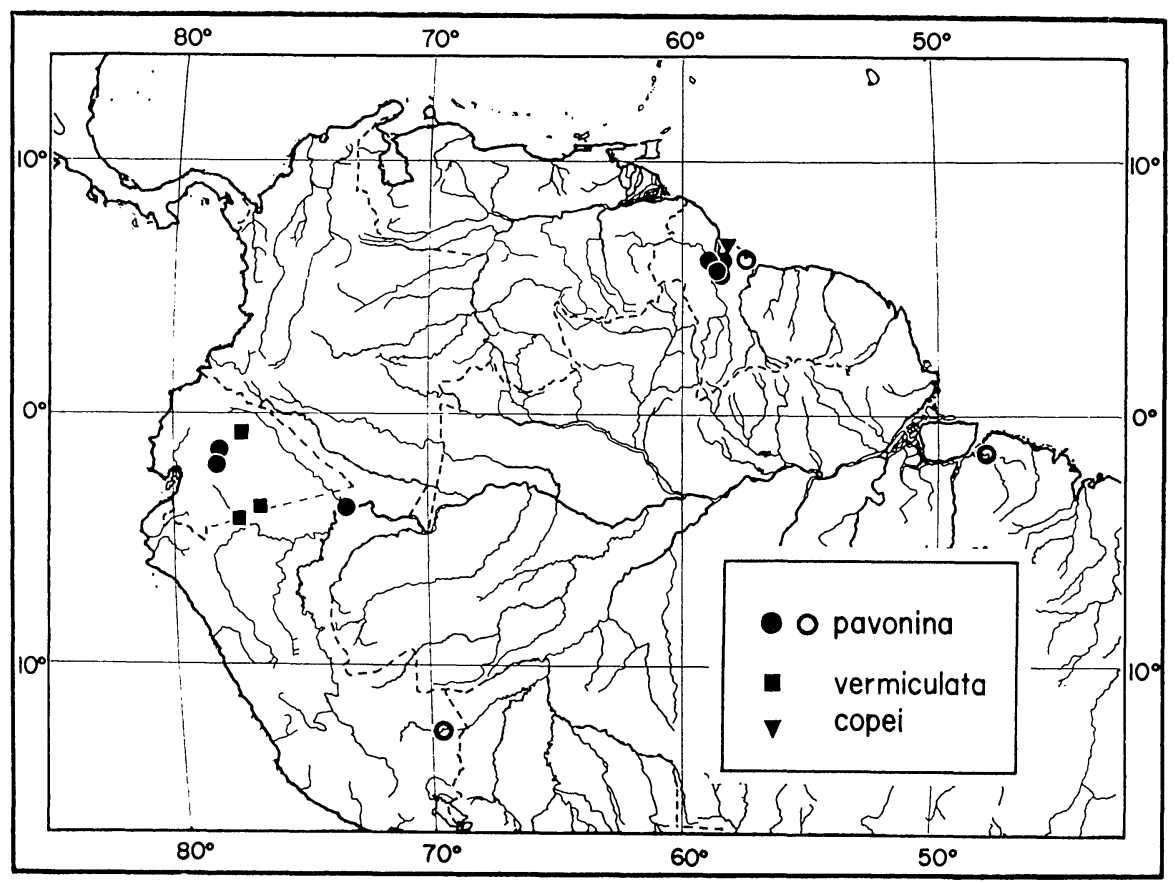

Map 4. Geographic distribution of the catesbyi group, except D. catesbyi (see Map 3). Solid symbols refer to localities for specimens examined; hollow. to literature records.

$$
\underline{6} \frac{2+3(11)}{2+3(10)} \underline{4} \frac{1+2(89)}{1+2(88)} \underline{2}(124+n \text { tip missing) }
$$

Body length of single male examined $376 \mathrm{~mm}$., tail incomplete.

Dorsal color light tan, with 14-15 rusty brown, white-bordered, rounded blotches, twice width of interspaces anteriorly, equal to or only slightly larger than interspaces posteriorly, usually opposite (one alternation only), fused completely across vertebral line anteriorly, only white borders fused posteriorly, blotch longest on midlateral scale rows, shortest middorsally and midventrally; interspaces darken and widen posteriorly, with darkbrown spot high on side, usually on outer edges of vertebral row, only one or two per interspace, often completely absent. Venter slightly lighter than dorsal interspaces, with irregular light-brown stippling, heaviest on midventral line, where it forms indistinct stripe, occasional larger darkbrown flecks, usually near ends of dorsal blotches; dorsal bands meet on midventer anteriorly, slightly separated posteriorly, shorter on belly than on first scale row. Tail (incomplete) with eight dorsal blotches, dorsally as body, ventrally with interspaces heavily suffused with dark brown, becoming indistinct posteriorly.

Dorsum of head with blackish-brown band across head, through eyes, and continuous across chin, connected with first dorsal blotch by posterior extension of color over parietals to vertebral row; occipitals, posterior 
temporals, and last labials straw-yellow, color continuous across throat, interrupted and rounded at vertebral row; entire snout to level of middle of prefrontals, entire chin to first pair of chin shields unicolor straw-yellow.

INDIVIDUAL VARIATION. - I had available only a single specimen and the type description. In BMNH 1920.1.13.2 the outer tips of the internasals are split off, producing a small scale between the nasals, internasals, and rostral on both sides. The prefrontal suture is incomplete posteriorly. The supraocular on the left side is fused with the upper postocular, leaving only a single postocular on that side. There is an extra scale below the postoculars on the right of the same individual, split off from the upper end of the sixth labial. It is directly below the eye. The primary temporals are two in the type, but in the second specimen the entire primary temporal row is fused, with obvious sutures still partially surviving, to the parietals on either side. The parietals thus extend to the labials. The secondary temporals are 2 in the type, 3 in the second specimen. Günther's type has 10 labials on one side, 11 on the other, with $4,5,6$, and 7 entering the orbit on one side, and 4, 5, and 6 on the other. The second specimen has the same number of labials as the type, but on the side with 11,5 and 6 enter the orbit, and on the side with 10, the 5th only. The latter situation is due to the presence of the subocular, which separates the 6 th from the orbit. The type has 10 lower labials, the second individual has 12 on the left and 11 on the right. In the other scales on the head there is no variation from the description given above.

The dorsals of the second specimen are extremely variable posteriorly, although they are regular over the most part of the body. The formula is:

(5) $17 \frac{3+4(7)}{3+4(9)} \underline{15} \frac{\mathrm{V}+7(195)}{\mathrm{V}+7(188-9,194)} \underline{13} \frac{\mathrm{V}-7(198-200)}{\mathrm{V}-7(199-200)} \underline{13}-\mathrm{V}$ (201 only) $\underline{13}$

$$
\underline{13} \mathrm{v}=\frac{7}{7}(204-06,210-11) \underline{14}(211)
$$

The width of the vertebral row varies directly with the number of dorsal scale rows, for it is moderately enlarged when there are 15 , and broadly enlarged when there are 13; and when there are 14 there is no vertebral row.

There is no apparent difference in the color and pattern of the two specimens.

REMARKS. - Boulenger $(1896 a: 450)$ placed this species in the synonymy of Dipsas pavonina, where it remained until a second specimen, the one discussed above, became available in 1920. Boulenger pointed out the error of his synonymy in a footnote to his description of Leptognathus hammondi, but his correction apparently slipped the attention of catalogers of the genus, for the species has been cited only once since 1896 as a synonym. Parker (1935:527) cited this species as belonging to his "Series A" grouping of species, which contains forms that are, to all intents and purposes, endemic to the Guianas. There have been no additional specimens of the species collected since his paper, and his analysis remains correct.

The variability between 15,14 , and 13 scale rows is perhaps an 
indication of the phylogenetic relationships within this genus, as has been discussed elsewhere. Dipsas pavonina closely resembles copei in general pattern and color, but has only 13 scale rows, and a wider vertebral row, indicating a direct relationship between width of vertebral row and total number of dorsal scale rows.

SPECIMENS EXAMINED.-

BRITISH GUIANA: Georgetown (BMNH 1220.1.13.2).

ADDITIONAL RECORDS. -

"Probably from Surinam" (BMNH, type).

\section{Dipsas pavonina Schlegel}

Dipsas pavonina Schlegel, 1837: 280.

Leptognathus pavoninus, Duméril, Bibron, and Duméril, 1854: 474.

Leptognathus catesbyi (part), Gïnther, 1858: 180.

Leptognathus pavonina, Cope, 1868: 107.

Cochliophagus pavoninus, von Thering, 1910: 330 .

Sibynomorphus pavoninus, Amaral, 1926a: 9.

Dipsas indica (non Laurenti), Beebe, 1946: 24.

COTYPES. - One in Paris Museum, four in Musée des Pays-Bas, all apparently from "Guyanes."

RANGE. - Guianas to Pará, Brazil, and to Amazonian slopes of Andes; Colombia to Bolivia, on eastern slope (Map 4).

DESCRIPTION. - Rostral broader than deep, not or scarcely visible from above; internasals slightly more than half length of prefrontals, which do not enter orbit; frontal as long as broad, shorter than parietals; nasal entire or semidivided; loreal enters orbit; preoculars 1 or 2 ; postoculars 2 or 3 ; suboculars none or 1 ; primary temporals 1 or 2 ; secondary temporals 2 or 3 ; tertiary temporals 3 , 4 , or none; upper labials $9-11,4$ and 5 , 5 and 6 , or 5, 6, and 7 entering orbit. Lower labials 11 or 12, first pair in contact behind mental, 5 or 6 pairs in contact with first chin shield; 3 pairs of chin shields.

Ventrals 203-210 (217) in males, (186) 190-200 in females; anal entire; subcaudals 119-131 in males, 101-122 in females. Dorsal scale rows 13 from level of fifth or sixth ventral to anus; vertebral row moderately to broadly enlarged; caudodorsals:

$$
\begin{aligned}
& \text { Males: } 6 \underline{6} 2+3(8-20) 4 \underline{4} 1+2(48-82) 2(119-131) \\
& \text { Females: } \underline{6} 2+3(3-8) \underline{4} 1+2(44-54) \underline{2}(101-122)
\end{aligned}
$$

Maxillary teeth $18-22$ (6 individuals); palatine teeth 8-12 (5); pterygoid teeth 2-7 (8).

Body length male $544 \mathrm{~mm}$., female $486 \mathrm{~mm}$., minimum $285 \mathrm{~mm}$. (no juveniles examined); tail length male $267 \mathrm{~mm}$., female $230 \mathrm{~mm}$.

Dorsal ground color brownish-tan to reddish-tan, with 14-26 whitebordered, brownish-black dorsal blotches on body, which are widest at vertebral row, edges sloping inward to rounded lower border that extends onto ventrals and, occasionally, fuses with opposite blotch on midline anteriorly but posteriorly reaches extreme outer edges of ventrals or first scale row. First four or five blotches behind head so closely approximated 
that their white borders fuse and interspace color infiltrates in increasing amounts until complete from venter to vertebral line, anteriormost blotches elongate, four times length of short interspaces, gradually narrow to twice length of interspaces; interspaces usually unicolor, occasionally with small dark-brown spots. Ventral ground color same as or somewhat lighter than dorsal interspaces, whitish with dark spotting anteriorly, where dorsal blotches approach closely or fuse on midline, posterior to this region dark-brown spots are more regular, elongate, often white-bordered, usually directly below dorsal interspaces, forming two distinct, broken, parallel rows as far as anus. Tail as body, with $9-15$ dorsal blotches, two to three times as wide as interspaces, not distinctly narrowed laterally. Widely separated paired dark spots on ventral side, below small interspaces.

Dorsum of head almost entirely brownish-black, occasionally lightly stippled with white, a white bar from posterior half of each nasal across anterior edges of prefrontals, narrow white occipital collar extends forward on lower temporals and upper lips, usually broken by dark spot below eye on labials. Chin white with several large brown spots on labials and midline of chin shields and gulars.

Beebe (1946:25) described the color in life as "brownish-gray, whiter toward head, with numerous very large saddles of black."

INDIVIDUAL VARIATION (Table III). - The color pattern and ventral and subcaudal counts are the characters that set off this species. The thirteen specimens I have seen which fit, so far as those characters are concerned, are extremely variable in many of their other characters, particularly in upper labials. The range from 8 to 11 is somewhat unusual even for a dipsadine species, and a change from having the $3 \mathrm{~d}$ through 5 th labial in the orbit to having the 6 th and 7 th in that position is quite extreme. These characteristics are discussed below under geographic variation. The loreal enters the orbit in all except AMNH 52998, which has a long thin preocular split off the loreal. UMMZ 47747 has extra scales in the snout region, which are the result of fragmentation of the normal plates; and there is a small triangular scale between the two internasals and the

TABLE III

INDIVIDUAL AND GEOGRAPHIC VARIATION IN Dipsas pavonina

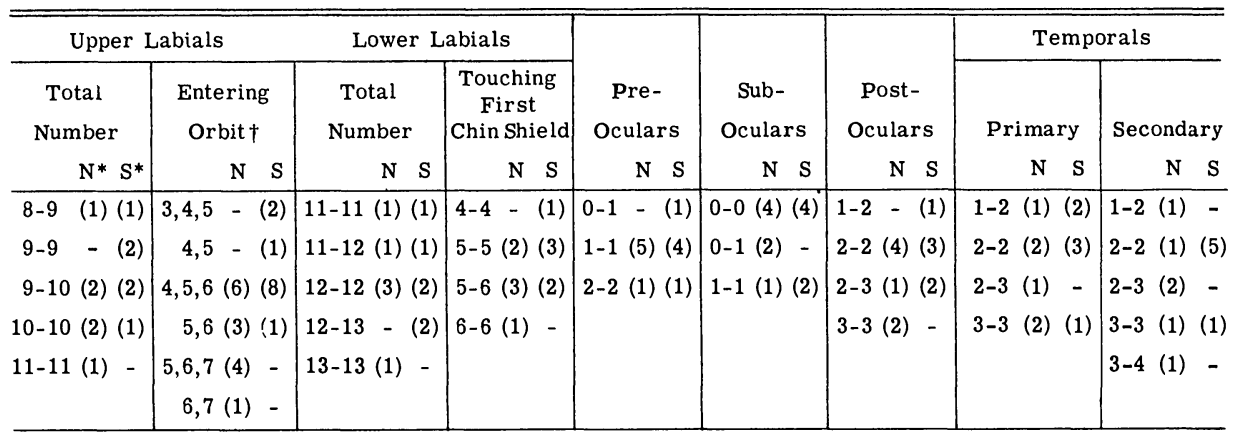

${ }^{*} \mathrm{~N}=$ Combined northern populations; $\mathrm{S}=$ Combined southern populations. † Single sides. 
rostral; another on each side of the upper posterior corner of the posterior half of the nasal; and a third inserted between the $1 \mathrm{st}$ and $2 \mathrm{~d}$ labials and the nasal on the right. This is another individual with two preoculars, but its loreal enters the orbit in the normal fashion, and the lower preocular is another of the small scales, here split off from the upper posterior corner of the loreal. Five of the seven individuals that lack suboculars are females. The subocular is usually quite small, and obviously split off from the upper end of what would otherwise be the first labial entering the orbit. From this it might be expected that those specimens with the subocular would have one less labial enter the orbit than those lacking it. When there is no subocular, three labials enter the orbit in 16 of 18 sides, and two enter the orbit on the other two sides. When the subocular is present, on the other hand, there are four sides which have only 2 labials entering the orbit, as anticipated above, but there are also four which have 3 labials entering the orbit. The correlation is obviously not precise. Fractionation is absent in the primary temporal row, but present on six of twenty-four sides in the secondary row. Between-row fusion, on the other hand, with primary and secondary rows involved, takes place on only two sides, but in neither specimen is fractionation also involved.

There is only a single pair of labials in contact behind the mental in all specimens. There are four shields on the right side paired with three on the left in AMNH 18154, otherwise all individuals have 3 pairs of chin shields.

Two of the thirteen individuals examined are slightly anomalous in their dorsal scutellation. In both of them it is a matter of occasional division of the vertebral row into two scales, raising the dorsal count to 14 for a row or two. In one specimen, AMNH 36027, the last ventral is divided as in Type 1, and in a second individual, EPN 742, there is partial fusion of the 84 th and 85 th ventrals on the midline, with the 84 th divided, in addition, as in Type 1. The caudodorsal reduction is 6-4-2 in all except two specimens, one of which, BMNH 1929.7.13.36, has the following formula:

$$
63+3(6) \underline{5} \frac{\mathrm{V}+2(7)}{4} \frac{\mathrm{V}+2 \quad(8)}{\mathrm{V}=\frac{2}{2}(8)} \frac{4}{1+2(52)} \frac{1+2}{1+2}
$$

This individual has a vertebral fusion, two lateral reductions and a vertebral division in abrupt succession. The other, EPN 744, has a crossvertebral reduction from four rows by fusion of both rows on the left side with the second on the right, followed shortly by the second on the right splitting off and then fusing with the first, to complete the reduction to two rows.

Variations in coloration or pattern are quite minor. The point at which the interspace color begins to invade the white borders of the blotches varies by only a blotch or two, and is usually after the fourth or fifth. The small dark spots high in the interspaces are quite often absent. The venter is usually not heavily spotted, but occasionally, as in AMNH 18154, the parallel streaks are almost continuous. The white streak usually present across the prefrontals may be quite reduced or almost totally absent. 
GEOGRAPHIC VARIATION (Table III) - The material available comes from two rather widely separated areas, one in British Guiana, represented by seven specimens, and one in Ecuador and northeastern Peru, whence I have six specimens. It is quite impossible to base any definite conclusions upon comparisons of such small samples, but the comparisons are interesting, nevertheless, and point out possibilities for future investigation. The entire range of variation in upper labials is found in the population from British Guiana. There is a difference in the specimens seen as to the actual labials that enter the orbit, for the third is not included in the range of variation of those from the north (British Guiana) and the seventh is not within the range of variation for those from the south (Ecuador and Peru). In practically all the remaining characters the material from the north contains the range of variation for the specimens from the south. There is at present certainly no obvious basis for separating the two populations on the subspecific level.

REMARKS. - Specimens of this species have been reported in the literature from Ilhéos, Brazil, by Boettger $(1898,129)$, "Brasilien" by Lampe (1902:41), and from Pará, Brazil, Amazonia, and Bolivia by von Ihering (1910:330), who took his records directly from Boulenger's catalogue (1896 :450), which also contains records for Berbice and Demerara, British Guiana; Pará, Brazil; West Ecuador; and Madre de Dios, Bolivia. There can be little doubt that Boulenger was working with the same species discussed here, for I have seen one specimen from the British Museum (Natural History) which has certainly been compared with Boulenger's material, and it is typical pavonina. If we accept all of his identifications, the range must extend into Bolivia on the south and to Pará on the Atlantic Coast. Lampe's very vague record is to be accepted until proven in error, but the same is not true of Boettger's record of a specimen from Ilhéos, for this is far from the known range of the species, and in a region quite different. He offered no data concerning coloration or scutellation, and I question the identity of his specimen.

Beebe (1946:24-25) discussed and figured this species under the name of Dipsas indica. I have examined at least one of the specimens mentioned, and possibly two, and both are typical pavonina. He stated that the species "is slow in movement and with large eyes, active both in daylight and at night. In disposition it is exceedingly gentle and wholly unresentfui of handling. All were taken among branches in second growth jungle." Moreover, he notes that the stomach contents were "(1) 5 small land snails, swallowed whole with a few bits of shell. (2) A mass of soft tissue, probably slugs, and 2 ants." The ants were probably unwittingly swallowed along with the slugs.

The entire group of specimens known for this species is from within the limits of the "Distrito Amazonico" as defined by Cabrera and Yepes $(1940: 14)$. All of the localities are peripheral in this district, however, and illustrate our lack of knowledge concerning the dipsadine fauna of the whole enormous Amazonas region. I entertain little doubt that pavonina ranges throughout the entire Amazon drainage system, at least at its lower altitudes. 


\section{SPECIMENS EXAMINED. -}

BRITISH GUIANA: Demerara River (BMNH 1929.7.13.36), Dunoon (UMMZ 47747), Kartabo (AMNH 8179, 18154; NYZS 3253), Parabam (AMNH 60855), Rockstone (CNHM 26664). ECUADOR: Canelos (AMNH 36027), Loreto (EPN 742, 744), Macas (AMNH 35808), Puyo (EPN 743). PERU: Iquitos (AMNH 52998).

\section{ADDITIONAL RECORDS. -}

BRITISH GUIANAS: Berbice (BMNH). BRAZIL: Pará (BMNH), no locality (Naturh. Mus. zu Wiesbaden, ex Lampe, 1902). BOLIVIA: Madre de Dios (BMNH).

\section{Dipsas vermiculata, new species}

HOLOTYPE. - EPN 741, male, Chichirota, Lower Bobonaza River, Napo-Pastaza Province, Ecuador, collected by Ramon Olalla (Pl. $\Pi b-c$ ).

DIAGNOSIS. - Dipsas vermiculata differs from all other members of the catesbyi group in that the prefrontals are fused, the loreal enters the orbit, the dorsum of the head is strongly vermiculated with light yellowishbrown and dark brown, and the upper labials are 7 with only 1 behind the last labial entering the orbit. It differs from both catesbyi and copei in having only one preocular, and from cope $i$ in that there are 13 scale rows and fewer subcaudals.

RANGE. - Amazonian Ecuador and Northeastern Peru (Map 4).

DESCRIPTION. - Rostral broader than high, visible from above; internasals shorter than prefrontals, which are fused, and do not enter orbit; frontal longer than wide, considerably shorter than parietals; nasal divided; loreal enters orbit; preocular 1; postoculars 2; suboculars none; primary temporals 2; secondary temporals 2 ; tertiary temporals none; upper labials 7 with 4 th, 5 th and 6 th entering the orbit, last labial exceedingly elongate, extends from postoculars to end of labial row. Lower labials 8 or 9 , first pair in contact behind mental, 5 pairs in contact with first pair of chin shields; 3 or 4 pairs of chin shields.

Ventrals 181-188 in males, $173-179$ in females; anal entire; subcaudals 107-117 in males, 103-106 in females. Dorsal scale rows 13, may reduce to 11 posteriorly; vertebral row moderately to broadly enlarged, caudodorsals:

Males: $62+3(8-12) 41+2(48-63) 2(107-117)$

Females: $\underline{6} 2+3(5-1 \overline{2}) \underline{4} 1+2(46-6 \overline{8}) \underline{2}(103-106)$

Maxillary teeth 19; palatine teeth 12; pterygoid teeth 21 .

Body length of male, $421 \mathrm{~mm}$. (holotype); of female, $349 \mathrm{~mm}$.; minimum, $171 \mathrm{~mm}$.; tail length of male, $188 \mathrm{~mm}$. (holotype); of female $156 \mathrm{~mm}$.; minimum, $76 \mathrm{~mm}$.

Dorsal ground color yellowish-brown, with 20-23 dark-brown, lightbordered blotches, rounded above and below, anterior blotches fused at vertebral line if opposing, not wider than posterior blotches, but always twice or more times the width of interspaces; blotches are separated by continuous white borders on vertebral line even if opposed, usually alternating posteriorly; interspaces darken to reddish-brown posteriorly and may be spotted with blotch color, ventral color extends to first and 
occasionally second dorsal scale rows between blotches. Venter yellowishwhite, with dark blotches, increasing in both size and number posteriorly; blotches do not meet on venter on body. Tail with 9-15 blotches, which are closely approximated anteriorly and fused posteriorly; in AMNH 35960, after point of fusion white borders form a continuous middorsal line to tip of tail, remainder of tail tip unicolor brown, with widely scattered yellow spots ventrally; blotches fused across ventral side of tail, and light-yellow ventral areas diminish in size posteriorly until completely absent.

Dorsum of head light yellowish-brown with streaks and large spots of dark brown giving vermiculated effect; brown spots distributed as follows: along rostral sutures, outer edges of internasals, outer edges of prefrontals, mutual borders of internasals, and prefrontals, posterior edge of prefrontal, anterior center of frontal, posterior suture of frontal, over eye on supraoculars, 4 or 5 on parietals, scattered over temporals, along each labial suture and extra one across center of elongate 7th labial (indicating lost suture and thus point of fusion?), posterior half of preocular, both ends of loreal, streaked on nasal. Chin also irregularly brown-spotted on white ground color.

HOLOTYPE. - (Characters in which the type is identical with the description of the species given above are not repeated here). No enlarged nuchal scales; 3 scales between parietal and enlarged vertebral scales. Eight lower labials on right, 7th straplike, result of fusion between 2 scales, first 5 labials in contact with first chin shields; 9 lower labials on left, with first six in contact with first chin shield. Three chin shields on left, first large and apparently the result of fusion of 2 scales; 4 chin shields on right. 181 ventrals, last divided, Type four; 107 subcaudals. Dorsal rows:

$$
\underline{15} \frac{3+4(4)}{3+4(5)} \underline{13}
$$

Caudodorsals:

$$
\underline{6} \frac{2+3(8)}{2+3(10)} \underline{4} \frac{1+2(48)}{1+2(47)} \underline{2}(107)
$$

Sixteen blotches on body; seven on tail.

INDIVIDUAL VARIATION. - On the five specimens available for examination, several features were noted that may or may not prove to be of consequence. In four of the five, the prefrontals are fused into a single scale, a situation found irregularly in several other dipsadine species. EPN 740 has 2 preoculars on both sides, and the loreal is excluded from the orbit. There is only a single anterior temporal on one side of the head in two of the five specimens. The postocular is single on both sides in UMMZ 89029, and on one side of AMNH 55889. Both the type and AMNH 35960 have a pair of enlarged, nuchal-like scales behind the parietals in a position usually occupied by occipitals much the same size as other dorsal scales. The upper labials in AMNH 55889 are only 6, with the 4th and 5th entering the orbit. The chin shields are 3 in UMMZ 89029, 4 in AMNH 35960 and 55889, 3-4 in EPN 741 and 2-3 in EPN 740. In both EPN 
specimens fusion of the two anteriormost on one or both sides is obvious. There are 3 to 5 scales between the parietals and the enlarged vertebrals.

The dorsals in the type and in EPN 740, and AMNH 35960 are entirely regular, and are 13 to the anus. In UMMZ 89029 the formula is:

$$
15 \frac{3+4(5)}{4+5(6)} \underline{13} \frac{\mathrm{V}+6(158-9,169-70,184)}{\mathrm{V}+6(160,162-71,176-77,185)} 11
$$

The dorsals reduce to 11 at a point anterior to the 150th ventral in AMNH 55889 , but the exact point could not be determined due to the condition of the specimen.

REMARKS. - The relationship of the species appear to be directly with Dipsas catesbyi. Their chief differences are the color pattern of the head and to a certain extent of the body, plus all of the points mentioned in the diagnosis. While many of the diagnostic characters are found in catesbyi as occasional variations, none of them occur sufficiently often to be considered typical of it. D. vermiculata is easily differentiated from other species of Dipsas, except, perhaps, for certain members of the articulata group. The difficulty there arises from the fact that the dorsal blotches in vermiculata are comparatively large and close together and fuse across the vertebral row when opposed. As a result, they resemble the full bands that are typical of the articulata group, but there is usually a gap between the ends of the blotches where they extend onto midventer, even though it may be quite small, on all parts of the body. In the species of the articulata group the bands that circle the body entirely (except in viguieri, which has a gap between the blotches posteriorly). The blotches in vermiculata are rounded above and below; those on the members of the articulata group have vertical borders.

Within the catesbyi group, vermiculata differs from catesbyi as pointed out above; from both pavonina and copei in the considerably lower ventral and subcaudal counts, fewer labials, both upper and lower, and in head coloration. In addition, it differs from cope $i$ in the number of scale rows.

SPECIMENS EXAMINED (all paratypes).-

ECUADOR: Chichirota (EPN 7.11, holotype, EPN 740); Turula (AMNH 35960); Río Napo watershed (UMMZ 89029). PERU: Gananashe, Far upper Río Santiago (AMNH $55889)$.

\section{THE INDICA GROUP}

\section{Dipsas indica indica Laurenti}

Dipsas indica Laurenti, 1768: 90.

Bungarus bucephalus, Oppel, 1810: 392 (in part).

Dipsas bucephala, Schinz (in Cuvier), 1822: 117 (in part).

Dipsadomorus indicus (in part), Duméril, Bibron, and Duméril, 1854: 470.

Leptognathus indicus, Günther, 1858: 180.

Dipsadomorus bucephalus, Jan, 1863: 99 (in part).

Leptognathus bucephalus, Cope, 1868: 107.

Dipsas latifasciatus (non Boulenger), Dunn, 1946: 19. 
HOLOTYPE. - Unknown, originally described on the basis of Seba's (1734) plate figures and descriptions, with Figure 5 of Plate 43 here designated as "iconotype" for the name. Type locality, originally given as "Ceylon," here restricted to the Amazonian region of South America.

RANGE. - Throughout region drained by Amazon River, in Brazil, Colombia, British Guiana, Ecuador, and Peru (Map 5).

DESCRIPTION. - Rostral slightly wider than deep or equally wide and deep, visible from above; internasals half length of prefrontals, which do not enter orbit; frontal longer than wide, shorter than parietals; nasal entire or semidivided; loreal enters orbit; preocular 1; postoculars 2; suboculars none; primary temporals 2 ; secondary temporals 2 or 3 ; tertiary temporals none; extra temporal scale more often present than absent; upper labials 9 , with 4 th, 5 th, and 6 th or 5 th and 6 th entering the orbit, one upper labial occasionally in contact with upper primary temporal, more often separated from it by extra te mporal scale. Lower labials 13 to 16 , two or three pairs in contact behind mental, 3 , 4, or 5 pairs of labials in contact with first pair of chin shields; 3 pairs of chin shields.

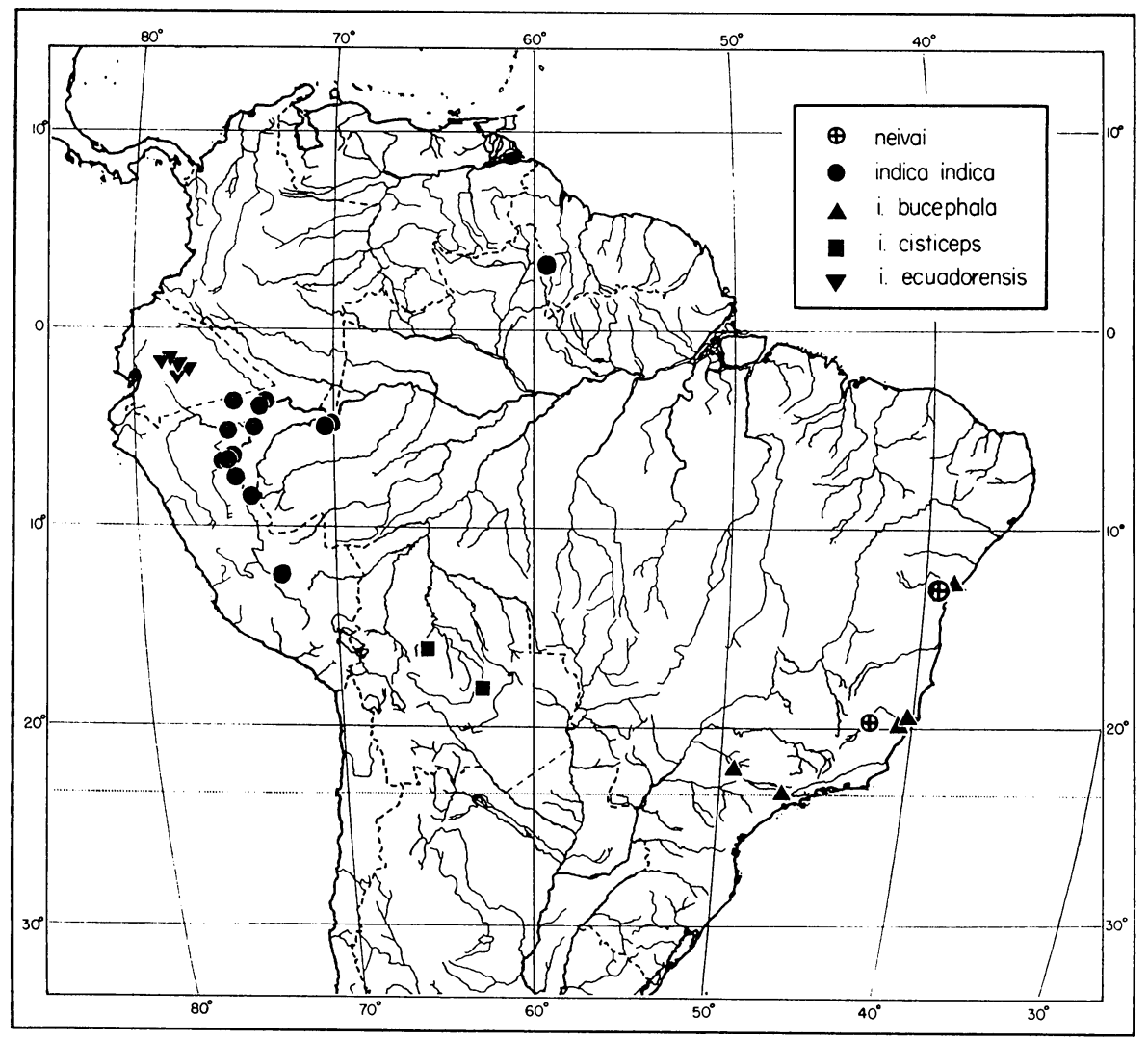

Map 5. Geographic distribution of the indica group. Records for D. neivai are based on the literature; all others, on specimens examined. 
Ventrals 192-204 in males, 180-200 in females; anal entire; subcaudals 100-117 in males, 87-110 in females; dorsal scale rows 13 on anterior half of body, reducing to 11 on posterior half, usually well forward, occasionally near anus; vertebral row broadly to strongly enlarged; caudodorsals:

$$
\begin{aligned}
& \text { Males: } \underline{6} 2+3(3-17) 4 \underline{4} 1+2(37-80) 2 \frac{2}{(100-117)} \\
& \text { Females: } \underline{6} 2+3(2-1 \overline{8}) \underline{4} 1+2(26-8 \overline{2}) \underline{2}(87-110)
\end{aligned}
$$

Dorsal ground color grayish-brown, often with reddish tinge, with 2547 light-bordered, blackish-brown blotches on body, distinctly wider at ventrals than at vertebral line, with sloping sides, first blotch broadly fused across vertebral line, occasionally with narrow, broken white line middorsally, white borders of posteriormost blotch often in contact with border of opposite one across vertebral line, blotches usually alternating posteriorly, ends of blotches of ten in contact with neighboring ones or narrowly separated by white or yellow spot, blotches occasionally with yellow spot centered on first scale row, spot very small or entirely absent posteriorly, spots may form row in first and second blotches, light border of blotches often broken into series of them (Pl. III $a$ ), interspaces occasionally with dark spots near vertebral line, more often unicolor, interspace color cut off by blotches and yellow interblotch spots, does not extend onto ventrals. Venter for most part unicolor dark brown, only slightly lighter than dorsal blotch color, which blends with it on ends of ventrals, yellow streaks and spotting often present and prominent on anterior third of belly, spots may form two parallel rows. Tail pattern as body, with 16-28 dorsal blotches, often difficult to detect, yellow spots at ends of blotches on first scale row retained even after blotch loses its identity; venter entirely unicolor.

Dorsum of head gray-brown (darkening in old adults), with large spots and variegations of reddish-brown on all scales, not lineolate on neck, single large spot with light borders on frontal and parietals plus many smaller spots on each, also prominent spots on prefrontals, internasals, temporals, loreals, and nasals; upper labials with dark sutures, first dorsal blotch extends anteriorly over occipital region to corner of mouth, and well onto throat. Chin and throat for most part light gray-brown, with dark brown mottling, except where solid brown edge of first dorsal blotch extends onto throat.

Juveniles considerably lighter in interspaces than adults, with more contrasting color pattern.

INDIVIDUAL VARIATION (Table IV). - Variation from the normal arrangement of the dorsal head scales is found in only two specimens: in AMNH 54265 the internasals and prefrontals are fused, with only a slight trace of sutures left; in AMNH 52264 there is a short median suture on the frontal just posterior to the suture between the prefrontals.

One specimen, AMNH 55764, has the loreal divided horizontally across its upper third. The nasal is single in thirty-one of the specimens for which it could be checked, and is semidivided in thirteen. It is not completely divided in any of the specimens. There is a single preocular in all individuals except AMNH 52399, in which it is fused with the prefrontal on 
TABLE IV

INDIVIDUAL VARIATION IN Dipsas indica indica

\begin{tabular}{|c|c|c|c|c|c|c|c|c|}
\hline \multicolumn{2}{|c|}{ Upper Labials } & \multicolumn{3}{|c|}{ Lower Labials } & \multirow[b]{2}{*}{$\begin{array}{c}\text { Paired } \\
\text { Chin } \\
\text { Shields }\end{array}$} & \multirow[b]{2}{*}{$\begin{array}{c}\text { Post- } \\
\text { Oculars }\end{array}$} & \multicolumn{2}{|c|}{ Temporals } \\
\hline $\begin{array}{c}\text { Total } \\
\text { Number }\end{array}$ & $\begin{array}{c}\text { Entering } \\
\text { Orbit }\end{array}$ & $\begin{array}{c}\text { Total } \\
\text { Number* }\end{array}$ & $\begin{array}{c}\text { Touching } \\
\text { First } \\
\text { Chin Shield }\end{array}$ & $\begin{array}{c}\text { Touching } \\
\text { Behind } \\
\text { Məntal }\end{array}$ & & & Primary & Secondary \\
\hline $7-8 \quad(2)$ & $3,4,5(3)^{*}$ & $12(1)$ & $2-4(1)$ & $1-1(2)$ & $1-1(1)$ & $1-1(3)$ & $1-1(2)$ & $2-2(8)$ \\
\hline $8-8 \quad(3)$ & $4,5(13)$ & $13(14)$ & $3-3(2)$ & $1-2(3)$ & $2-2(4)$ & $1-3(1)$ & $1-2(3)$ & $2-3(7)$ \\
\hline $8-9 \quad(7)$ & $4,5,6(50)$ & $14(19)$ & $3-4(2)$ & $2-2(18)$ & $3-3(24)$ & $2-2(38)$ & $2-2(33)$ & $3-3(23)$ \\
\hline $9-9 \quad(27)$ & $4,5,6,7(2)$ & $15(18)$ & $3-5(5)$ & $2-3(4)$ & $3-4(7)$ & $2-3(1)$ & $2-3(2)$ & $\mathrm{F}^{\dagger}(6)$ \\
\hline $9-10(3)$ & $5,6(16)$ & $16(17)$ & $4-4(10)$ & $3-3(10)$ & $4-4(1)$ & $1-2(1)$ & $3-3(2)$ & \\
\hline $10-10(2)$ & $5,6,7(4)$ & $\begin{array}{l}17(2) \\
18(1)\end{array}$ & $\begin{array}{l}4-5(11) \\
5-5(5) \\
5-6(3)\end{array}$ & & $4-5(1)$ & & & \\
\hline
\end{tabular}

*Single sides, ${ }^{\dagger}$ Fractionated.

each side. The suboculars are lacking in all except five specimens, two of which have the formula $0-1$, and three with the formula 1-1. In one of those with $0-1$, the subocular is posterior to the labials entering the orbit; in all the others it is a presubocular. The small extra temporal scale seen in occasional specimens of the other subspecies of indica is very commonly present in $i$. indica and often is enlarged to the size of the lower primary temporal. It is present on both sides of the head in eighteen individuals, on one side in eight, and on neither side in thirteen, for those specimens for which it is recorded. In AMNH 55404 the extra temporal is present on the left, and two more small scales are present above it, separating the upper primary from the postoculars as well as the lower primary; and another small scale is inserted between the upper and lower primaries, separating them anteriorly. The situation is similar in ANSP 10214, although that specimen has only 2 extra temporals, rather than 3 , on the left. In AMNH 55039 the middle secondary temporal seems to have been divided into two parts by a vertical suture, followed by fusion of the anterior portion with the upper secondary.

The upper labials are 9 in 74 percent of the specimens examined. A definite correlation exists between the total number of labials and the number entering the orbit (Table V). There are 3 labials behind the last one entering the orbit in 89 percent of the specimens, an indication that the

TABLE V

Correlation between Number of Upper Labials and Labials Entering Orbit in Dipsas indica indica

Labials Entering Orbit

\begin{tabular}{|c|c|c|c|c|c|c|c|}
\hline$\underline{2}$ & & $3,4,5$ & 4,5 & $4,5,6$ & $4,5,6,7$ & 5,6 & $5,6,7$ \\
\hline ] & 7 & 1 & 1 & $\cdots$ & $\cdots$ & $\cdots$ & $\cdots$ \\
\hline 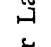 & 8 & 2 & 12 & 1 & $\ldots$ & $\ldots$ & $\cdots$ \\
\hline वै. & 9 & $\cdots$ & $\cdots$ & 48 & 2 & 14 & $\cdots$ \\
\hline 5 & 10 & $\ldots$ & $\ldots$ & 1 & $\cdots$ & 2 & 4 \\
\hline
\end{tabular}


variation in labial count takes place from the level of the eye forward. Thirty-two percent have only 2 labials in the orbit, 2 percent have 4 , and 66 percent have 3 . When only 2 enter the orbit, it appears to be a result of fusion between the 4th and 5 th, for the 4th becomes a somewhat larger scale. Although only the 4th and 5th labials out of 8 enter the orbit on the right side of the head of AMNH 53929, a partial suture is present on the 4th, and this suture is bordered by dark pigment, as in the normal situation. This intermediate condition is indicative of what actually happens in those in which the fusion is complete, and only 2 labials enter the orbit. There may be from 2 to 4 scales anterior to the first that enters the orbit, but there are 3 in 75 percent of the specimens. In four of the specimens examined there are 2 labials in contact above the labial between them, with a single instance in three, and two in the fourth (AMNH 52792) in which the $3 \mathrm{~d}$ and 5 th are in contact above the 4 th on both sides of the head.

The mental is a fairly stable scale, and displays little variation from its normal condition. In one specimen, AMNH 52792, it has an incomplete suture on the right, and a labial is almost formed. The suture does not extend out to the lip line. In three specimens the posterior end of the mental extends between the first pair of labials and prevents their contact. In two specimens there is a tiny scale split off the anterior end of one of the first pair of chin shields, and in one it prevents the contact of the second labial pair. There are ten specimens which have 2 lower labials in contact behind the labial between them. Six of the ten have a single contact, three have two, and one has three.

All of the variations in the dorsal scale rows occur in the vertebral row, and generally involve absorption of the paravertebrals, usually in an abrupt fashion, with the vertebral row widening greatly. Only two specimens lack a reduction to 11 rows altogether. In the rest not only are the rows reduced to 11 , but the reduction is quite far anteriorly on the body, as the formula tor a male, ANSP 11375, shows:

$$
\text { (8) } 13 \frac{\mathrm{V}+6(152)}{\mathrm{V}+6(149)} \underline{11}(201)
$$

This formula, or a slight variant from it, is typical for the subspecies. In the variant there is a simple series of inconclusive fusions and replacements anterior to the final reduction to 11, as in the formula for ANSP 10214:

$$
\text { (6) } 13 \frac{V+6(160,168-69,172 \rightarrow)}{V+6(161-62,167-8,171 \rightarrow)} 11
$$

This type of formula is found in fourteen specimens. In two specimens, a division of the vertebral row into two equal parts occurs, as in the formula for AMNH 52399:

$$
\text { (7) } 13 \mathrm{~V}=\frac{7}{7}\left(37-38,67-68 \text { only) } \underline{13} \frac{\mathrm{V}+6(153)}{\mathrm{V}+6(155)} \underline{11}\right.
$$


Four specimens have various combinations of the above formulas, and all have a large number of reductions and additions, with AMNH 52770 having: the most, a total of 19 .

The caudodorsal reductions are as given above in all except six specimens. There are two variations of the normal pattern, one of which is illustrated by the formula for AMNH 55764:

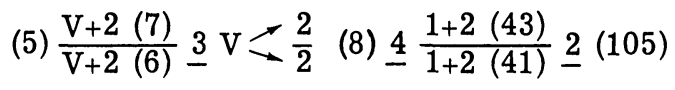

and the other is displayed by AMNH 55213:

$$
\text { (6) } \frac{}{2+3+\mathrm{R} 3(7)} \underline{4} \mathrm{~V}+\mathrm{R} 2(8) \underline{3} \mathrm{~V} \succ \frac{2}{2}(9) \underline{4} \frac{1+2(55)}{1+2(63)} \underline{2} \text { (98) }
$$

There are three specimens with each of these variations.

Seven specimens have divided ventrals. Five of them have only a single division, two of Type 1, two of Type 3, and one of Type 4. In all of the five it is the last ventral before the anus. AMNH 52399 has the 160 th and 170th ventrals of 188 divided as in Type 1, and AMNH 55375 has both Type 1 (on ventrals 109 and 123) and Type 3 (on ventrals 117 and 120) divisions. The umbilical scar was noted on a single female only, AMNH 55039, on ventral 173 (body length, $175 \mathrm{~mm}$.). Only a single specimen, ANSP 10143, has fused subcaudals, with the second and 109th single across the tail.

GEOGRAPHIC VARIATION. - The largest series of specimens of this subspecies comes from the Bassler collections in the American Museum of Natural History, and is entirely Peruvian. Several other single specimens serve to indicate that the range extends throughout the Amazonian Basin, but in no other instance is the material of sufficient size to allow a comparison with the Bassler material. The single specimen from British Guiana is one of two which lacks the reduction from 13 to 11 dorsal scale rows; the other, USNM 119013, is from Peru. This indicates that the absence of reduction is sporadic throughout the range. The specimen from British Guiana, with 27, also has the lowest number of body blotches recorded for females. No other specimen has less than 30. The USNM specimen from Peru mentioned above has the lowest counts recorded for females for both ventrals and subcaudals. The highest counts of ventrals and subcaudals for females are recorded for MNB 688, from the state of Amazonas, Brazil. The entire range of ventrals and subcaudals for the males of the subspecies is found in the Peruvian specimens.

REMARKS. - Laurenti, in his original description of indica, cited Seba (1734, Pl. 43, Figs. 4 and 5) as the source of his information concerning the species. He apparently did not himself examine any additional material, for his description is exceedingly vague, and provides only a single clue as to which figure might be selected as the type of the species. This clue is his statement that the head is variegated with red, which can apply. only to the specimen shown in Figure 5, according to Seba's descriptions (1734:71) of the head patterns. Seba points out that only one pair of spots is evident on the head of the specimen in Figure 4, but that the head of the 
specimen in Figure 5 is elegantly variegated. Since this remark is applicable only to the subspecies found in the Amazonian region or to the one from Ecuador herein described as new, I feel justified in restricting Seba's name to the Amazonian form. There is little question that Seba had material available from Amazonian Brazil, for he described and figured several species in his original work which are now known to be restricted in their ranges to that region. The mistaken reference to Ceylon in the original description by Seba was not an uncommon error, for early collectors were not particularly painstaking in labeling their material, and collections often changed hands many times before being utilized in such works as Seba's. As far as is now known, the Ecuadorian subspecies, which also has a variegated head, is extremely restricted in its range, and it is most unlikely that Seba had a specimen belonging to that form.

There are several literature records for the species which seem attributable to this subspecies. It is probable that Gomes' specimen (1918: 525) from Ceara, Brazil, belongs to this form. Although I have not seen the specimen from Chanchamayo, Peru, that Schmidt and Walker (1943:288) discussed, I have seen others from the same locality, and they are representative of this subspecies. The one considered by Beebe (1946:24), from Kartabo, British Guiana, is not a member of this species, but an example of Dipsas pavonina. I have seen no specimens from coastal British Guiana, but it is quite possible that this subspecies may be found there. I have examined a specimen, discussed by Dunn (1946:19), from the province of Loretta in Peru, and that described by Shreve (1947:314) from Leticia, Colombia, and find that both of them are members of this subspecies. Dunn's specimen was discussed under the name of Dipsas latifasciatus (Boulenger).

\section{SPECIMENS EXAMINED. -}

"BRAZIL": (ANSP 10214). Amazonas; Río Javary, Benjamin Constant (MNB R688). BRITISH GUIANA: Marudi (AMNH 60857). COLOMBIA: Leticia (MCZ 48976), Mitu, Vaupes R. (ANSP 25732). ECUADOR: (ANSP 10143). PERU (ANSP 11375), Cashiboya (AMNH 52303), Chanchamayo (AMNH 53321), Comberciato (USNM 50734), Río Cushabatay (AMNH 52792, 52795), Fundo Sinchono (USNM 119013), Isla Lupuna (AMNH 52722), Iquitos (AMNH 522§4, 52ن̈25-26, 52770, 53492, 52399), Monte Carmelo, near Isla Cedro (AMNH 55507), Ollanta (AMNH 52102, 52929, 54574), Pampa Hermosa (A MNH 53560, 53780, 53929, $54192,54213,54235,54315,54411,54488,55039,55213,55238,55375,55404,55764,55867)$, Payerote (AMNH 52552), Pébas (MCZ 12424, 16384), Puente Reforma (AMNH 52978), Roaboya (AMNH 52478), Santa Teresa (AMNH 53173), Utoquinia (AMNH 52940).

\section{Dipsas indica bucephala Shaw}

Coluber bucephalus Shaw, 1802: 422.

Bungarus bucephalus, Oppel, 1810: 392.

Dipsas bucephala, Schinz (in Cuvier), 1822: 117 (in part).

Dipsadomorus Indicus, Duméril, Bibron, and Duméril, 1854: 470 (in part).

Leptognathus indicus, Günther, 1858: 180 (in part).

D. [ipsadomorus] bucephalus, Jan, 1863: 99 (in part).

Dipsas indica, Boulenger, 1896a: 461 (in part).

HOLOTYPE. - Unknown, described on the basis of Seba's figure of species (1734, Pl. 43, Fig. 4). Type locality originally given as "Ceylon," here restricted to Brazil. 
RANGE. - Southeastern Brazil (Map 5).

DESCRIPTION. - Rostral broader than deep, visible from above; internasals half or more length of prefrontals, which do not enter orbit; frontal as long as or longer than wide, shorter than parietals; nasal divided wholly or in part; loreal enters orbit; preocular 1; postoculars 2; suboculars none or 1 ; primary temporals 2 ; secondary temporals 2 ; tertiary temporals none; extra temporal scale absent; upper labials 8, with 4th and 5th entering orbit, or 9 with 5 th and 6 th in the orbit, 1 labial in contact with upper primary temporal, separating postoculars and lower primary temporal. Lower labials 12 to 14,2 pairs in contact behind mental, 4 or 5 pairs of labials in contact with first pair of chin shields; 3 pairs of chin shields.

Ventrals 180-188 in males, 174-185 in females; anal entire; subcaudals 83-109 in males, 76-96 in females. Dorsal scale rows 13 from level of 6 th to 16 th ventrals to anus, lacking posterior reduction to 11 , vertebral row broadly to strongly enlarged; caudodorsals:

Males: $6 \underline{6} 2+3(15-28) \underline{4} 1+2(62-95) \underline{2}(83-109)$

Females: $\underline{6} 2+3(9-24 \overline{)} \underline{4} 1+2(47-75) \underline{2}(76-96)$

Dorsal ground color brownish-tan darkening to light brown in older individuals, with 21-30 faintly white-bordered, chestnut-brown blotches, anteriormost constricted and rounded above, sides parallel or even slightly rounded laterally, separated on vertebral line only by narrow light borders when opposite, begin to alternate only short distance behind head, two to three times width of interspaces; posteriormost rounded above, may also be rounded at ventrals, sides parallel, edges at first dorsal scale row and ventrals widely separated from neighboring blotches, as wide as or slightly narrower than interspaces; large yellow spot centered in all blotches on first scale row and adjacent ventrals, spots form streak or series of spots on first and second blotches, yellowish stippling on sides in center of blotches above spots (Pl. III $a$ ); interspaces often with large brown spot near vertebral line centered between neighboring blotches, otherwise unicolor dorsally and laterally, ventrally with large yellow spot between blotches anteriorly, with yellow spot at end of each blotch posteriorly, with dark-brown area between each pair. Venter yellowish-brown anteriorly with dark-brown spotting and stippling, progressively darkening to darkbrown posteriorly with yellowish stippling, dark-brown spotting on two rows anteriorly, rows very faintly defined posteriorly, ventral color extends onto sides between neighboring blotches where yellow spots are paired. Tail as in body, with 12-20 dorsal blotches, venter very dark brown with scattered yellow stippling.

Most of dorsum of head unicolor light tan to brown, very small, darkbrown, light-bordered blotches occupying less than one quarter of area of parietals and frontal, single small spot on occipitals, often confined to single scale behind parietals, rest of head lacks spotting or stippling entirely. Chin and throat unicolor yellow or with dark stippling along sutures in older individuals.

INDIVIDUAL VARIATION. - Variations in the normal arrangement of dorsal head scales occur in four specimens. The prefrontals are 
completely fused in UMMZ 62794, and only the anterior half of the suture between the prefrontals is present in UMMZ 62708. One specimen, MCZ 1927, has an extra suture on the right prefrontal, running anteriorly from the posterior margin about half the length of the scale. Extra sutures are present also on the parietals in MCZ 20857, where they run from the outer edges at level of the anterior corner of the upper secondary temporals diagonally forward across the parietal; they are not complete. In addition to the anomaly mentioned above, UMMZ 62708 has the posterior point of the frontal sutured off to form an extra scale, and also has a small scale at the junction of the frontal, parietal, and supraocular.

There is a fairly large amount of variation in the sides of the head. In specimen the loreal is split into two scales by a horizontal suture on both sides of the head. On the left side the upper half of the scale is excluded from the orbit by the preocular; on the right side it enters the eye. The loreal is normal and enters the orbit in all other individuals; the preoculars are 1-1 in all specimens; the postoculars are 2-2 in all except one which has only a single scale on one side with two on the other, a second that has 2-3, and a third that has 3-3. The suboculars are normally absent, but one specimen has one on a single side only, three have one on each side, and one has two on each side. The primary temporals are 2-2 in all except three specimens, one of which has 2-3, the other two have 3-3. In all three it is the result of horizontal splitting of the upper primary temporal. The secondary temporals are 2-2 in nine, 2-3 in two, 3-3 in one, and fractionated in two. In both cases of fractionation it is the upper of two scales which is divided. MCZ 17829 has two small scales, one above the other, between the upper primary and secondary temporals, and above the lower primary. The upper labials are 8-8 in six individuals, 8-9 in four, 9-9 in five, and 10-10 in one. In all that have 8 , the 4 th and 5 th enter the orbit, and in all that have 9 , the 5 th and 6 th are in the orbit. In the one individual (MP 2460) with 10, the 5th through 7th enter the orbit on the left side, and the 6th and 7th are in the orbit on the right. In the same individual, the upper halves of the $3 \mathrm{~d}$ and 4 th labials on the right are fused and sutured off from their lower ends, which are completely separate from each other. In MCZ 17829 the 3d labial on the left is divided horizontally. One of the upper labials, usually the 7 th or 8 th, is in contact with the upper primary temporal on 23 of 28 sides. The small extra temporal between the postoculars and lower primary temporal is present on three sides of the 28 , and prevents this contact. In the other two cases of noncontact, the lower primary temporal is in direct contact with the postocular.

The lower labials are 13 on sixteen sides, which represents 57 percent of those counted. There are 12 in five specimens, 14 in three, 15 in three, and 16 in one. There are 2 pairs of lower labials in contact behind the mental in ten specimens, 3 pairs in contact in two specimens, and 2 pairs on one side in contact with 3 pairs on the other side in two individuals. There are 2 pairs of chin shields in one individual, 3 pairs in nine, 4 pairs in two, and 3 on one side paired with 4 on the other in two. One specimen, MNB R687, has a tiny scale behind the mental, anterior to the first labials, on the midline.

There are only two individuals, of the fourteen examined, that have a 
reduction of dorsal scale rows to 11 anterior to the anus. One of them, MCZ 17830, has the following formula:

$$
15 \frac{3+4(6)}{3+4(8)} \underline{13} \mathrm{~V}+6+6 \frac{(144,147-9,151-2,160 \rightarrow)}{(148,151,154-5,157,159 \rightarrow)} 11 \mathrm{~V} \succeq \frac{6}{6}(164,174) \underline{11}
$$

That is, irregular reductions to 11 occur between the 114 th and 160 th ventrals, but from there on the number of scales rows remains constant. In the second specimen, MCZ 1927, a reduction occurs one scale row anterior to the anus. In three specimens, the broad vertebral row occasionally divides into two scale rows, with the suture on the vertebral line, as in MP 2460:

$$
\text { (6) } \underline{13} \mathrm{~V}<\frac{7}{7}(28 \text { only) } \underline{13} \text { (183) }
$$

Both of the other two have more than a single vertebral division. On a single specimen, UMMZ 62794, the vertebral row divides unequally to give 7 rows on the left, leaving 6 on the right, while still retaining the vertebral row; it's formula is:

$$
\underline{15} \frac{\mathrm{V}+7(9)}{\mathrm{V}+7(10)} \underline{13} \frac{}{\mathrm{V}-7(59,63-65,70-74,79-80,91-92)} \underline{13}
$$

Increases in dorsal scale rows are present in four specimens, therefore, and decreases in only two. Both increases and decreases are very irregular.

Three specimens vary from the normal caudodorsal reduction. In them these reductions take place by cross-vertebral fusion, as in UMMZ 62794:

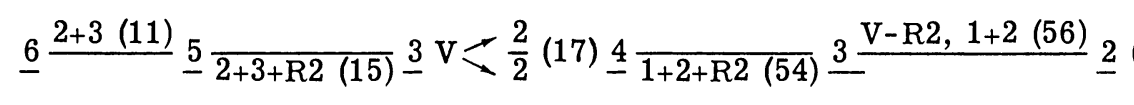

This specimen, however, is the only one of the three to have the crossvertebral fusion at the reduction of four to two rows; the other two have the normal fusion of the two lateral rows.

Three specimens have divided ventrals, one with Type 3 division and two with Type 1 . In each only a single ventral is involved, and in two it is the last ventral before the anus. Three specimens, one of which also has divided ventrals, have undivided caudals. The caudals involved are 2-9; $5-9 ; 4-12,34,42$, and 48; respectively. One specimen, UMMZ 62706, has two small scales inserted between the ends of the first pair of caudals on the midline.

The most obvious variation in coloration is that, with age, the interspaces become much darkened and the blotches slightly so. The spots high in the interspaces are sometimes absent. UMMZ 62709 has the anterior blotches completely and broadly fused across the vertebral line. MNB R687 is extremely light, but this may be due to fading after preservation. It has practically no discernible spots on the head. 
MCZ 1927, from Bahia, is badly faded, but it retains enough color pattern to demonstrate its individuality. It has much larger head spots and more variegation than normal bucephala, and shows a strong approach to indica. The body pattern, on the other hand, is more like that of bucephala.

GEOGRAPHIC VARIATION. - Nine of the fourteen specimens examined are either from unknown localities or from São Paulo, Brazil. All of those listed from São Paulo, either by state or by city (except the one from Lenções) were received from the Instituto Butantan, and the name of the city may be the point of reception rather than the actual place of collection. The single specimen (MP 1516) from the landward slope of the coastal range of southeastern Brazil is very badly faded, and it may not belong to this subspecies, even though it fits completely as far as scutellation is concerned.

The two specimens from the state of Espirito Santo have the highest and next to highest subcaudal counts observed: MP 2460 has 107 and MNB $\mathrm{R} 1272$ has 109 . One other specimen, UMMZ 62709, from the Instituto Butantan, has 107; the nearest to that count in the remaining specimens is 96. MP 2460 has three secondary temporals on both sides of the head. MCZ 1927, from the next state to the north, is the only other specimen with that count. The upper labials in MP 2460 are 10-10, the highest count observed for this subspecies.

The specimen from Bahia, MCZ 1927, is intermediate between indica and bucephala, and perhaps indicates an intergrading area between those two subspecies.

REMARKS. - When Shaw described and figured bucephala, he apparently used Seba's figure (1734: Pl. 43, Fig. 4) as his basis for the name. It is unlikely that he examined any additional specimens. There can be little doubt that he used Seba's figure, since the copy is obvious, though poor. While Shaw's artist duplicated the position and head shape of the original, he almost doubled the number of body blotches, from 59 in Seba to 82 ; he doubled the dorsal scale rows, which vary from 6 to 8 in Seba, and from 13 to 16 in Shaw; he distorted the dorsal head scales very much from the regular pattern shown by Seba, particularly in the snout region; and he omitted the blotches on the parietals, which Seba shows very clearly. Shaw mentioned the parietal spots in his description, however. Seba almost certainly had a specimen of indica at hand when that particular figure was drawn, and it resembles most distinctly the subspecies restricted to the southeastern coast of Brazil. Shaw's name, based upon Seba's figure, is therefore confined here to that population. Fortunately, Laurenti, who also described indica on the basis of Seba's figures, based the major part of his description on the second figure that Seba (1734: Pl. 43, Fig. 5) presented, and that figure seems to be drawn from a specimen from Amazonian Brazil. On the assumption that this is so, both names are available for use for different subspecies.

The hiatus between the ranges of the subspecies bucephala and cisticeps, as drawn from the specimens I have been able to examine, can be somewhat closed from the literature. I have seen the specimen (MP 1516) von Ihering (1910:337) examined and verify his identification. The locality is Lenções, Estado do São Paulo, Brazil, and the specimen is a bucephala. The one 
described by Serie $(1915 b: 105)$ from Misiones, Argentina, should be reexamined to determine which subspecies it represents. Serie's data could fit either cisticeps or bucephala, but on a zoogeographical basis I expect it to be cisticeps. Although the inclusion of the species Dipsas indica in his list of the species of snakes known from Misiones by Cranwell (1943:65) is probably based upon Serie's record, Cranwell had collections from that state and possibly had duplicated the original record.

SPECIMENS EXAMINED. -

BRAZIL: no added locality (MCZ 17829-30). Bahia; Bahía (MCZ 1927). Espirito Santo; Santa Thereza (MNB R1272), Linhares, Sooretama (MP 2460). São Paulo (MCZ 20856-57); Lencões (MP 1516), São Paulo (UMMZ 62706-09, 62794). Data lacking entirely: (MNB R687).

\section{Dipsas indica cisticeps Boettger}

Leptognathus (Dipsadomorus) cisticeps Boettger, 1885: 237. Dipsas bucephala (part), Boulenger, 1896a: 461. Dipsas cisticeps, Bertoni, 1914: 29.

HOLOTYPE. - Naturh. Inst. Linnaea in Frankfort, sex not known, from "Paraguay."

RANGE. - Bolivia and Paraguay (Map 5).

DESCRIPTION. - Rostral wider than deep, visible from above; internasals more than half length of prefrontals, which do not enter orbit; frontal longer than wide or as wide as long, shorter than parietals; nasal undivided; loreal enters orbit; preocular 1; postoculars 2; suboculars none; primary temporals 2 ; secondary temporals 2 or 3 ; tertiary temporals none; extra temporal scale absent; upper labials 8 with 4 th and 5th entering eye, or 9 with 5 th and 6 th in the orbit, 1 labial in contact with upper primary temporal, separating lower primary and postocular. Lower labials 12 to 14 , two pairs in contact behind mental, four or five pairs in contact with first pair of chin shields; 3 pairs of chin shields.

Ventrals 183-192 in males, 173-187 in females; anal entire; subcaudals 89-99 in males, 76-92 in females. Dorsal scales 13 from level of 6 th to 9 th ventral to anus, usually lacking posterior reduction to 11 ; vertebral row moderately to broadly enlarged; caudodorsals:

$$
\begin{aligned}
& \text { Males: } \underline{6} 2+3(11-23) 41+2(51-86) 2(89-99) \\
& \text { Females: } \underline{6} 2+3(5-18) \underline{4} 1+2(46-74) \underline{2}(76-92)
\end{aligned}
$$

Maxillary teeth 14-15 (2 individuals); palatine teeth 8 (2); pterygoid teeth $0(2)$.

Dorsal ground color light tan, with 22-27 white-bordered, dark-brown blotches on body, anteriorly opposed and fused across vertebral line, two to three times width of interspaces, posteriorly rounded above, usually alternating, when opposed, not fused across vertebral line, slightly wider than interspaces, sides of blotches parallel, as wide at first scale row as at vertebral row; yellow spot centered in blotch at first scale row, which in elongated anterior blotches is either long streak or series of spots equal in size (Pl. $\mathrm{III} b)$; interspaces unicolor, with yellow spot on first scale row 
and adjacent ventral tips. Venter brownish-yellow anteriorly, olive-brown posteriorly, with dorsal blotches extending well onto ventrals, but in no instance fused across midline; lateral extensions of midventer color usually continuous onto first scale row, may be cut off by extension of ends of blotches to neighboring blotches; if so, yellow spot present between blotches on first scale row and adjacent ventral tips; dark-brown spots usually present between neighboring blotches; midventer may be heavily peppered or spotted with light brown. Tail with 10-17 blotches that are only slightly darker than interspaces, blotches extend onto ventral surface, where they retain outline in yellow or blend into almost uniform dark-brown color.

Dorsum of head tan with one dark-brown, yellow-edged spot almost entirely filling frontal, one in each parietal, and single ovate or teardrop spot on occipitals at posterior end of parietal suture on midline, rest of head unicolor or with very few additional regular spots. Chin unicolor yellowishwhite, with few paired spots on throat.

Juveniles lighter than adults, with stronger contrast between blotch and interspace colors, otherwise as in adults.

INDIVIDUAL VARIATION. - The internasals and the prefrontals on either side are fused, but the midline suture is present in CNHM 35723. This is the only individual that does not have a completely normal arrangement of dorsal head scales. There is no variation from the description given above in the snout, loreal, or ocular region. The temporal region, is, of course, quite irregular, as in all the subspecies of indica. The tiny extra temporal, which when present is inserted between the labials, postoculars, and primary temporals, is absent in all except one specimen. The primary temporals are 2 in all except two individuals, which have only 1 on each side. The upper primary temporal is in contact with a labial, with the lower primary crowded posteriorly behind the labial, in all except one individual, in which the extra temporal prevents contact between the lower primary and the postocular. The secondary temporals are 2-2 in five specimens, 2-3 in one, 3-3 in four, and 3-4 in one. In CNHM 35723 the upper primary and upper secondary are fused on both sides, making an extremely elongate scale running the length of the parietal. Usually, when only two are present, the upper is quite large, and seems to be a result of fusion vertically between two scales. The upper labials are 7-8 in one, 8-8 in five, 8-9 in four, and 9-10 in one. On only two sides of the 22 seen were there 3 labials entering the orbit; all the others have only two. The single side with 7 labials has the $3 \mathrm{~d}$ and 4 th entering the orbit; those with 8 have the 4 th and 5 th, except for one, which has the $3 d$ through 5 th. When the labials are 9 , the 5 th and 6 th enter the orbit; in one exception the 4 th and 5 th enter instead. In the one side with 10 , the 4 th, 5 th and 7 th enter the orbit, with the 5 th and 7 th in contact above the 6 th. These data indicate that most of the variation in labial count in this subspecies takes place anterior to the labials that enter the orbit.

Of the 22 sides (eleven specimens) examined, one has 11 lower labials, four have 12 , seven have 13 , and ten have 14 . Two pairs are in contact behind the mental in eight specimens, two have only a single labial on one side in contact with two on the other, and one has two on one side in contact with three on the other. In UMMZ 67904 the first labial on the right 
appears to be fused to the mental, which is quite asymmetrical, and a single labial, the "first" in counting but actually the second, is in contact with two on the left side. The number of labials in contact with the first chin shield are 4 or 5 in ten sides each, and are 3 or 6 in one side each. Three of 11 specimens have 2 lower labials in contact behind the labial between them, at least once on each. The paired chin shields are 2-2 in two specimens, 2-3 in one, 3-3 in seven, and 3-4 in one. In UMMZ 63252 the first and third pairs of chin shields are in contact with each other on both sides on the midline, completely separating the second pair.

The dorsal scales are 13 from a short distance behind the head to the anus, with no reductions, in seven of the eleven specimens. In one there is a reduction to 11 six scales anterior to the anus. In the other three the reduction to 11 takes place 26 to 41 ventrals anterior to the anus, and the dorsal scale rows are 11 over a considerable part of the posterior portion of the body, with the vertebral row strongly enlarged. The caudodorsals are as given in the description above, except in UMMZ 63252 the formula of which is:

$$
\underline{6} \overline{2+3+\mathrm{R} 3(16)} \underline{4} \frac{2+3(20)}{\mathrm{V}-\mathrm{R} 3(20)} \underline{4} \frac{1+2(63)}{1+2(63)} \underline{2}(96)
$$

Three of the specimens have divided ventrals. All divisions are of Type 1.

A few specimens have more spots on the head than the usual prominent ones on the frontal, parietals, and occipitals. These additional spots are small, uniform, and occur on the supraoculars, the prefrontals, and the larger temporals; they are usually centered and single on each scale. Several individuals lack the yellow spots on the lower center of the blotches. The variation in ventral color, and the connections between the tips of the dorsal blotches on the venter have been mentioned above.

REMARKS. - One year after Boettger described cisticeps Boulenger placed it, with a question mark, in the synonymy of Dipsas indica. It was used by Bertoni (1914:29) without discussion in his list of Paraguayan species, but was omitted by both Werner (1922) and Amaral (1929) in their resumés of the species of Dipsas. Neither of these authors even included it in a synonymy.

The type of cisticeps does not entirely fit into the description given above for this subspecies. According to Boettger, it has 7-8 upper labials, which is a number recorded for one of the specimens examined, but he adds that the $3 \mathrm{~d}$ through 5 th enter the orbit on one side, and the 4th through 6 th on the other (it was observed above that normally this subspecies has only 2 labials in the orbit). Boettger said the type has 2 preoculars, but he did not discuss the loreal. He probably did not include the loreal as a preocular, for he stated that the 2 preoculars are equal in size, and this could not be true if the loreal were included. He gave the ventrals as 187 , and the caudals as 87 , both of which are included in the range of variation given above. The coloration of the body is quite similar to the subspecies discussed here, however, and Boettger's description of the "Auf dem Kopf 5 grössere, dunkel kastanienbraune, weissgesäumte Flecke, je einer auf den Parietalen, 3 in einer Querreihe hinter denselben" is sufficient to indicate that the 
diagnostic character for the subspecies described above is possessed by the type of cisticeps. Boettger did not mention a spot on the frontal, and it may be absent. He did say that the head is unicolor with the exception of the dorsal spots.

\section{SPECIMENS EXAMINED. -}

BOLIVIA; no other data (CM 2941). Cochabamba (AMNH 6780). Santa Cruz: (CM 2954; CNHM 16794, 35723; UMMZ 63252-53, 67902-05).

\section{Dipsas indica ecuadorensis, New Subspecies}

HOLOTYPE. - EPN 715, male, from the Río Solis, Caveceras del Río Bobonaza, $14 \mathrm{~km}$. ESE of Puyo, Napo-Pastaza Province, Ecuador, collected by Ramon Olalla, June, 1954 (Pl. III $c-e$ ).

DIAGNOSIS. - Dorsal ground color brownish-gray, dorsal blotches triangular and numerous; first pair of blotches does not meet across vertebral row; neck strongly lineolated with dark brown; head with many spots and vermiculations; reduction to 11 scale rows present. 5).

RANGE. - Known only from the Amazonian drainage of Ecuador (Map

DESCRIPTION. - Rostral as deep as wide, visible from above; internasals half as long as prefrontals, which do not enter orbit; frontal slightly longer than wide or as wide as long, shorter than parietals; nasal not or semidivided; loreal enters orbit; preocular 1, postoculars 2; subocular none; primary temporals 2 ; secondary temporals 2 or 3 ; tertiary temporals none; extra temporal scale between postoculars, anterior temporals and upper labials often present; upper labials 9, with 4th, 5th, and 6 th or 5 th and 6th entering orbit, one labial usually in contact with upper primary temporal when extra temporal scale is absent. Lower labials 13 to 15, two or three pairs in contact behind mental, 3, 4, or 5 pairs of labials in contact with first pair of chin shields; 2 or 3 pairs of chin shields.

Ventrals 181-205 in males, 181-93 in females; anal entire; subcaudals 99-114 in males, 87-101 in females; dorsal scale rows thirteen anteriorly reducing to eleven posteriorly; vertebral row broadly to strongly enlarged; caudodorsals:

$$
\begin{aligned}
& \text { Males: } 6 \underline{6} 2+3(5-18) \underline{4} 1+2(39-84) 2(99-114) \\
& \text { Females: } \underline{6} 2+3(3-7) \underline{4} 1+2(41-72) \underline{2}(87-101)
\end{aligned}
$$

Maxillary teeth 13-15 (7 individuals); palatine teeth 5-9 (8); pterygoid teeth 0 (8).

Dorsal ground color brownish-gray, with 32-47 chocolate-brown, triangular dorsal blotches on body, which are very faintly yellow-edged, often with yellow spots and speckling at center, first pair of blotches are not in contact across vertebral line, but reach only to paravertebrals, no other blotches in contact, usually alter'nating, ends of neighboring blotches meet or are separated by yellow spot of color on first dorsal scale row (Pl. IIIc); interspaces sometimes unicolor, often with dark-brown spots high on sides and with some scales outlined in yellow. Venter spotted with yellow, streaked with brown anteriorly, unicolor brown posteriorly, occasionally 
with irregular yellow stippling. Tail as in body, with 20-25 blotches, when countable, usually not distinct enough to enumerate.

Dorsum of head gray, extremely spotted and vermiculated with yellowedged, dark-brown areas on all scales; vermiculations become lineolate on occipitals and neck and form longitudinal streaks or bars; upper labials unicolor yellow or streaked on sutures with dark brown. Entire chin and throat may be unicolor yellowish-white, or spotted irregularly with dark brown.

DESCRIPTION OF HOLOTYPE. - (Any character of scutellation that is normal for the subspecies, i.e., that is given in the description, is not repeated here if the same for the holotype) nasal semidivided; primary temporals 3 ; secondary temporals 4 ; small scale inserted between postoculars, primary temporals, and upper labials on both sides of head; upper labials 9,4 th, 5 th and 6 th entering orbit. Lower labials 15 , first two on left in contact with only first on right, 4 labials on left and 3 on right in contact with first chin shields; 3 chin shields on left and 4 on right. 199 ventrals; 113 subcaudals. Dorsal reduction:

$$
\text { (8) } \underline{13} \frac{\mathrm{V}+6(197)}{\mathrm{V}+6(196)} \underline{11}
$$

Caudal reduction:

$$
\underline{7} \frac{\mathrm{V}+3(4)}{\mathrm{V}+3(5)} \underline{5} \frac{\mathrm{V}+2(13)}{\underline{\mathrm{V}}+2} \frac{\mathrm{V}+2(14)}{\mathrm{V}-2(14)} \underline{4} \frac{1+2(74)}{1+2(75)} \underline{2}
$$

Total length $689 \mathrm{~mm}$., body length $495 \mathrm{~mm}$., tail length $194 \mathrm{~mm}$.

INDIVIDUAL VARIATION. - In the 31 specimens examined there was a single irregularity in the normal pattern of dorsal head scales. EPN 712 shows a partial fusion of the prefrontal and internasal on the left side. The nasal scale is completely divided in five specimens, semidivided in eleven, and not divided in fourteen. The loreal enters the orbit in all specimens; the preoculars are 1-1 in all; the postoculars are 2-2 in all except two, one of which, EPN 102, has 1-1, due to a fusion of the lower postocular with the 7th labial on both sides, and the other, AMNH 28858, has only a single postocular on the right side. The suboculars are absent in all except two, each with one on one side only, EPN 100 and again AMNH 28858. The primary temporals are 2-2 in 25 specimens, 3-3 in two, $1-1$ in one, 1-2 in two, and one has the upper on the left side divided vertically into two scales (AMNH 35959). Fifteen specimens have 3-3 secondary temporals, eight have 2-2, six have 2-3, two have 3-4, and one has 4-4. Only one specimen AMNH 28859, shows a fusion between primary and secondary temporals. It has the lower pair on both sides fused into a single long scale bordering the labials. The extra temporal scale is present in 55 percent of the specimens, and in those lacking it there is often an obvious fusion between it and one of the primary temporals. Seventeen specimens have 9 upper labials, ten have 8 on one side and 9 on the other, and three have 8 on both sides. The correlation between the number of labials and the labials which enter the orbit is shown in Table VI. When the labial 
TABLE VI

Correlation between number of upper Labials and Labials Entering Orbit in Dipsas indica ecuadorensis

\begin{tabular}{|c|c|c|c|c|c|}
\hline \multirow{2}{*}{$\begin{array}{l}\frac{n}{\pi} \\
\stackrel{\pi}{0} \\
\stackrel{0}{0}\end{array}$} & \multicolumn{4}{|c|}{ Labials Entering Orbit } & \multirow[b]{2}{*}{$4,5,6,7$} \\
\hline & 4,5 & $4,5,6$ & 4,6 & 5,6 & \\
\hline 8 & 10 & 2 & $\cdots$ & 4 & $\ldots$ \\
\hline - & . & 23 & 2 & 19 & 6 \\
\hline
\end{tabular}

count is 9 , the 4 th labial usually enters the orbit only by its posterior corner, and is often crowded out, leaving only the 5 th and 6 th in the orbit. Two labials enter the eye in 52 percent; 3 in 38 percent, and 4 in 10 percent. Four specimens have the $3 \mathrm{~d}$ and 5 th labial on one side in contact above the 4th, on the right side of AMNH 23293 and EPN 705 and on the left side of AMNH 35814 and EPN 746. AMNH 49086 has the 4th and 6th labials in contact above the 5th, which is thus excluded from the orbit. In UMMZ 89028 there is a partial suture on the 4th labial, which is followed by dark pigment for its length.

The lower labials were determinable for a total of 59 sides. Of these, five have 12 , ten have 13 , thirty have 14 , thirteen have 15 , and one has 16 . This comparatively wide range is reflected in the number of labials in contact behind the mental, which ranges from a single pair to as many as four. There is a single specimen with 1-1 labials in contact, two with 1-2, fifteen with 2-2, two with 2-3, eight with $3-3$, and three with 3-4. Nine specimens have 2 pairs of chin shields, fourteen have 3 pairs, one has 4 pairs, two have 2 on one side with 3 on the other, three have 3 and 4 , and two have 4 and 5. EPN 100 has the first chin shield on the left partly fused with the second on the left, along their common border.

In all except two specimens there is a reduction in dorsal scale rows from 13 to 11 . There is considerable variation in the point at which the reduction takes place. The difference can be emphasized by use of the proportion $\frac{\text { ventral at reduction }}{\text { total ventrals }}$, which gives a figure that should eliminate effect of the dimorphism of the ventrals (Fig. 6). The lowest value found was 67 percent, in a female. There is a slight indication of sexual dimorphism in this character, but it is not strong, nor is there a correlation with provenance of the specimens. Both this subspecies and $i$. indica are characterized by this scale row reduction, but is rarely found in $i$. bucephala or i. cisticeps.

There are six specimens that add a sixth row on one or both sides posterior to the reduction to 11 rows. This extra row persists for only a short distance before it is reabsorbed by the vertebral row.

Eight specimens show irregularity in caudodorsal reductions. In all, the irregularity involves a reduction to 5 rows rather than 6 , usually at the base of the tail, and then fusion of the vertebral row with the paravertebral (second) row on both sides followed immediately by division of the vertebral row, leaving 4 rows of scales.

Four individuals have one or more divided ventrals. Two have only 


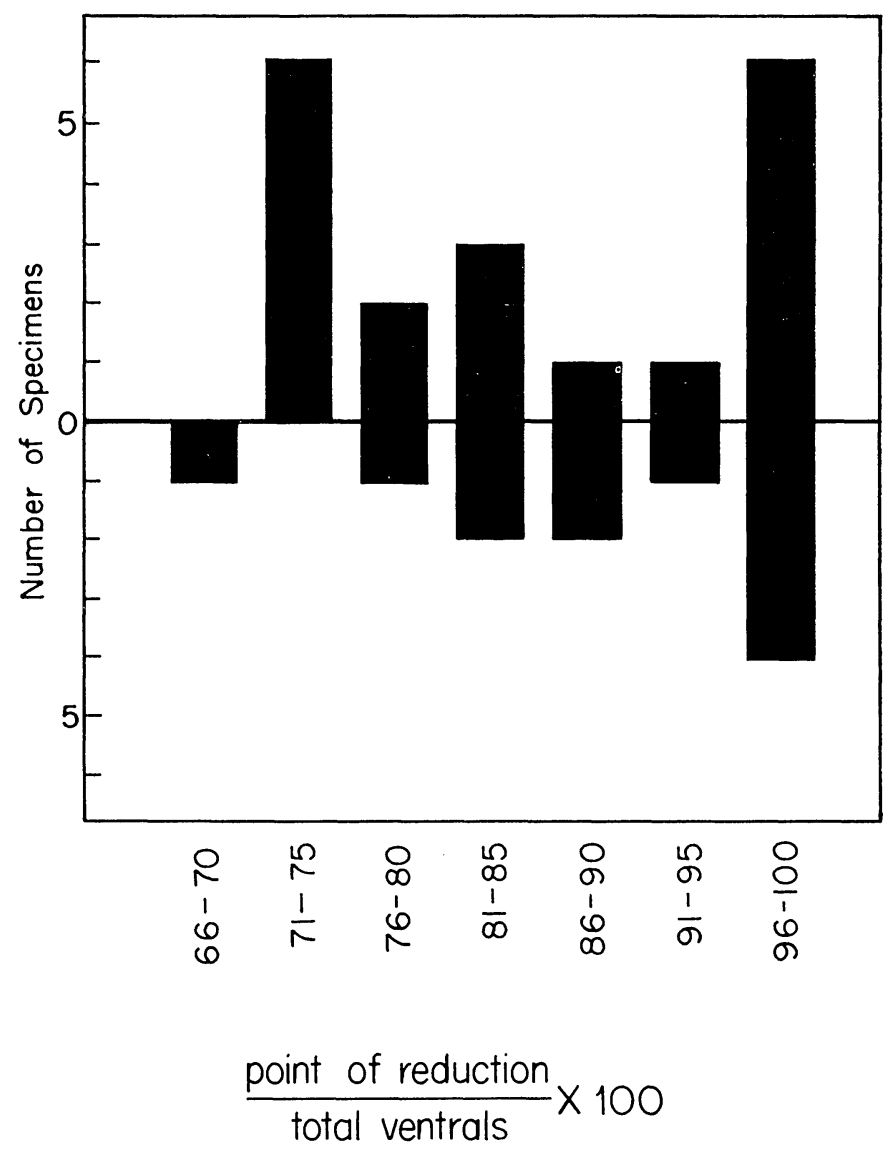

Fig. 6. Correlation between sex and point of reduction of dorsal scale rows from 13 to 11 in Dipsas indica ecuadorensis. Males above the line, females, below.

the last ventral divided, one (EPN 749) as in Type 1, and one (EPN 708) as in Type 2. Both of the others have two divisions, one (EPN 100) with both as in Type 1, and the other (EPN 710) with the 73d ventral divided as in Type 1 and the 75th ventral as in Type 3 .

REMARKS. - There is considerable doubt as to the validity of "Riobamba" as a collecting locality for this species. All of the specimens 
from there are American Museum of Natural History specimens, and were received from E. Feyer. I think it most likely that Feyer used Riobamba as a base, and it is probable that many specimens were brought to him there from other parts of the Ecuadorian Oriente. During my recent visit to Ecuador I was surprised at the number of people who keep snakes in bottles, waiting for natural history collectors to buy them, particularly in the towns along the road to and through Baños. It appears that collectors have been buying specimens from natives in this area since shortly after the time of Orellana, and presumably Feyer did the same. I have been in Riobamba, and I consider that there is small likelihood that a jungle snake such as Dipsas indica could live in that dry, cool, treeless region on the inter-Andean plateau.

SPECIMENS EXAMINED (all paratypes). -

ECUADOR (EPN 103, 710): Andoas (AMNH 49086), Arajuno (EPN 102), "Canelos and Baños" (AMNH 35873-74), Chichirota (EPN 712), Cotapino (EPN 100), Loreto (EPN 713-14, 746-49), ?Macas Region (AMNH 28825, 28834), Macas and vicinity (AMNH 28858-60, 35814), Macuma (EPN 705-06), Río Pastaza (UMMZ 89028), Puyo (EPN 708), Riobamba (AMNH 23246, 23293, 23316), Río Solis, Caveceras de Río Bobonaza (EPN 715, holotype), Tambo Union (EPN 704), Tarqui (AMNH 57338), Turula (AMNH 35959).

\section{Dipsas neivai Amaral}

Dipsas neivai Amaral, 1926b: 14.

HOLOTYPE. - Instituto Butantan 307, male, from Caratinga, Minas Geraes, Brazil, collected by Snr. J. E. A. Coutinho.

RANGE. - Known only from the type locality and Catú, Baía, Brazil (Map 5).

DESCRIPTION (from original). - Rostral wider than deep, visible from above; internasals two-thirds length of prefrontals, which enter orbit; frontal longer than wide, shorter than parietals; nasal semidivided; loreal enters orbit; preocular absent; postoculars 2; suboculars absent; primary temporals 1 or 2 ; secondary temporals 3 ; tertiary temporals 3 ; upper labials 8 to $10,2 \mathrm{~d}$ to 6 th may enter orbit. Lower labials 13-14, two pairs in contact behind mental; 2 pairs of chin shields.

Ventrals in single male 188, in single female 189; anal entire; subcaudals in male 86 , in female 78 . Dorsal scale rows 15 , reductions not mentioned in type description; vertebral row moderately enlarged; caudodorsals unknown.

Body length, male $520 \mathrm{~mm}$., female $760 \mathrm{~mm}$.; tail length, male $160 \mathrm{~mm}$., female $220 \mathrm{~mm}$. (taken from type description of male holotype and female paratype).

Dorsal ground color light grayish, with two series of triangular or lozenge-shaped, dark-gray blotches, alternating or opposed along vertebral row, opposing blotches not in contact across vertebral row; interspaces (apparently) unicolor. Ventral surface yellowish-white, stippled with olive or grayish; dorsal blotches extend onto ends of ventrals, but do not come in contact with opposing blotch.

Dorsum of head irregularly spotted with darker color; labial region, and gulars lighter, immaculate. 
INDIVIDUAL VARIATION. - The type, a male, has the following characters not shared by the paratype: ventrals 188 , caudals 86 , upper labials 9 , with the $3 \mathrm{~d}$ through 5 th in the orbit, on one side, and 8 , with the $2 \mathrm{~d}$ through 4 th in the orbit, on the other, a single primary temporal (see in Remarks, below). The paratype, a female, has the following counts and characters: ventrals 189 , subcaudals 78 , upper labials 9 , with $3 \mathrm{~d}$ through 5 th in the orbit, on one side and 10 , with $3 \mathrm{~d}$ through 5 th in the orbit, on other, 2 primary te mporals.

REMARKS. - The group to which this species belongs cannot be determined with certainty until the types are re-examined, but I have provisionally placed it in the indica group because of the strong similarities between the two species. The pattern is much the same, and most of the scutellation is sufficiently similar to justify such an action. The greatest discrepancy is perhaps the presence of tertiary temporals in neivai, but several of the other groups contain some species with and others without tertiaries. The figure of the type shows a situation frequent in indica; one of the upper labials is in contact with the upper primary temporal, and the lower primary is crowded back almost into the secondary row (Amaral recorded this as a single primary temporal). The lower labials are extremely crowded anteriorly, and the type appears to have 3 labials in contact with the midline on the left side, not 2, as Amaral stated, also a common situation in indica. The head of neivai is not as shortened as that of indica, and the crowding of scales on the dorsum and sides of the head is, therefore, not as prominent.

The only known representatives of this species are the type and paratype, one from the state of Minas Geraes and the other from Baía.

\section{THE OREAS GROUP}

\section{Dipsas elegans Boulenger}

Leptognathus mikanii (non Schlegel), Günther, 1895: 141.

Leptognathus elegans Boulenger, 1896a: 452 .

Sibynomorphus elegans, Amaral, 1926a: 9 (by inf.); Amaral, 1929: 197.

Dipsas elegans, Parker, 1926: 206 (by inf.); Smith and Taylor, 1945: 51.

HOLOTYPE. - BMNH, from “Tehuantepec," Oaxaca, México, collected by M. F. Sumichrast.

RANGE. - Known only from the type specimen.

DESCRIPTION. - (Taken from published data and figure). Rostral nearly as deep as broad, not visible from above; internasals one-third the length of the prefrontals; frontal slightly broader than long, much shorter than the parietals; nasal entire; loreal enters orbit; preocular 1; postoculars 2; suboculars none; primary temporals 2; secondary temporals 2 or 3 ; tertiary temporals 3 ; upper labials 8 , 4th and 5 th enter orbit; none greatly enlarged. Lower labials not known; first pair in contact behind mental, four pairs in contact with first pair of chin shields; no enlarged lower labials; 4 pairs of chin shields.

Ventrals 185 (188?): anal entire; subcaudals 94 (85?). Dorsal scale rows 15; vertebral row broadly enlarged; caudodorsals not known. 
Dorsal ground color pale brown with narrow blackish-brown blotches, 44 on body, 23 on tail. Blotches have yellowish centers bisecting them, division more complete anteriorly than posteriorly, and are as broad as interspaces, which have irregular spotting of blackish-brown. Venter whitish, spotted or checkered with black; blotches do not extend onto belly but end on first or second scale row.

Dorsum of head black, spotted and marbled with yellow. Side of head light, with black postocular stripe to corner of mouth; irregular black spotting on labials. Chin apparently light with irregular black spotting.

INDIVIDUAL VARIATION. - The only variations that can be expressed for this species are those between the description given by Günther and that by Boulenger. Günther said that there are 3 secondary temporals on one side and 2 on the other, but Boulenger gave the secondaries as 3 , without qualification. Günther's ventral and subcaudal counts were 188 and 85 , whereas Boulenger's are 185 and 94 (I have given Boulenger's figures more prominence in the description above; his is the type description, and it seems plausible that he was more painstaking than Günther).

REMARKS. - Even though many collectors have worked in the Tehuantepecan region, since the days of Sumichrast, this species has never been retaken. I have not, therefore, seen any specimens and have utilized the combined descriptions of Boulenger and Günther and the excellent figure of the type given by Boulenger (1896a: Pl. 23, Fig. 3).

The color pattern is similar to that in Dipsas ellipsifera, from Ecuador, in which the blotches appear to be ellipses, because their centers are so light.

SPECIMENS EXAMINED. - None.

PUBLISHED RECORDS. -

MÉXICO: Oaxaca; Tehuantepec (BMNH, type).

\section{Dipsas ellipsifera Boulenger}

Leptognathus ellipsifera Boulenger, 1898a: 117.

Sibynomorphus ellipsifer, Amaral, 1929: 19.

COTYPES. - BMNH, “several” specimens, from Ibarra, Ecuador, collected by Mr. W. F. H. Rosenberg.

RANGE. - Known only from western Ecuador (Map 6).

DESCRIPTION. - Rostral considerably broader than deep, visible from above; internasals one-half to two-thirds as long as prefrontals, which do not enter orbit; frontal wider than long or as long as wide, shorter than parietal; nasal divided; loreal enters orbit; preocular 1, not reaching frontal; postoculars 2; suboculars none; primary temporals 2; secondary temporals 3 ; tertiary temporals 3 or 4 ; upper labials 7 or 8,4 th, 5 th and 6 th may be in eye, 6th or 7 th often enlarged, occasionally in contact with postocular and first two rows of temporals. Lower labials 9 or 10, one or two pairs in contact behind mental, four or five pairs in contact with first chin shield; 3 or 4 pairs of chin shields.

Ventrals 153-187 in males, 156-167 in females (147 recorded by Peracca, $1940 a$, for a female); anal entire; subcaudals $72-105$ in males, 62-83 in females (60 by Peracca). Dorsal scale rows on neck 17, reduction 


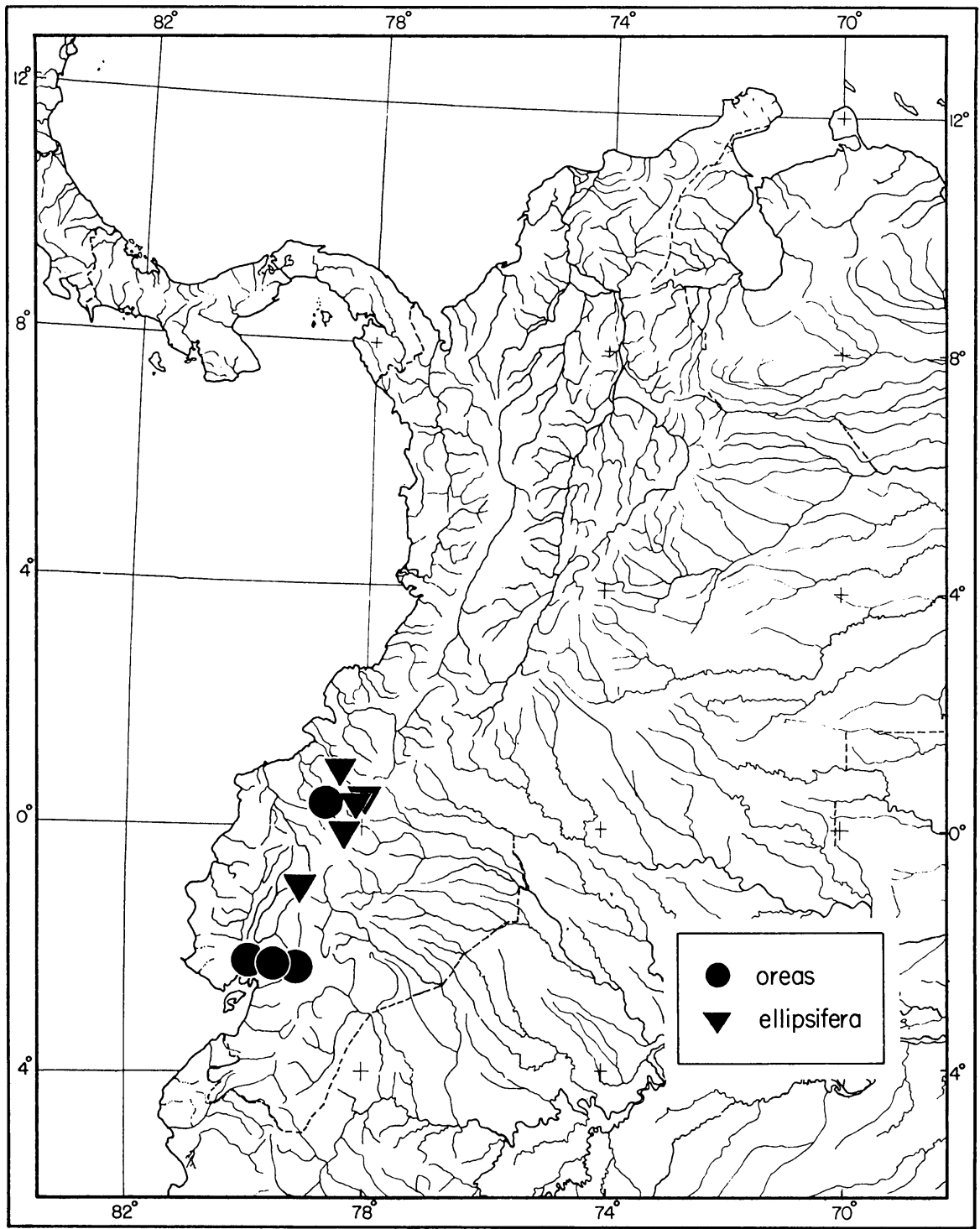

Map 6. Geographic distribution of the oreas group except Dipsas elegans (the locality of elegans was given as Tehuantepec).

at 7-11 ventrals to 15 , no other reductions over most of body, occasionally reducing to 14 or 13 short distance anterior to anus; vertebral row moderately to broadly enlarged; caudodorsals (for typical population only):

Males: $62+3(20-30) 41+2(61-68) 2(72-79)$

Females: $\underline{6} 2+3(14-2 \overline{1}) \underline{4} 1+2(47-5 \overline{7}) \underline{2}(62-63)$ 
Maxillary teeth 15-17 (5 individuals); palatine teeth 8-9 (5); pterygoid teeth 8-12 (5).

Body length male $499 \mathrm{~mm}$., female $222 \mathrm{~mm}$. , minimum $174 \mathrm{~mm}$.; tail length male $146 \mathrm{~mm}$., female $71 \mathrm{~mm}$., minimum $42 \mathrm{~mm}$.

Dorsal color olive-brown, with 27-37 brownish-black, vertically ellipsoid blotches on body, from vertebral row to edges of ventrals, centers of blotches same color as interspaces and about one scale-row wide, edges irregular and jagged, anterior blotches no wider than posterior, fail to meet on vertebral row when opposed, which seldom occurs, blotches and interspaces about equal in width over entire body; interspaces of ten heavily stippled with light brown and spotted with dark brown (Pl. IV $a$ ). Venter brownish-white, with two irregularly parallel rows of rectangular black spots on sides of midline, third poorly marked row on midline, made up of much smaller and more isolated spots; edges of ventrals spotted and streaked with black, lower end of each dorsal blotch usually forms short horizontal bar on tips of ventrals and first scale row. Tail as body, with 14-23 blotches, a mount of lighter color in center of blotches decreases regularly posteriorly; ventral side of tail has blotched effect of brown and whitish rectangular spots.

Dorsum of head heavily vermiculated with dark and light brown, darker pigment more abundant on parietals and frontal, lighter pigment in majority on temporals, labials, and snout. First dark, dorsal ellipse encroaches onto posterior part of head, leaving light occipital collar. Anterior labials dark brown, rest of chin and throat yellowish tan with rectangular black spots.

Juvenile with emphasized adult pattern, contrast between blotches and interspaces more definite, interspaces more yellowish. Head vermiculation strongly defined, light areas bright yellowish-tan, not light brown.

INDIVIDUAL VARIATION. - There is no splitting or fusion of the snout scales, and the only variation worthy of comment is that concerning the nasal. Boulenger $(1898 a: 117-18)$ says it is entire or semidivided in the types. I have found it to be semidivided in three specimens, and completely divided in ten. The ocular region is also quite stable in the 14 specimens seen, with the preoculars 1-1 in all except two individuals. One of these lacks the preocular on the right side, the second lacks it on both sides. The postoculars are two in all, and the suboculars are missing in all except two. In these two the subocular is formed by a horizontal suture on the fourth labial, on one side only in one and on both sides in the other. Boulenger (1898 a: 118) said that the postoculars are "rarely one." which would indicate that he had an individual or a single side on which fusion had taken place. He stated that "a small preocular is usually present," which certainly implies its absence at least once in one of the cotypes. Boulenger gives the primary temporals as 2, the number true of thirteen of the fourteen specimens seen in the present study. The fourteenth has 3 on the left side only. The secondary temporals are 2 or 3 in the types, and also in my specimens. UMMZ 83698 has the upper secondary fused to the middle secondary (with this fusion very obvious since the tip of the middle secondary remains free) and to the upper tertiary, so that it forms an elongate scale along the posterior border of the parietal; on its left 
side, the upper secondary and upper tertiary temporals are also fused, and the lowest tertiary is divided vertically, with the anterior half crowded under the posterior half of the lower secondary. Fusion of the upper secondary and tertiary temporals occurs on 11 of the 28 sides examined. The upper labials are 6-7 in one specimen, 7-7 in seven, 7-8 in three, 8-8 in one, and $8-9$ in one. The cotypes apparently have 7-7 throughout, as do four of the six topotypes. No good correlation exists between the total number of labials and the number of labials which enter the orbit. Of eighteen sides on which 7 labials were counted, thirteen have the 4th and 5th entering the orbit, one has only the 4th, three have only the 5 th, and one has the $3 \mathrm{~d}$, 4th and 5th. Of eight sides with 8 labials, three have the 4th and 5th entering the orbit, four have the 4th, 5th, and 6 th, and one has the 5 th and 6 th only. The single side with 6 labials has the $3 \mathrm{~d}$ and 4 th entering the orbit, and the only side with 9 has the 4 th through the 7 th. Apparently, as much fusion takes place posterior to the eye on the labial row as anterior to it, for the 4 th and 5th labials enter the orbit in the majority, for both the 7 and 8 labial counts. The penultimate labial is usually the largest, and on six of the twenty-four sides it is in contact with the postocular, primary and secondary temporals, as it is in Sibon. In addition to these variations in the labials, five specimens have the labial below the primary temporals split or sutured to form an extra scale in the labial line. In two of them it is formed by a diagonal split across the labial, and forms a wedge between the 5th and 6th labials (UMMZ 83698 and EPN 717); in the other three, by a horizontal suture of the 6th labial on four sides and the 5th labial on the fifth side. The upper half of the sutured labial is usually the larger. The lower labials are determinable on twenty-seven sides, with the following distribution: 8 on one side only, 9 on six, 10 on thirteen, 11 on three, and 12 on four. Five specimens have two pairs of labials in contact behind the mental, nine have only a single pair in contact. All the cotypes (Boulenger, $1898 a: 118)$ and topotypes have only a single pair in contact. The cotypes have 3 or 4 pairs of chin shields; the specimens examined have 3 pairs in five individuals, 4 pairs on seven, and 5 pairs on the other two. There are from 4 to 6 labials in contact with the first pair of chin shields, with fourteen sides having 4 , thirteen with 5 , and one with 6 .

Seven of the fourteen specimens possess irregularities in dorsal scale rows. Five have posterior reductions of dorsal scales to below 15; one to 14 , and four to 13 . In the first the reduction occurs within four scales anterior to the anus; in the other four, within three scales. Two individuals have many divided vertebral scales, with counts of 16 and 17 scale rows as a result. The vertebral row varies from moderately to broadly enlarged. A single specimen, UMMZ 83700 , varies from the pattern given in the description above for reduction of caudodorsals. Its formula is:

$$
\underline{6} \overline{2+3+\mathrm{R} 3(19)} \underline{4} \frac{\mathrm{V}+2(21)}{\mathrm{V}+2(21)} \underline{4} \frac{1+2(63)}{1+2(63)} \underline{2}(75)
$$

Only one specimen, UMMZ 83697, has a divided ventral, the penultimate being divided as in Type 3 . There were no fused subcaudals observed.

Except for the apparent ontogenetic change, discussed above, there 
are no striking variations in color or pattern. An occasional blotch lacks the light center, often the first one on the back of the head. The amount of spotting and the size of individual spots on the chin and ventral surface varies slightly from individual to individual.

POPULATIONAL VARIATION. - The material available can be divided into two groups as to provenance, the first coming from the Rio Mira drainage and referred to as the "typical population," and the other from the western slopes of the Andes in Ecuador, to the south of the Río Mira. Ibarra, the type locality, is near the headwaters of the river, in an intermontane basin. Although the indicated differences between these two populations suggest subspecific status, I am not assigning them a name, because no satisfactory holotype is available. One of the four specimens is an adult, but it is not well preserved and lacks most of its tail. The other three are juveniles.

The most striking differences between the two populations are in counts involving body segments. In the typical population the ventrals range from 155 to 163 in males, and 156 to 158 in females; in the second population, from 177 to 187 in males, the single female has 167 . The range of variation in subcaudals in the typical population is 72-79 in males, 62-63 in femaies; the males of the second population have from 101 to 105 , and the single female has 83 subcaudals.

Three of the four specimens representing the second population have two pairs of lower labials in contact behind the mental, but only two of ten specimens from the typical population show this character. One specimen from the second population has less than 11 lower labials, All from the typical population have 10 or less on at least one side, and this is true of both sides of eight specimens. An enlarged upper labial contacts the postocular, primary temporal and lower secondary temporal on six of twenty sides in the typical population, a condition not found in the second population.

The four specimens in the second population are those from El Corazon, "Camino al Mindo," and Peñaherrera.

REMARKS. - The species has been reported from Valle del Chota and Ibarra (Peracca, 1904a:15). There is little reason to doubt this identification. Werner $(1909 a: 279)$ mentioned two specimens in the Musee Royal d'histoire naturelle de Belgique, and gave ventral and subcaudal counts. Since he did not mention either locality or sex, his counts have not been utilized in this study, but they are within the ranges of variation given in the description above. The specimens in the typical population are from within a 50-mile radius of the type locality, which is in the inter-Andean region of extreme northern Ecuador, at an altitude of $2211 \mathrm{~m}$. It is within the biotic zone designated as the "Region Andina Sub-Tropical" by Jijon y Caamano (1943: Map 1). It is difficult to interpret Chapman's classification of this region, for he stated (1926:77) that the Western Division of the Subtropical Zone in northwestern Ecuador "extends but little below Mindo (alt. 4,140 ft.) and does not reach Paramba (alt. 3,500 ft.)." Elsewhere Chapman (1926:95) said "generally speaking, the Temperate Zone lies between the altitudes of 9,000 and 12,000 feet." It appears that the intermediate altitudes are unclassified. Actually, it would seem from other parts 
of his discussion that the localities in question are in the forested parts of the Temperate Zone.

SPECIMENS EXAMINED. -

ECUADOR: “Camino a Mindo" (EPN 719), El Corazon (EPN 717-18), Ibarra (EPN 90-92; MCZ 8431), Lita (EPN 93-94), near Peñaherrera (UMMZ 92073), Pimampiro (UMMZ 83697-700).

\section{Dipsas oreas Cope}

Leptognathus oreas Cope, 1868: 109.

Leptognathus Andiana Boulenger, 1896a: 452.

Leptognathus Mikanii (part), Günther, 1872: 29.

Leptognathus Mikanii (in errore), Despax, 1910: 36.

Sibynomorphus mikanii oreas, Amaral, 1929: 198.

Sibynomorphus andianus, Amaral, 1929: 195.

Dipsas mikanii oreas, Parker, 1934: 271.

HOLOTYPE. - ANSP 10115, male, "From the elevated valley of Quito," Ecuador, collected by the Orton Expedition. $6)$.

RANGE. - Higher parts and western slopes of Ecuadorian Andes (Map

DESCRIPTION. - Rostral broader than deep, visible from above; internasals half or more length of prefrontals, which may or may not enter orbit; frontal equally broad and long, shorter than parietals; nasal divided wholly or in part; loreal enters eye; preocular 1 or none; postoculars 2 or 3 ; subocular none; primary temporals 1 or 2 ; secondary temporals 3 ; tertiary temporals 3 or 4 ; upper labials 7 or 8 , $3 \mathrm{~d}$ through 6 th may enter orbit, none enlarged. Lower labials 11 or 12 , one pair in contact behind mental, five or six pairs in contact with first pair of chin shields; 3 or 4 pairs of chin shields.

Ventrals 175-181 in males, 167-177 in females; anal entire; subcaudals 83-86 in males, 79-88 in females. Dorsal scale rows 15 over entire body, no posterior reductions to 13 ; vertebral row scarcely to broadly enlarged; caudodorsals:

$$
\begin{aligned}
& \text { Males: } \underline{6} 2+3(20-23) \underline{4} 1+2(59-72) 2(83-86) \\
& \text { Females: } \underline{6} 2+3(16-2 \overline{1}) \underline{4} 1+2(62-7 \overline{0}) \underline{2}(79-88)
\end{aligned}
$$

Maxillary teeth 14-16 (2 individuals); palatine teeth 7-11 (2); pterygoid teeth 9 (1).

Body length male $512 \mathrm{~mm}$. (holotype), female $275 \mathrm{~mm}$., minimum 147 $\mathrm{mm}$.; tail length male $176 \mathrm{~mm}$. (holotype), female $84 \mathrm{~mm}$., minimum $54 \mathrm{~mm}$.

Dorsal ground color dull yellow, with 23-33 dark-brown blotches that are approximately same width as interspaces over entire body; blotches somewhat rounded above and below, with poorly defined light border and with lighter centers due to yellow spotting in older individuals, opposite and fused across vertebral line anteriorly, usually alternating posteriorly; interspaces speckled with brown, heaviest posteriorly, stippling forms longitudinal streaks on sides; large dark-brown spot on vertebral and paravertebral rows on both sides between dorsal blotches, smaller spot on first scale row and on tips of adjacent ventrals. Venter dull yellow-white, 
usually checkered with large rectangular spots between ends of neighboring dorsal blotches, which do not meet on midventral line. Tail as body, darker ventrally.

Dorsum of head predominantly dark brown, yellow vermiculations irregularly present, particularly on sutures, ends of dark-brown area may be drawn out over parietals and occipitals to form U-shaped mark; upper labials with more yellow than brown, the brown confined to sutures when present. Chin and throat yellowish-white, often with scattered brown spots.

INDIVIDUAL VARIATION. - There are no variations in the dorsal head scales of any of the specimens examined. Two of the eight have entire nasals, in the remainder they are divided wholly or in part. The loreal enters the orbit in all. Three have a preocular on both sides, four have none. Suboculars are lacking in six specimens, one has 1 on each side, and the eighth has 1 on the left and 2 on the right. The postoculars are quite variable, with four specimens possessing 2-2, two with 3-3, one with 2-3, and one with 3-4. The primary temporals are 1-1 in two individuals, 2-2 in four, and 2-3 in the other two. The secondary temporals are 3-3 in six, 2-2 in one, and 2-3 in one. The tertiary temporals are 4-4 in four, 3-3 in one, 3-4 in one, and 2-3 in one. The upper labials range from 7 to 9 . Usually when they are seven, the 4 th and 5 th enter the orbit, but the type has the $3 \mathrm{~d}$ to 5 th. There is a variation in the scales posterior to the eye in this species. When there are 2 labials posterior to the last one in the orbit, they are both rather wide, when there are 3 , they are much reduced in width. The extra temporal scale between the primary temporals, upper labials, and postoculars is present in four specimens.

Lower labials range from 10 to 13 . Broken down into sides, they are as follows: 10 , one side; 11 , five sides; 12 , six sides; and 13 , three sides. A single pair of labials is in contact behind the mental in all except BMNH 1940.2.20.32, which has two. The number of labials in contact with the first pair of chin shields varies from 4 to 7 . There is a strong correlation between this variation and the number of lower labials, but it is not complete. All the variation in lower labials is not confined to the area anterior to the second pair of chin shields. Six specimens have 3 pairs of chin shields, one has 4 pairs, and one has 4 on the left and 5 on the right.

There is little variation from the usual formula of dorsal scale-row counts, but two specimens show increases and one a decrease. The increases are by division of the vertebral row into 2 or 3 scales. In the single specimen with a decrease the paravertebral on one side is fused to the vertebral 2 ventrals anterior to the anus. The caudodorsals are normal in their reductions in all specimens. Divided ventrals were noted on two specimens, one with a single Type 1 division, and the other with a single Type 2. No fused subcaudals were seen.

REMARKS. - There can be little doubt that the type of the species andiana belongs to this species. I have examined the type of oreas, and have compared it directly with the specimen discussed here and with the type description and figure of andiana, which Boulenger (1896a:452) said came from Quito. They are the same in all important points. Although Boulenger said that the type of andiana has only 2 chin shields, it is fairly 
obvious from his plate that the third pair is fused across the midline to form a single scale. Boulenger's type is a very young individual, and the centers of the blotches have not begun to lighten, a condition duplicated in several of the specimens I have seen. Boulenger followed Günther in his synonymy of oreas with mikani, and apparently both were misled by Cope's statement that the body of oreas was less compressed posteriorly than anteriorly. This was somewhat exaggerated by Cope, for I detected little difference in degree of compression. Since mikani is a member of a different genus based upon the degree of body compression, it is not surprising that both Boulenger and Günther placed more weight on the character than was warranted. There is only one statement in Boulenger's description that I cannot demonstrate applies equally well to members of the species oreas, and that is his remark "lower parts uniform white." While several of the specimens seen lack spots for the most part, a few are always present.

The types of oreas and andiana are supposed to have been collected near Quito, Ecuador. I have discussed this type locality elsewhere (Peters, 1955:347). Presumably, Quito was not the place of collection, since only one species of snake is known to occur in the Quito valley; I think it most unlikely that this species is to be found there.

SPECIMENS EXAMINED. -

ECUADOR: Chanchan Valley (MCZ 17083; UMMZ 56491), Guayaquil (USNM 60006), Huigra (ANSP 18117, 18120, 18123), "elevated valley of Quito" (ANSP 10115, holotype), Río Saloya, 4000 feet (BMNH 1940.2 20.32).

ADDITIONAL RECORDS. -

ECUADOR: Alausi (Despax, 1910, 36).

\section{THE POLYLEPIS GROUP}

Dipsas longicaudata Andersson

Tropidodipsas longicaudata Andersson, 1901: 17.

Siphlophis cervinus cervinus, Amaral, 1929: 202.

HOLOTYPE. - Royal Museum at Stockholm, female, from "Brasilia," in the collections of Dr. Touzet.

RANGE. - Unknown

ORIGINAL DESCRIPTION. - "Maxillary teeth 15, solid, in an interrupted series, rather small, a little decreasing in size behind. Mandibular teeth about 14, decreasing in size behind. Head very distinct from neck; eye moderate, the horizontal diameter as long as the distance to the nostril and $11 / 3$ as long as the distance to the snout; pupil vertical. Rostral twice as long as broad, just visible from above. Two internasals a little broader than long, considerably smaller than the praefrontals. Nostril lateral, between two nasals. Loreal nearly twice as long as deep, not reaching the eye. Frontal hexagonal, longer than its distance to the tip of the snout and slightly shorter than the parietals. One praeocular, not reaching the frontal. Two postoculars; temporals 2+3. Eight upper labials, the fourth and 
fifth entering the eye; the sixth and seventh being the largest. Eight lower labials, four of which are in contact with the anterior chin shields, which are longer than the posterior.

"Body elongate and compressed, especially the anterior part. Scales in 19 rows, all smooth and equal in size, without apical pits. Ventral shields 225, anal entire. Tail long, nearly one fourth of the total length, gradually tapering to the narrow end; subcaudals 101, in two rows.

"Colour above brownish and greyish white by numerous more or less regular, broad, brown, dark edged, crossbands, alternating with narrower light ones. The brown crossbands are broadest on the back, where they sometimes merge into each other. On the sides they are contracted, wherefore the white-greyish colour there is more expanded. Lower parts yellowish white, marbled with dark. The head above light brown with dark distinct spots on the shields. Behind the eye a broad dark edged brown band, extending to the eighth upper labial. The head below, the upper labials and the throat yellowish white with dark dots on the labials."

Body length of female holotype, $700 \mathrm{~mm}$.; tail length $220 \mathrm{~mm}$.

REMARKS. - Recognition of this species as a member of the genus Dipsas is on such a very insecure basis that the form should perhaps be transferred to incertae sedis, rather than be included with polylepis and the other species of its group. Amaral (1929:202) synonymized Andersson's species with Siphlophis cervinus, and it has been unrecognized since. A letter requesting re-examination of the type in light of Amaral's synonymy reached Stockholm shortly after Dr. Andersson's death, but was answered by Dr. Ulf Bergström. He stated that the scales are without apical pits (true of Dipsas, not true of Siphlophis), there is a broad dark band behind the eye, as stated by Andersson (and missing in S. cervinus), and the pterygoids extend directly back, with no divergence and no contact with the quadrates. Since the posterior maxillary teeth of Siphlophis are grooved, and all maxillary teeth in Dipsas are solid, I asked that this also be checked. Dr. Bergstrom found that the maxillary on one side is defective and the kind of teeth could not be determined, and that the posteriormost tooth on the other side is broken off near its base, but that a groove can be clearly seen on the trunk, forming a deep invagination. In the original drawing of the type, the mental groove is certainly present and appears to be rather prominent.

The inconclusive evidence seems to indicate that the specimen might not belong to either Dipsas or Siphlophis. Because of the possibility that it legitimately deserves a place in this species group, I retain it here rather than allow an available name to vanish into the synonymy of a species to which it almost certainly cannot belong.

\section{Dipsas poecilolepis Amaral}

Heterorhachis poecilolepsis (sic) Amaral, 1923: 94.

Heterorhachis poecilolepis, Amaral, 1929: 195.

HOLOTYPE. - Instituto Butantan 3002, female, from Villa Bumfim, State of São Paulo, Brazil. Collected by Mr. J. R. da Silva. 
RANGE. - Known only from the type locality.

ORIGINAL DESCRIPTION. - "Snout short, a little longer than the diameter of the eye. Rostral broader than deep, scarcely visible from above; internasals short, twice as broad as long, less than half as long as the praefrontals; an azygous internaso-praefrontal shield present; frontal very short, a little broader than long, as long as its distance from the end of the snout, much shorter than the parietals (4:7); nasal divided; loreal longer than deep, entering the orbit; a small praeocular between the loreal and the supraocular; 2 postoculars; temporals 1-2; 6 upper labials, $3 \mathrm{~d}$ and 4 th entering the orbit, 5 th and 6 th very long; 3 pairs of chin shields, the middle larger. Scales smooth, without pits, and showing remarkable peculiarity as follows: $15,16,17,18$, or 19 rows, the vertebral sometimes only slightly and sometimes strongly enlarged transversely all along the body by the fusion of the middle row with $1,2,3$ or 4 paramedian ones; $1,2,3$ or sometimes 4 paraventral rows also enlarged. Ventrals, 153, rounded laterally; anal entire; subcaudals, $36 / 36+\mathrm{n}$. "

REMARKS. - Amaral made this species the type of a new genus of dipsadine snakes because of its long and slightly diverging pterygoids and the absence of a mental groove, a combination of colubrid and amblycephalid characters. If Amaral had had available the pterygoids of the snakes that I have included under the name Sibon, it is unlikely that he would have been so impressed. The long, divergent pterygoid is characteristic of the species of Sibon, and several of the species here considered to belong to Dipsas also have fairly long pterygoids. Actually, this species does not differ very greatly from several of the forms of the genus called Pseudopareas by Boulenger, and which I consider to be Sibynomorphus The major discrepancy is the high number of scale rows, which may not be as significant as Amaral suggested, particularly if the higher numbers are infrequent. A dorsal scale-row formula must be provided for comparison. Provisionally, I have included the species in the polylepis group of Dipsas, because of its high scale-row count. It may eventually be transferred to Sibynomorphus, and perhaps synonymized with either turgida or ventrimaculata.

\section{Dipsas polylepis Boulenger}

Leptognathus polylepis Boulenger, 1912: 422.

Tropidodipsas polylepis, Amaral, 1929: 194.

HOLOTYPE. - BMNH, female, from Huancabamba, Peru, above 3000 feet, "from the collection of Mr. E. Boettger."

RANGE. - Known only from the type locality.

ORIGINAL DESCRIPTION. - "Body slender, rather strongly compressed. Eye large. Rostral broader than deep, scarcely visible from above; internasals nearly half as long as the praefrontals; frontal as long as broad, a little longer than its distance from the end of the snout, much shorter than the parietals; nasal divided; loreal as long as deep, bordering the eye, with a praeocular above it; two postoculars; temporals 2-3; nine upper labials, fourth, fifth, and sixth entering the eye; first lower labial in contact with its fellow behind the symphysial; three pairs of chin-shields, anterior a 
little longer than broad. Scales in 19 rows, vertebrals not enlarged. Ventrals 199; anal entire; subcaudals 94. Black, with narrow, whitish, blackspotted cross-bars above, widening or bifurcating on the sides; a few whitish spots on the upper lip, behind the eye; belly lineolate with white.

"Total length 950 ; tail $240 \mathrm{~mm}$."

REMARKS. - Boulenger's work on the dipsadines extended over many years, and apparently his interest in these particular snakes was great. It seems unlikely, therefore, that he misassigned a member of Tropidodipsas to Leptognathus, as Amaral's transferal of the form to the former genus would imply. Tropidodipsas, as currently recognized is endemic to Middle America, and it is improbable that polylepis, from Peru, belongs to that genus. A detailed formula for the dorsal scale rows of the type might be helpful in settling the question, since so many specimens within the genus Dipsas are variable in the division of the vertebral row. It is possible that the count of 19 dorsal scale rows is not consistently so from head to tail. Until Boulenger's type can be re-examined, therefore, in the light of this study, his species must be retained.

\section{Dipsas leucomelas Werner}

Tropidodipsas leucomelas Werner, 1916: 309.

HOLOTYPE. - Vienna Museum, from Cañon de Tolima, Colombia, collected in 1910 by Fassl.

RANGE. - Known only from type locality.

ORIGINAL DESCRIPTION. - "Verschieden von $T$. fasciata durch: Internasalia halb so lang wie Praefrontalia; Frontale etwas langer als breit; etwas langer als sein Abstand von der Schauzenspitze, etwas kurzer als die Parietalia. Loreale langer als hoch. 5 Sublabialia in Kontakt mit den vorderen Kinnschildern, die etwas langer sind, als die hinteren. 8 Supralabialia, das 4. und 5. am Auge. Ein Praeoculare, 2 Postocularia, Temporalia 2-3. Schuppen in 17 Reihen, vollkommen glatt. V. 206, A. 1, Sc. $80 / 80-1$.

“33-15 schwarze Ringe auf weissem Brunde, in der Mitte des Rumpfes z. T. alternierend, auch auf der Bauchseite; die dunklen Ringe sind ebenso breit oder breiter als die hellen Zwischenraume. Ein Querband, welches die hinteren zwei Drittel der Parietalia, die Temporalia, das 6.-8. Supralabialia und 5 Schuppenreihen hinter den Parietalen einnimmt, weiss, davor der Kopf schwarz; unterseits sind auch Kinnschilder, Kehlschuppen und vorderste 3 Ventralen weiss. Lange $240 \mathrm{~mm}$ (Schwanz $54 \mathrm{~mm}$.).”

REMARKS. - The type of this species must be re-examined to determine its generic affinity with certainty, for the description omits all of the important points for such assignment. My doubt that it belongs to Tropidodipsas is primarily based on the geographical provenance, for that genus (as currently defined) does not extend farther south than Honduras. Of course, it is not impossible that this species represents Tropidodipsas in South America. The presence of 17 scale rows is an indication that this is not a Dipsas, but there are several species with slightly higher scalerow counts that are considered to be members of that genus. A complete 
scale-row count of the type is most desirable, in order to learn if any reductions to 15 or less take place. With the exception of the scale-row count, all of the characters given by Werner can be duplicated in many dipsadine species. Obviously, current information is insufficient to assign definitely the species to any genus.

\section{THE PRATTI GROUP}

\section{Dipsas boettgeri Werner}

Leptognathus boettgeri Werner, 1901: 11.

Leptognathus boliviana Werner, 1909 b: 240.

S. [ibynomorphus] bolivianus, Amaral, 1923: 93.

Sibynomorphus boettgeri, Dunn, 1923: 186.

Sibynomorphus mikanii peruanus (in part), Amaral, 1929: 198.

HOLOTYPE. - Dresden Museum D 1671, from Chanchamayo, Peru. 7).

RANGE. - Andean slopes of southern Peru and northern Bolivia (Map

DESCRIPTION. - Rostral broader than deep, visible from above; internasals more than half length of prefrontals, which do not enter the orbit; frontal broader than long, much shorter than parietals; nasal divided; loreal enters orbit; preocular 1; postoculars 1 or 2; suboculars apparently none; primary temporal 1 ; secondary temporals 2 or 3 ; tertiary temporals apparently present (not countable on single specimen examined, 2 on figure of type of boliviana); upper labials 9 , 4th to 6th in eye. Lower labials 11 or 12, a single pair in contact behind mental, five pairs in contact with first pair of chin shields; 3 to 5 pairs of chin shields.

Ventrals 195-203 in females, unknown for males; anal entire; subcaudals 83-100 in females. Dorsal scale rows 15, no reductions on posterior portion of body to 13 ; vertebral scale row moderately enlarged; caudodorsals (for CNHM 5597):

$$
\underline{6} \overline{-3(13)} \underline{5} \frac{2-2(16)}{2+\mathrm{R} 3(14)} \underline{4} \frac{1+2(70)}{1+2(70)} \underline{2}
$$

Body length of single female examined $635 \pm \mathrm{mm}$. , tail $218 \mathrm{~mm}$.

(From CNHM 5597) Dorsal ground color yellowish-brown, with 27-40 dark-brown to black blotches, which are much wider than interspaces, usually fused across vertebral row, occasionally alternating and rounded above; interspaces only one to two scale-rows wide, often with single black spot in each scale. Ventral color as interspaces, with single or double line down center of belly, made up of rectangular black spots, dorsal blotches extend onto ends of ventrals, black spots often present between neighboring blotches on ventrals. Tail as in body, with 11-15 blotches, ventral side almost entirely black.

(From type descriptions) Dorsum of head reddish-brown, spotted with black, labials with dark sutures. Chin yellowish-brown, with few large black spots. 


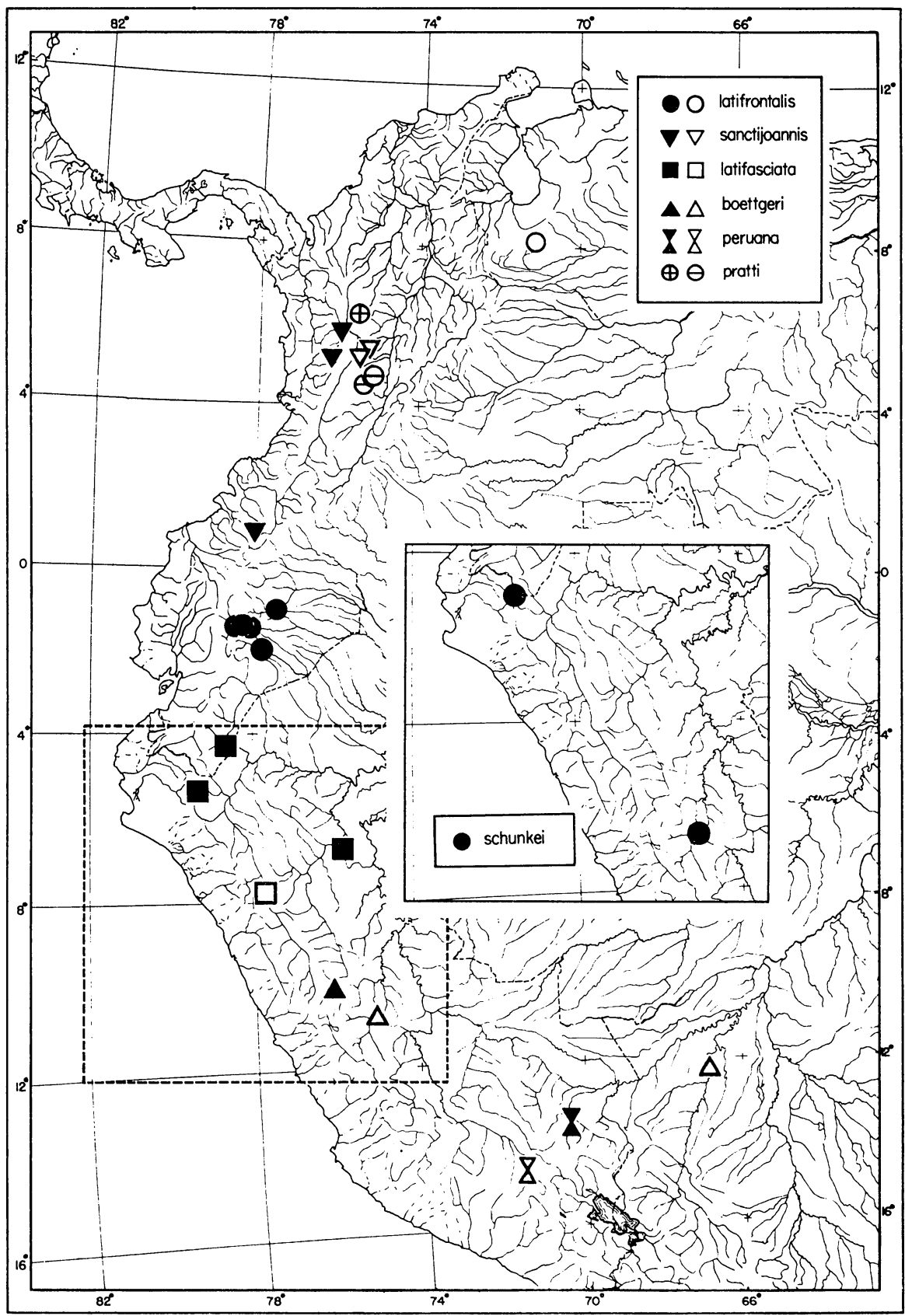

Map 7. Geographic distribution of the pratti group. Symbols on the left refer to specimens examined; those on right, to literature records. 
INDIVIDUAL VARIATION. - The dorsal head scales are all normal, with no fusions or divisions noted. All specimens known have a preocular, and the loreal enters the orbit in all. The postoculars are 2 except in the type of boettgeri, which has 1 on each side. The primary temporals are 1-1 in all, and the secondaries are 3-3 except in the type of boliviana, which has 2-2. Tertiary temporals are present in the type of boliviana, judging from the original figure, but the head of CNHM 5597 is too badly smashed to determine whether it has them or not, and the situation is unknown in the type of boettgeri. The upper labials are 9-9 in all specimens except in the type of boliviana, which has 8-9. In the type of boettgeri the 4 th through 7th enter the orbit; in that of boliviana the 4th through 6 th on the side with 9 labials and the $3 d$ through 5 th on the side with 8 labials enter the orbit. In CNHM 5597 the 4th through 6 th enter the orbit on both sides.

The lower labials are given as 11-12 for the type of boettgeri, and a count of 12 was made on one side of CNHM 5597. A single pair of labials is in contact in all three. The type of boettgeri has 5 pairs of chin shields, that of boliviana has 3, and CNHM 5597 has 4 .

The dorsal scale-row formulas for the two types are unknown. The body of CNHM 5597 is so badly broken that a complete formula cannot be drawn up, but the rows are 15 where countable. The caudodorsal formula given above for CNHM 5597 is perhaps abnormal, for similar reductions are known in many other species of Dipsas, but always as variations on the normal pattern.

REMARKS. - The descriptions of boettgeri and boliviana are almost identical, and there is little reason to retain both names. It is interesting to note that, although the type of boettgeri has 195 ventrals, Werner (1901: 12) keyed it out in the group having 156-180 (Section 2, A of key). Later, when he added boliviana (1909a:281), it was placed in the section of the key concerned with forms having 197-215 ventrals; it was thus not even compared with boettgeri, but only with alternans. Actually, if boettgeri is placed in the proper section of Werner's keys, it runs directly through to boliviana.

SPECIMENS EXAMINED. -

PERU: Ambo (CNHM 5597).

ADDITIONAL RECORDS. -

PERU: Chanchamayo (Dresden Mus. D 1671, type of boettgeri). BOLIVIA: Beni River (Hamburg Museum, type of boliviana).

\section{Dipsas latifasciata Boulenger}

Leptognathus latifasciatus Boulenger, 1913b: 72.

Sibynomorphus latifasciatus, Dunn, 1923: 186.

Sibynomorphus mikanii peruanus, (part), Amaral, 1929: 198.

Dipsas palmeri (non Boulenger), Parker, 1934: 271.

HOLOTYPE. - BMNH, sex not known, from the Upper Marañon, Eastern Peru, collected by Mr. A. E. Pratt.

RANGE. - Amazonian slopes of the Andes of northern Peru and extreme southern Ecuador (Map 7).

DESCRIPTION. - Rostral wider than high, visible from above; 
internasals one-half to two-thirds length of prefrontals, which do not enter the orbit; frontal slightly broader than long, slightly more than half length of parietals; nasal divided wholly or in part; loreal enters orbit; preocular 1 ; postoculars 2; suboculars none; primary temporals 1 or 2; secondary temporals 3 ; tertiary temporals 2 or 3 ; upper labials 8 or 9 , 4th and 5 th or 4th through 6 th entering orbit, no enlarged labials. Lower labials 10 to 12 , first two pairs in contact behind mental, four or five pairs in contact with first chin shield; 3 pairs of chin shields.

Ventrals 180-194 (2) in males, 181 (1) in female; anal entire; subcaudals 93-114 in males, 92 in female. Dorsal scale rows 17 to level of 5 th to 7 th ventral, reduction there to 15 , which is number over most of body; posterior reduction to 14 or 13 slightly anterior to anus; vertebral row between moderately and broadly enlarged; caudodorsals:

Males: $\underline{6} 2+3(18-23) \underline{4} 1+2(65-96) \underline{2}(93-114)$

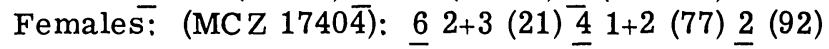

Maxillary teeth 15; palatine teeth 8; pterygoid teeth 13 (all from a single individual).

Body length male $218 \mathrm{~mm}$., female $243 \mathrm{~mm}$.; tail length male $93 \mathrm{~mm}$., female $89 \mathrm{~mm}$.

Dorsal ground color yellowish-brown with 20-33 white-edged, blackishbrown blotches, anteriormost with parallel edges, not narrowed above or below, three to four times wider than interspaces, fused across vertebral line, posteriormost alternating, slightly wider than interspaces, narrowed at ends of ventrals but not at vertebral line, where blotch tips often fuse with tips of blotch on other side even if alternating; interspaces unicolor anteriorly, suffused with light brown, and occasionally with dark-brown spots high on sides, posteriorly (Pl. IV $c$ ). Venter same color as dorsal interspaces anteriorly, darker than interspaces posteriorly, with large, rectangular, olive-brown spots between ends of dorsal blotches; blotches are complete across belly and same width as dorsal portion anteriorly, end on tips of ventrals and narrowed on first dorsal scale row posteriorly, olive-brown color occupies almost entire ventral surface posteriorly. Tail as body, with 13-18 dorsal blotches, fused above but not below; ventral surface almost totally olive-brown.

Dorsum of head unicolor black, with occasional yellow or white sutures anteriorly, occiput with yellowish-white band which curves forward on side of head to corners of mouth and is usually continuous with white color of throat; upper labials spotted and sutures streaked (Pl. IV $f$ ) with yellow, mental and lower labials brown, with chin shields and gulars principally yellowish-white with dark-brown spots.

INDIVIDUAL VARIATION. - The scales on the dorsum of the head are uniform, except that the prefrontals in AMNH 52444 are fused, with a very short section of the suture still present on the anterior edge. The ocular region is also uniform, again with the exception of AMNH 52444, which has a subocular on the right side, situated at the lower end of the postocular row. The primary temporals are 1-1 in two individuals, 1-2 in one, and 2-2 in one. The secondary temporals are 3-3 in three of them, the fourth 
has the lower of two on the left side vertically divided into two small scales, and two normal temporals on the right side. The tertiary temporals are 2-2 in one, AMNH 52444, which has the upper tertiary fused with the upper secondary on both sides, and 3-3 in the other for which they are known. BMNH 1933.6.24.109 has a tiny extra temporal scale inserted between the postoculars, primary temporals, and upper labials on both sides. The upper labials are 8-9 in one, 9-9 in two, and 8-10 in the fourth specimen, with the 4 th and 5 th labial in orbit when 8,4 th through 6 th when 9 , and 5 th through 7 th when 10 . Direct comparison between those with 9 and those with 8 and 10 indicates that 10 results from a division of the $2 \mathrm{~d}$ labial, making 4 rather than 3 anterior to the eye, and that 8 is the result of fusion between the 4th and 5th in the orbit, which produces 2 large labials below the orbit, rather than 2 narrow ones followed by a broader scale. In AMNH 52444 the 2d labial behind those entering the orbit is in contact with the postocular, primary and secondary temporals, but it is not particularly enlarged, nor does it extend above the other labials into the primary temporal row.

The lower labials are 10-10 in one specimen, 10-12 in one, and 12-12 in one. There are two labial pairs in contact behind the mental in two individuals, a single pair in contact in the third, and the fourth has 2 labials on the left in contact with 1 on the right, with the second labial crowded off the line of contact by a slight posterior extension of the tip of the first. The number of lower labials in contact with the first paired chin shield is 3-4 in one individual, and 4-5 in two. The paired chin shields are 3-3 in three specimens, and $3-4$ in the fourth.

In the two males examined, there is a reduction in scale-row number slightly anterior to the anus. The formula for AMNH 52444 is:

$$
17 \frac{2+3(6)}{3+4(7)} \underline{15} \frac{\mathrm{V}+7(176)}{\mathrm{V}+7(177)} \underline{13}
$$

and the formula for BMNH 1933.6.24.109 is:

$$
17 \frac{3+4(7)}{3+4(5)} \underline{15} \frac{7-7(191)}{\mathrm{V}+7(190)} \underline{14}
$$

In both males the reduction is by fusion of the vertebral and the paravertebrals, but in the second there is an enlargement of the paravertebral on the right side, and it extends to the vertebral line, making an even number of scale rows on both sides. The other specimen examined, MCZ 17404, a female, had no reductions posteriorly. No divided ventrals or fused caudals were observed in the limited series available. The caudodorsals are uniform in their reductions.

The description of coloration and pattern given above is based for the most part on one of the males, AMNH 52444, and on the description of the type given by Boulenger. The other male and the female display a certain amount of variation not covered by the description. In neither do the anterior dorsal blotches meet ventrally, although they extend quite far onto the ventrals, and both have more yellow vermiculation on the head. The 
blotches are wider than the interspaces on the posterior part of the body on BMNH 1933.6.24.109, but the interspace color is considerably more reddish. MCZ 17404 has lighter brown blotches that are widely separated and narrowed dorsally on the posterior part of the body, and it also has more dark spotting in the interspaces.

REMARKS. - One of the specimens (BMNH 1933.6.24.109) included here as latifasciata was discussed in some detail by Parker (1934:271) as Dipsas palmeri, considered here to be a synonym of Dipsas latifrontalis. Parker stated that "... the second pair of lower labials very nearly make contact in front of the chin shields." Actually, the second is on the midline on the left side, and is crowded out on the right, so that the formula is $2-1$. $\mathrm{He}$ also remarked that "The colour-pattern is more sharply defined and the anterior annuli are broken ventrally; down the centre of the belly is a black line, rather indistinct posteriorly and broken up anteriorly into a series of elongate spots which alternate with the dorsal annuli." The break ventrally between the anterior annuli has been shown to be typical of latifrontalis, although it appears that the type of palmeri has them complete. The formation of a black line down the center of the belly, which is in part broken up into a row of spots, is normal in latifasciata, as is the contact between two pairs of lower labials. The latter condition occurs as a variant in latifrontalis also. Since practically all the other diagnostic characters for latifrontalis are shared by latifasciata, further comparison is somewhat fruitless. The subcaudals of Parker's specimen are perhaps slightly high for latifasciata, but the actual range for that species is as yet unknown. This specimen and the individual from Tabaconas (MCZ 17404) are intermediate in some characters between what might be called typical latifrontalis and latifasciata, and they are also intermediate geographically. It seems likely that additional collections from the ranges of the two forms, particularly if they come from the overlapping area indicated by the somewhat aberrant specimens mentioned above, will demonstrate that the relationship between them is at best on the subspecific level.

The specimen from Peru reported as Dipsas latifasciatus by Dunn (1946:19) is Dipsas indica indica, and is referred to under that heading. SPECIMENS EXAMINED.-

ECUADOR: Zamora, $3250 \mathrm{ft}$. (BMNH 1933. 6.24.109). PERU: Tabaconas (MCZ 17404), Cumbre Uchpayacu-Mishquiyacu, Río Cushabatay (AMNH 52444).

\section{Dipsas latifrontalis Boulenger}

Leptognathus latifrontalis Boulenger, 1905a: 561 .

Leptognathus praeornata Werner, 1909b: 240.

Leptognathus palmeri Boulenger, 1912: 422.

Sibynomorphus latifrontalis, Amaral, 1926a: 9 (by inf.); Amaral, 1929: 197.

Sibynomorphus palmeri, Amaral, 1926a: 9 (by inf.); Amaral, 1929: 199.

Sibynomorphus incertus (part), Amaral, 1929: 197.

Dipsas palmeri, Parker, 1926: 206 (by inf.); 1934: 271.

HOLOTYPE. - BMNH, female, from Aricaqua, Venezuela, 1000 m. altitude, collected by $\mathrm{Sr}$. Briceño (see remarks).

RANGE. - Lower Amazonian slopes from Venezuela to southern Ecuador (Map 7). 
DESCRIPTION. - Rostral broader than deep, visible from above; internasals two-thirds to three-fourths length of prefrontal, which does not enter orbit; frontal as long as broad, much shorter than parietal; nasal divided wholly or in part; loreal enters orbit; preocular 1 ; postoculars 2; suboculars none; primary temporals 2; secondary temporals 2 or 3 ; tertiary temporals 3,4 , or occasionally crowded off temporal row; upper labials 8 or $9,3 \mathrm{~d}$ to 5 th or 4 th to 6 th labials enter orbit, no greatly enlarged labials. Lower labials 10,11 or 12, first pair in contact behind mental, four, five or six pairs in contact with first pair of chin shields; 3 pairs of chin shields.

Ventrals 187-201 in males, 182-198 in females; anal entire; subcaudals 98-116 (120) in males, 90-109 in females. Dorsal scale rows 16-19 immediately behind head, a lateral and/or vertebral reduction on each side changes count to 15 at level of 7-11 ventrals, very seldom further reduction to 14 or 13 slightly anterior to anus, irregularities due to fusion and splitting in vertebral row common; vertebral row moderately enlarged; caudodorsals:

$$
\begin{aligned}
& \text { Males: } \underline{6} 2+3(17-40) \underline{4} 1+2(63-110) \underline{2}(98-116) \\
& \text { Females: } \underline{6} 2+3(10-28) \underline{4} 1+2(61-98) \underline{2}(90-109)
\end{aligned}
$$

Maxillary teeth 16-20 (15 individuals); palatine teeth 8-10 (15); pterygoid teeth 8-13 (14).

Body length male $671 \mathrm{~mm}$., female $731 \mathrm{~mm} .$, minimum $187 \mathrm{~mm}$.; tail length male $278 \mathrm{~mm}$., female $285 \mathrm{~mm}$., minimum $73 \mathrm{~mm}$.

Dorsal ground color in very old adults dark brown to black, interspaces same color as or only slightly lighter than blotches, with paired yellow bands each approximately one scale-row wide marking boundaries between blotches and interspaces; interspaces occupying smaller areas between yellow bands, which are most prominent anteriorly, and weakest posteriorly (Pl. IVd). Ventrally unicolor dark brown to black; yellow bands run slight distance onto ventrals and tips may be connected under each dorsal blotch by very narrow semicircle of yellow; on dark-brown venters vague blackish brown streaking present. Tail colored as body, may approach unicolor. Head, chin, and neck almost totally unicolor, sutures of labials with yellowish-white; irregular whitish streaks on chin may be present or absent.

Dorsal ground color in adults and subadults reddish-brown, often somewhat suffused with darker brown on anterior part of body, lightly spotted with dark brown on or near vertebral row on posterior part, one or two fairly large spots occasionally present on vertebral row between dorsal blotches; anteriorly, blotches dark brown or blackish, about twice width of interspaces; posteriorly lighter brown and about same width or narrower than interspaces; white or yellowish edge on blotches about one scale-row wide, blotches usually subovate, opposite and fused across vertebral line anteriorly, usually alternating or separated along vertebral line by light borders when opposed posteriorly. Venter light yellowish-brown, with irregular, more or less prominent paired rows of dark-brown, light-edged spots; spots largest between ends of neighboring blotches, smallest or 
absent between ends of opposing blotches; all ventral spots may be absent; blotches narrowed at ends of ventrals, extend almost to midline anteriorly but none fused across midline, end on tips of ventrals posteriorly. Tail with widely spaced blotches which do not meet dorsally or ventrally, interspaces above and below unicolor, slightly lighter brown than body interspaces, with little or no dark spotting. Dorsum of head unicolor dark brown or black, with yellowish-white occipital collar continuous across back of head through angle of jaw and with ventral color; upper labials fairly heavily spotted with yellowish-white, temporal and snout region unicolor dark. Chin for the most part yellowish-brown, with black spots heaviest on mental and labials and forming paired row down chin shields.

Dorsal ground color in juveniles light yellowish-tan, dorsal blotches strongly contrasting with interspaces, white borders quite prominent; occasionally with vague yellow vermiculations on dorsum of head, which is otherwise as in adults. Chin with slightly more yellow area than adults.

INDIVIDUAL VARIATION (Table VII). - The scales on the head are of ten broken up or have smaller scales split off their ends. Four specimens have a tiny scale inserted between the nasal, internasal, and prefrontal on at least one side, and a fifth has the entire outer end of the internasal sutured off to form a large scale from the rostral to the prefrontal. UMMZ 88989 has a small scale inserted between the rostral, nasal, and first labial on the right side. UMMZ 88983 has an extra scale between the prefrontal, loreal, preocular, and nasal on both sides, which appears to be sutured off the end of the prefrontals. In two specimens a pair of small scales is sutured off the parietals on the median suture, in one at the anterior end of the parietal suture, in the other at center of parietals. UMMZ 88991 has an incomplete median suture on the frontal, beginning at the anterior edge. Fusions, other than on the temporal rows, are more unusual. UMMZ 92045 has partly fused prefrontals anteriorly, and UMMZ 88982 has the supraocular on the left side fused with the upper postocular. CNHM 23531 has the loreal fused with the nasal on both sides of the head, the situation also found in the type of latifrontalis. The ocular region is quite stable, with all except two individuals having a single preocular. One

TABLE VII

INDIVIDUAL VARIATION IN Dipsas latifrontalis

\begin{tabular}{|c|c|c|c|c|c|c|c|c|}
\hline \multicolumn{2}{|c|}{ Upper Labials } & \multicolumn{2}{|c|}{ Lower Labials } & \multicolumn{2}{|c|}{ Temporals } & \multicolumn{3}{|c|}{ Teeth } \\
\hline $\begin{array}{c}\text { Total } \\
\text { Number }\end{array}$ & $\begin{array}{c}\text { Entering } \\
\text { Orbit* } \\
\end{array}$ & $\begin{array}{c}\text { Total } \\
\text { Number }\end{array}$ & $\begin{array}{c}\text { Touching } \\
\text { First } \\
\text { Chin Shield }\end{array}$ & Primary & Secondary & Maxillary & Palatine & Pterygoid \\
\hline $7-7 \quad(2)$ & $3,4(2)$ & $9-11(1)$ & $3-4(1)$ & $1-1(4)$ & $2-2(7)$ & $16(2)$ & $8(4)$ & $8(1)$ \\
\hline $7-8 \quad(2)$ & $3,1,5(30)$ & $10-11(6)$ & $4-4(2)$ & $1-2(6)$ & $2-3(12)$ & $17(6)$ & $9(8)$ & $9(1)$ \\
\hline $8-8 \quad(13)$ & $3,4,5,6(3)$ & $10-12(5)$ & $4-5(9)$ & $2-2(36)$ & $3-3(26)$ & $18(2)$ & $10(3)$ & $10(2)$ \\
\hline $8-9 \quad(16)$ & $4,5(12)$ & $11-11(4)$ & $5-5(27)$ & $2-3(1)$ & $3-4(1)$ & $19(2)$ & & $11(5)$ \\
\hline $9-9 \quad(16)$ & $4,5,6(55)$ & $11-12(13)$ & $5-6(8)$ & $3-3(4)$ & $4-4(1)$ & $20(1)$ & & $12(4)$ \\
\hline $9-10(2)$ & $4,5,6,7(3)$ & $11-13(4)$ & $6-6(6)$ & & & & & $13(1)$ \\
\hline $10-10(2)$ & $5,6,7(2)$ & $12-12(9)$ & $6-7(1)$ & & & & & \\
\hline $10-11(1)$ & & $12-13(6)$ & & & & & & \\
\hline & & $13-13(3)$ & & & & & & \\
\hline
\end{tabular}

*Single sides. 
specimen has two on one side only, a second has two on both sides. The loreal is excluded from the eye whenever 2 preoculars occur. Forty-seven of the specimens have 2-2 postoculars, three have 1-1, one has 1-2, three have 2-3, and one has 3-4. Suboculars are lacking in all individuals. The temporal region is the scene of many fusions and fractionations. Fifteen specimens have an extra scale inserted in the temporal rows; in twelve of them it is situated between the postoculars and the primary temporals; in two it lies between the primary and the secondary temporals; and in one, UMMZ 84103, there are extra scales between the postoculars and the primaries, the primaries and the secondaries, and the secondaries and tertiaries on the right side. In a single specimen, UMMZ 92053, the upper primary temporal enters the eye between the postoculars on the right side of the head. Vertical divisions of temporal scales into two equal sized scales occur in eleven individuals. Horizontal fusions, between rows of temporals, take place in eight.

A comparison of the total number of labials with the number of labials entering the orbit (Table VIII) indicates that the normal condition is either 8 labials with the $3 \mathrm{~d}$ through 5 th entering the orbit, or 9 labials with the 4 th through 6 th in the orbit. These two combinations occur in 71 percent of the sides. The difference between these two combinations appears to be in the number of labials anterior to the eye, for in both 3 enter the orbit

TABLE VIII

Correlation between Number of Upper Labials and Labials Entering Orbit in Dipsas latifrontalis

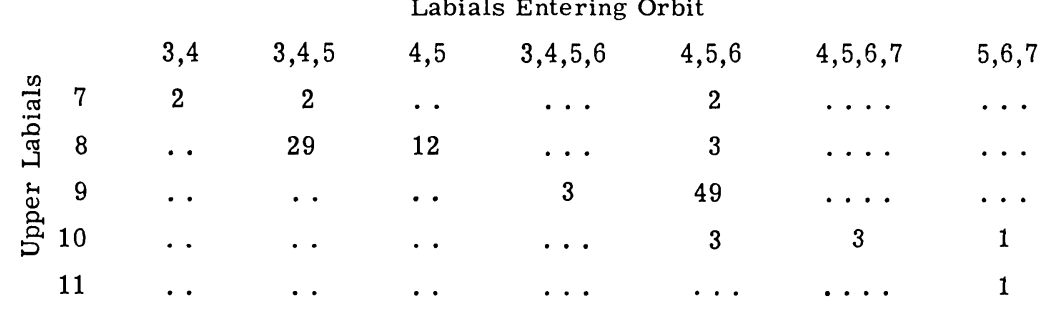

and 3 are posterior to the last in the orbit. If it is assumed that the combination of 9 labials with 4 through 6 in the orbit is the normal one, then the remaining variations may be explained in terms of labial fusions and divisions below the orbit. Thus, in two examples, when the total is 7 , there are only 2 labials in the orbit, and presumably 2 of the original 3 have fused. If there are 2 labials in the orbit, when the count is 8 , as is true of 12 sides, there is a combination of the normal condition anterior to the eye for 9 labials with a fusion under the orbit. Only the low counts have less than 3 labials entering the orbit, but the high count of 10 in three sides has 4 in the orbit, and results from a splitting of 1 of the normal 3 . This is probably not true of the three sides that have 9 labials with 4 entering the orbit, because this is the result of crowding and a posterior extension of the third to barely enter the orbit. The assumption of fusions or divisions below or anterior to the orbit thus accounts for all except ten of the 110 
sides. The condition of these ten can be explained only by postorbital fusion in seven and by postorbital splitting in three. Sides with the $3 \mathrm{~d}$ through 5 th entering the orbit, with a total of 7 , and sides with the 4 th through 6 th, with a total of 7 or 8 , have less than 3 posterior to the eye and are due to postorbital fusion. The individuals with 10 labials with only the 4 th through 6 th in the orbit indicate a splitting posterior to the orbit. The single individual with 11 on one side has a division both anterior and posterior to the orbit.

Seventy-three percent of the specimens examined have 10 to 12 lower labials on both sides, and 94 percent have that number on at least one side. The 5th and 7th lower labials are in contact behind the 6th on two of the 51 specimens. Forty-seven individuals have a single pair of lower labials in contact behind the mental, three have a single labial on one side in contact with two from the other side, and five specimens have two pairs in contact. The paired chin shields are only 2 in one specimen, 3 in forty-two, 4 in seven, and 3-4 in five.

The normal pattern for the dorsal scale rows consists of reductions from 17 or 19 rows immediately back of the head, one lateral and one vertebral, to 15, a number which is then maintained to the anus. Fifteen specimens of the fifty-five show variations on that pattern. Six of these individuals have reductions to 13 rows as in CNHM 28027:

$$
\underline{15} \frac{\mathrm{V}+7(161,186,188)}{\mathrm{V}+7(151,156)} \underline{15} \frac{\mathrm{V}+7(193)}{\mathrm{V}+7(192)} \underline{13}
$$

One individual, UMMZ 92055, has at least 16 irregular fusions of the vertebral row with the paravertebrals, but still ends up with 15 rows at the anus. Six other individuals have increases to 17 dorsal rows by splitting of the vertebral row, four of which are as in UMMZ 92048:

$$
\underline{17} \frac{\mathrm{V}+8(20)}{\mathrm{V}+8(21)} \underline{15} \frac{\mathrm{V}-8(21-23)}{\mathrm{V}-8(22 \text { only })} \underline{15}
$$

In this example the vertebral row splits off an extra row on both sides, and the splitting takes place far anteriorly, the usual condition. In several of the specimens the vertebral row is entirely lost by a division on the vertebral line, and the scale rows are 16, and this often happens far posteriorly. The fifth specimen (UMMZ 88979) has the unique formula:

$$
\underline{15} \frac{3-4(183)}{3-4(182)} 17
$$

This is a lateral increase to 17 rows, immediately anterior to the anus. AMNH 24149 has a very complicated dorsal reduction pattern, involving a reduction to 13 rows at the level of the 13 th ventral, and then a series of irregular divisions of the vertebral row over the entire length of the body with counts of 13,14 , or 15 scale rows. EPN 701 is also extremely irregular, with a majority of counts of 17 or 16 to the level of the 145th ventral, at which point the vertebral row widens and counts of 15 are more common; 
practically every row is different on this individual. UMMZ 92045 shows a unique variation in the dorsal scales. On the left side the scales of the sixth row of dorsals at the level of the 180-182d ventral are fused longitudinally, plus the scale in the fifth row at the $182 \mathrm{~d}$. This fusion is followed by the normal sutures of the final scales included, and then immediately thereafter the scales of the fifth, sixth, and seventh rows at ventrals 183184 are all fused, with only the suture between the fifth and sixth at 184 remaining. This produces two very large, patchlike scales on the side of this specimen.

Twelve specimens show variation from the normal pattern for caudodorsal reduction given in the description, five of which also displayed variations on the dorsal pattern. The first variation has the following formula (UMMZ 92059):

$$
6 \underline{3}+3(21) \underline{5} \frac{2-2(23)}{\mathrm{V}+2(22)} \underline{4} 2+2(91) \underline{3} \frac{1-1(95)}{\mathrm{V}+1 \quad(92)} \underline{2}
$$

This is the only individual that repeats the vertebral fusion when reducing from 4 to 2 , but six others duplicate the 6 to 4 reduction. The second variation combines a vertebral fusion with a lateral one, as shown in the formula for UMMZ 92053:

$$
6 \frac{6}{2+3+\mathrm{R} 3(21)} \underline{4} \stackrel{2-2(23)}{4} \underline{4} \frac{1+2(94)}{1+2(97)} \underline{2}(108)
$$

This type of reduction was noted on five specimens. The twelf th specimen (UMMZ 92052) has a unique pattern:

$$
\begin{gathered}
\underline{6} \overline{-3(17)} \underline{5}-\mathrm{V}(19) \underline{4}+\mathrm{V}(20) \underline{5} \underline{\mathrm{V}+2(21)} \underline{4} \underline{\mathrm{V}-2(22)} \underline{5} \underline{\mathrm{V}+2(24)} \underline{4} \\
\underline{4} \frac{-2(86)}{1+2(89)} \underline{2}(92)
\end{gathered}
$$

In this individual scale rows are lost, not fused with another, but in an irregular fashion.

Six specimens have a single ventral either divided as in Type 1, or incomplete across the belly, and a seventh has a total of three Type 1 divisions. Three individuals have at least one pair of subcaudals fused across the tail, and one of them has three fused pairs. The anal plate is divided in a single individual.

The size and number of dark spots on both the ventral surface and the dorsal interspaces varies somewhat between individuals at all levels of ontogeny. In specimens which do not have a dorsal blotch at the level of the anus a dark-brown spot extends almost across the anal plate, and up the sides to the level of the third or fourth scale row. The yellow border on the dorsal blotches varies in its prominence. The single specimen from Venezuela examined, AMNH 59452, differs from the rest of the individuals. There are no well-marked borders on the dorsal blotches, and the head, 
although unicolor anteriorly, is lightly spotted with dark brown posteriorly. The labials and temporals are almost entirely light. The venter is without spotting.

ONTOGENETIC VARIATION. - The sequence of ontogenetic change in color, discussed above in detail, is gradual and there are no abrupt changes from one "stage" to another.

The umbilical scar is present in all individuals under $250 \mathrm{~mm}$. in length. The anterior end of the scar is found from the 160th to the 180th ventral, a range of 20 ventrals. If the ventrals are counted from the scar to the anus, however, the position of the umbilicus is more definitely ascertained. Its anterior end is on the 17 th to 26 th ventral from the anus, a range of only nine ventrals. Two specimens, one $268 \mathrm{~mm}$. and one $269 \mathrm{~mm}$. long, retain vague traces of the scar, and a third, also $269 \mathrm{~mm}$. long, has lost it completely. The closure of the scar progresses from the anterior to posterior edge on each of the three ventrals usually included, until just before its disappearance it is in the form of a notch on the posterior border of the scales involved. The actual scab is still present on two of the specimens, one $187 \mathrm{~mm}$. long, the other 213 . The remainder had lost the scab, and retained only the scar. Smith $(1947: 153)$ indicates that the navel opening was completely closed, with scab tissue apparently gone, 96 hours after birth in Thamnophis radix. Probably this estimate of age is close to correct for this species also, and indicates that the young are about $200 \mathrm{~mm}$. long at birth.

GEOGRAPHICAL VARIATION. - Practically the entire series discussed here came from a single region on the Amazonian slopes of Ecuador, near the type locality of Leptognathus palmeri. The type of latifrontalis is from Aricaqua, Venezuela, a considerable distance to the north, but every single character given by Boulenger for this specimen is included within the variation of the series of near topotypes of palmeri. Leptognathus praeornata was also described from Venezuela. All of the known characters for this species are also contained in the range of variation of the topotypes.

REMARKS. - Boulenger, when he described Leptognathus palmeri, did not compare it with his earlier latifrontalis but with alternans and boliviana. His descriptions of palmeri and latifrontalis are almost identical, practically the only difference is in ventral and subcaudal counts, given as 187-120 for the type of palmeri, a male, and as 194-95 for the type of latifrontalis, a female. In reality, the two species were based upon a sexual variation in ventral and subcaudal counts.

The original description of Leptognathus praeornata Werner is too vague to characterize it. The author compared praeornata with alternans and viguieri. It would be difficult to find two more completely different species in the genus Dipsas. The range of alternans (here considered a synonym of incerta) is the southeastern coastal area of Brazil; the representative of its species group found in Venezuela is Dipsas variegata variegata. It is possible that praeornata belongs in that species, but it has only a single pair of labials in contact behind the mental, and has a preocular, whereas $v$. variegata has 2 pairs of labials in contact and lacks the preocular. Werner provided a better comparison in his key to the dipsadine snakes (1909a:282); for praeornata and latifrontalis are linked together 
through most of the key, and are finally separated on the basis of number of paired chin shields. According to Werner, praeornata has 3 pairs, while latifrontalis has only 2. Boulenger stated in his original description that latifrontalis has 3 , not 2 , pairs of chin shields, and my work has demonstrated that 3 is the normal number for this species.

I have synonymized praeornata with latifrontalis, because Werner himself considered them sufficiently similar to key out together, and then based his final separation of the two on a mistake. His original description, however, includes mention of color-pattern differences, which are not utilized in the key. If it is found upon re-examination of Werner's type that the head color differs from that given for latifrontalis in this study then the name will have to be transferred, probably to the synonymy of variegata. D. v. variegata has a dark spot on each parietal, and the dorsal blotches are narrowed (and widely separated) posteriorly. The description of praeornata implies such is the condition in the type. Certainly the type, $733 \mathrm{~mm}$. long, is extremely large and should have lost a large proportion of the contrasting colors in the dorsal pattern, and be dark, if it is actually a specimen of latifrontalis.

Although Boulenger gave the type locality for latifrontalis as simply Aricaqua, there are three towns called Aricaqua in Venezuela but two of them can be eliminated through information furnished by Juan Rivero (in litt.) concerning the "Sr. Briceño," named as the original collector. There were two Briceño brothers, José and Salomon, who collected professionally in the Mérida region of Venezuela. The Aricaqua at which they collected is the town of that name in the state of Mérida, which is on the southeastern flank of the Andes.

SPECIMENS EXAMINED. -

ECUADOR: Llanganate area (CNHM 23530-32), Río Napo (UMMZ 88978-80), Río Pastaza, 1800 m. (UMMZ 88995), Rí Pastaza, 500 m. (UMMZ 88996-97). Napo-Pastaza; Abitagua, 1100 m. (UMMZ 92059), Río Cotopino (JAP 2262), Loreto (EPN 701). SantiagoZamora; Zamora (BMNH 1933.6.24.109). Tungurahua; Baños (AMNH 24146, 24149; CNHM 28027-29; UMMZ 88981-82, 84102-03, 88983-93, 89027, 92045, 92047-58), Mapoto (UMMZ 88977, 88994), Palmera (AMNH 37939), San Francisco de Mapoto (UMMZ 88976), El Topo? (EPN 95), Yungilla (UMMZ 92016). VENEZUELA: Curupao, Miranda (AMNH 59452).

\section{Dipsas peruana Boettger}

Leptognathus peruana Boettger, 1898: 128.

Sibynomorphus peruanus, Barbour and Noble, 1920: 620.

Sibynomorphus mikanii, Amaral, 1925: 9.

Sibynomorphus mikanii peruanus, Amaral, 1929: 198.

Dipsas mikanii peruanus, Schmidt and Walker, 1943: 288.

HOLOTYPE. - Senckenberg Museum 20801, female, from Santa Ana, Cuzco Province, Peru, collected by F. Emmel (Pl. V, $a-b$ ).

RANGE. - Known only from eastern slopes of the Andes in southern Peru (Map 7).

DESCRIPTION. - Rostral broader than long, visible from above; internasals half as long as prefrontals, which may or may not enter orbit; frontal as broad as long, shorter than parietals; loreal enters orbit; nasal divided; preocular 1 or none; postoculars 2; suboculars none; primary 
temporals 2; secondary temporals 3 ; tertiary temporals 3 ; upper labials $8,3 \mathrm{~d}$ to 6 th may enter orbit, none enlarged. Lower labials 11 to 14 , one or no pairs of labials in contact behind mental, four or five pairs in contact with first chin shield; single unpaired chin shield following mental may be present; 3 or 4 pairs of chin shields.

Ventrals 180-190 in females, no males known; anal entire; subcaudals 79-105. Dorsal scale rows 15; vertebral row moderately enlarged; caudodorsals (for BMNH 1911.12.20.15):

$$
\underline{6} 2+3(12-13) \underline{4} 1+2(71-73) \underline{2}(105)
$$

Body length, female $610 \mathrm{~mm}$., tail length $155 \mathrm{~mm}$.

Dorsal ground color reddish-brown, with 24-34 rounded, white-edged, black blotches on body, slightly broader than interspaces, fused across midline when opposed, usually alternating posteriorly; white edges on neighboring blotches fused anteriorly, so that interspace color is absent between first 4 or 5 blotches; interspaces lightly stippled with black, small black spot may be present on vertebral and paravertebral rows. Venter whitish anteriorly with large, elongated, rectangular black spots, which form irregular row posteriorly; ventral color posteriorly changing to reddish-brown. Tail as in body, lacks spots ventrally.

Head unicolor black, slight white streaks on edges of prefrontals and internasals, upper labials flecked and spotted with white. Chin white and with large black spots.

INDIVIDUAL VARIATION. - I have only examined a single specimen but have had available for comparison an excellent series of photographs of the type, provided by Dr. Robert Mertens. The differences between the two are considerable.

The type appears to have a preocular on the right side, although Boettger said it had none; the BMNH specimen has one on each side. Mertens said that the type has 3 postoculars on the left side. The primary temporals are 2-2 in the type, in the second specimen they are 1-2. A tiny extra temporal inserted between the postoculars, upper labials, and primary temporals is present on both sides in the type. Fusions and divisions of temporal scales occur on the two specimens. While the upper labials are 8-8 in both, the type has the 3d, 4th and 5th in the orbit, and the second specimen has the 4 th, 5 th and 6 th on one side and the 4 th and 5 th on the other. The lower labials are 13-14 in the type, and 11-12 in the second specimen. There is a single pair of labials in contact behind the mental in the type; in the second specimen the ends of the first pair are separated by an unpaired scale behind the mental (a character that, although common in Sibon, has not been observed in any other specimen of Dipsas). There are 4 pairs of chin shields in the type, and 3 in the BMNH specimen.

There is little difference in ventral counts between the two, but the difference in number of subcaudals is quite large. Both specimens are females, and there is a difference of 26 subcaudals between them. The tail of the type may possibly be incomplete, but Boettger does not say so. The measurements he gave for the tail are slightly shorter than is usual in 
species of the pratti group. It appears to be somewhat stubby in the photograph of the type, but this is quite difficult to judge ( $\mathrm{Pl} . \mathrm{V} b)$.

As far as one can tell from Boettger's original description, the color patterns of the two are practically identical. The only difference noted is the presence of small black spots high in the interspaces and a very slight streaking with white on the otherwise black head in the BMNH specimen. Although not mentioned by Boettger, spots and streaking are clearly visible in my photograph.

REMARKS. - Results are usually unfortunate when the author of a new name compares his species with others of which he has seen no specimens. This seems to be particularly true in this instance, for, while Boettger compared peruana with catesbyi and mikani in his original description, its relationships are actually with neither; the color pattern places it in the pratti group of Dipsas. The species is obviously more closely related to latifrontalis and latifasciata but has been consistently synonymized with mikani since its description. Amaral even made it a subspecies of mikani. These actions have all been a natural consequence of Boettger's point by point comparison of the species with mikani, which is at present considered to be confined to southern Brazil.

SPECIMENS EXAMINED.-

PERU: Chaquimayo (BMNH 1911.12.20.15).

ADDITIONAL RECORDS. -

PERU: Santa Ana, Cuzco Province (SMF 20801, type).

\section{Dipsas pratti Boulenger}

Leptognathus Pratti Boulenger, 1897: 523.

Leptognathus triseriatas Cope, 1899: 13.

L. [eptognathus] triseriata, Werner, 1909a: 280.

Leptognathus nigriceps Werner, 1916: 309.

Dipsas pratti, Parker, 1926, 206 (by inf.); Amaral, 1929: 200.

Sibynomorphus triseriatus, Amaral, 1929: 199.

Dipsas variegata (part), Amaral, 1929: 201.

(Sibynomorphus?) pratti, Dunn, 1933: 194.

Dipsas niceforoi Prado, 1940b: 14.

Dipsas tolimensis Prado, 1941: 345.

HOLOTYPE. - BMNH, female, from Medellín, Colombia, “obtained” by Mr. A. E. Pratt.

RANGE. - Cordillera Central in Colombia (Map 7).

DESCRIPTION. - Rostral as broad as or slightly broader than deep, visible from above; internasals about half length of prefrontals, which do not enter orbit; frontal as long as or slightly shorter than broad, considerably shorter than parietals; loreal enters orbit; preocular 1; postoculars 2; suboculars none; primary temporals 2; secondary temporals 3 ; tertiary temporals 4 or 5 ; upper labials 8 or 9,4 th and 5 th or 5 th and 6 th entering orbit, posteriormost two somewhat longer than others. Lower labials 11 to 13 , two pairs in contact behind mental, four or five pairs in contact with first pair of chin shields; no enlarged lower labials; 2 or 3 pairs of chin shields.

Ventrals (168)-173 (175?) in males, 169-(176) in females; anal entire; 
subcaudals (65)-83 (89?) in males, $60-73$ in females. Dorsal scale rows may be 17 for short distance anteriorly, 15 on rest of body; vertebral row broadly enlarged, paravertebral row also larger than rest of dorsals; caudodorsals:

Male: $62+3(32-34) 41+2(78-80) 2$ (83) (ex AMNH 17525)

Females: $\underline{6} 2+3(23-\overline{2} 5) \underline{4} 1+2(47-\overline{6} 6) \underline{2}(60)$

Body length male $237 \mathrm{~mm}$., female $530 \mathrm{~mm}$. (620 recorded for type of pratti), minimum $177 \mathrm{~mm}$.; tail length male $75 \mathrm{~mm}$., female $136 \mathrm{~mm}$. (150 recorded for type of pratti), minimum $50 \mathrm{~mm}$.

Ground color dark brown above and below, with paler brown cross bars, one-scale wide, disposed in pairs; belly with interrupted light longitudinal streaks.

Dorsal ground color in older juveniles or young adults cream-white, with 14-21 dark-brown, yellowish-bordered bands on body, 7-8 on tail, wider dorsally than laterally, wider than interspaces on anterior portion of body, about equal posteriorly, those from either side may be in contact or alternating on vertebral row; if alternating, they extend to center of vertebrals; interspaces more or less spotted and streaked with dark brown. Venter whitish, first three or four dorsal bands in contact across midline, remainder separated on belly, in contact on ventral side of tail; interspaces spotted and streaked with dark brown.

Top of head unicolor dark brown; yellowish-white spots in centers of posterior occipital scales increase in size on neck and form nuchal collar from one corner of mouth to other. Upper labials unicolor, with yellow spot below eye; lower labials unicolor, chin shields and gulars with obscure yellowish spots which are anterior continuations of nuchal collar.

INDIVIDUAL VARIATION. - I have drawn on the original descriptions of all five of the species included in the synonymy in this discussion of individual variation. The upper labials are 8-8 in four, 8-9 in two, and 9-10 in one. When they are 8 , the 4 th and 5 th enter the orbit, when 9 , the 5 th and 6 th, and in the individual with 10 , the 6 th and 7 th. The preocular is absent in the type of nigriceps and in AMNH 35607. In AMNH 35607 partial sutures show its position. Similar sutures are also present in the type of pratti. Postoculars are other than 2 on one side of the head of the type of tolimensis, where the normal 2 are fused into a single scale, and on the right side of the type of niceforoi, which, from Prado's figure, has the end of the supraocular split off to add a scale at the top of the postocular row, making the count 3 rather than 2 . Suboculars are consistently absent. The primary temporals are 2-2 in all except one, the type of tolimensis, which appears to have an unusually large temporal on both sides, probably resulting from a fusion of the normal 2. Secondary temporals are 3-3 in all the types, but AMNH 35553 has 3-4, and AMNH 35607 has 2-3. Five specimens have 3 pairs of chin shields, two have 2 , but one of these, the type of tolimensis, has the suture half complete across the first unpaired scale following the 2 pairs. There are 5 scales in contact with the first pair of chin shields in one individual, 4-5 on two, and 4 on both sides in two (situation not known on type of nigriceps). 
The dorsal scales are normal and there are 15 rows throughout the body in two of the three specimens examined. In the third specimen the vertebral row is irregularly divided to form 16 rows on the posterior part of the body. The paravertebral row is definitely enlarged, and is twice the size of the 6th row on AMNH 35553. The caudal reductions are entirely as described above.

ONTOGENETIC VARIATION. - All four species included in the synonymy of pratti are based upon stages in the change that takes place between young and old individuals. The change is from a light and dark banded pattern to an almost totally dark pattern, with narrow yellow bands. The first stage, that of very young individuals, is typified by the specimens described as triseriatas, nigriceps, and tolimensis. In these the bands are still distinct from the interspace color, and the yellow borders of the dark-brown bands are sharply set off from the ground color. Bands are slightly longer than to almost twice as long as the interspaces for the most part, and the interspaces are unicolor or lightly stippled with dark brown. The second stage is perhaps exemplified by niceforoi, in which dark bands are still recognizable but the ground color is beginning to be invaded by dark color (interspaces "com algumas escamas guarnecidas de escuro"). An example of the next, or third, stage is AMNH 35607, which is not only intermediate in length between the group of specimens discussed above and the type of pratti, but is also intermediate between them in color. Although it has the interspaces almost completely obscured by the deposition of dark pigment, they are still slightly lighter than the original dark bands, and are recognizably interspaces; yellow borders of the dark bands are still prominent. It still retains the isolated yellow spot under the eye that Cope noted in the type of triseriatas. The fourth and final stage in this series of color changes is that exemplified by the type of pratti, which, according to Boulenger, is entirely dark brown, with "paired" yellow bands about a scale wide. The significance of the word "paired" cannot be overemphasized, for this is the only remaining indication that the now completely darkened interspaces were originally narrower than the bands they now resemble. These yellow bands retain their identity throughout the series of ontogenetic color changes and provide the most important clue to what has taken place. I have little doubt that traces of a yellow spot under the eye could be seen in the type of pratti, for it seems certain that the yellows are retained after the white or light-brown areas disappear.

REMARKS. - In addition to the fairly evident ontogenetic sequence discussed above, there is other evidence that supports my synonymy of these five species. First, and most important, is the uniformity throughout in scutellation. The range of variation in all characters is surprisingly small for a dipsadine species. Second, all of the known specimens come from a fairly restricted area in a rather homogeneous mass, the Cordillera Central of Colombia, and it is likely that the species is endemic to this region, living only at moderately high altitudes. That this region would support five distinct species of a genus which shows a high degree of ecological specificity is quite unlikely.

Inclusion of nigriceps in the synonymy is based upon the great similarity between its color and that of triseriatas and tolimensis, and its 
general conformation in scale characters with those given for pratti. Werner's original description is just sufficiently vague to make placing his species in the synonymy somewhat hypothetical, in that it is based upon a certain amount of assumption and extrapolation. The exact situation in the loreal region, for example, is not clear, for Werner said "Kein Loreale, 1 Präoculare, 2 Postocularia ..." If it were any other author, the assumption would be that he was following the lead of certain others who have worked with dipsadines, and was calling the scale between the eye and the nasal a preocular. Werner, however, had done much work with the group before writing this description, and had followed usual dipsadine terminology; for example in his description of temporalis, in which the loreal was properly labeled, and he called the scale above it in the eye a preocular. His type should be rechecked for this character. Although Werner did not specify the sex of his snake, the high subcaudal count indicates that it is a male. The ventral count given is probably too high, since he stated that they begin immediately behind the 3 pairs of chin shields. In view of the method I use in counting ventrals, this is tantamount to adding 2 or 3 ventrals to any of my counts.

Amaral (1929:201) synonymized nigriceps with Dipsas variegata, an action accepted by Maria (1942:95) and Daniel (1949:320). While there is similarity in head scutellation, to accept this synonymy one must totally ignore the obvious differences in dorsal color. According to Werner, $n i$ griceps has black rings on the body which are almost twice as broad as the light interspaces; variegata has somewhat darker but very poorly defined blotches on the body which are about one-half to one-third the width of the interspaces. The variegations in the interspaces, the basis for the name variegata, are not mentioned by Werner, and one can safely assume them to be lacking. Probably, Amaral's synonymy is based upon the superficial resemblance created by the presence of two pairs of lower labials in contact in both variegata and nigriceps and the fact that he had no material of any of the species now synonymized with pratti available for comparison.

As I pointed out above, all of the four species synonymized here are considered the same on the basis of assumed ontogenetic color change. If added data, either from the original types or from additional specimens, prove this assumption to be incorrect, I would still synonymize triseriatas and tolimensis, for they are alike in all respects. The latter was described without comparison with the former, and may well have received its name in ignorance of the prior synonym.

SPECIMENS EXAMINED. -

COLOMBIA: no other data (AMNH 17525, cotype of triseriatas), Medellín (AMNH 35553, $35607)$.

\section{ADDITIONAL RECORDS. -}

COLOMBIA: Medellín (BMNH, type of pratti), Quindío (Museu do Instituto de La Salle, Bogota, type of niceforoi), Tolima, Líbano (Museum do Colégio del Sagrado Corazón, Cúcuta, type of tolimensis), Cañon del Tolima (mahrischen Landesmuseums in Brünn, type of nigriceps).

\section{Dipsas sanctijoannis Boulenger}

Leptognathus sancti-joannis Boulenger, 1911: 24.

Leptognathus sancti-johannis (sic), Werner, 1916: 310. 
Sibynomorphus mikanii peruanus (part), Amaral, 1929: 198.

Sibynomorphus sancti-joannis, Amaral, 1926a: 9 (by inf.); Amaral, 1932: 67.

Sibynomorphus caucanus Rendahl and Vestergren, 1941: 11.

COTYPES. - BMNH 1910.7.11.34 and others, from Pueblo Rico, slopes of San Juan River, Choco, Colombia, 5200 feet, collected by Mr. G. Palmer.

RANGE. - Slopes of Cordillera Occidental in Colombia; also recorded from Medellín (Map 7).

DESCRIPTION. - Rostral considerably broader than deep, not visible from above; internasals half to two-thirds as long as prefrontals, which do not enter orbit; frontal as long as or slightly shorter than broad, considerably shorter than parietals; nasal divided wholly or in part; loreal does not enter orbit; preoculars 2 or 3; postoculars 2; suboculars 1; primary temporals 2; secondary temporals 2 or 3 ; tertiary temporals 3 ; upper labials 8 or 9,4 th and 5 th or 5 th and 6 th enter orbit. Lower labials 12 or 13, first pair in contact behind the mental, five pairs in contact with first pair of chin shields; no enlarged lower labials; 2 or 3 pairs of chin shields.

Ventrals 181-187 in males, 171-183 in females; anal entire; subcaudals 89-94 in males, $70-83$ in females. Dorsal scale rows may be 17 to level of 15th ventral, usually 15 on rest of body, may reduce irregularly to 14 or 13 (see below); vertebral row moderately to broadly enlarged; caudodorsals:

$$
\begin{aligned}
& \text { Males: } \underline{6} 2+3(23-31) \underline{4} 1+2(82-89) \underline{2}(89-94) \\
& \text { Female: } \underline{6} 3+3(24) \underline{5} \overline{\mathrm{V}+2(33)} \underline{4} \underline{2}+2(79) \underline{3}(83)
\end{aligned}
$$

The caudodorsal reduction is known for only a single female, as given.

Maxillary teeth 15 ( 1 individual); palatine teeth 9 (1); pterygoid teeth 11 (1).

Body length male $689 \mathrm{~mm}$., female $445 \mathrm{~mm}$. (cotype), minimum 176 mm.; tail length male $209 \mathrm{~mm}$., female $132 \mathrm{~mm}$. (cotype), minimum $64 \mathrm{~mm}$.

Dorsal ground color grayish-brown, with 21-28 broad, slightly rounded, black-edged, cream-bordered blotches; blotches two to three times width of interspaces, extend well onto vertebral row if alternating with one on other side, fused across vertebral row if opposite; cream border narrowly separated from blotch by black streak, heavily speckled and streaked with dark brown, anterior blotches so close together that cream borders fuse and interspace color is absent; interspaces, when present, usually with dark spot on vertebral and/or paravertebral row, dark variegations on other interspace scales. On venter both blotches and cream borders extend well onto belly anteriorly, and may be fused with those of opposite side; after interspaces form, all three (blotch, border, and interspace) merge into an irregularly unicolor pattern, darker than interspaces and lighter than blotches. Tail with 8-15 blotches, pattern and color as on posterior part of body, with interspaces present; yellow borders of blotches quite prominent ventrally.

Dorsum of head yellowish, with rather regular dark-brown vermiculation; a solid preorbital bar traverses prefrontals, bilaterally symmetrical spots on parietals, single large spot on occipitals immediately behind and 
partially including median parietal suture; labials below eye solidly dark brown, other upper labials with yellow (white) black-edged spots. Chin principally yellowish, with brown labials and mental, former occasionally yellow-spotted, series of fairly prominent brown spots down midline sutures.

Juveniles with regular reddish-brown blotches on tan ground color; blotches lack prominent yellow border, about equal width to interspaces, which are occasionally spotted with dark brown at midlines both above and below; head more prominently spotted with larger spots of adult, but vermiculations are absent. Chin not so prominently spotted.

INDIVIDUAL VARIATION. - In addition to the five specimens examined, the three specimens called Sibynomorphus caucanus by Rendahl and Vestergren are included in the following tabulation.

The upper labials are 8-9 in six specimens, 7-7 in one, and 9-9 in one. When 7 or 8 , the 4 th and 5 th labials enter the orbit; when 9 , the 5 th and 6 th. The preoculars are 2 on both sides in three specimens, 1-2 in one, and 2-3 in four. The postoculars are consistently 2. The suboculars are 1-1 in all except the cotype, which lacks it on the right side. The temporal region is quite irregular. The primary temporals are 1-2 in two specimens, 2-2 in three, including the type of santijoannis, which also has a tiny scale between the primary temporals, postoculars, and upper labials, on both sides, 2-3 in one, and indeterminate in one. The last individual, AMNH 35245, has the lower primary vertically divided on both sides, to form a $\frac{1}{1-1}$ formula. Its secondary temporals are normal, and are 3-3, which is true of two other specimens, another has 2-3 secondaries, and three have 2-2. In ANSP 25436 the upper secondary on the left is in contact with a labial anterior to the lower secondary.

The lower labials (count unknown for Rendahl and Vestergren's specimens) are 11-12 in one individual, 12-12 in two, 12-13 in one, and 13-13 in one. Of these, the number in contact with the first chin shield are 4-5 in one, 5-5 in two, and 5-6 in two. There are 3 pairs of chin shields in five specimens, two individuals have only 2 , and one has 2-3.

The dorsal scale rows normally reduce to 15 a very short distance behind the parietal and remain constant for the rest of the body. Three of the specimens seen do not conform to this pattern. The formula for ANSP 25436 is:

$$
\underline{17} \frac{3+4(7)}{3+4(8)} \underline{15} \frac{\mathrm{V}+7(168,176-8)}{\mathrm{V}+7(116,166-8)} \underline{15} \frac{\mathrm{V}+7(180)}{\mathrm{V}+7(176)} \underline{13}
$$

In this specimen several short fusions take place between the vertebrals and paravertebrals, and finally a permanent fusion occurs considerably farther posteriorly. The situation is much the same in CNHM 54898, which has 16 such fusions, beginning at the 21 st ventral, and there are 13 scales in the dorsal rows almost as frequently as there are 15. AMNH 35245 varies in the opposite direction, for its vertebral row is occasionally divided, and the dorsal count of ten goes up to 16,17 , or even 18 .

The only variation from the normal caudodorsal reduction is that given 
above for the single female seen. Ventral divisions of Types 1 and 5 were noted on a single specimen, CNHM 54898. The umbilical scar is on ventrals 165-167 in AMNH 35245, the smallest individual examined.

REMARKS. - In addition to the specimens discussed above, three others have been reported. Amaral (1932:67) gave a brief description of a specimen from Pensilvania, Colombia; Daniel (1939:596) recorded a specimen from "Andes" of Colombia; and Prado (1940a:9) published notes on a young female from Manizales, Colombia. Amaral described his specimen as an adult female, with 202 ventrals and 91 subcaudals. Such a ventral count is considerably higher than the maximum for the four males I have examined. The specimen also has 2 preoculars; 1 subocular; 10 upper labials, with the 6 th and 7th in the orbit; primary temporals 2-2; secondaries 4-2 (3); and 3 pairs of chin shields. His color description is vague enough to include this species. Even though several of the characters mentioned are slightly deviant, I feel that Amaral's identification is to be accepted, at least provisionally. Prado reported that his specimen has 178 ventrals, 74 subcaudals, 9-8 upper labials with the 4th, 5th, and 6th entering the orbit, and temporals 2-3-3. If all three of the labials actually do enter the orbit on each side, then this is the only specimen of the species known with more than 2. With this slight exception, there is no obvious reason in Prado's brief presentation of data to doubt the identification of the individual.

Daniel's identification of his specimen is somewhat doubtful. The scale characters he presented are as follows: 195 ventrals, 84 subcaudals, 10-9 supralabials, 5th through 7th entering the orbit on one side and 6th through 7 th on the other, lower labials 10-11, preoculars 1-2, postoculars 2-2. Sex is not mentioned, The figure of the dorsum of the head lacks any indication of vermiculation or spotting, but the anterior part of the neck has a pattern very like that of sanctijoannis. The specimen has a high ventral count, extra supralabials (which apparently result from division of one of those entering the orbit), a single preocular on one side, and an unusual color pattern, at least on the head. Since several of these characters are in agreement with the specimen discussed by Amaral, however, it seems inadvisable to reject Daniel's identification.

Daniel reported that the common name for this species is "Yaruma tabaca." The adjective "tabaca" is attached to distinguish this species from Dryadophis boddaerti, which is known as "yaruma." The name in both instances is derived from the fact that the species lives among the roots of the "yarumo" or "guarumo" tree, a tree which, according to Daniel, belongs to the genus Cecropia.

Rendahl and Vestergren (1941:11) described Sibynomorphus caucanus but without comparison to other dipsadine species, and there can be little doubt that they did not compare their specimens with the description of sanctijoannis. When I compared their specimens with those of sanctijoannis available to me, I found no characters that are both unique to and uniform within their three. The type of caucanus is unique in having 2 labial pairs in contact behind the mental, the other two specimens each have only a single pair. The type is also unique in having 7 upper labials, but since the 4 th and 5 th enter the orbit, this labial count appears to be a consequence 
of a single postorbital fusion of 2 labials. In all other respects of scutellation and coloration, caucanus seems to be identical with sanctijoannis.

This species appears to be confined to what Chapman $(1917: 145)$ has called the "West Andean Subtropical Lifezone" in Colombia. The heavy forests of this zone stretch along both slopes of the Cordillera Occidental of Colombia and the subtropical western slope of the Cordillera Central. In the northern section of the Department of Antioquia the two Cordilleras are separated only by the Cauca River, "from opposite banks of which they respectively arise," according to Chapman. The subtropical forests of the two ranges lie within a short distance of each other at this point, and probably provide an avenue for exchange of faunal elements from one mountain range to the other.

SPECIMENS EXAMINED. -

COLOMBIA: Pueblo Rico (BMNH 1910.7.11.34, cotype, CNHM 54898), Medellín (AMNH 35727), Jericó (AMNH 35245), Tambo (ANSP 25436).

ADDITIONAL RECORDS. -

COLOMBIA: Manizales (Mus. Instituto de La Salle 168), Pensilvania (Mus. Instituto de la Salle 51), "Andes" (Mus. de Ciencias Naturales del Colégio de San José-Medellín 44).

\section{Dipsas schunkei Boulenger}

Leptognathus schunkii Boulenger, 1908: 115.

Leptognathus schunckii (sic), Werner, 1922: 197.

[Sibynomorphus] schunkii, Dunn, 1923: 186.

Sibynomorphus mikanii peruanus (part), Amaral, 1929: 198.

Dipsas schunkii, Parker, 1926: 206 (by inf.); Dunn, 1946: 19.

COTYPES. - BMNH, three specimens from Chanchamayo, Peru, collected by Mr. C. Schunke.

RANGE. - Amazonian slopes of the Andes in Peru (Map 7).

DESCRIPTION. - Rostral considerably broader than deep, visible from above; internasals more than half length of prefrontals, which do not enter orbit; frontal approximately as wide as long, shorter than parietals; nasal divided; loreal enters orbit; preocular 1; postoculars 2; suboculars none; primary temporals 1 ; secondary temporals 2 ; tertiary temporals 2 , 3 , or crowded off temporal row; upper labials 8 with 4th and 5th in the orbit or 9 with 5 th and 6 th, none enlarged. Lower labials 10 to 14 , single pair in contact behind mental, four or five pairs in contact with first chin shield; 3 pairs of chin shields.

Ventrals unknown in males, 177-188 in females; anal entire; subcaudals unknown in males, 87-93 (102?) in females. Dorsal scale rows reduce from 17 on neck to 15 at about level of 6 th to 14th ventrals, no posterior reductions to 13; vertebral row moderately to broadly enlarged; caudodorsals:

Males: Reduction formula unknown.

Females: 6 2+3 (13-24) $\underline{4} 1+2(52-84) 2(87-93)$

Maxillary teeth 15 , palatine teeth 11 , pterygoid teeth 15 - (all from a single specimen). 
Body length, female $709 \mathrm{~mm}$., minimum $230 \mathrm{~mm}$.; tail length female $235 \mathrm{~mm}$., minimum $83 \mathrm{~mm}$.

Dorsal ground color reddish or brownish gray, with 14-19 (25+) whitebordered, dark-brown to black bands on body; white borders in contact between blotches anteriorly, excluding interspace color, which appears after 4th or 5th blotch; blotches wider anteriorly than posteriorly, where they are approximately equal to interspaces; interspaces usually lightly stippled with dark spots in young adults, completely infiltrated by dark color in old adults, so that only pattern appears to be paired white bars, which still mark old borders of dorsal blotches (Pl. IV $b$ ). Venter dark, with tips of blotches fused across midline or closely approximating; in old adults entire belly is black, in younger individuals interspaces retain their identity across belly. Tail as in body, often much darker, white stripes may be completely lost.

Dorsum of head black, with yellow spotting and vermiculation which tends to disappear in old adults, but is prominent in young adults on all ocular scales, particularly along supraocular above eye, on temporals, parietals, frontal and rostral sutures; labials, predominantly yellow with black sutures ( $\mathrm{Pl}$. IVe); yellow bar across snout includes anterior edges of loreals and prefrontals; white nuchal collar with fairly regular black spotting on individual scales. Chin white or yellow with prominent black spots and black sutures; apparently completely black in old adults.

Juvenile pattern unknown, but assumed to be one of contrasting dorsal blotches and interspaces, as in other juveniles within the pratti group.

INDIVIDUAL VARIATION. - The dorsal head scales are entirely uniform in the four specimens seen. The nasal is completely divided in three and whole in the fourth. The loreal enters the orbit in all four. All of them have a single preocular on each side; one has 3 postoculars on one side; another has 1 subocular on one side. All four have one primary temporal; the secondary temporals are 2 except in AMNH 52184, which has one on the right and also has the upper tertiary fused with a secondary on both sides. Of the total eight sides, five have 8 labials with the 4 th and 5 th entering the orbit, and three have 9 with the 5th and 6 th. Apparently this is not true of the types, for Boulenger says there are 3 labials in the orbit in all of them.

The lower labials are quite irregular. The four specimens examined have $10-10,11-12,12-12$, and 13-14. Those sides with 10 or 11 have four pairs in contact with the first chin shield, those with 12 have five, and those with 13 or 14 have six. There is a single labial pair in contact behind the mental in all four specimens. There are 3 pairs of chin shields in three specimens (and apparently all the cotypes), and 4 pairs in one individual.

The dorsal scale rows are 15 over most of the body, although in the topotype (AMNH 52184) a reduction from 17 to 15 takes place at the level of the 14th ventral, which is somewhat farther back than usual. One specimen, BMNH 1912.11.1.8, has a very irregular pattern on the posterior quarter of the body, which is as follows: 


$$
17 \frac{-4(7)}{3+4(6)} 15 \frac{\mathrm{V}+7(150-52,155-6,162-3)}{\mathrm{V}+7(152)} 13 \mathrm{~V} \leq \frac{7}{7}(164) \underline{14}+\mathrm{V} \text { (165) } \underline{15}
$$

$$
\underline{15} \frac{\mathrm{V}+7(171)}{\mathrm{V}+7(168)} 13 \mathrm{~V}<-\frac{7}{7}(180 \text { only) } \underline{13} \text { (188) }
$$

The caudodorsal reductions are as given above for all four individuals. No divided ventrals or fused subcaudals were observed.

Variation in color and pattern is primarily a matter of ontogenetic change, as was intimated in the description.

REMARKS. - In accordance with current practice, the orthography of the specific name of this species has been revised so that the patronym agrees completely with the name of the person it was derived from, $\mathrm{Mr}$. C. E. Schunke.

SPECIMENS EXAMINED. -

No data (CNHM 1). PERU: Chanchamayo (AMNH 52184-topotype), Huancabamba (BMNH 1912.11.1.8), Fundo Sinchono (USNM 119014).

\section{THE VARIEGATA GROUP}

\section{Dipsas albifrons Sauvage}

Dipsadomorus albifrons Sauvage, 1884: 145.

Leptognathus albifrons, Boulenger, $1896 a: 451$.

Dipsas albifrons, Mocquard, 1908: 897.

Cochliophagus albifrons, von Thering, 1910: 331.

Dipsas albifrons cavalheiroi Hoge, 1950: 154.

HOLOTYPE. - Museum d'Histoire Naturelle de Paris, 2 cotypes, type nos. 6106 and 6293 , both females, from Brazil, collected by H. Ferry.

RANGE. - Extreme southern Brazil; known from states of Santa Catarina and São Paulo. Also reported from Paraguay and Mato Grosso, Brazil (Map 8).

DESCRIPTION. - Rostral broader than deep, visible from above; internasals consistently shorter than prefrontals, which are excluded from the orbit 60 percent of the time; frontal usually longer than broad, considerably shorter than frontal; nasal divided wholly or in part; loreal enters orbit; preoculars 1 or none; postoculars 2; suboculars none; primary temporal 1 ; secondary temporals 2 ; tertiary temporals 2,3 , or crowded off temporal row; upper labials 7 or $8,3 \mathrm{~d}$ through 6 th may enter the orbit; last upper labial enlarged, elongate, lanceolate. Lower labials 10 to 12, two or three pairs in contact behind mental, three or four pairs in contact with first chin shield; 2 or 3 pairs of chin shields.

Ventrals $167-183$ in males, (157) $160-178$ in females; anal entire; subcaudals 82-92 in males, 71-87 in females. Dorsal scale rows 17 or 16 to level of 7-12 ventrals, 15 on most of body, occasional reduction to 14 or 13 slightly anterior to anus; vertebral row scarcely to moderately enlarged; caudodorsals: 


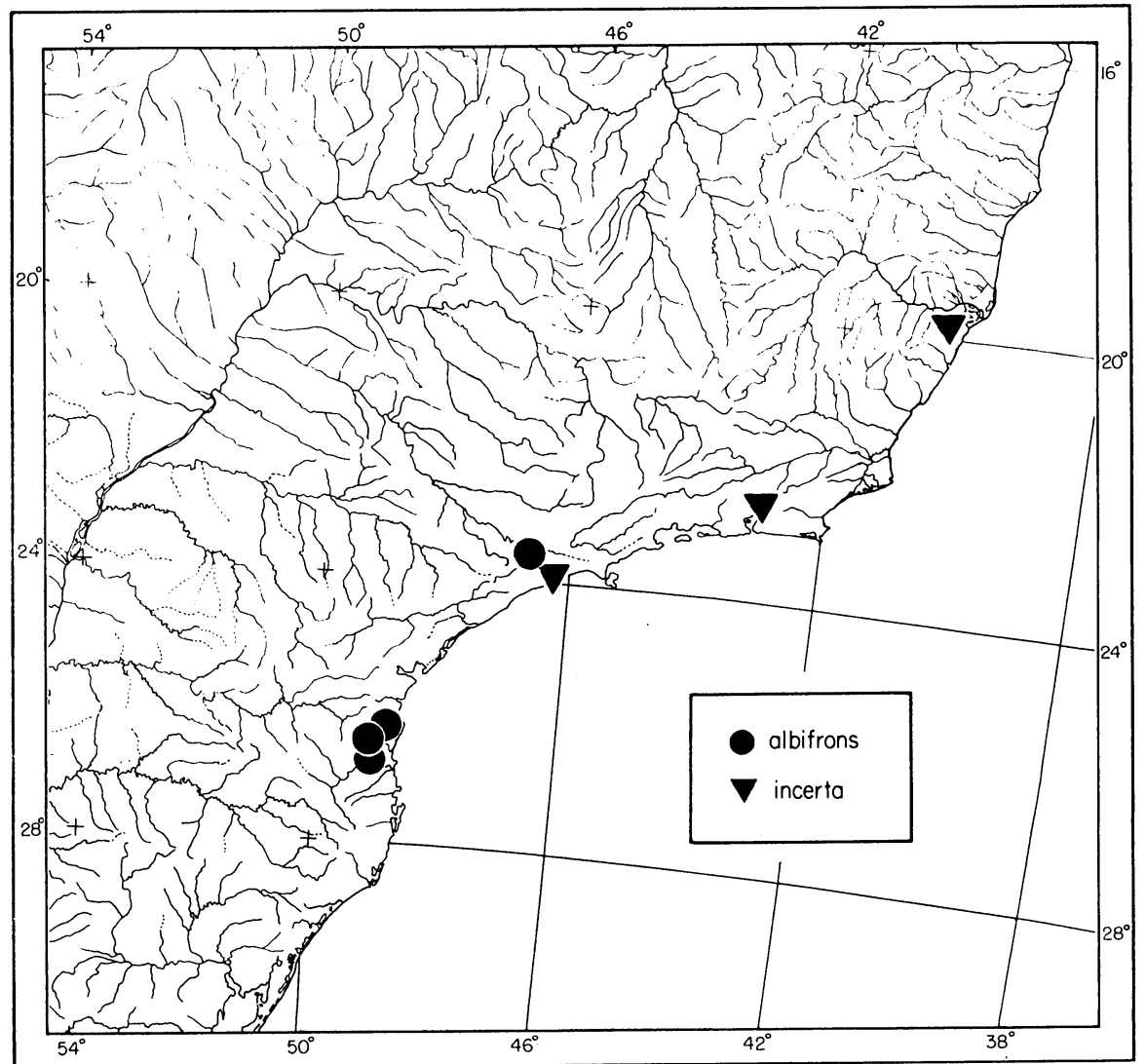
group.

Map 8. Geographic distribution of the southeastern Brazilian species of the variegata

Males: $62+3(10-24) 41+2(58-78) 2$ (82-92)

Females: $\underline{6} 2+3(6-27 \overline{\underline{4}} \underline{4} 1+2(47-72) \underline{2}(71-87)$

Body length male $551 \mathrm{~mm}$, female $710 \mathrm{~mm}$. , minimum $186 \mathrm{~mm}$.; tail length male $197 \mathrm{~mm}$., female $197 \mathrm{~mm}$., minimum $65 \mathrm{~mm}$.

Dorsal ground color grayish- or yellowish-tan, with 19-27 narrow, jagged-edged, widely spaced light-brown bands or blotches on body, 11-19 on tail, occasionally with lighter centers, usually with whitish area between blotches and interspaces; first blotch large, elongate, 10-12 scale rows long, second and all remaining narrow, higher than long, 2-3 scale-rows long; interspaces considerably wider than blotches, unicolor or lightly streaked and spotted with light brown high on sides, irregular spots may be present on vertebral and adjacent scale rows, spot centered between dorsal blotches on first scale rows and tips of ventrals commonly absent, may be faintly defined, never prominent $(\mathrm{Pl} . \mathrm{V} d)$. Venter often unicolor yellowish-cream, may be stippled more or less heavily with gray or brown, 
forming fairly broad ventral stripe that increases in prominence posteriorly; blotches extend onto tips of ventrals in some, end at first scale row on others. Tail as body, with dorsal blotches much closer together, lacking lighter margins; ventral side of tail more heavily stippled than venter of body, often with large rectangular brown spots, occupying more of surface than does yellow ground color.

Dorsum of head light tan, unicolor or with poorly defined, rectangular brown spot on frontal and parietals that has its posterior corners drawn out to form hornlike projections on posterior part of parietals and adjacent occipitals; temporal region, snout, labials very light tan, unicolor. Chin and throat light yellow or tan, unicolor, no darker pigment in labial sutures.

Juveniles somewhat lighter, with sharper contrast between blotch and interspace color.

INDIVIDUAL VARIATION (Table IX). - The internasal is shorter than the prefrontal in all specimens examined, and usually is less than 90 percent of prefrontal length. The frontal is longer than wide in all except two individuals. The number of specimens available (22) is sufficient to provide data concerning irregularities in head scales. UMMZ 79679 has the preocular on the left fused with a scale split off from the lower edge of the prefrontal, and this elongate scale extends anteriorly to the internasal and nasal. MNB R708 has a small scale inserted between the internasals and the rostral, and has the loreal fused with the posterior half of the nasal. MCZ 20853 has the end of the prefrontal sutured off to form an elongate scale between the prefrontal, internasal, nasal, loreal, and preocular on the left side.

The scales in the ocular region also show considerable variation. MNB R710 has the supraocular divided into two scales on the right by a transverse suture, and an indication of a similar suture on the left, above the eye. This is the only dipsadine I have seen with sutures on the supraocular. In two individuals the preocular is very small and the prefrontal enters the eye below it. In all other specimens having the preocular the prefrontal is excluded from the eye. Suboculars at the lower posterior corner of the loreal were not observed but four individuals have one or two labials horizontally divided below the eye to produce a scale in the subocular position. MCZ 20855 has the third and fifth labial in contact with each other and entering the orbit, excluding the fourth.

The temporal region is exceptionally uniform, in view of the normal tendency in dipsadines to have fusions and splittings there. The primary temporals are $1-1$ in all six males and in thirteen of sixteen females. In the other three females, the single temporal is apparently split horizontally, and they all have a 1-2 formula. Seven specimens of the 22 examined show fractionation of secondary temporals which is unilateral in four cases and bilateral in three. In all seven the upper of the normal two is entire, while the lower is divided vertically to produce the formula $2-\frac{1}{2}$. Betweenrow fusions were observed in only two specimens. In one, BMNH 1895.10.26.27, a tiny extra scale is inserted between the anterior ends of two tertiary temporals on the right side. 
TABLE IX

INDIVIDUAL VARIATION IN Dipsas albifrons

\begin{tabular}{|c|c|c|c|c|c|c|c|c|c|c|}
\hline \multicolumn{3}{|c|}{ Upper Labials } & \multicolumn{2}{|c|}{ Lower Labials } & \multirow[b]{2}{*}{$\begin{array}{c}\text { Paired } \\
\text { Chin Shields }\end{array}$} & \multirow[b]{2}{*}{$\begin{array}{l}\text { Pre- } \\
\text { Oculars }\end{array}$} & \multirow[b]{2}{*}{$\begin{array}{l}\text { Post- } \\
\text { Oculars }\end{array}$} & \multirow[b]{2}{*}{$\begin{array}{l}\text { Secondary } \\
\text { Temporals }\end{array}$} & \multicolumn{2}{|c|}{ Teeth } \\
\hline $\begin{array}{c}\text { Total } \\
\text { Number }\end{array}$ & $\begin{array}{c}\text { Entering } \\
\text { Orbit* }\end{array}$ & $\begin{array}{c}\text { Total } \\
\text { Number }\end{array}$ & $\begin{array}{c}\text { Touching } \\
\text { First } \\
\text { Chin Shield } \\
\end{array}$ & $\begin{array}{c}\text { Touching } \\
\text { Behind } \\
\text { Mental }\end{array}$ & & & & & Maxillary & Palatine \\
\hline $7-7(6)$ & $3,4 \quad(6)$ & $9-9 \quad(1)$ & $2-3(1)$ & $1-2(1)$ & $2-2(4)$ & $0-0 \quad(7)$ & $2-2(19)$ & $2-2(14)$ & $11(11)$ & $6(4)$ \\
\hline $7-8(6)$ & $3,4,5$ (16) & $9-10(1)$ & $3-3(3)$ & $2-2(6)$ & $2-3(1)$ & $0-1 \quad(1)$ & $2-3 \quad(3)$ & $2-3 \quad(1)$ & $12 \quad(1)$ & $7(2)$ \\
\hline 8-8(8) & $3,5 \quad(1)$ & $10-10(3)$ & $3-4(8)$ & $2-3(7)$ & $3-3(14)$ & $1-1(14)$ & $3-3 \quad(1)$ & $\mathrm{F}^{\dagger} \quad(7)$ & $13 \quad(2)$ & $8(4)$ \\
\hline 8-9 (1) & $4 \quad(2)$ & $10-11(4)$ & $4-4(5)$ & $3-3(7)$ & $3-4 \quad(1)$ & & & & $14 \quad(2)$ & $9(2)$ \\
\hline $9-9(1)$ & $4,5(13)$ & $10-12(1)$ & $4-5(1)$ & $4-4(1)$ & $4-4 \quad(2)$ & & & & $15 \quad(6)$ & \\
\hline & $4,5,6^{-}(5)$ & $11-11(4)$ & 5-5(1) & & & & & & $16 \quad(1)$ & \\
\hline & & $11-12(4)$ & & & & & & & & \\
\hline & & $11-13(2)$ & & & & & & & & \\
\hline & & $12-12(1)$ & & & & & & & & \\
\hline & & $13-13(1)$ & & & & & & & & \\
\hline
\end{tabular}

*Single sides. ${ }^{\dagger}$ Fractionated. 
Contact of a pair of lower labials behind the labial between them takes place in five individuals. The labials taking part are anterior to the last in contact with the first chin shield, as this is the area of greatest crowding of labials. Most often, the second and fourth meet below the third. In the single specimen, MNB R710, in which there is only one labial (right side) meeting the first two on the left, the first on the right is crowded off the contact by a broadened second labial which touches the mental. In two specimens one of the chin shields is fused with a lower labial.

The last ventral is divided in seven specimens, six of which are Type 1 divisions and one is Type 2. Two other specimens have divided ventrals; in UMMZ 62705 the 168th ventral is a Type 1 division, in MCZ 20854 the 68 th is a Type 2. There are no undivided subcaudals on any of the specimens examined.

There are two principal types of reduction from 17 to 15 scale rows on the neck, each of which is directly correlated with the width of the vertebral row following the reduction. The formula for the first is (UMMZ 62705):

$$
\underline{17} \frac{\mathrm{V}+8(8)}{\mathrm{V}+8(10)} 15
$$

and for the second (MNB R712):

$$
\frac{2+3(9)}{2+3(11)} 15(170)
$$

In the first type the fusion of the vertebral row with the paravertebrals produces a moderately enlarged vertebral row immediately. In the second type, although the scale rows are 15, the vertebral row is not, or is only scarcely, enlarged; it does not become moderately enlarged at all, or if so only far posteriorly. The second type seems to be the more common in this species. Reductions to 14 or 13 were observed in seven individuals, none more than 11 scales anterior to anus, with the exception of MNB R710. In this specimen, there are 12 reductions or additions between the 45 th and 166th ventrals, both dorsal and lateral, and there are 13-15 dorsal rows.

A final variant on the normal dorsal scale-row pattern is caused by division of the vertebral row to produce 16 scale rows, as in the following specimen (UMMZ 79679):

$$
\text { (9) } \underline{16} 8+8 \text { (11) } \underline{15} \mathrm{~V} \succ \frac{8}{8}(49-52,58,64) \underline{15}
$$

The divisions occur at isolated spots, and often involve only a single scale in the vertebral row in this individual. The same pattern was observed in another specimen, which has 11 scales on the vertebral row divided in this fashion, again irregularly and at isolated points on the body.

Variation in color is primarily a matter of degree of darkness or lightness in ground color, with little change in pattern relationships. The rectangular spot on the head may be absent, with only the "horns" on the 
parietals and occipitals remaining, but the horns are invariably present, as far as my material is concerned. MNB R708 has very broad, rounded blotches even far posteriorly; they are equal to or wider than the interspaces and have light centers. It has the ventrolateral spots between the blotches, and the blotch on its head is reduced to a few spots on the frontoparietal suture.

REMARKS. - Sauvage's type apparently fits the above description, based upon 22 specimens, in all characters that he gives for it. Because the original description is abbreviated, the species as I describe it may not be the proper one to accompany Sauvage's type. The type has a brown spot between each band; this a character of variegata, for the spot is usually missing in the albifrons I have seen. There are exceptions, of course, such as MNB R708 (above), and it is quite possible that the spots are not prominent in the type. Also, the type lacks the preocular, which is true of only 32 percent of the individuals looked at in this study. The remaining characters are "typical" for the species.

Werner (1896:363-64) gave detailed descriptions of three individuals from Blumenau, Santa Catarina, Brazil, and in a footnote added data on two more. Werner discussed variations that Boulenger (1896a:451) was unable to include in his description of the species, because he had only one specimen. Since all of Werner's variations fall within the limits given above, they need not be discussed here. He also gave a comparison of albifrons and variegata, and elaborated on methods of separating the two species.

Mocquard (1908:898) suggested that the species Boulenger placed in Leptognathus and called albifrons was not the same as that named by Sauvage. He pointed out that all Leptognathus, by Boulenger's definition, possess pterygoid teeth, and, because the specimens he identified with Sauvage's species lacked teeth on the pterygoid, the two concepts of the species were incompatible. Fortunately, I have been able to re-examine the specimen from Blumenau on which Boulenger based his conclusions. It does not have any teeth on the pterygoid, and I conclude that Boulenger placed it in Leptognathus through pure lapsus mentis. Since two specimens of albifrons possessed three tiny, weakly attached teeth at the anterior end of the pterygoid, although there are usually none, the argument is somewhat academic.

Since the typcs of this species are in Paris, it seems strange that Mocquard did not mention them in his work (1908:898). He based all his statements on two specimens from "Brazil" and just gave sufficient analysis of their characters to make it questionable whether or not he had examined the type or types. For example, he said that his specimens have 8 labials, and that the larger is $598 \mathrm{~mm}$. long, but the type has 7 labials and is $630 \mathrm{~mm}$. long. He qualified his count of "eight labials," however, by saying that the two posteriormost ones may be fused and perhaps a difference of 32 millimeters is not enough grounds for question. The specimens that Mocquard discussed are entirely within the range of variation of albifrons, in the sense of this study, and I feel justified in assuming that this amounts to a comparison with the type.

Serié (1915a:582) added albifrons to Bertoni's list of snakes found in Paraguay, recording it from "Pto. Bertoni, Alto Parana." Although he did not give a description of the individual, it is not far geographically from 
Santa Catarina, Brazil, to Alto Parana, Paraguay, and I see no reason to doubt his record. Amaral's record $(1926 c: 28)$ for the species from Mato Grosso includes a description and seems perfectly legitimate. On the other hand, all of the specimens I have examined from Saõ Paulo are a good deal more suspect as to exact provenance. There is little justification in assuming that specimens received from the Instituto Butantan with the label "Saõ Paulo, Brazil" were actually collected there, and the MCZ specimens were received with that data. The UMMZ specimens are all recorded as received from Afranio do Amaral, but it is likely that they too are Butantan specimens.

Hoge (1950:154) described a new subspecies, Dipsas albifrons cavalheiroi, from "Ilha da Queimada Grande." This island is about 40 miles from the Brazilian port of Santos, in the state of Saõ Paulo. The diagnostic characters he gave for the new form are ventral number (157-163), subcaudal number (74-77), and the shape of the dorsal scales (rounded, not lanciform). All of Hoge's specimens were females. The observed variation in ventrals for the mainland specimens I have seen is $160-178$, and in subcaudals is 71-87. The ventral counts given for the four individuals from Queimada Grande are 157, 159 (type), 159, 163. While all of these are at the lower end of the known variation, the differences are not great, and a larger series is required to justify the use of this character in the separation of two races. The subcaudal counts are within the known variation of the mainland material. Only the shape of the dorsal scales is left, then, as a diagnostic character, but I have had no opportunity to compare material of the new form with the mainland specimens and cannot comment on its validity. Since, however, the character stands by itself and is rather subjective in nature, I do not consider it evidence of sufficient genetic divergence to warrant subspecific designation of a population, and have accordingly treated the new name as a synonym of albifrons.

Several authors have concerned themselves with the differences between albifrons and variegata, and the similarities are admittedly great. On the basis of the material I have examined, it seems that the lower ventral and subcaudal counts, the comparatively shorter internasal, the presence of a preocular, the absence of lateral spots between the blotches, the contact of the first upper labial with the loreal, and the elongate posterior upper labial are all specific characters which set albifrons off from variegata. The relationship between the species is close, of course, but they are not so alike that confusion should exist about their identities.

SPECIMENS EXAMINED.-

BRAZIL: “South-East" (MCZ 17832-33). Mato Grosso (MNB R377). Santa Catarina; Blumenau (BMNH 1895.10.26.27), Joinville (MNB R711-16), Jaraguá (UMMZ 79679). São Paulo; São Paulo (MCZ 20851-55; UMMZ 62704-05, 63028).

\section{Dipsas incerta Jan}

Leptognathus incertus Jan, 1863: 101.

Leptognathus alternans Fischer, 1885: 105.

Cochliophagus incertus, von Thering, 1910: 335.

Cochliophagus alternans, von Thering, 1910: 334 .

S. [ibynomorphus] incertus, Amaral, 1923: 93. 
Sibynomorphus barbouri Amaral, 1923: 92.

Sibynomorphus garbei Amaral, 1923: 93.

S. [ibynomorphus] alternans, Amaral, 1923: 94 .

Dipsas incerta, Parker, 1935: 527.

HOLOTYPE. - Present location unknown to me, supposedly from "Gujana francese."

RANGE. - Southeastern coastal area of Brazil; from state of Espírito Santo to state of Santa Catarina (Map 8).

DESCRIPTION. - Rostral considerably broader than deep, visible from above; internasals shorter than prefrontals, which do not enter orbit; frontal as broad as long; considerably shorter than parietal; nasal semidivided; loreal enters orbit; preocular 1; postoculars 2; suboculars none; primary temporals 1 or 2 ; secondary temporals 2 or 3 ; tertiary temporals 2 , 3 , or crowded off temporal row; upper labials 9 , 3d to 5th or 4th to 6th enter orbit, no enlarged upper labials, posteriormost somewhat elongate. Lower labials 9 or 10, a single pair in contact behind mental, four or five pairs in contact with first chin shield; 2 or 3 pairs of chin shields.

Ventrals 192-202 in males, 182-195 in females; anal entire; subcaudals 101-117 in males, 91-111 in females. Dorsal scale rows 16 or 17 to level of 6 th to 14th ventral, 15 on remainder of body, occasional reduction to 14 or 13 slightly anterior to anus; vertebral row scarcely to moderately enlarged; caudodorsals:

Males: 6 2+3 (23-27) 4 1+2 (86-91) 2 (101-117)

Females: $\underline{6} 2+3(10-2 \overline{1}) \underline{4} 1+2(69-9 \overline{1}) \underline{2}(91-111)$

Maxillary teeth 17-18 (2 individuals); palatine teeth 8 (2); pterygoid teeth 12-15 (2).

Body length male $598 \mathrm{~mm}$., female $501 \mathrm{~mm}$. , minimum $170 \mathrm{~mm}$.; tail length male $241 \mathrm{~mm}$., female $194 \mathrm{~mm}$., minimum $66 \mathrm{~mm}$.

Dorsal ground color grayish-brown, with 19-25 well-defined, rounded, dark-brown, black-bordered dorsal blotches, as wide as or wider than interspaces, extend onto vertebral row and narrowly contact opposite blotch, or end on paravertebral row, centers of blotches slightly lightened; interspaces unicolor or occasionally very sparsely speckled and streaked with dark brown. Venter yellowish brown, with elongate grayish-brown to darkbrown streaks, 2 to 6 ventrals long, in two parallel rows, usually absent below tips of dorsal blotches but may be irregularly present, always present below interspaces, with possible exception of anteriormost. Tail with 11-16 blotches, color and pattern as on body.

Dorsum of head slightly darker than interspaces, unicolor with exception of prominent dark-brown, white-bordered spot centered in each parietal; dorsal color lightens gradually to yellowish labial row; first dorsal blotch not rounded anteroventrally, extends forward along first and second scale rows almost to corners of mouth.

Chin and throat brownish-white, completely unicolor, no trace of spots or blotches.

Ground color lighter in juveniles, contrasts strongly with blotch color, 
more streaking in interspaces of single juvenile available, may or may not typically disappear in adults.

INDIVIDUAL VARIATION. - The upper labials are 9-9 in four specimens, 9-8 in two. Where the labials are 9, the 4 th through 6 th enter the orbit, with two exceptions. In one, the $3 d$ through 5 th enter the orbit as a result of a labial fusion anterior to the $3 \mathrm{~d}$ labial; in the second, the $3 \mathrm{~d}, 5$ th and 6 th enter the orbit due to a contact between the $3 \mathrm{~d}$ and 5 th above the 4th. When only 8 labials are present, the 4th and 5th only enter the orbit. The ocular region is quite uniform, with all six specimens having 1-1 preoculars, all except one with 2-2 postoculars, and all except one without suboculars. In MNB R704 the upper postocular is fused with the supraocular on the left side; MCZ 17828 has a single subocular on the right side only. The primary temporals are 1-1 in two individuals, 1-2 in one, 1-3 in one, and 2-2 in two. The secondary temporals are 2-2 in three specimens, 3-3 in two, and 2- $\frac{1}{2}$ in one. Fractionation and fusion is thus rather exceptional in the few specimens available.

The lower labials are 9-9 in two individuals, 9-10 in three, and 10-10 in one. There is only a single pair of lower labials in contact behind the mental in all six specimens. While the type has 4 pairs of chin shields, according to Jan's figure, three of the individuals seen have only 2 pairs, three have 3 pairs, none have 4 . There are 4 labials in contact with the first pair of chin shields in two individuals, and 4-5 in four. The internasal is less than half the length of the prefrontals in three specimens, and only slightly more than half in the other three. The frontal is almost exactly as broad as long in all six.

There are three types of reduction to 15 scale rows on the neck, two of which are exemplified by MCZ 17828:

$$
17 \frac{3+4(6)}{3+4(6)} \underline{15} \frac{\mathrm{V}+7(187)}{\mathrm{V}+7(184)} 13
$$

and by MNB R703:

$$
\underline{16} 8+8 \text { (9) } \underline{15}-\mathrm{V}(189) \underline{14}(192)
$$

These are, respectively, a lateral reduction from an odd number of rows to 15 , and a vertebral reduction from an even number of rows to 15 . A vertebral reduction from an odd number of rows has been observed in three specimens.

The only variant on the normal caudodorsal reduction given above in the description is as follows ( $\mathrm{MCZ} 17828$ ):

$$
\underline{6} \frac{2+3(11)}{2+3(10)} \underline{4} \frac{3}{1+2(73)} \underline{3} \mathrm{~L} 1+\mathrm{R} 2(74) \underline{2} \underline{\mathrm{V}+1(77)} \underline{1} \mathrm{~V} \succeq \frac{1}{1}(78) \underline{2}(98)
$$

A single specimen has an incomplete ventral which extends more than three-fourths of the distance across belly. There were no divided ventrals 
observed. The umbilical scar is on the $168-169$ ventrals in the single specimen retaining it.

The size of the spots on the head is somewhat variable. They are so reduced on MNB R703 that they are practically lacking, while on MNB R704 they fill almost the entire parietal. The latter specimen, a juvenile, has additional speckling on the occiput, a spot on the suture between the prefrontals, and irregular spots on the temporals. The dorsal blotches have lightest centers in the oldest individuals, and this seems to be an ontogenetic change.

GEOGRAPHIC VARIATION. - The five localities from which specimens have been taken are very poorly represented in number of individuals (one each). The two specimens from the most northern localities have 2 primary and 3 secondary temporals, on both sides, the other three have 1 and 2. The lowest ventral and subcaudal counts are those of the southernmost specimen, a female; they are 182 and 91 . The northernmost specimen, also a female, has the second highest ventral and the highest (of the females) subcaudal count, 190 and 111 . These variations are poorly substantiated, and cannot be proven to have the slightest significance. One or two additional specimens could destroy the pattern exhibited.

REMARKS. - The many records for French Guiana seem to be entirely an echo of Jan's type locality, for I find no additional reports from that country in the literature or in museums. Comparison with Jan and Sordelli's excellent figures (1860-81, (1870), liv. 37, Pl. 6) leaves little room for doubt as to the conspecific position of the specimens that I have recorded in this paper with incerta. Most of them had been previously identified as alternans, but at best this can be considered only an indication of synonymy, not proof.

Von Ihering (1910:335) was the first to doubt the validity of the two species, but he continued to use the name alternans for the one with which he was concerned, He pointed out the distinctions between them as described by Boulenger (1896a) are the greater number of ventrals and subcaudals in incerta. In addition, Boulenger said that the type of alternans has two preoculars, while incerta has only one. The variation for the ventrals and subcaudals in the specimens examined is sufficient to include the recorded counts for both the species. Although I have not seen the type of alternans, I have examined the specimen called incerta by Boulenger as well as two of the three specimens on which von Ihering based his opinions. All of them, plus others examined which have not been reported in the literature before, fit either the description of altermans or the illustration of incerta equally well, with the exception of a single character. That is, all material I have seen of incerta is uniform in having only a single preocular above the loreal, whereas alternans has two. This would indicate that all the specimens belong to incerta. According to Fischer, the type of alternans was received from "angeblich aus Santos," which Boulenger gave as Santos, with no question. This is the region whence all of the specimens I examined come, while incerta is supposed to be found in French Guiana. Thus, the characters that distinguish incerta occur throughout the range of alternans. It seems likely, the refore, that the type of alternans is slightly 
aberrant in possessing the lower preocular, a variation neither unexpected nor unusual in dipsadine snakes, and that the two are conspecific.

When Amaral (1923) described garbei he compared it with alternans. At the same time, he described barbouri, which he compared with incerta, among others. Since incerta and alternans are considered conspecific in this study, both new species need only to be compared with incerta. The type of barbouri is a female and, although the sex of the type of garbei is not mentioned, I would surmise from the data presented that it is a male. The species barbouri is said to differ from incerta in the absence of a preocular, in possessing a semidivided nasal, and in having four chin shields, while garbe $i$ is distinguished from incerta by "the color and markings of the head and in having no praeocular" (Amaral, 1923:94). Although I have had no opportunity to see the types of either species, I have had available a second specimen collected by Garbe at the type locality of the species named for him, which is Colonia Hansa, in Santa Catarina, Brazil. This topotype provides much information useful in comparing the forms. The absence of a preocular in both of Amaral's species is puzzling, since it is present in the specimens of incerta examined, but its lack is not an unusual occurrence in dipsadine snakes, and both other species in the variegata group may or may not have a preocular. Amaral's other characters for differentiating barbouri cannot be used, for all specimens of incerta I have seen have a semidivided nasal, and the type of incerta has four pairs of chin shields (although no other specimen seen has that many). All other characters given for barbouri are included in the normal variations of incerta, as given above. The head coloration of garbei is unique, since the type, MP 1576, has four dark-brown spots, one on the frontoparietal suture, one on each parietal, and one of the parieto-occipital suture. The topotype, MP 1574, lacks the spot at the frontoparietal suture, but has the other three. The spot at the parieto-occipital suture is small and faint, while the other two are as is typical of incerta. The topotype also has vague markings in the interblotch areas, but nothing resembling "one darker blotch, which changes into a short transverse line along the middle of the body," as in the type of garbei. The topotype has a preocular on both sides. While it might be argued that the topotype is actually a specimen of incerta, the fact that it is intermediate in appearance between the two forms in the critically diagnostic characters indicates that it represents an individual variation only.

The range of incerta seems to correspond rather closely to the "Distrito Tupi" of Cabrera and Yepes (1940:15), at least in its north-south boundaries. Mello-Leitão (1942:129) pointed out that the Sierra del Mar probably acts as a confining factor in the distribution of animals on the southeastern coast of Brazil, and limits the Tupí province to the coastal strip, from the state of Bahía to Santa Catarina.

SPECIMENS EXAMINED. -

BRAZIL (MCZ 17828). Espírito Santo; Santa Thereza (MNB R704). Rio de Janeiro; Therezopolis (MNB R703). São Paulo; Alto da Serra (MP 1575), San José dos Campos (BMNH 1891.9.25.11). Santa Catarina; Hansa (MP 1574).

ADDITIONAL RECORDS. -

BRAZIL. Alagoas: Utinga (holotype of barbouri). Minas Geraes (Amaral, 1929, 196). Santa Catarina: Colonia Hansa (holotype of garbei). 


\section{Dipsas variegata variegata Duméril, Bibron and Duméril}

Leptognathus variegatus Duméril, Bibron and Duméril, 1854: 477.

Dipsadomorus variegatus, Jan, 1863: 100.

Leptognathus variegata, Cope, 1868: 107.

Cochliophagus variegatus, von Thering, 1910: 332.

Dipsas variegata, Gomes, 1918: 525.

Leptognathus robusta Müller, 1923: 155.

Sibynomorphus variegatus, Amaral, $1926 a, 7$.

COTYPES. - One in the Museum d'Histoire Naturelle de Paris, and one in the Leyden Museum, from "Surinam."

RANGE. - Venezuela, the Guianas, Ecuador, and Peru (Map 9).

DESCRIPTION. - Rostral broader than deep, visible from above; internasals slightly shorter to longer than prefrontals, which enter orbit; frontal as long as broad, shorter than parietals; nasal divided wholly or in part;

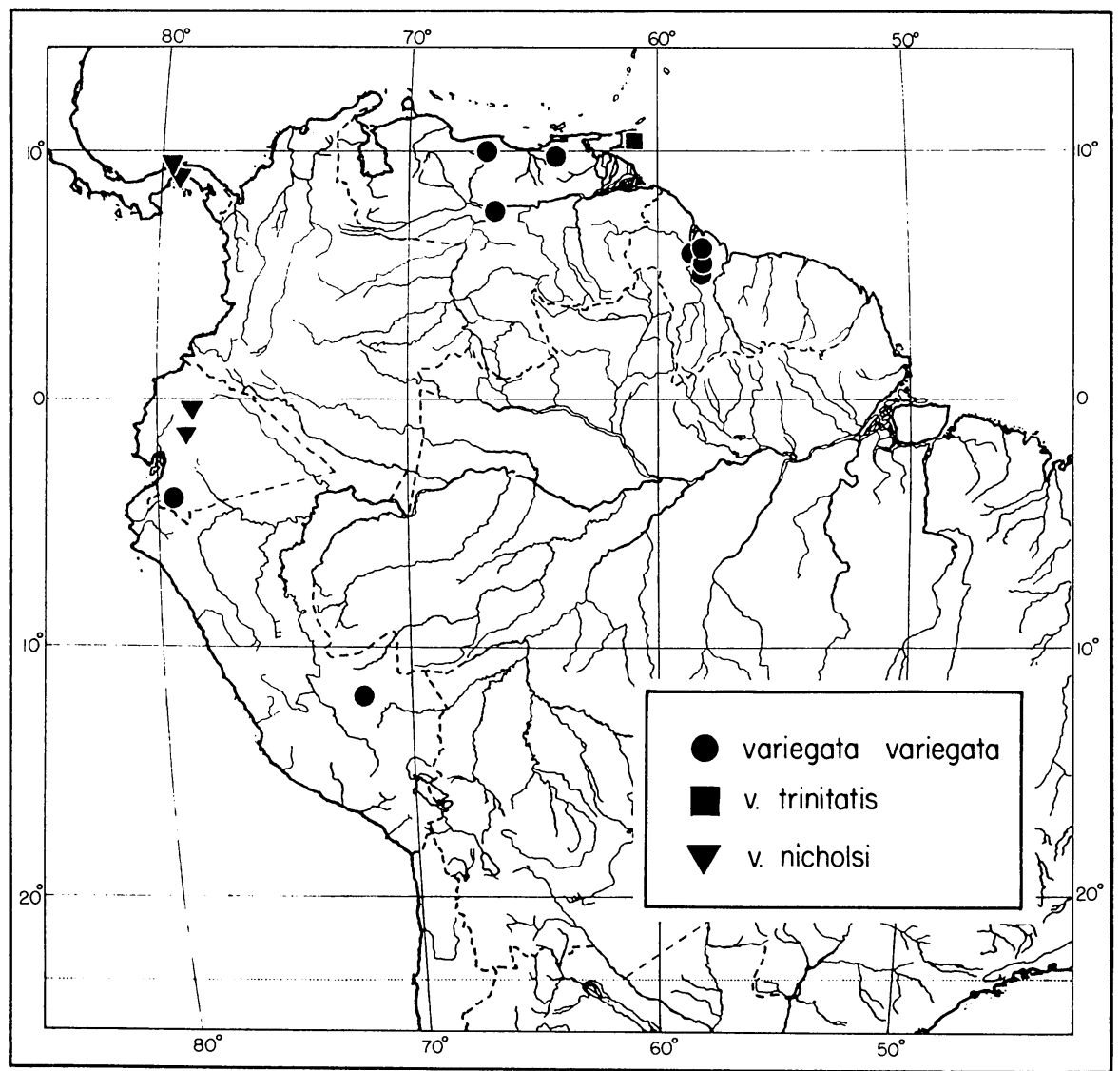

Map 9. Geographic distribution of Dipsas variegata. 
loreal enters orbit; preoculars none; postoculars 2; suboculars none; primary temporals 2; secondary temporals 3 ; tertiary temporals 3 or 4 ; upper labials 7 to $10,3 \mathrm{~d}$ through 6 th may enter orbit; no enlarged upper labials. Lower labials 11 to 13 , first two pairs in contact behind mental, three, four, or five pairs in contact with first chin shield; 2 or 3 pairs of chin shields.

Ventrals $181-187$ in males, $170-187$ in females; anal entire; subcaudals $86-100$ in males, $73-86$ in females. Dorsal scale rows 17 to level of 8-12 ventrals, 15 on rest of body, vertebral row moderately enlarged; caudodorsals:

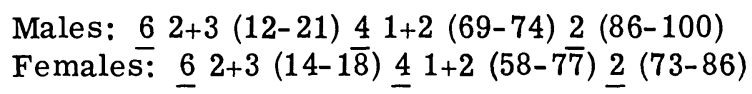

Maxillary teeth 11-12 (3 individuals); palatine teeth 7 (2); pterygoid teeth 0 (1).

Body length male $640 \mathrm{~mm}$., female $639 \mathrm{~mm}$., minimum $211 \mathrm{~mm}$.; tail length male $226 \mathrm{~mm}$., female $206 \mathrm{~mm}$., minimum $67 \mathrm{~mm}$.

Dorsal ground color reddish-brown, with poorly defined, slightly darker brown blotches on sides which usually reach up to and include vertebral row, light-centered, narrow (1 to 3 scale rows wide), about one-half to onethird width of interspaces, edges very irregular, jagged; interspaces shot with blotch color, spots, variegations, horizontal streaks abundant, each individual scale bordered with darker brown; large brown spots on first and occasionally on second scale row as well as tips of adjacent ventrals alternate with dorsal blotches ( $\mathrm{Pl} . \mathrm{V} e)$. Venter dull yellow, with ends of both dorsal blotches and lateral spots extending onto lateral fourth of ventrals; a more or less distinct midventral line of brown stippling which may be narrow and scattered or broad and heavy. Dorsum of tail as on body, ventrally almost entirely dark brown, with series of light-yellow spots on tips of ventrals between ends of dorsal and lateral blotches.

Dorsum of head dull reddish-brown with single more or less elongate dark-brown spot on posterior half of parietals and adjacent occipitals and not extending to first dorsal blotch; all sutures weakly defined in darker brown; ground color gradually lightens on side of head, no postocular pattern. Chin unicolor yellow except for faint deposition of brown along sutures.

Juveniles somewhat lighter than adults, blotches more sharply defined, interspaces brownish-tan.

INDIVIDUAL VARIATION (Table X). - The dorsal head scales are normal. The ocular region is quite uniform in the 15 specimens examined, for only one of them possesses a preocular, the loreal enters the orbit in all, only three have a subocular, two on one side only, and the postoculars are other than 2-2 in two specimens, which have 1-1 as a result of fusion of the normal two. The nasal is divided in three individuals, semidivided in seven, entire in two, and indeterminate in three (Jan and Sordelli showed it to be divided in their figure (1860-81 (1872), liv. $37, \mathrm{Pl} .3)$ of this species). In addition to its normal complement of full-sized scales, the temporal region often has tiny scales inserted between the larger. The most 
common occurrence of these scales is the insertion of a single one between the lower postocular, the lower anterior temporal, and the upper labials bordering those scales. Such a scale is present in seven of the 15 specimens. The temporals themselves are often divided, both horizontally and vertically, and as often fused in the same manner. The upper labials apparently owe their range of variation to various fusions and splittings. When the labials are 8 , the last labial is elongate and appears to be a result of fusion of the 8th and 9th; when the labials are 10, either the 4th or 5th is halved by a vertical split. Contact of 2 upper labials above or 2 lower labials below the one between them is present on five of 15 individuals. On BMNH 1862.12.15.35 there are three such contacts between lower labials, the other four have only one or two. One individual has only a single pair of labials in contact behind the mental, and a second has a single labial on one side in contact with two on the opposite side of the midline.

TABLE $X$

INDIVIDUAL VARIATION IN Dipsas variegata variegata

\begin{tabular}{|c|c|c|c|c|c|c|}
\hline \multicolumn{2}{|c|}{ Upper Labials } & \multicolumn{2}{|c|}{ Lower Labials } & \multirow{3}{*}{$\begin{array}{l}\text { Paired } \\
\text { Chin } \\
\text { Shields }\end{array}$} & \multirow{2}{*}{\multicolumn{2}{|c|}{ Temporals }} \\
\hline \multirow{2}{*}{$\begin{array}{c}\text { Total } \\
\text { Number }\end{array}$} & \multirow{2}{*}{$\begin{array}{c}\text { Entering } \\
\text { Orbit* }\end{array}$} & \multirow{2}{*}{$\begin{array}{c}\text { Total } \\
\text { Number }\end{array}$} & \multirow{2}{*}{$\begin{array}{c}\text { Touching } \\
\text { First } \\
\text { Chin Shield }\end{array}$} & & & \\
\hline & & & & & Primary & Secondary \\
\hline $7-8 \quad(2)$ & $3,4(6)$ & $10-11(1)$ & $2-2(1)$ & $1-1(1)$ & $1-1(2)$ & $2-2(1)$ \\
\hline $7-10(1)$ & $4,5(9)$ & $11-11(1)$ & $3-3(2)$ & $2-2(7)$ & $1-2(2)$ & $2-3(3)$ \\
\hline $8-8 \quad(2)$ & $5,6(2)$ & $11-12(2)$ & $2-4(5)$ & $2-3(2)$ & $2-2(9)$ & $3-3(9)$ \\
\hline $8-9 \quad(2)$ & $3,4,5(11)$ & $12-12(4)$ & $4-4(2)$ & $3-3(5)$ & $3-3(1)$ & $\mathrm{F}^{\dagger}(2)$ \\
\hline $9-9 \quad(6)$ & $4,5,6(2)$ & $12-13(4)$ & $4-5(2)$ & & $\mathrm{F}^{\dagger}(1)$ & \\
\hline $10-10(2)$ & & $13-13(1)$ & $5-5(1)$ & & & \\
\hline & & $13-14(1)$ & $4-6(1)$ & & & \\
\hline & & & $6-7(1)$ & & & \\
\hline
\end{tabular}

*Single side. $\quad \dagger$ Fractionated.

The dorsal scale rows are often 19 immediately posterior to the head, but reductions to 17 and then 15 take place in abrupt succession, one laterally and the other on the vertebral row. A typical formula is exhibited by UMMZ 76690A:

$$
\underline{19} \frac{2+3(7)}{\mathrm{V}+9(7)} \underline{17} \frac{\mathrm{V}+8(8)}{2+3(8)} \underline{15}
$$

Here (true of 8 specimens) the vertebral row reaches its maximum width by absorption of the paravertebral rows into the vertebral row. A variation on this pattern is shown by UMMZ 76690B:

$$
18 \frac{3+4(9)}{3+4(8)} \underline{16} 8+8 \text { (11) } 15 \text { (183) }
$$


Here (4 specimens) the dorsal scales are an even number immediately behind the head, and continue thus until a fusion takes place between the two scale rows on the vertebral line. The vertebral row is actually nonexistent until this middorsal fusion occurs. An even more unusual pattern was observed in a single specimen (NYZS 30465):

(3) $21 \frac{4+5(4)}{3+4(5)} \underline{19} \frac{-3(6)}{-3(6)} \underline{17} \frac{\mathrm{V}+8(23)}{\mathrm{V}+8(23)} \underline{15}\left[\mathrm{~V}-\frac{8}{8} \underline{16}\right.$ or $\frac{\mathrm{V}-8}{\mathrm{~V}-8} \underline{17}$

irregularly to level of 113 th ventral] 15 (179)

At the places where the scale rows are as many as 17 , the vertebral row is no wider than the paravertebrals. In all the other specimens examined, the vertebral row is moderately widened, and is not divided after the fusion which results in 15 rows.

The caudodorsal reductions are all in the pattern described above, except for two individuals, which have a vertebral reduction rather than a lateral one. This is shown by the formula for NYZS 30465:

$$
\underline{6} 3+3(18) \underline{5} \frac{}{\mathrm{V}+2(20)} \underline{4} \underset{\mathrm{V} \rightarrow 2(22)}{\mathrm{V} \rightarrow 2} \frac{4+2(77)}{1+2(76)} \underline{2}
$$

One specimen has six divided ventral scales, including one of Type 1, one of Type 2, three of Type 3, and one of Type 5. Another individual has four caudal pairs fused across the tail.

The most obvious color variant, USNM 22351, has much less variegation in light-tan interspaces; blotches which are three to four scale-rows wide, well-defined, and do not extend onto vertebral row; and no parietal spots. In other specimens from the same locality the spots on the parietals vary from well defined and quite elongate to poorly marked and small.

Two specimens, USNM 60718, from Peru, and USNM 98923, from Ecuador, have not been included in the above summaries of variation because of their considerable geographic separation from the rest of the specimens. Both of them have only a single pair of lower labials in contact behind the mental. The one from Peru has a single preocular on both sides; 3 postoculars on the left side only; and 4 pairs of chin shields. That from Ecuador has 4 secondary temporals on both sides. With these exceptions, the scutellation of both specimens is encompassed by that discussed above. The Peruvian specimen is colored much as described above, although the midventer is unspotted. The Ecuadorian specimen has the interspaces light, with little variegation, and the individual scales lack dark-brown borders; there are no large lateral spots and no midventral line of spots or stippling; and the venter of the tail is almost entirely light brown. This specimen comes from an area physiographically more closely related to the range of the subspecies nicholsi, but it does not resemble it in coloration.

REMARKS. - The identity of specimens which have been reported in the literature as belonging to this species is somewhat difficult to verify without further examination of the various authors' material. Gomes 
(1918:525) discussed a specimen from Ceara, Brazil, and Amaral (1926c:28) gave a description of a female from Mato Grosso, Brazil. Amaral's specimen has an extremely high ventral count for variegata (202), the number of caudals is not known, and its coloration is somewhat unusual. It is grayishbrown with black transverse bands; the head is also gray-brown, with obscure spots on the frontal, parietals, and occipitals. There are females of indica that have that high a ventral count, and answer all the other descriptive characters given by Amaral. I think it extremely doubtful that Amaral had variegata in hand, but the original specimen must be checked. On the other hand, Gomes' record of a specimen from Ceara is probably legitimate, since all of the characters mentioned fit well into the range of variation known for variegata, and its occurrence at this locality is not too unexpected. Parker (1935:527) stated that the species is endemic to the region from Trinidad to Grão Para, but, if all of my assignments of specimens are correct, the range is considerably greater than that, for the species ranges into Peru and Ecuador as the subspecies variegata. In addition, trinitatis represents the species on the island of Trinidad, of course, and the subspecies nicholsi extends the range of the species into Panamá and western Ecuador.

Although Maria (1942:95) listed this species from Colombia, there are no existent records of its occurrence there. Maria's inclusion of the species in the Colombian fauna was based upon Amaral's synonymy of Leptognathus nigriceps Werner with variegata, since the type of the former species came from Cañon del Tolima. It is shown elsewhere (see remarks under Dipsas pratti) that this synonymy is erroneous.

I have tentatively synonymized Leptognathus robusta Müller (1923:155) with this species. The synonymy appears valid on the basis of information presented in Müller's original description, but re-examination of the type material could prove it wrong. There is no character given for robusta that is not duplicated by specimens of variegata, as here understood. The diagnostic characteristics listed by Müller are all typical of variegata, and robusta has little or nothing in common with Leptognathus ventrimaculata (=Sibynomorphus ventrimaculatus) with which Müller compared it. The only character of scutellation given in the description of the type that is not typical of variegata is that of a single labial pair in contact behind the mental, for variegata usually has two pairs of labials in contact. Occasional individuals of both $v$. variegata and $v$. nichols $i$ have the robusta condition, however, and this is true of the single Ecuadorian and the single Peruvian specimen seen. The name robusta could perhaps be applied to the material from the lower eastern slopes of the Andes, but as yet the subspecies could be characterized solely by the number of labials in contact behind the mental. I prefer to leave it as a synonym until additional material affirms or denies the validity of this and other characteristics as a means of subspecific definition.

Dipsas variegata Duméril, Bibron, and Duméril, 1854, is a secondary homonym of Dipsas variegata Reinhardt 1843. Reinhardt's species is now considered to be a member of the genus Tarbophis, however, ard, since the condition of homonymy is not currently existent, there is no need to substitute a name for Duméril, Bibron, and Duméril's taxon. 
Two forms, trinitatis and nicholsi, considered by some authors to be separate species, are combined with variegata as subspecies in this study. The relationships of variegata with each of them is discussed under their separate headings.

\section{SPECIMENS EXAMINED. -}

NO DATA: (NYZS 30465, 31301B). BRITISH GUIANA: No other data (BMNH 1862.12. 15.35), Demerara River (UMMZ 53900), Dunoon (UMMZ 47757-58), Kartabo (AMNH 21275, NYZS 552), Wismar (UMMZ 76690 (2), 77504). ECUADOR: Catamayo Valley (USNM 98923). PERU: Puquiura (USNM 60718). VENEZUELA: Aragua, Rancho Grande (MBUCV unnumbered), Cumanacoa (CM 7827, 7839), La Guayra (USNM 22531).

\section{Dipsas variegata nicholsi Dunn}

Sibynomorphus nicholsi Dunn, 1933: 193.

Sibon nicholsi, Dunn, 1940: 117.

HOLOTYPE. - MCZ 37884, sex unknown, from mid-basin of Chagres River and mouth of Pequeni River, Panamá, collected for Dr. H. C. Clark.

RANGE. - Atlantic side of Panamá to northwestern Ecuador (Map 9).

DESCRIPTION. - Rostral considerably broader than deep, visible from above; internasals slightly more than one-third length of prefrontals; frontal width approximately equal to length, somewhat shorter than parietals; nasal divided, wholly or in part; loreal enters orbit; preoculars none; postoculars 2; suboculars none; primary temporals 2; secondary temporals 3 or 4; tertiary temporals 4 or 5 ; extra small scales quite often inserted between temporal rows; upper labials 7, 8, or 9, 3d and 4th or 4th and 5th entering orbit. Lower labials 11 or 12 , first two pairs in contact behind mental, four to six pairs in contact with first pair of chin shields, no enlarged lower labials; 2 or 3 pairs of chin shields.

Ventrals 192 in two males, 186-201 in two females; anal entire; subcaudals 93 in one male, 84 in one female. Dorsal scale rows 15 , vertebral row moderately to moderately broadly enlarged; caudodorsals:

$$
\begin{aligned}
& \text { Males: } \underline{6} 2+3(18-23) 4 \underline{4} 1+2(69-76) 2(92) \\
& \text { Females: } \underline{6} 2+3(12-1 \overline{3}) \underline{4} 1+2(54-5 \overline{8}) \underline{2}(84)
\end{aligned}
$$
$3(2)$.

Maxillary teeth 15 (1 individual); palatine teeth 7 (1); pterygoid teeth

Body length male $496 \mathrm{~mm}$., female $639 \mathrm{~mm}$., minimum $249 \mathrm{~mm}$.; tail length male unknown, female $182 \mathrm{~mm}$., minimum $93 \mathrm{~mm}$.

Dorsal ground color brownish-tan, with rounded, dark chocolate-brown blotches high on sides, interspaces with irregular spots and streaks of same color as blotches, spots may be quite large; first blotch considerably more elongate than second, two to three times longer than broad, occasionally confluent with head markings; second blotch shorter and more rounded; blotches may extend to second or third row or may reach to ventrals; widely separated posteriorly, with less variegation in interspaces, which may be almost entirely unicolor or with isolated spots (Pl. Vc). Venter yellowish-tan with irregular brown spots on either side of midline and prominent row of fairly large brown spots on either side of body at ends 
of ventrals and first scale row, which alternate with large dorsal blotches; unicolor with small spots and darker brown ground color posteriorly. Tail as body, with no spotting in interspaces, above or below.

Dorsum of head yellowish-tan, with large U-shaped brown blotch extending from between eyes to occipitals, opening posteriorly and including frontal, outer edges of parietals, upper tertiary temporals, and occipitals; rest of dorsum of head unicolor with slightly darker sutures. Poorly defined band from eye to corner of mouth may be broken into spots; labials principally ground color, with brown sutures. Chin unicolor yellowish or streaked with brown, with single spot below labials just anterior to corner of mouth. In a living specimen the snout and anterior portion of head were olive, the body more brownish; the eye was greenish-gray, and the tongue grayish-black ( $\mathrm{Pl} . \mathrm{V} c)$.

INDIVIDUAL VARIATION. - In addition to the specimens examined, I have included several details of scutellation sent to me by E. R. Dunn concerning specimens examined at the Barro Colorado Laboratory and the Gorgas Institute, Panamá, and by J. A. Oliver concerning a living specimen in the Bronx Zoo, New York City. The upper labials are 7, with the $3 \mathrm{~d}$ and 4 th entering the orbit, on four sides of the 18 for which data is available, and 9 with the 4 th and 5 th in the orbit on 10 sides. Four sides have 8 , one with the $3 \mathrm{~d}$ and 4 th in the orbit, two with the 4th and 5 th, and one with the $3 \mathrm{~d}$ through the 5th. The final side, the left one of EPN 89, has 7 , with the 4th and 5th in the orbit. The 6th labial is quite elongate, and is apparently the result of fusion of the 6th, 7th, and 8th labials normally present. One specimen, ERD 7170, has a preocular on one side only. Two individuals have suboculars; the type has one on the left side only, and the other has one on each side. Seven individuals have 2-2 primary temporals. The type has the upper primary on the right divided into two small scales, with two on the left; while AMNH 35955 has a single temporal on the left side with two on the right. The secondary temporals are 3-3 in seven, with one of them having a fusion between the primary temporal and the middle secondary, and two specimens have 4-4 secondaries. The nasal is divided in three specimens, semidivided in two, and entire in one.

Four specimens have 2 pairs of labials in contact behind the mental; in two, only a single pair meet. Five specimens have 3 pairs of chin shields, three individuals have 2 pairs. One side of one individual has only 3 labials in contact with the first pair of chin shields, four sides have 4 , seven sides have 5, and six have 6 . All except two specimens have 11 lower labials on at least one side, although one specimen has 10 on the other side, two have 12, and ane 13. Of the two exceptions, one has 9 on both sides, the other has 10.

The principal variation in color is the presence or absence of contact between the U-shaped mark on the head and the first dorsal blotch. The arms of the "U" are fused with the dorsal blotch on both sides in two specimens, completely separate on both sides in four, and fused on the left while separate on the right in another. The first dorsal blotch extends as a continuation of the head blotch, without fusion over the vertebral row, in the Bronx Zoo specimen. In the Ecuadorian specimens the lateral blotches 
reach to the ventrals; in the Panamanian material they extend to the first or second row of scales.

REMARKS. - Steindachner (1901:108) described a snake from Babahoyo, Ecuador, that he called Leptognathus variegata. The two specimens of nichols $i$ I have examined from Balzapamba make it obvious that Steindachner's specimen belongs to this subspecies. He did not mention the sex of his specimen, but the high ventral (201) and caudal (98) counts indicate that it is a male. All of the characters that Steindachner mentioned are within the range of variation expressed above, with the exception of the ventralcaudal counts, which are close to those of nicholsi. The description of the head as sulphur yellow, with a brown horseshoe-shaped mark on the temporal and occipital regions is a final verification of the identity.

Unfortunately, all of the Panamanian specimens of this subspecies are preserved as head and neck only. They were collected during the Panamanian Snake Census, conducted by Dr. H. C. Clark. Although sex cannot be determined, the type is probably a male. There are enlarged tubercles on the chin shields, prefrontals, and internasals.

That nichols $i$ is a direct derivative of variegata through a comparatively minor change in color pattern can hardly be questioned. Although variegata usually lacks a distinct head pattern, certain specimens show strong indications of the steps necessary to form an inverted $U$ on the parietals and frontal. As to scutellation, there is no character expressed in the specimens of nicholsi examined that is not included within the variation of the subspecies variegata.

\section{SPECIMENS EXAMINED.-}

ECUADOR (NYZS, living specimen): Balzapamba (AMNH 35949, 35955), road between Santo Domingo de los Colorados and Quinindé (EPN 89). PANAMÁ: - Chagres Villages (ANSP 21907; ERD 7170), mid-basin of Chagres River and mouth of Pequeni River, Madden Dam Area (MCZ 37884, type).

\section{ADDITIONAL RECORDS. -}

ECUADOR: Babahoyo (Steindachner, 1901: 108). PANAMÁ (Barro Colorado Island Coll. 7157; Gorgas Institute Coll. 7153): Agua Clara (Dunn, 1940: 117).

\section{Dipsas variegata trinitatis Parker}

Dipsas trinitatis Parker, 1926: 206.

HOLOTYPE. - BMNH 1926.5.1.1, male, from Trinity Hill Reserve, Trinidad, British West Indies, collected by Dr. E. Lehner.

RANGE. - Known only from the island of Trinidad (Map 9).

DESCRIPTION. - Rostral considerably broader than deep, visible from above; internasal shorter or longer than prefrontal; frontal as broad as long, shorter than parietals; nasal semidivided or divided; loreal enters orbit; preoculars none or 1; postoculars 2; suboculars none; primary temporals 1 ; secondary temporals 2 ; tertiary temporals 3 ; upper labials 8 , 4th and 5 th entering orbit; no enlarged upper labials. Lower labials 10,11 , or 12 (not known for type), first two pairs in contact behind mental, four pairs in contact with first pair of chin shields; 2 or 3 pairs of chin shields.

Ventrals $185-188$ in two males, 179 in single female; anal entire; 
subcaudals $92-95$ in two males, 82 in female. Dorsal scale rows 17 for short distance anteriorly, 15 on most of body (see formula below), vertebral row scarcely to moderately enlarged; caudodorsals:

$$
\begin{aligned}
& \text { Male: } \underline{6} 2+3(20-21) \underline{4} 1+2(65) 2(92) \\
& \text { Female: } \underline{6} 2+3(19-2 \overline{0}) \underline{4} 1+2(6 \overline{6}-67) \underline{2}(82)
\end{aligned}
$$

Maxillary teeth 14 (1 individual); palatine teeth 7 (1); pterygoid teeth 5 (1).

Body length male $488 \mathrm{~mm}$., female $493 \mathrm{~mm}$., minimum $218 \mathrm{~mm}$.; tail length male $166 \mathrm{~mm}$., female $158 \mathrm{~mm}$., minimum $93 \mathrm{~mm}$. (from two specimens only).

Dcrsal ground color brownish-tan, with 21-23 irregular, whitish-edged, dark chocolate-brown blotches on body (1.5+ on tail), those on body do not extend above 7 th scale row, leaving vertebral row unicolor at all times; blotches about equal in width to interspaces anteriorly, considerably narrower than interspaces posteriorly, lighter center area in lower half of blotch; series of dark-brown, lighter-centered blotches low on sides and tips of ventrals alternate with dorsal blotches; interspaces variegate, lineolate or spotted with dark brown. Ventral surface yellow-white, unspotted anteriorly, stippling and spotting steadily increase toward rear; lower surface of tail almost unicolor brown.

Dorsum of head brownish-tan, with a pair of indefinite dark streaks from parietals to sides of neck, rest of head unicolor, darker at sutures, lighter toward labials, lower portions of which are yellowish. Chin entirely yellowish, no spotting or stippling, but sutures outlined with brown.

INDIVIDUAL VARIATION. - Comparisons can be made only between the two individuals examined and the type description. The type and one of the other specimens have a preocular on both sides, the third specimen has none. Parker said the lower postocular is much larger than the upper in the type; the converse is true of the two specimens seen, in which the upper is at least twice as large as the lower. The type has 2 primary and 3 secondary temporals, the other individuals have $1-1$ and 2-2, respectively. Parker did not mention the tertiary temporals of the type, but in the specimens seen there are 3-3. The internasals are shorter than the prefrontals in the type; in one specimen they are longer $(1.6 \mathrm{~mm}: 1.3 \mathrm{~mm}$.); the head of the third is slightly crushed. On one side of the type the $3 \mathrm{~d}$ and 4th labials enter the orbit, in AMNH 73124 the $3 \mathrm{~d}$ through the 5th. The type and one other has 2 pairs of chin shields, the third has 3.

Parker said that the scale-row formula is "17.15.15," but he did not indicate the point of reduction. The second BMNH specimen is somewhat irregular in its dorsal scale row formula:

$$
17 \frac{\mathrm{V}+8(11)}{\mathrm{V}+8(13)} 15 \underline{\mathrm{V}-8(15)} 16 \underline{7+8(16)} 15 \frac{\mathrm{V}+7(178)}{\mathrm{V}+7(176)} 13
$$

All of this variation takes place within 16 scale rows of the head and three of the anus; the scale rows are 15 on the major portion of the body. The AMNH specimen has a reduction to 13 immediately anterior to the anus. The caudodorsal formulae for both specimens have been given above. 
The pair of indefinite dark streaks from the parietals to the sides of the neck which Parker described for the type is absent in one specimen and visible in the other.

REMARKS. - Parker pointed out the following features which distinguish trinitatis from variegata: “... the presence of a praeocular, two instead of three upper labials entering the eye, eight instead of nine or ten upper labials, and the colour pattern." The preocular is absent in one specimen, and is present as a variant in both $v$. variegata and $v$. nicholsi. In 15 specimens of $v$. variegata examined, nine have 3 labials in the orbit on at least one side, but eleven have only 2 on at least one side (six individuals have 3 on one side and 2 on the other); all five specimens of nicholsi examined have only 2 labials entering the orbit, with a single exception on one side only. Seven of the 15 variegata have 8 or less labials on at least one side of the head, and the same is true of four of the five nicholsi. None of Parker's points of difference in scutellation appears sufficient to characterize a distinct species. On the other hand, the differences in color are sufficient to provide a basis for separation of the two other subspecies of variegata from trinitatis. The insular population is different enough to warrant subspecific status.

SPECIMENS EXAMINED. -

TRINIDAD: no added data (BMNH 1934.7.5.37); Port of Spain (AMNH 73124).

\section{GENUS SIBYNOMORPHUS FITZINGER}

Sibynomorphus Fitzinger, 1843: 27. Genotype: mikani Schlegel.

Anholodon Duméril, Bibron and Duméril, 1854: 1165. Genotype: mikani Schlegel.

Cochliophagus Duméril, Bibron, and Duméril, 1854: 478. Genotype: inaequifasciatus Duméril, Bibron, and Duméril.

Pseudopareas Boulenger, 1896a: 462. Genotype: vagus Jan.

DESCRIPTION OF GENUS. - Dorsum of head with normal colubrid head-scale complement, that is, internasals, prefrontals, frontal, supraoculars, and parietals; nasal may lie in undivided scale, in semidivided scale, or between two scales; loreal present, enters orbit in all species (occasionally not in vagrans); preocular usually absent, 1 or 2 may be present; suboculars usually absent, present in occasional specimens of all species; postoculars 2 , occasionally 1 or 3 ; primary temporals 1 , may be 2 or 3 ; secondary temporals 2 , occasionally 1 or 3 ; tertiary temporals often absent, often 2, 3, or 4; upper labials 5 to 10; no single labial in contact with postoculars, primary and secondary temporals. Lower labials not crowded, usually 11 or less, a single pair in contact behind mental, no single labial greatly enlarged and extending beyond labial row to contact posterior chin shields; mental groove poorly defined or absent; paired chin shields squarish, irregular.

Body cylindrical or only slightly compressed laterally; head distinct from neck, not particularly shortened or prominent; eye not enlarged or protruding; tail rather short.

Dorsal scale rows smooth, without keels or apical pits, characteristically 15 , with occasional reductions or additions involving vertebral and 
paravertebral rows only; vertebral row not or only slightly widened in most species; caudodorsals reducing short distance behind anus to 6 rows and considerably posteriorly thereafter to 4 and then 2 rows, which is number at tip. Ventrals rounded, occasionally divided, usually less than 175; anal single; subcaudals in 2 rows, less than 85 , often very low number, may be as low as 37 .

Color pattern of single type in all except one species (vagus), consisting of light ground color with regular cross bands or saddles, which are wider on anterior part of body, narrower posteriorly, where they often are broken across vertebral row and form series of rounded spots on sides. Distance that blotches extend down sides variable, and blotch may often be broken into two parts laterally on posterior portion of body. The species vagus is unicolor brownish-gray or gray dorsally. Venter with either several rows of spots on ends of ventrals or immaculate.

Hemipenis short, not or only slightly capitate, sulcus spermaticus bifurcate; tip undivided; proximal portion with hooks and spines; distal portion calyculate; collar at border between spinose and calyculate portions weakly defined or absent.

Maxillary with toothed edge directed inward, teeth subequal in length, anterior end edentate; ectopterygoid present, connecting maxillary and pterygoid, rather long and attenuate, part visible between end of maxillary and juncture with pterygoid considerably longer than anterior $\mathrm{Y}$-shaped portion is wide; palatine short, weak, edentate anteriorly; pterygoid with teeth on anterior half, free from quadrate, not or only slightly divergent toward the quadratomandibular joint, posterior end lies free in roof of mouth. Mandible with teeth decreasing in length posteriorly; no hingelike joint between dentary-splenial and compound bone; posterior end of dentary appears to lie free along dorsal edge of compound bone.

RANGE. - Southern half of Brazil, Amazonian Peru, eastern Bolivia, Uraguay, Paraguay, and northern Argentina (Map 10).

NOMENCLATURAL HISTORY. - While Fitzinger (1843:27) gave no description of his new genus Sibynomorphus he did name a genotype, and was the first author to assign a generic name to any of the species included in the taxon. He selected Dipsas mikani Schlegel as the genotype, not aware that in doing so he was using a composite description. The two specimens that Schlegel useci were not members of the same geographic unit, but, as considered here, represent two different subspecies. I have used mikani Schlegel for the form found in inland southeastern Brazil, and have assigned the name neuwiedi to the subspecies that inhabits the southeastern coastal strip of Brazil, the unit to which Schlegel's second specimen belongs. This arrangement is taxonomically sound, because the inland subspecies is a fairly typical representative of the genus as here defined, while the coastal form is definitely strong in characters that show an approach to the conditions typical of members of the genus Dipsas.

Fitzinger's names were not readily accepted by his contemporaries and 11 years after Sibynomorphus appeared, Duméril, Bibron and Duméril used mikani Schlegel as genotype of a new genus they called Anholodon. At the same time these authors described a new genus Cochliophagus and new species $C$. inaequifasciatus. The genus is here considered to be congeneric 


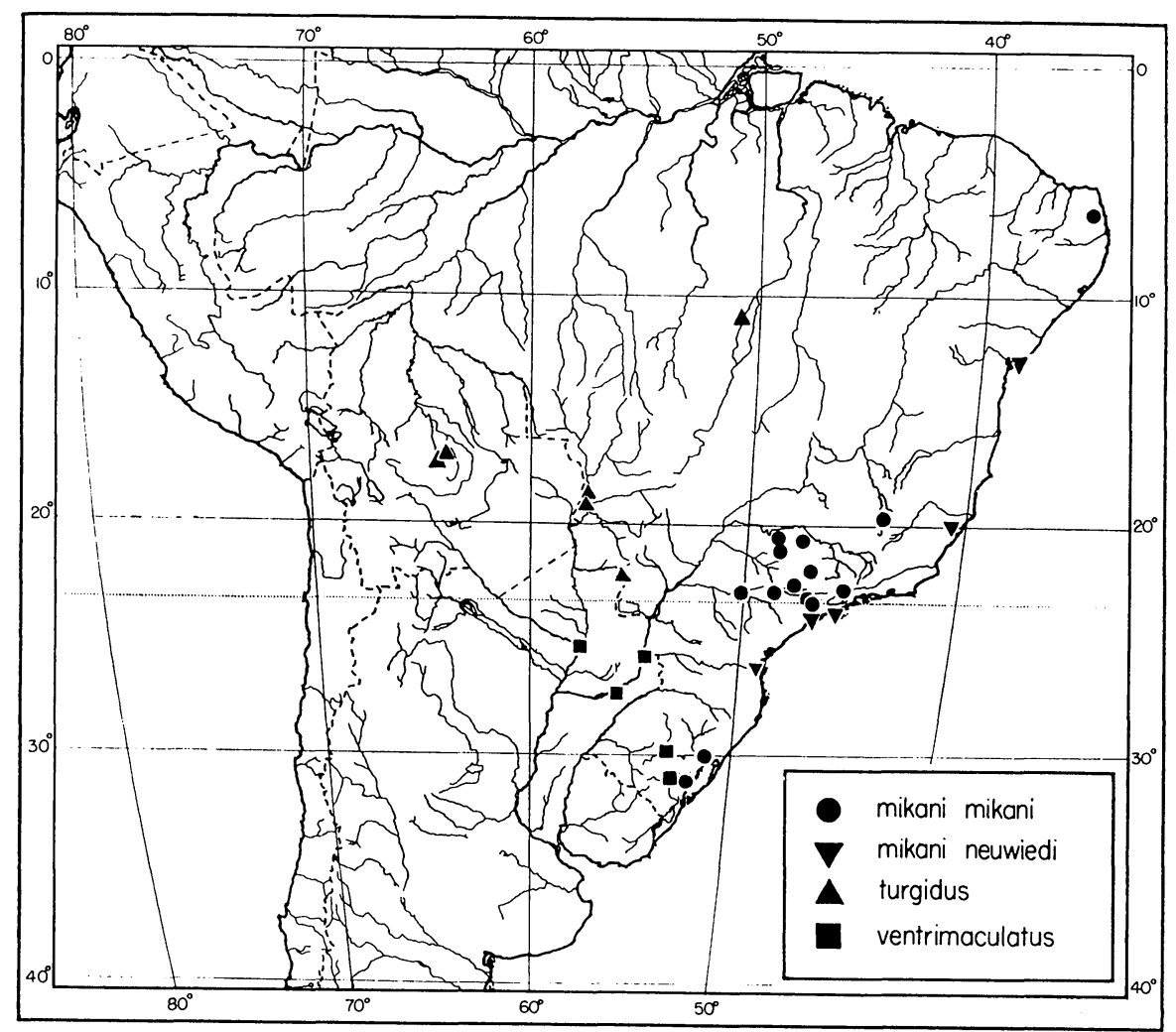

Map 10. Geographic distribution of Sibynomorphus species for which localities are known.

with Sibynomorphus, and the species was the second of that genus to be described. They also described Leptognathus, which I regard to be a generic synonym of Dipsas, but which was used by many authors (following Duméril, Bibron, and Duméril) to include practically all of the species of dipsadine snakes. Boulenger, for example, used Leptognathus for all the American snakes included in the Amblycephalidae, with the exception of indica and two species he placed in a new genus Pseudopareas (1896a:462). This new genus was based in its entirety on the characters that typify Sibynomorphus as I define it.

Berg (1901:291) pointed out that Leptognathus was not available for these snakes, as the name was preoccupied by Leptognathus Swainson, 1839, for a genus of fishes. He proposed the substitution of Cochliophagus for it, and was followed by several of his South American colleagues in this usage (e.g., von Ihering, 1910, and Serié, 1915a). About this time, however, several North American herpetologists (Barbour and Noble, 1920; Dunn, 1923) adopted the use of Sibynomorphus as a replacement for Boulenger's Leptognathus Amaral (1926a:7-9) reviewed the facts concerned, and fixed the name as Sibynomorphus. At the same time, Parker (1926) noted that the 
biological distinction between Dipsas and what had been variously called Leptognathus, Sibynomorphus, Cochliophagus, and so on, was not a valid one, and he combined all forms under the single generic designation, Dipsas. As mentioned elsewhere, I agree in part with Parker. I feel that the generic distinction between the many species formerly included in the genus Sibynomorphus and the monotypic species of the genus Dipsas is not valid, but I use the name Sibynomorphus in an extremely restricted sense, confining it to the stem forms found in southern Brazil and neighboring countries.

\section{VARIATION WITHIN GENUS}

The genus Sibynomorphus is a fairly uniform group of species, which replace each other in a sequential fashion geographically, and may well prove to be no more than a subspecific series when sufficient material becomes available. The only likely exception to this generalization is the species vagus, which appears to be sufficiently isolated from the other members of the genus to retain permanent specific status. Other than this there is no clear cut infrageneric grouping.

While the scales of the head are more uniform and regular in this genus than in Dipsas, many of the variations noted in Dipsas can occasionally be found. Several cases of incomplete or complete fusion of the two prefrontal scales were observed, and irregularities in the internasal scales occur in several specimens. In the species vagrans the internasals are completely separated by a contact between the rostral and the prefrontals in one specimen, and almost totally separated in a second individual. This variation, important only on the individual level in this genus, is a valid specific character within some genera (such as Chilomeniscus), and even serves as a basis for distinguishing genera on occasion (such as Gyalopion).

The nasal scale is usually divided, either wholly or in part. Only nine specimens have entire nasals. The scale is completely divided in all specimens of vagus and vagrans, while ventrimaculatus specimens have it either partly divided or entire. The loreal enters the orbit in all except two of the specimens examined, and the preocular is absent in the majority in all species except vagus and vagrans, in which it is typically present. Suboculars occur only as individual variations, and are usually lacking. The postoculars are fairly consistently two, but fusion of the scales into one or division of a postocular to produce three has been noted in four of the species. The primary temporals are single in more than 95 percent of the specimens of all species except vagrans, which consistently has two. A slightly smaller percentage have two secondary temporals, and again vagrans is the exception, since a majority of the specimens of that species have three. The tertiary temporals, as mentioned in the description above, are often crowded off from the temporal row, or have been absorbed by the other two rows. There may be 2,3 , or 4 of them and the row is not well defined as in the primaries or secondaries, but is often irregular. With the exception of ventrimaculatus, more than 85 percent of the specimens of all species have either 7 or 8 upper labials. Occasional specimens have as 
few as 5 (but never on both sides of the head), ventrimaculatus typically has 6 , inaequifasciatus has 10 in the only known specimen, the type, and 9 or 10 occur frequently in vagrans. As in Dipsas, specimens can be found that demonstrate that this variation in upper labial count can be charged to either fusions or divisions of labials in all areas defined in relation to the orbit; that is, preorbital, postorbital, orbital (labials entering the orbit).

The number of lower labials in specimens belonging to this genus can be as low as 6 (in mikani mikani) or as many as 12 (in vagrans). With the exception of vagrans, more than 95 percent of the specimens examined have 10 lower labials or less, and there are none with more than 10 in mikani mikani, mikani neuwiedi, and turgidus. This is in contrast to the species of Dipsas where the majority have more than 10 . Two specimens of mikani neuwiedi and two of vagus have other than a single pair of labials in contact behind the mental, otherwise the entire genus is uniform in this character. The number of paired chin shields is variable both within and between species, with a range of from 2 to 5 pairs observed. This entire range has been recorded for both mikani mikani and ventrimaculatus. There were no specimens seen with unpaired chin shields.

More than 75 percent of the specimens have 15 scale rows on all parts of the body, and those showing reductions do so only on the posteriormost portion of the body, a short distance anterior to the anus for the most part. One specimen of mikani mikani is unique in having a reduction involving fusion of the first and second rows of scales. All other reductions, as well as the occasional individual that possesses extra scale rows, involve the vertebral and paravertebral scale rows only.

Divided ventral scales were noted in all species seen except vagus, and one specimen of mikani mikani, MP 1531, had 30 divisions on the left side of the body. There were fused subcaudals only in two specimens of vagrans and in one of mikani mikani, otherwise this variation is missing entirely.

The range of ventrals for the genus is from 145 (in vagus) to 182 (in mikani neuwiedi). More than 90 percent of the specimens examined have 175 or less, however, and there are none with more than 170 in the species turgidus, ventrimaculatus, vagus, and vagrans. This count is another mark of distinction between this genus and Dipsas, since in Dipsas there are only six species that include specimens with ventral counts of less than 175.

The total range in subcaudal counts as observed in Sibynomorphus is from 37 (in mikani mikani) to 87 (in vagrans). If vagrans is omitted, over 93 percent of the specimens have less than 75 subcaudals. In contrast, there are only seven species in the genus Dipsas with that low or a lower number of subcaudals; five of these seven are also included in the six with low ventral counts (brevifacies, gaigeae, ellipsifera, pratti, and albifrons).

The tail in Sibynomorphus is considerably shorter than that in the other genera of the Dipsadinae; this is apparently correlated with the absence of other characters resulting from an adaptation to arboreal life, and would seem to indicate that the snakes of this genus are much less arboreal in their habits than those of Dipsas and Sibon. 


\section{KEY TO SPECIES OF SIBYNOMORPHUS}

1. Color pattern of clearly defined dorsal blotches or spots over entire body . . . . . 2 Lacking clearly defined dorsal blotches; narrow lateral spots anteriorly, jagged,

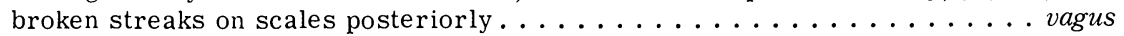

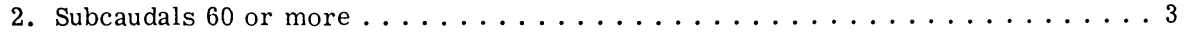

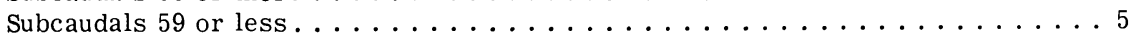

3. Ventrals less than 162 , dorsal blotches reduced posteriorly to vertebral spots

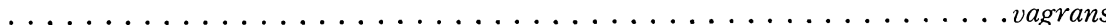
Ventrals more than 163 , dorsal blotches narrow posteriorly but reaching to first row of dorsal scales. ....................... 4

4. Upper labials $10 \ldots \ldots \ldots \ldots \ldots \ldots \ldots \ldots \ldots \ldots \ldots \ldots \ldots$ inaequifasciatus Upper labials 9 or less . . . . . . . . . . . . . . mikani neuwiedi

5. Upper labials usually 7 or more, blotches only slightly wider than or equal to interspaces posteriorly on body .................. 6 Upper labials usually 6 , blotches much wider than interspaces on posterior part of body $(\mathrm{Pl} . \mathrm{VI} d) \ldots \ldots \ldots \ldots \ldots$. . . . . . . . . . . . . . . . . . .

6. Blotches on posterior part of body reach only fourth or fifth row of scales

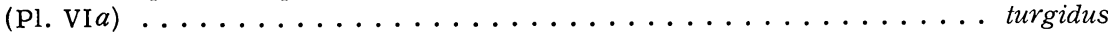
Blotches on posterior part of body reach first or second row of scales

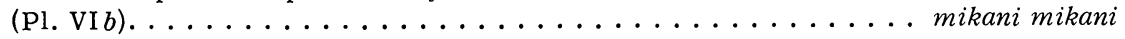

\section{Sibynomorphus inaequifasciatus Duméril, Bibron and Duméril}

Cochliophagus inaequifasciatus Duméril, Bibron, and Duméril, 1854: 480. Leptognathus inaequifasciatus, Jan, 1863: 100. (Sibynomorphus) inaequifasciatus, Amaral, 1926a: 7 .

HOLOTYPE. - Probably in Paris Museum, "certainly from South America, doubtfully from Brazil," collected by M. Verreaux.

RANGE. - This species has never, to my knowledge, been collected again, although Cope had a specimen from Paraguay that he considered to belong here.

DESCRIPTION. - Rostral slightly wider than high; internasals onehalf length of prefrontals, which enter orbit; frontal equally as long as broad, shorter than parietals; nasal divided; loreal enters orbit; preoculars none; postoculars 2; suboculars 1 or 2; primary temporals 1; secondary temporals 3; tertiary temporals 3 ; upper labials 10 , 4th and 5 th entering orbit. Lower labials 10, first pair in contact behind mental, four in contact with first pair of chin shields; 3 pairs of chin shields.

Ventrals 174; anal undivided; subcaudals 61 . Dorsal scale rows 15, unknown whether any dorsal reductions take place; vertebral row moderately enlarged.

Maxillary teeth 12; palatine teeth 9 ; pterygoid teeth 15 ; dentary teeth 21.

The dorsum of the body and the sides are a dead-leaf or tawny brown. On the back is a series of 6 or 7 large, wide, irregular, blackish-brown spots, followed by 30 small, narrow, transverse stripes of the same color; 15 additional bands, similar to those on the body cover the dorsum of the tail. The head is livid; the snout is peppered with russet, as are the upper labials and the temples. Dorsum of the head marbled with brown. A rounded, chestnut-brown spot, whitish-bordered, is present on the occiput. White ventrally, without spots. (This account of the coloration is a free rendering of the original description in Duméril, Bibron, and Duméril). 
Boulenger $(1896 a: 455)$ said there is a lateral series of small brown spots on the venter.

REMARKS. - My description is based upon a combination of the original description, and the plate published by Jan and Sordelli (1860-81 (1870), liv. 37, Pl. 4, Fig. 2). The description in Boulenger (1896a:455) is a composite itself of the two citations preceding it, since Boulenger had no specimens of this species. It is not known where Jan and Sordelli obtained a specimen to use for their illustration; it may well have been the type.

This species has continued to maintain its place in checklists and faunal surveys purely on the basis of its indisposability. It has never been justified on the strength of additional specimens, but the characters on which it is based are sufficiently out of the ordinary that it cannot be synonymized easily. There can be little question that it properly belongs in this genus, because of its general coloration, body proportions, and fully toothed pterygoid. It is characterized by having 10 upper labials, with five posterior to the last one entering the orbit, suboculars, 3 secondary te mporals, and the spotless venter. Most of these characters have been noted individually within the various species of Sibynomorphus and all except one have been recorded for specimens of $S$. vagrans. Twelve specimens of $S$. mikani neuwiedi have been recorded as having immaculate bellies. Of the twelve ten come from the southern part of the subspecies' range, two from the northern. The presence of suboculars or a scale that has been sometimes called a postocular (e.g., Boulenger said this species has 3 postoculars; my count is 2 postoculars and 1 subocular) is not uncommon throughout this genus. There are 10 specimens of neuwied $i$ which have more than 2 ocular scales behind the eye, as in inaequifasciatus, seven of which originate in the southern part of the range of neuwiedi. Three of these belong to the 10 that possess immaculate bellies. Three secondary temporals are normal in vagrans, 34 sides of a total of 48 have that number. Only one other specimen in the genus has more than 2 secondary temporals, MCZ 43318, a mikani mikani. Two is the typical number for the genus, with many specimens having only one. I have seen two specimens of vagrans with 10 upper labials, an uncommonly high number for the genus. Three specimens of vagrans have 9 upper labials, all others in the species have 8 . Also, there are two specimens of neuwiedi that have 9 labials on one side, and nine that have 8 on one side. Of the 12 specimens of neuwied $i$ with 8 or 9 labials, 7 originated in the southern part of its range. Three of these were included above as also having immaculate bellies, three had more than two postocular scales. Two of these three, MP 1527 and MNB R697, combine all three characters; both are from the southern part of the range of neuwiedi.

All of these facts seem to point to the possibility that the unique type of inaequifasciatus is a variant individual of either $S$. vagrans or $S$. mikani neuwiedi. That it may be one of neuwiedi has been previously suggested by von Thering $(1910: 334)$. It would be unfortunate if either possibility proves to be correct, since the type is such an aberrant individual, for it would then, by priority, be the type of that taxon, the name of which would have to be changed to inaequifasciatus.

Obviously, the aberrant nature of the specimen, the lack of additional 
specimens to verify the existence of a distinct species, and the totally inadequate knowledge concerning the original provenance of the type combine to make it quite uncertain as to where the name should be assigned. The forlorn nature of this nomenclatural waif is such that it would perhaps be best treated by mercifully discarding it.

SPECIMENS EXAMINED. - None.

\section{Sibynomorphus mikani mikani Schlegel}

Dipsas mikani Schlegel, 1837: 277.

Sibynomorphus mikani, Fitzinger, 1843: 27.

Anholodon mikanii, Duméril, Bibron, and Duméril, 1854: 1165.

Leptognathus mikani, Günther, 1858: 178.

Leptognathus garmani Cope, $1887 a$ : 60 (see remarks below).

Cochliophagus mikani, von Thering, 1910: 332.

Sibynomorphus turgidus (nec Cope), Amaral, 1926d: 61 .

Sibynomorphus mikanii mikanii, Amaral, 1929: 198.

Sibynomorphus mikanii fasciatus, Schmidt and Inger, 1951: 461.

HOLOTYPE. - Vienna Museum (?), from "Brazil," lectotype designated as specimen possessing 167 ventrals and 46 subcaudals.

RANGE. - Internal drainage areas of southeastern Brazil, not including coastal areas except in north, in states of Mato Grosso, Minas Gerais, Paraná, Río Grande do Norte, Río Grande do Sul, and São Paulo (Map 10).

DESCRIPTION. - Rostral wider than high; internasals one-half length of prefrontals, which enter orbit; frontal approximately as wide as long, more than one-half length of parietals; nasal partly or totally divided; loreal enters orbit; preoculars none; postoculars 2; suboculars none; primary temporal 1 ; secondary temporals 2 ; tertiary temporals 2 or 3 ; upper labials 7, 3d and 4th enter orbit (may be normally 6 in some parts of range) no labials greatly enlarged. Lower labials 7 or 8 , first pair in contact behind mental, three or four in contact with first pair of chin shields; 3 or 4 pairs of chin shields.

Ventrals 155-171 in males, 153-177 in females; anal undivided; subcaudals 48-62 in males, 37-57 in females. Dorsal scale rows 15, with occasional specimens showing reductions to 14 or 13 far posteriorly; vertebral row usually not enlarged; caudodorsals;

$$
\begin{aligned}
& \text { Males: } \underline{6} 2+3(14-22) 41+2(35-45) 2(48-59) \\
& \text { Females: } \underline{6} 2+3(7-18) \underline{4} 1+2(25-51) \underline{2}(37-55)
\end{aligned}
$$

Maxillary teeth 10-14 (6 individuals); palatine teeth 5-8 (6); pterygoid teeth 15-18 (7).

Body length male $455 \mathrm{~mm}$., female $513 \mathrm{~mm}$., minimum 151; tail length male $107 \mathrm{~mm}$., female $103 \mathrm{~mm}$., minimum $28 \mathrm{~mm}$.

Dorsal ground color light brownish-tan, with 25-44 light-bordered, black or brownish-black blotches, which are wider anteriorly (5-8 scale rows) than posteriorly (2-4 scale rows) and wider dorsally than lateroventrally; edges irregular, jagged; anteriormost extend onto ventrals, wider than interspaces, opposing and continuous across back; posteriormost end on first or second scale row, slightly wider than or equal to interspaces, 
usually opposite, occasionally alternating (Pl. VI $b$ ); interspaces unicolor, may be same color as border of blotch or slightly darkened by black or dark brown; squarish spot on first few scale rows and tips of ventrals between dorsal blotches. Venter cream-white, with squarish black blotches on outer ends of ventrals, increasing in number posteriorly, often forming two parallel rows. Tail as body, with 7-18 blotches, all reaching ventrals, and heavier concentrations of black squares on ventral surface.

Dorsum of head with dark area from eye to eye and from posterior half of prefrontals to occipitals, vaguely streaked and vermiculated with yellow, tip of snout to center of prefrontals dark yellow with irregular, often vague dark spots on some scales, temporal region yellowish with dark spots, upper labials uniform yellowish, may have small brownish spot in upper half only, sutures same color as labials. Lower labials, chin shields, and anterior ventrals unicolor or with irregularly placed spots.

INDIVIDUAL VARIATION. - The prefrontal scales are fused into a single scale in UMMZ 62713 and in UMMZ 63007, with a slight remnant of the suture remaining posteriorly in the latter. In UMMZ 62712 the prefrontal on the left side is partly fused with the preocular. In MNB R1333 there is a large nuchal scale immediately behind the parietal, rather than the normal dorsal body scales. In all other specimens examined, the head scales are entirely regular.

One specimen, MP 1776, has the loreal on both sides fused with the prefrontal; BMNH 1885.6.26.31 has the loreal fused with the nasal on both sides. The nasal scale is completely divided in 24 specimens, partly divided in 23 , entire in five, and is entire on one side while partly divided on the other on a single specimen. Forty-seven specimens lack preoculars, six have a preocular on one side only, and two have a preocular present on both sides. Three specimens have a subocular on one side only, and one specimen has a subocular on both sides, otherwise the scale is consistently absent. The normal two postoculars are fused into a single scale on one side of three specimens, and on both sides of another. The anterior temporals are other than single in two specimens, each of which has two on one side only. The secondary temporals are 2-2 in 42 specimens, 1-2 in two and 1-1 in nine. Twenty-six specimens have between-row fusions in the temporal region; in 12 of them a fusion between the single primary temporal and the upper secondary has taken place and in eight of these twelve the upper tertiary is fused with the primary and upper secondary temporals to form a single elongate scale extending from the postoculars to the post temporals. Two specimens, UMMZ 113837 and MP 1528, have a tiny extra scale inserted between the primary temporals, upper labials, and postoculars. A rather wide range of variation occurs in the upper labial count. Seven is the normal number, with 41 out of 55 having that count on both sides. Variation on a single side accounts for eight more, since five have 6-7 labials, one has 7-8, and one has 7-9. Five individuals have 6 labials, a count considered typical of ventrimaculatus, three have $6-5$, the lowest observed number in the genus. Even when the labials are only 6 , there are still 3 behind the last one to enter the orbit in the majority of the specimens (Table XI). Of the 96 sides examined, only 11 have less than 3 labials posterior to the orbit. In addition to these variations in the actual 
TABLE XI

Correlation between Number of Labials and Labials Entering Orbit in Sibynomorphus mikani mikani

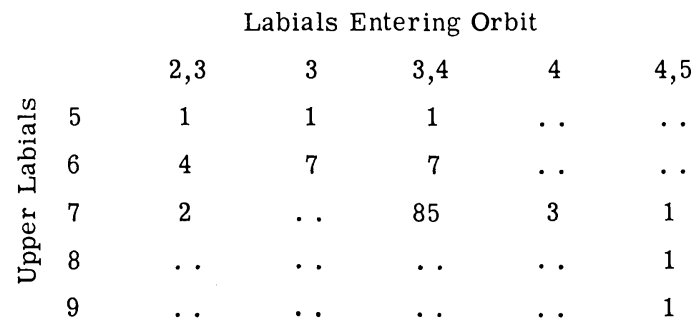

number of labials, two specimens show a fusion between the 6th labial and the lower secondary temporal, and one (MP 1532) has the 3d labial on the left extremely reduced, with the $2 \mathrm{~d}$ and 4 th labials meeting below it.

The number of lower labials varies from 6 to 10 , with the distribution as follows: 6 on seven sides; 7 on $35 ; 8$ on $55 ; 9$ on eight; and 10 on one (the type of garmani). A single specimen has only two labials contacting the first chin shield on one side. There are three labials contacting the first chin shield on 40 sides, four on 68 , and five on only 2 . When these two characters are correlated (Table XII), it appears that the most common variation involves a loss of a single one of those labials that are in contact with the first chin shield. Variation in the number of labials posterior to the last one in contact with the first chin shield also takes place. This is indicated (1) by those individuals with 6 labials and 3 in contact with the chin shield, and those with 7 and 4 , both of which indicate a fusion posteriorly of 2 shields, or (2) by those with 8 labials and 3 in contact and those with 9 and 4 , both of which indicate a division posteriorly. The single specimen with only 2 labials in contact with the first chin shield has the first chin shield divided into two scales on the right side only, so that the variation is not in the labial row but in the chin shield (ANSP 11101). The number of chin shields is somewhat variable; there are two specimens with 2-2, one with $2-3,31$ with $3-3$, nine with $3-4$, eight with 4-4, one with 4-5, and two with 5-5.

\section{TABLE XII}

Correlation between Number of Lower Labials and Labials in Contact with First Chin Shield in Sibynomorphus mikani mikani

Labials in Contact with First Chin Shield

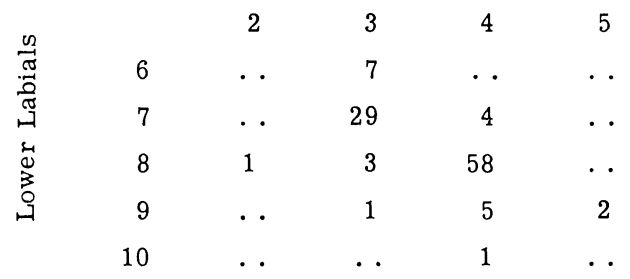


The dorsal scale rows are 15 throughout the length of the body on the majority of specimens examined, but there are several variations on the pattern. The first of these, involving ir regular splitting and fusion along the vertebral row and resulting in counts of 16 and 17 rows, was noted in six specimens. Eight specimens show fusion of the vertebral row with one or both of the paravertebrals, always far posteriorly, with a resultant count at the anus of either 14 or 13 . Three individuals have the paravertebral rows in contact anteriorly to each single vertebral scale, which is usually much reduced in size. The vertebral row invariably drops out far anteriorly on these specimens. One specimen, UMMZ 62711, is quite unusual in that it shows a ventrolateral reduction, a situation seldom met with in dipsadine snakes, as follows:

$$
\text { (4) } 15 \frac{15}{1+2(160)} \frac{14}{\frac{1+2(161)}{\mathrm{V}+6(161)}} \underline{12} \frac{+2(163)}{+2(163)} \underline{14}
$$

The caudodorsals are very regular in this species, with only a single specimen varying from the normal pattern. This individual, MP 1776, has a single cross-vertebral fusion, otherwise it is normal.

Eighteen specimens have divided ventrals. Eleven of these have a single Type 1 division, and eight of them are divisions of the last ventral before the anus. One specimen has two ventrals divided as in Type 1, one individual has a single ventral divided as in Type 2, four have Type 3 divisions on a single ventral, and one has a single Type 4 division. One specimen, MP 1531, has an extraordinary number of divisions, a total of 30 , all on the left side of the body. This leads to a discrepancy in ventral counts on the two sides, with 134 on the right side of the body, and 160 on the left side. One specimen, MP 1543, retains the umbilical scar, on 136-137th ventrals. Only one specimen of those examined had fused caudals. The fourth through seventh caudals are undivided on MNB R1330.

GEOGRAPHIC VARIATION. - The observed range of variation for this species, as given above, in almost every character is greater than that of any of the other species within the genus. In view of this fact, an analysis of the geographical distribution of several of the variable characters was made (Table XIII), but only a small proportion of the available specimens could be included due to the meager data on many individuals. A sufficient number of localities are represented, however, to divide a part of the series into four groups. The first group includes the specimens from Lagôa Santa, located on the head waters of the Río São Francisco; the second, those from Barretos, Andes, Franca, and Cascavel, all in the drainage of the Río Grande, a tributary of the Alto Paraná; the third, those from São Paulo and environs, Piracicaba, Botucatu, and Leoflora, all from drainages to the south of the Río Grande; and the fourth all specimens from Río Grande do Sul Province. Comparison of the upper labials, already shown above to be a character with wide limits of variability, shows that the northernmost group, that is, the sample from Lagôa Santa, contains all except one of the individuals with a labial count above 8 , and only one with a count lower than 8 , while the third group has seven out of ten specimens with a labial count 
TABLE XIII

Geographic Variation in Sibynomorphus mikani mikani

Groups are identified on p. 151 of the text.

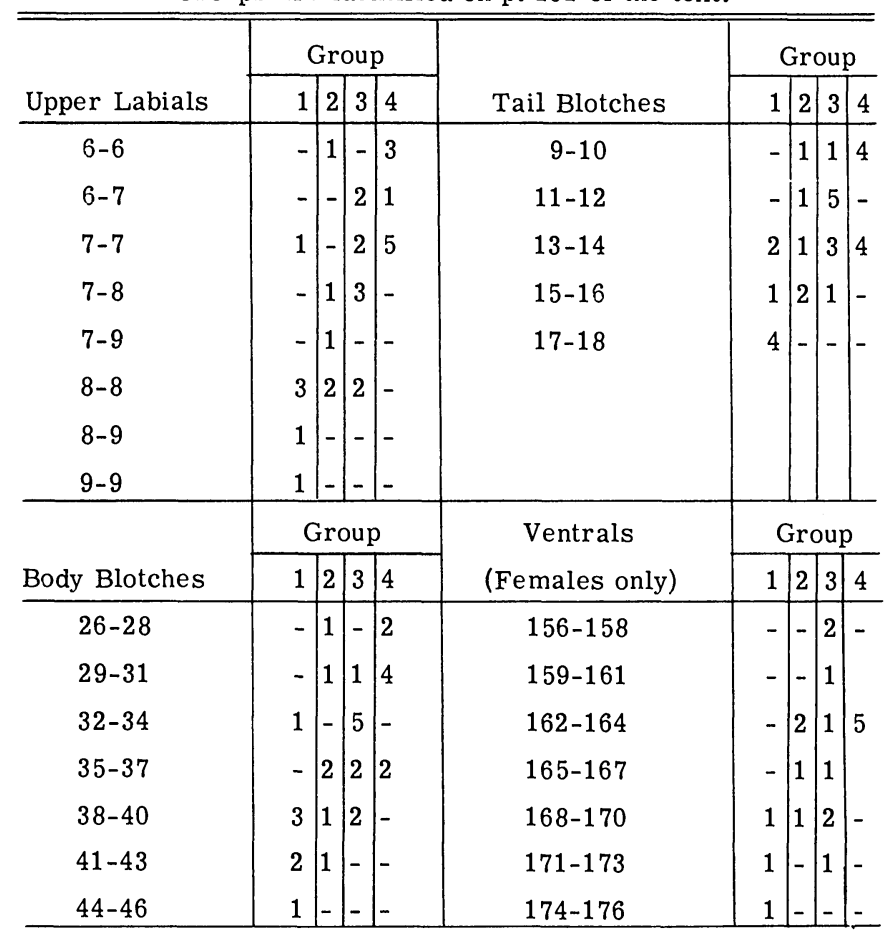

of less than eight, and the fourth, southernmost group, has approximately equal numbers with 6 or 7 labials. The second group is intermediate.

If the first three groups are combined with all other specimens and compared with the fourth group a difference in what has taken place on the labial row can be detected. If only 6 upper labials are present, it can be assumed that a fusion of 2 of the normal 7 has taken place. Also, when the labials are 7 there are normally 2 before the eye, 2 that enter the orbit, and 3 posterior to the eye. From this, it can be determined where the single fusion took place, since, for example, if the labials are 6 and the $3 \mathrm{~d}$ and 4 th enter the orbit, then a fusion between 2 of the normal 3 postorbital labials has occurred (Table XI). In the combined northern sample, there is an equal number of fusions of preorbital and of orbital scales, and almost as many of postorbital scales, indicating fusions on all parts of the labial row. In the Rio Grande do Sul sample, however, four of seven sides with 6 labials have only 2 postorbital labials, that is 63 percent as compared with 27 percent in the northern sample. There are no individuals in the former series with other than 2 preorbital labials of a total of 6, compared with 37 percent in the northern series. In the northern sample, fusion of the labials is more common than division, since only four sides show situations that might be interpreted as the results of a scale division. These 
four include one with 8 , one with 9 labials, and two with 7 labials that have only the $2 \mathrm{~d}$ and $3 \mathrm{~d}$ entering the orbit. In the two with 7 there appears to have been a fusion anterior to the orbit, and a division posterior to it, since there are 4 scales, rather than 3 , behind the last labial to enter the orbit. In the Río Grande do Sul series, there are no obvious divisions of labials, since none have more than 7 . The individual with the 4th and 5th labials entering the orbit indicates a fusion posterior to the orbit as well as a division anterior to it.

The number of dorsal blotches on the body and tail tends to be higher in the specimens from Lagôa Santa. There is a difference of 24 ventrals from highest to lowest in mikani, a span 29 percent greater than that in any other species of the genus (e.g., range is 17 ventrals in neuwiedi males); in this character, also, there seems to be a geographical difference. Further and complete analysis of these differences must await the collection of better series with accurate locality data.

REMARKS. - Schlegel used two specimens in the preparation of the type description of this species, and, so far as I know, no subsequent author has designated either of them as lectotype of the species. The only point in the original description where the two specimens are discussed separately is in the listing of lengths and of body segment counts. One individual had 170 ventrals and 71 subcaudals, the other 167 and 46 . The only other characters offered are concerned with coloration, and the two specimens are not discussed separately. Insofar as color is concerned, any one of the species considered to belong to the genus Sibynomorphus as here defined might fit Schlegel's description. Only one form, neuwiedi, has a combination of ventral and subcaudal count sufficient to include the specimen with 170 ventrals and 71 subcaudals, but the species Dipsas albifrons also has a range of variation in these characters to include this specimen, and the similarity in color between the two species is very great. On the other hand, the counts of the second specimen are well within the range of variation of the form found in southeastern Brazil, and the color description fits it equally well. For these reasons that I have chosen to designate as lectotype of this species the individual with 167 ventrals and 46 subcaudals. According to Schlegel's description, it was, and presumably is, in the Vienna Museum.

Leptognathus garmani Cope, originally supposed to have come from São Paulo, has recently been shown by Vanzolini $(1953: 124)$ to be almost certainly based on a specimen from São João de Monte Negro, in the state of Río Grande do Sul. His arguments for this transferal of type locality are cogent. They are to a certain extent verified by my examination of the type of garmani, which appears to belong to an intermediate population that is known to exist in the state of Río Grande do Sul, forming an intergrading area between the two forms considered here to be subspecies of mikani, that is, the typical form and neuwiedi. These specimens are discussed in more detail above, where they are designated the "Río Grande do Sul" sample. I have been most reluctant to use the subspecific designation for this material, although the name garmani is certainly available. There is no character or combination of characters that would be sufficient to define the subspecies that would not be duplicated in the known range of variation 
of typical mikani. The characteristics that make it distinctive, such as the low labial counts, are the extremes of a north-south clinal trend. In addition the fact that many of the characteristics strongly approach those of typical ventrimaculatus suggests a probably intermediate nature for this series, and added material may indicate that ventrimaculatus should be a member of the mikani subspecies chain. A few individuals from extreme eastern Río Grande do Sul Province exhibit strong similarities to $m$. neuwiedi in color. This area, then, is not only peripheral but also intermediate, and as such makes taxonomic recognition of little value.

SPECIMENS EXAMINED.-

No data: MP 1514-15, 1518, 1996-97, 2447. BRAZIL: (AMNH 27345, 27347; MCZ 17825; UMMZ 62694). Mato Grosso (MP 1776); Chapada (ANSP 11100-01). Minas Gerais; Lagôa Santa (MNB 1329-1334; UMMZ 113837), Presidente Soares (UMMZ 113836). Paraná; Leoflora (UMMZ 79676). Rio Grande do Norte; Papery (CAS 49301). Río Grande do Sul (MP 1520-21, 1528); Montenegro (ANSP 11201, holotype of garmani), São Lourenco (BMNH 1885.6.26.31; MP 1509-10, 1512, 1529). São Paulo (MP 1533, 1537, 1548; UMMZ, 62710-12,62714-16, 63007); Andes (UMMZ 62713), Barretos (MP 1539), Botucatú (MP 1989, UMMZ 79677), "Butantan" (MP 17965), Campinas (MP 1536), Cascavel (MP 1538), Cidade Jardim (MP 2448), Franca (MP 1540-41, 1547), Jaquaritinga (AMNH 6495), Jundiahy (MP 1544), Piracicaba (MCZ 17964, MP 1530-32, 1543), São Paulo (MP 1706).

\section{Sibynomorphus mikani neuwiedi von Ihering}

Dipsas mikanii Schlegel (in part), 1837: 277.

Leptognathus mikani, Boulenger (var. B), $1896 a$ : 454 .

Leptognathus mikani, Werner, 1909a: 276 et seq.

Cochliophagus mikani neuwiedi von Thering, 1910: 333.

Sibynomorphus mikanii fasciatus Amaral, 1930: 28.

HOLOTYPE. - Museo Paulista, several specimens, number of individuals not known, presumably from the Brazilian state of São Paulo and Espírito Santo.

RANGE. - Southeastern coastal strip of Brazil, from Baía on the north to the state of Rio Grande do Sul on the south (Map 10).

DESCRIPTION. - Rostral wider than high; internasals one-half to three-fourths length of prefrontals, which enter orbit; frontal slightly longer than broad or equally as broad as long, considerably more than half length of parietals; nasal wholly or partly divided; loreal enters orbit; preoculars none; postoculars 2; suboculars none; primary temporal 1 ; secondary temporals 2; tertiary temporals usually 2, often missing; upper labials 7, 3d and 4 th enter orbit, no labials enlarged. Lower labials 8 or 9 , first pair in contact behind mental, four or five in contact with first pair of chin shields; 3 or 4 pairs of chin shields.

Ventrals 165-182 in males, 167-181 in females; anal undivided; subcaucals 63-84 in males, 60-72 in females. Dorsal scale rows 15, occasional increases or reductions on individuals; vertebral row moderately enlarged; caudodorsals:

Males: $62+3(13-27) 441+2(43-73) 22(63-84)$

Females: $\underline{6} 2+3(10-2 \overline{2}) \underline{4} 1+2(36-6 \overline{4}) \underline{2}(60-72)$ 
Maxillary teeth 13-18 (14 individuals); palatine teeth 6-10 (15); pterygoid teeth 14-19 (10).

Body length male $523 \mathrm{~mm}$., female $754 \mathrm{~mm}$., minimum $169 \mathrm{~mm}$.; tail length male $171 \mathrm{~mm}$., female $197 \mathrm{~mm}$., minimum $56 \mathrm{~mm}$.

Dorsal ground color light brownish-tan, with 25-37 brown to blackishbrown blotches, anteriormost equal to or slightly wider than interspaces, narrower below and extending onto ventrals; posteriormost narrow, higher than wide, half or less width of interspaces, about 1-2 scale-rows wide, ending on first row of dorsal scales; edges of all dorsal blotches irregular and zigzag, often with whitish border; interspaces usually with dark streaking and stippling, often with dark-brown spots on paravertebral or midlateral rows, large spot on first dorsal scale rows and adjacent ventral tips, centered between ends of dorsal blotches (Pl. VIc). Venter brownish-white, may be immaculate, usually with more or less prominent brown streaks or lines along outer ends of ventrals that may form two parallel lines, rest of belly more or less heavily stippled with brown. Tail as in body with 11-21 blotches, where countable, except that interspaces are considerably darker, and blotches are often obscured; ventral surface very dark brown.

Dorsum of head light chocolate-brown with more or less regularly placed small dark-brown or black spots on parietals, frontal, and supraoculars, with spot on posterior edge of prefrontals often forming bar from eye to eye; side of head light brown with darker stippling, upper labials uniformly yellowish-brown. Chin and throat immaculate yellowish-brown with light dusting of dark brown along sutures.

INDIVIDUAL VARIATION (Table XIV). - There are only two specimens that show deviations from the normal arrangement of head scales in this species. MNB R692 has a small scale inserted at the mutual contact of the internasals and the rostral, and MNB R702 has an extra suture invading the parietals, arising at the suture of the upper postoculars and the supraoculars.

The nasal scale is completely divided in 23 specimens, only partly divided in thirteen, and is entire on two. In AMNH 14540 the first labial is crowded out of the lip by a contact between the second labial and the rostral.

TABLE XIV

INDIVIDUAL VARIATION IN Sibynomorphus mikani neuwiedi

\begin{tabular}{|c|c|c|c|c|c|c|c|c|}
\hline \multirow{2}{*}{$\begin{array}{c}\text { Upper } \\
\text { Labials } \\
\text { Total } \\
\text { Number }\end{array}$} & \multicolumn{2}{|c|}{ Lower Labials } & \multirow[b]{2}{*}{$\begin{array}{l}\text { Paired } \\
\text { Chin } \\
\text { Shields } \\
\end{array}$} & \multirow[b]{2}{*}{$\begin{array}{c}\text { Pre- } \\
\text { Oculars }\end{array}$} & \multirow[b]{2}{*}{$\begin{array}{c}\text { Sub- } \\
\text { Oculars }\end{array}$} & \multirow[b]{2}{*}{$\begin{array}{c}\text { Post- } \\
\text { Oculars }\end{array}$} & \multicolumn{2}{|c|}{ Temporals } \\
\hline & $\begin{array}{c}\text { Total } \\
\text { Number }\end{array}$ & $\begin{array}{c}\text { Touching } \\
\text { First } \\
\text { Chin Shield } \\
\end{array}$ & & & & & Primary & Secondary \\
\hline $6-6(1)$ & $7-8 \quad(2)$ & $3-4(8)$ & $2-2(1)$ & $0-0(35)$ & $0-0(37)$ & $1-1(1)$ & $1-1(42)$ & $0-1(1)$ \\
\hline $6-7(2)$ & $7-9 \quad(1)$ & $4-4(25)$ & $2-3(1)$ & $0-1(3)$ & $0-1(3)$ & $1-2(2)$ & $1-2(1)$ & $1-1(7)$ \\
\hline $7-7(30)$ & $8-8 \quad(10)$ & $4-5(7)$ & $3-3(28)$ & $1-1(5)$ & $1-1(4)$ & $2-2(38)$ & $2-2(1)$ & $1-2(4)$ \\
\hline $7-8(7)$ & $8-9 \quad(15)$ & $5-5(5)$ & $3-4(5)$ & $2-2(1)$ & & $2-3(2)$ & & $2-2(27)$ \\
\hline $8-8(3)$ & $8-10(1)$ & & $4-4(9)$ & $2-3(1)$ & & $3-3(1)$ & & \\
\hline $8-9(2)$ & $9-9 \quad(11)$ & & & & & & & \\
\hline & $9-10(3)$ & & & & & & & \\
\hline & $10-10(1)$ & & & & & & & \\
\hline
\end{tabular}


One specimen, UMMZ 113838, has the loreal completely excluded from the orbit. Variations in the orbital scales are given elsewhere (Table XIV), but one specimen, MCZ 17827, has the upper postocular on the right elongated posteriorly and in contact with the secondary temporal, above the primary temporal, which is greatly reduced in size. MNB 695 has a small scale inserted between the upper postocular, the parietal, and the anterior temporal, on both sides of the head. The tertiary temporals are recorded for nineteen specimens, eight of which have 2-2, one has 3-3, eight have none, and one has 2-0. The increase in size of the primary and secondary temporals at the expense of the tertiaries is typical of the trend observed in many of the species groups of Dipsas. Obvious fusions between rows are rare in this species, due to the stable situation of a single primary temporal and two secondary temporals that seems to have evolved. Two specimens have an upper labial in contact with the postocular, the primary and the lower secondary temporal. One specimen, UMMZ 79678, has the 4 th and 6th labial on the left in contact above the 5th.

Two specimens, MNB R694 and MNB R692, have a single labial on one side in contact with two on the other side behind the mental, and one, UMMZ 62693 , has two pairs of labials in contact behind the mental, in contrast to the usual single pair. A single $m$. mikani, MCZ 43316, and these specimens are the only ones in the genus that have shown this character, which is typical of many species groups of Dipsas.

Ten of the specimens examined show variations on the normal arrangement of dorsal scale rows. Four of these, MP 1526-27, MNB R702, and UMMZ 79678, have an increased number of scale rows as a result of splitting of the vertebral row. This may be either a median splitting of the vertebral row into two scales, or a lateral loss, giving rise to an additional paravertebral row. In all, the number of splittings is quite high, sometimes as many as ten. Five specimens have reductions immediately anterior to the anus, either through loss of the vertebral row or fusion of it and paravertebral rows. This takes place not more than four ventrals anterior to the anus in all cases. UMMZ 62692 has a series of irregular fusions and divisions, beginning at the level of the 138th ventral, and involving not only the vertebral and paravertebral rows, but also the 6 th.

Ten specimens show ir regularities in the caudodorsal reductions, of which four also have dorsal scale row irregularities (ANSP 10116, MNB R702, MP 1526, and UMMZ 62692). All 10 have cross-vertebral reductions, and thus often have an odd number of scale rows on the tail, with either five or three rows, with a subsequent division of the vertebral row to return the total to an even number.

Seven specimens have divided ventrals, and for the four that are recorded, two are of Type 1 and two are of Type 3, with a single scale divided on each. There are no specimens with fused subcaudals.

GEOGRAPHIC VARIATION. - There is little geographic difference in the variation shown by nine specimens from the state of Espíritu Santo, four from Río de Janeiro, nine from São Paulo, and 15 from Santa Catarina (Table XV). Five of the nine specimens that possess one or more preoculars are from Santa Catarina (some of them are omitted from Table XV, because they are either from an indeterminate locality or from a state not 
TABLE XV

VARIATION IN Sibynomorphus mikani neuwiedi

\begin{tabular}{|c|c|c|c|c|c|c|c|c|c|c|}
\hline \multirow[b]{3}{*}{ Locality } & \multirow{3}{*}{$\begin{array}{l}\text { Speci- } \\
\text { mens }\end{array}$} & \multirow{3}{*}{$\begin{array}{c}\text { Pre- } \\
\text { oculars } \\
\text { (One or } \\
\text { more) }\end{array}$} & \multicolumn{2}{|c|}{ Ventrals } & \multicolumn{2}{|c|}{ Subraudals } & \multirow{3}{*}{$\begin{array}{l}\text { Sub- } \\
\text { oculars } \\
\text { (One or } \\
\text { more) }\end{array}$} & \multirow{3}{*}{$\begin{array}{l}\text { Secondary } \\
\text { Temporals } \\
\text { (Less than } \\
\text { two per side) }\end{array}$} & \multirow{2}{*}{\multicolumn{2}{|c|}{ Blotches }} \\
\hline & & & \multirow[b]{2}{*}{ Males } & \multirow{2}{*}{$\begin{array}{c}\mathrm{Fe}- \\
\text { males }\end{array}$} & \multirow[b]{2}{*}{ Males } & \multirow{2}{*}{$\begin{array}{c}\mathrm{Fe}- \\
\text { males }\end{array}$} & & & & \\
\hline & & & & & & & & & Body & Tail \\
\hline Espíritu Santo & 9 & 1 & $172-176$ & $167-174$ & $67-80$ & $65-71$ & 2 & 2 & $27-34$ & $12-16$ \\
\hline Río de Janeiro & 4 & 0 & $167-182$ & 160 & $73-78$ & 63 & 0 & 0 & $27-35$ & 13 \\
\hline São Paulo & 9 & 0 & $165-180$ & $172-176$ & 90 & $60-71$ & 2 & 1 & $25-35$ & $11-20$ \\
\hline Santa Catarina & 15 & 5 & $167-182$ & $168-181$ & $63-84$ & $63-72$ & 2 & 7 & $26-34$ & $12-19$ \\
\hline
\end{tabular}

included). However, this is only one-third of the specimens from Santa Catarina. In addition, seven of the twelve specimens showing a reduction in number of secondary temporals on at least one side have their place of origin in Santa Catarina - but this is still less than one half the specimens known from that state. The lower labials, which vary in number from 7 to 10 , also show no geographic correlations in their variations.

Twelve individuals show practically no spotting on the belly. Of these twelve, six come from Santa Catarina, four from São Paulo, and two from Espiritu Santo. It is possible that color-pattern difference, combined with the variations in scutellation mentioned above, might provide sufficient basis for the separation of several races now contained in this subspecies, since most of the specimens involved come from the southern part of the range (see remarks under Sibynomorphus inaequifasciatus).

REMARKS. - The use of the name neuwiedi for this subspecies is based upon a statement made by von Ihering in his discussion of Cochliophagus mikanii. He said (1910:333), "The examples from the latter localities [referring to localities in São Paulo and Espírito Santo] mentioned represent a variety which diverges somewhat from the forma typica, by the color of the head, which has a greater number of well defined spots, and by the bands of the body, which are much narrowed, widely spaced, and with other lesser bands inserted between them. It will be necessary to obtain more abundant material in order to verify whether the constancy of this form will allow the establishment of a subspecies, which we then will call Cochliophagus mikani neuwiedi subsp. $\mathrm{n}$." (This has been translated freely from the original Portuguese.) While it is obvious that the author had little faith in the actual existence of a recognizable subspecies, it is equally true that the name is formed in full accordance with valid systematic procedure, and is available for use. It antedates by 19 years Amaral's description of S. (ibynomorphus) mikanii fasciatus and, therefore, takes precedence over that name - a most fortunate occurrence, since fasciatus is a homonym of both Dipsas fasciata Fischer and of Dipsadomorus fasciatus Bocourt. It should be clearly understood that Amaral's diagnosis of the new subspecies is entirely based upon the variety " $\mathrm{b}$ " of Leptognathus mikani in Boulenger's "Catalogue" $(1896 a ; 454)$, with the range of variation in both ventrals and subcaudals the same as those listed by Boulenger. It seems legitimate, therefore, to consider Boulenger's list of specimens a series of cotypes, from which a lectotype can be selected, if at some future time it becomes 
desirable to separate the subspecies into several forms. Proper lectotype selection, of course, would make the name again available for use.

As pointed out in the remarks concerning Sibynomorphus mikani mikani, Schlegel's original description of the species was based upon two specimens, one of which is apparently a member of the subspecies I have called neuwiedi. The reasons for restricting the name to the inland subspecies are discussed above.

\section{SPECIMENS EXAMINED.-}

BRAZIL (AMNH 14540; MCZ 17825-27; UMMZ 62692-93). Baia; Baía (ANSP 10116). Espírito Santo (MP 1523); Ita (MCZ 39446), Santa Thereza (MNB R700-02, 1265). Minas Gerais; Tambos (UMMZ 113838-40). Parana; Curityba (UMMZ 113841). Rio de Janeiro (MP 1534-35; MCZ 2920); Floriana (MCZ 39447), São Luis (UMMZ 79678). Santa Catarina (ANSP 10126); Humboldt (MNB R689-96), Joinville (CNHM 11380; MNB R697-99). São Paulo (MCZ 20858-62), Itanhaém (MP 1546), São Sebastião (MP 1522, 1526-27).

\section{Sibynomorphus turgidus Cope}

Cochliophagus inaequifasciatus (nec Duméril, Bibron, and Duméril), Cope, 1862: 347. Leptognathus turgida Cope, 1868: 136.

Leptognathus atypicus Cope, 1874: 65.

Pseudopareas atypicus, Boulenger, 1896a: 463.

Cochliophagus turgidus, Berg, 1901: 291.

Leptognathus mikani (nec Schlegel), Lönnberg, 1902: 461.

Tropidodipsas spilogaster Griffin, 1915: 197.

Pseudopareas spilogaster, Dunn, 1923: 188.

Sibynomorphus turgidus, Amaral, 1926c: 5 .

HOLOTYPE. - Two cotypes, USNM 5815, from "northern part of the Paraguay River."

RANGE. - Northern portion of Paraguay; southeastern part of Bolivia; Mato Grosso, Brazil (Map 10).

DESCRIPTION. - Rostral wider than high; internasals one-half to twothirds length of prefrontals, which enter orbit; frontal approximately equally as broad as long, more than half length of parietals; nasal divided; loreal enters orbit; preoculars none; postoculars 2; suboculars none; primary temporal 1 ; secondary temporals 2 ; tertiary temporals 2 or 3 ; upper labials 7, 3d and 4th enter orbit, no labials enlarged. Lower labials 8 or 9 , first pair in coutact behind mental, four in contact with first pair of chin shields; 3 or 4 pairs of chin shields.

Ventrals $153-160$ in males, $153-168$ in females; anal entire; subcaudals 47-52 in males, 41-51 in females. Dorsal scale rows 15 over major part of body, with occasional reductions to 14 or 13; vertebral row not to scarcely enlarged; caudodorsals:

$$
\begin{aligned}
& \text { Males: } \underline{6} 2+3(17-23) 4 \frac{4}{1+2}(36-44) 2(47-52) \\
& \text { Females: } \underline{6} 2+3(8-24) \underline{4} 1+2(32-44) \underline{2}(41-51)
\end{aligned}
$$

Maxillary teeth 14-15 (5 individuals); palatine teeth 7-9 (5); pterygoid teeth 10-15 (4).

Body length male $328 \mathrm{~mm}$. (cotype), female $499 \mathrm{~mm}$., minimum $144 \mathrm{~mm}$; tail length male 80 (cotype), female $126 \mathrm{~mm}$., minimum $29 \mathrm{~mm}$. 
Dorsal ground color grayish-brown, with 25-40 white-bordered, darkbrown to blackish blotches, with first three to five much broader than interspaces and extending well onto ventrals, white borders of anteriormost fused and excluding ground color; remaining blotches much smaller, rounded, extend down sides to fifth row only, occasionally confined to vertebral and paravertebral scale rows; large series of lateral spots extend from ventrals to third or fourth row and alternate with vertebral spots; interspaces streaked and spotted with brown (Pl. VIa). Venter yellowishwhite, immaculate or with two rows of small, rectangular spots, one on each outer quarter of ventrals, more prominent posteriorly. Tail as in body, except 9-17 dorsal blotches that extend to subcaudals, and ventral surface more liberally and ir regularly spotted with black.

Dorsum of head for most part dark brown with symmetrical yellow vermiculations; side of head lighter, with yellow areas predominating, labials entirely light or somewhat streaked with black. Chin yellowish-white, immaculate or lightly spotted with dark brown.

INDIVIDUAL VARIATION. - No variations from the normal condition of the dorsal head scales were observed. In CNHM 42275 the right nasal is partly fused with the internasal. The nasal scale is entirely divided in ten specimens, partly divided in one, and entire in one. The loreal enters the eye in all specimens, and none of them has a preocular. Nine of the thirteen specimens have 2-2 postoculars, one has 1-1, and three have 2-5. Suboculars are lacking, except for one on the right side of CNHM 42275. The anterior temporal is single on all specimens, and only UMMZ 113835 has other than 2 secondary temporals; it has only 1 on the right side. Fusions between rows of temporals are present in nine specimens, with the upper secondary and the upper tertiary scale being most frequently fused. The upper labials are 7 , with the $3 \mathrm{~d}$ and 4 th entering the orbit, in all except two specimens. One of these, CM 2864, has 8 , with the $3 \mathrm{~d}$ through 5 th entering the orbit, indicating a division of either the $3 \mathrm{~d}$ or 4 th labial; the other, CM 47 , has only 6 on the left side, with the normal 7 on the right. In CM 47 the $3 \mathrm{~d}$ and 4 th labials enter the orbit, pointing to a fusion of two postorbital scales on one side, a situation similar to the usual arrangement in ventrimaculatus.

Six of the specimens have 8-8 lower labials, two have 8-9, two have $9-9$, one has $7-10$, and one has $9-10$. The number of paired chin shields is quite irregular, with six specimens having 3 pairs, three having $3-4$, three with 4 pairs, and one with 4-5. The irregularities have not led to equal variability in the number of labials in contact with the first chin shield as might be expected, since 4 labials make this contact in 24 of the 26 sides, with one of the remaining two having only 3 in contact, the other having 5 . This is a reflection of the fact that variability of the chin shields is a matter of fusion or division of the posterior pair, and that the posterior labials are more irregular than the anterior.

Only four specimens have reductions in the dorsal-scale number posteriorly. Two of these are simple fusion of the vertebral row with one of the paravertebral rows a short distance anterior to the anus, so that the count at the anus is 14 . The third specimen, UMMZ 113835, has fifteen rows at the anus, but at several points along the body there are contacts 
between the scales of the paravertebral rows, crowding out the vertebral row. The fourth specimen, $\mathrm{MCZ} 47027$, has at least 12 reductions to either 14 or 13 rows with return to 15 a few scale rows posteriorly. Most of the reductions resulted from a fusion of the 6 th and 7 th rows, with the increase to 15 again resulting from a division of the vertebral row. There are no irregularities in caudodorsal reductions. Two specimens have divided ventrals, one with two of Type 1 , the other with two of Type 5. There are no fused subcaudals.

REMARKS. - When Cope (1874:65) described Leptognathus atypicus, he pointed out that it belonged in section vi of his monograph of the genus (Cope, 1868:107 et seq.). The only species previously included in that group was Leptognathus turgida Cope. The description of atypicus and the diagnosis of turgidus given in Cope's monograph (1868:108), differ only in labial counts. L. atypicus has 6 upper and 10 lower labials, while according to the diagnosis, turgidus has 11 upper and 8 lower labials. The high upperlabial count given for turgidus is probably the result of a typographical error. I have re-examined the cotypes of turgidus in the United States National Museum, and find that they both have 7-7 upper labials and 8-8 lower labials. In the material that I have assigned to turgidus, one specimen, $\mathrm{CM}$ 47 , has 6 labials on the left side, with the $3 \mathrm{~d}$ and 4 th in the orbit, just as the type of atypicus; on its right side the count is 7 as is usual in turgidus. Two postorbital labials on the left side are obviously fused. The lower labials vary from 7 to 10 in turgidus, with one specimen having 7-10. Two specimens have 10 on one side only. Thus both diagnostic characters of atypicus occur as bilateral variants in turgidus.

The type of atypicus is no longer in the Philadelphia Academy of Natural Science, and I have been unable to locate it elsewhere. Moreover, the type locality is quite possibly erroneous. Cope says "This serpent and two fishes were presented to the Academy of Natural Science with the statement that they were derived from some portion of the Peruvian Andes, from an elevation of twelve thousand feet." This altitude is so out of line for any species of the Dipsadinae that I cannot readily accept it, since exact annotation of the locality and collector are lacking.

Tropidodipsas spilogaster Griffin was synonymized with this species by Amaral (1929:199). I have not seen the type, but the paratype has been available, and there is little question as to the validity of Amaral's action. The type, as described by Griffin, differs from turgidus in having only 1 postocular rather than 2 , and only 2 pairs of chin shields. Three of the specimens examined in this study, however, have 1-2 postoculars, indicating that this is not an uncommon variant character. No other specimen seen has as few as 2 pairs of chin shields; on the other hand, the paratype, from the same locality as the type, has 3 pairs of chin shields, and this is the most common number for turgidus. The paratype does agree with the type in having a single postocular.

Cope $(1887 c: 58)$ mentioned a specimen from Mato Grosso, Brazil, as "Leptognathus turgida Cope var." in which the top of the head is uniform blackish. I have seen only two specimens from Mato Grosso; neither of them has a completely black head, but it tends to be considerably darker 
than in extra-Brazilian individuals. I have not seen the specimen upon which Cope based his remarks.

Berg (1898:29) listed turgidus as a member of the Argentina fauna, but this was apparently based upon specimens from Corrientes and Misiones, states which I do not consider to be within the range of this species. It could occur in Argentina only in the most northern parts of that country, since turgidus is replaced by ventrimaculatus in southern Paraguay and in the Argentinean states mentioned. Koslowsky $(1898 a: 198)$ recorded the species from the states of Salta, Tucuman, and Corrientes in Argentina, and it is geographically possible that the first two are within the range of turgidus. This cannot be verified until the specimens are re-examined, however, since Koslowsky did not describe them. The specimen called Cochliophagus turgidas by Bertoni (1914:29), and recorded as collected at Asunción, Paraguay, I assigned to ventrimaculatus on the basis of geographical probability. The record for this species from Cachoeira de Emas, São Paulo, Brazil, given by Vanzolini (1948:382 et seq.), probably refers to a specimen of mikani.

\section{SPECIMENS EXAMINED. -}

BOLIVIA: Santa Cruz; Buenavista (CM 2764; UMMZ 113342). Sara (CM 47, paratype of spilogaster); Río Colorado (CM 2864). BRAZIL: Mato Grosso; Corumba (UMMZ 113835; BMNH 1892.4.20.15), Urucum (CNHM 9200). PARAGUAY: "Northern part of Paraguay river" (USNM 5815, two cotypes); Pedro Juan Caballero (CNHM 42264, 42273-75); "Depto. Villeta" (MCZ 47027).

\section{ADDITIONAL RECORDS. -}

BOLIVIA: Caiza (Peracca, 1897: 15), Tatarenda (Lönnberg, 1902: 461). BRAZIL: Miranda, Mato Grosso (Koslowsky, 1898b: 32); Carandasinho, Mato Grosso (Peracca, $1904 b$ : 11). PARAGUAY: Depto. Bahía Negra (Boulenger, 1898b: 126).

\section{Sibynomorphus vagrans Dunn}

Pseudopareas vagrans Dunn, 1923: 187.

Pseudopareas vagus vagrans, Amaral, 1929: 201.

HOLOTYPE. - MCZ 17284, female from Bellavista, Peru.

RANGE. - Known only from the type locality.

DESCRIPTION. - Rostral slightly more wide than deep; internasals one-third the length of prefrontals; frontal as long as or slightly longer than broad, shorter than parietals; nasal divided; loreal may or may not enter orbit; preoculars 1 or 2; postoculars 2; suboculars none; primary temporals 2; secondary temporals 3 ; tertiary temporals 2, 3, or none; upper labials 8, 4th and 5th enter orbit. Lower labials 10 to 12, first pair in contact behind mental; 3 pairs of chin shields.

Ventrals 149-156 in males, 154-160 in females; anal entire; subcaudals 74-87 in males, 72-79 in females. Dorsal scale rows 15 from level of 8 th to 13 th ventrals over entire body to anus; vertebral row not to scarcely enlarged; caudodorsals:

Males: $62+3(27-36) \underline{4} 1+2(58-73) 22(74-87)$

Females: $\underline{6} 2+3(11-2 \overline{3}) \underline{4} 1+2(47-6 \overline{7}) \underline{2}(72-79)$ 
Pterygoid teeth 15-18 (12 individuals); palatine teeth 6-9 (12); maxillary teeth 14-18 (11).

Body length male $389 \mathrm{~mm}$., female $330 \mathrm{~mm}$., minimum $144 \mathrm{~mm}$.; tail length male $156 \mathrm{~mm}$., female $125 \mathrm{~mm}$., minimum $51 \mathrm{~mm}$.

Dorsal ground color light brown to tan, with 28-38 blotches, which are much wider anteriorly than posteriorly, anteriormost dark-edged with lighter centers, complete on sides and extending onto ventrals, two to three times width of interspaces; remainder uniform in color, without darker edges, reduced gradually to vertebral series only, equal to or narrower than interspaces, with an irregular series of smaller spots on sides below vertebral spots and alternating with spots on tips of ventrals and adjacent scale rows; latter two series of ten quite faint or poorly defined; interspaces unicolor or with irregular, poorly defined spots high on sides between blotches (Pl. VIe). Ventral color light cream or creamy white, with two rows of light-brown spots on outer quarters of ventrals, often weakly defined or absent, most prominent in middle third of body, fewer anteriorly and posteriorly; dorsal spots extend onto ventrals on anterior portion of body only. Tail as body, dorsal spots very poorly defined, often missing, venter light without brown spotting, brown stippling along sutures of subcaudals.

Dorsum of head light brown, with symmetrical dark-brown spots on individual scales, often with irregular edges, usually with large, fairly prominent spot on posterior edge of parietals and adjacent occipitals that sends one anterior prong forward over each parietal; spots across prefrontals form broken bar from eye to eye, labials light cream or white with lightbrown sutures, temporal region light brown with scattered dark-brown spots. Lower jaw and throat immaculate cream-white, occasionally with light-brown sutures on labials.

INDIVIDUAL VARIATION. - Three of the 23 specimens seen show irregularities in the arrangement of the dorsal head scales. The rostral completely separates the internasals and contacts the prefrontals in MCZ 17432 , and the internasal suture is very short, with the prefrontals almost in contact with the rostral, on MCZ 17441. The prefrontals are incompletely fused, with the posterior part of the suture remaining in MCZ 17446. The lateral head scales anterior to the eye are subject to some variation, particularly the preoculars. Eleven specimens have 1-1 preoculars, eight have 2-2, and five have 1-2. On MCZ 17448 the posterior half of the right nasal is divided horizontally. The loreal enters the orbit on both sides in eleven specimens, it is excluded from the orbit in 8, and enters the orbit on one side but not on the other in five. MCZ 17439 has a subocular on the right side; otherwise this scale is absent in all specimens. All specimens have 2-2 postoculars with the exception of two with 3-3 and one with 2-3. The temporal region is very irregular, with extra scales often inserted and many fusions or division of the normal scale complement. The presence of a small scale inserted between the postoculars, the upper labials and the primary temporals, has been noted in six specimens, two of which have it on both sides. Often when the extra scale is absent, there is an upper labial in full contact with the upper primary temporal, crowding out the contact between the lower primary temporal and the postoculars. If each 
side of the head in the 24 specimens examined is considered individually, there are 41 sides with 2 primary temporals, five with 1 temporal, and three with 3. The upper primary is often fused with the upper secondary. There are 34 sides with 3 secondary temporals, and 14 sides with 2 . Three specimens show a vertical division of a secondary temporal into 2 scales. In the 21 specimens for which data are available, there are 28 sides with 3 tertiary temporals, three sides with 4 , one side with two, and ten with none. Fusions between scales in the secondary and tertiary rows are very common, and the rows are not regularly arranged, making accurate counts difficult.

Three specimens have 8-9 upper labials, one has $9-9$, one has $9-10$, one (the type) has 8-10, and the rest have 8-8. One specimen has the 4 th, 5 th, and 6 th labials entering the orbit on both sides, a second has labials $3-5$ on one side and 4-5 on the other, a third (the type) has 4-6 on one side and 4-5 on the other. All of the others have 4-5 in the orbit.

The lower labials are normally 10 or 11 , but one specimen has 9 on one side, one has 12 on one side, and four have 12-12. The paired chin shields are 4 in one specimen, one individual has 3 on one side opposed by 4 on the other, a third has 2 opposed by 3, and the rest have 3 pairs. In MCZ 17444 the first and second chin shields on the left side are fused, with the outer end of the suture still present.

Only three specimens show a reduction in dorsal scale-row number on the posterior part of the body, and in none does the reduction take place more than nine ventrals anterior to the anus. In each of the three, the reduction results from a fusion of the vertebral with one or both of the paravertebral rows.

Divided ventral scales were found on five specimens. Three of these are Type 1 , one is Type 3 , and the fifth had the $153 \mathrm{~d}$ ventral incomplete on the left side and about five-sixths the width of a normal ventral. Fused subcaudals were found on two specimens, with two pairs fused on MCZ 17430 , and three pairs on MCZ 17439. Two specimens have irregular reduction formulae for the caudodorsals, both showing vertebral rather than lateral fusions.

Several specimens differ in their dorsal pattern from the description given. The dorsal blotches in these variants tend to remain complete across the body, and do not break up into vertebral and ir regular lateral spots. This pattern is strongly reminiscent of that in S. mikani. In some specimens the first body blotch is broken at the vertebral line making two lateral blotches.

REMARKS. - Although Amaral (1929:201) made vagrans a subspecies of Pseudopareas vagus (Jan), I find no valid reason to consider the relationship that close. The color pattern of vagus is quite different from any other dipsadine species, while that of vagrans resembles that of the other species in its genus. There is, on the basis of the known specimens, a complete dichotomy in subcaudal scales. The localities from whence the specimens examined come are widely separated geographically, and there is little to demonstrate that the range of the two species overlap.

SPECIMENS EXAMINED. -

PERU: Bellavista (AMNH 63372-73; MCZ 17284 (holotype), 17428, 17430-32, 17436-52). 


\section{Sibynomorphus vagus Jan}

Leptognathus vagus Jan, 1863: 100.

Leptognathus vaga, Cope, 1868: 108.

Pseudopareas vagus, Boulenger, $1896 a$ : 462.

Pseudopareas vagus vagus, Amaral, 1929: 201.

HOLOTYPE. - Present location unknown.

RANGE. - Known only from Huancabamba, Peru.

DESCRIPTION. - Rostral broader than deep; internasals half or more of length of prefrontals; frontal as long as or a little longer than broad, somewhat more than half length of parietals; nasal divided; loreal enters orbit; preocular 1; postoculars 2; subocular none; primary temporal 1; secondary temporals 2 ; tertiary temporals 2 or 3 ; upper labials 7 or 8 , 4th and 5th enter orbit. Lower labials 8 to 11 , first pair in contact with each other behind mental; 4 pairs of chin shields.

Ventrals 145-151 in males, 151-156 in females; anal entire; subcaudals 63-70 in males, 56 in single female. Dorsal scale rows 15 over entire body; vertebral row moderately enlarged; caudodorsals:

$$
\begin{aligned}
& \text { Males: } \underline{6} 2+3(18-24) 4 \underline{4} 1+2(50-67) 2(63-70) \\
& \text { Females: } \underline{6} 2+3(12-1 \overline{3}) \underline{4} 1+2(34-4 \overline{4}) \underline{2}(56)
\end{aligned}
$$

Maxillary teeth 14-16; palatine teeth 8-10; pterygoid teeth 16-20 (all from three specimens).

Body length male $364 \mathrm{~mm}$., female $299 \mathrm{~mm}$. , minimum $134 \mathrm{~mm}$. ; tail length male $114 \mathrm{~mm}$., female $174 \mathrm{~mm}$., minimum $40 \mathrm{~mm}$.

Dorsal ground color brownish-gray or gray, with no clearly defined dorsal blotches, anteriorly with regularly placed lateral spots, very narrow and extending from ventrals to vertebral line when complete, often broken; posteriorly, dark color confined to posterior edges of scales and forming jagged, often broken dark streaks on scales. Venter creamy white with single series of dark-brown rectangular spots on each end of ventrals, spots may be very large and forming almost continuous series or small with each spot isolated from its neighbor. Tail without spots dorsally, dark gray, ventrally darker than belly, immaculate or very irregularly spotted with black.

Dorsum of head grayish-brown, with poorly defined spot on each parietal, and smaller spots present or absent on other dorsal scales; sides of head grayish-brown, abruptly becoming cream-white on labials, labial sutures may be dark brown; dark-brown spot at corner of mouth. Chin grayish-white, immaculate; ventral spotting begins on throat immediately behind head.

INDIVIDUAL VARIATION. - There is no variation in the dorsal head scutellation nor in the ocular scales. The loreal enters the orbit in all. The temporals, while always single in the primary row and double in the secondary row, show fusion between rows in two specimens, both on the left side only. The anterior is fused with the upper secondary in both. The upper labials are 8-8 in four specimens, 7-7 in two. The 4 th and 5 th enter the orbit in those with 8-8 and one of those with 7-7. In the other with 7-7 the $3 \mathrm{~d}$ and 4 th are in the orbit. 
The lower labials vary from 8 to 11 . On a total of 12 sides, two have 8 , three have 9 , five have 10 , and two have 11 . The lower numbers apparently result from fusion of two or more labials, for some are extremely elongated. In MCZ 17425 the 8th on the left and the 7th on the right are much elongated. There is only a single lower labial entering into a contact with labials from the opposite side on the midline in 10 of the 12 sides, with 2 labials in the contact on the other two sides, 1 in $\mathrm{MCZ} 17425$ and 1 in MCZ 17426. There are 4 pairs of chin shields in ten sides, but fusion has left only 3 on the right side of both MCZ 17423 and 17425. There are 4 labials in contact with the 1st chin shield on five sides, and 5 labials in similar contact on seven sides.

The dorsal scales are uniformly 15 over the entire body. No divided ventrals or fused subcaudals were observed.

REMARKS. - Cope borrowed the type from Jan and published the following remarks concerning it (1868:136): “It ... has but two postocular plates; of its preoculars nothing can be said. Superior labials eight. There are four pairs of genials. General form less compressed than the types, with rather short body and tail. Above wood-brown, with indistinct cross series of spots. Below yellowish, tessellated with brown. Size not large for the genus." Although Jan gave the type locality of the species as "HongKong," Cope (1868:136) postulated that it must be South America. Boulenger merely questioned the original locality (1896a:463); Dunn (1923:187), however, fixed it in South America on the basis of the specimens examined and described here.

SPECIMENS EXAMINED. -

PERU: Huancabamba (MCZ 17420-23, 17425-26).

\section{Sibynomorphus ventrimaculatus Boulenger}

Leptognathus ventrimaculatus Boulenger, 1885: 87.

Leptognathus Mikani (nec Schlegel), Boettger, 1885: 237.

Leptognathus turgida (partim non Cope), Berg, 1898: 29.

Cochliophagus ventrimaculatus, Berg, 1901: 291.

Cochliophagus mikani, Berg, 1901: 291.

Leptognathus intermedius Steindachner, 1903: 16.

Leptognathus mikani (part), Werner, 1909a: 280.

Cochliophagus intermedius, von Thering, 1910: 331.

Cochliophagus turgidas (non Cope), Bertoni, 1914: 29.

Cochliophagus mikani (nec Schlegel), Bertoni, 1914: 29.

Sibynomorphus ventrimaculatus, Amaral, 1929: 200.

Sibynomorphus turgidus (part), Amaral, 1929: 199.

HOLOTYPE. - Two cotypes, BMNH 1885.6.26.32, male, and BMNH 1885.6.26.33, sex unknown, from colony of São Lorenço, Serra dos Tapes, Río Grande do Sul Province, Brazil, received from von thering.

RANGE. - Southern Paraguay; Northeastern Argentina; and Río Grande do Sul Province, Brazil (Map 10).

DESCRIPTION. - Rostral broader than deep; internasals half or more of length of prefrontals; frontal wider than broad, two-thirds as long as parietals; nasal entire or semidivided; loreal enters orbit; preocular none or 1; postoculars 2; suboculars none; primary temporals 1; secondary 
temporals 2; tertiary temporals 2 or 3 ; upper labials 6 , 3d and 4 th enter orbit, 5th labial elongate and in contact with postocular, primary and secondary temporals. Lower labials 8 or 9 , first pair in contact behind mental; 3 or 4 pairs of chin shields.

Ventrals 156-165 in males, 157-169 in females; anal entire; subcaudals 48-58 in males, 44-53 in females. Dorsal scale rows usually 15 over entire body, may be occasionally reduced to 13 shortly anterior to anus; vertebral row either moderately enlarged or between moderately and broadly enlarged; caudodorsals:

Males: $62+3(18-26) 41+2(41-47) 2(48-58)$

Females: $\underline{6} 2+3(7-24) \underline{4} 1+2(29-44) \underline{2}(44-53)$

Maxillary teeth 11 (3); palatine teeth 7-9 (3); pterygoid teeth 7-13 (3).

Body length male $422 \mathrm{~mm}$., female $485 \mathrm{~mm}$., minimum $151 \mathrm{~mm}$.; tail length male $109 \mathrm{~mm}$., female $122 \mathrm{~mm}$., minimum $33 \mathrm{~mm}$.

Dorsal ground color light yellowish-brown, with 36-49 chocolate-brown to dark-brown blotches, anteriormost opposite, fused, extending onto ventrals, posteriormost often alternating, ending on second or third rows; all with slightly lighter centers, and poorly defined black borders; often squarish, may be slightly constricted on sides; interspaces unicolor, narrow, considerably smaller than blotches on all parts of the body (Pl. VId); large spot between ends of dorsal blotches posteriorly, on ventrals and first and second scale rows. Venter yellowish-white, with large, rounded brownish spots in irregular row along outer quarter of ventrals on both sides, smaller rounded spots along midline, somewhat scattered. Tail with 1223 dorsal blotches.

Dorsum of head dark brown with yellow vermiculation on parietals and frontals, yellow color more prominent on snout; sides of head yellowish with brown streaking along sutures, upper labials whitish, with color continuous with the first light band behind parietals, labial sutures may be dark brown. Chin yellow or yellowish-white, immaculate or very lightly spotted with small brown spots.

INDIVIDUAL VARIATION. - The dorsal scales of the head are uniform in all individuals except MNB R705, which has the left prefrontal partly fused with the frontal. The nasal is semidivided in seven of the individuals in which the character can be determined, and is entire in three others. One specimen, CNHM 9259, has a small scale inserted between the nasal, prefrontal, and internasal on the left side; the remaining specimens have uniform scutellation in the loreal region. Three specimens show fusion between scales of adjacent rows of temporals, and one individual has one of the tertiary temporals divided into two scales. The upper labials are 6-6 in all except two, one of which has 6-7 and the other, CNHM 9258, has 8-8.

The lower labials are 8-8 in four specimens, 8-9 in two, 9-9 in one, 910 in one, $10-10$ in one, and 11-11 in one. The number of paired chin shields are quite variable; one specimen has 2 pairs, four have 3 pairs, one has 3 on one side paired with 4 on the other, four have 4 pairs, and one has 5 pairs. One specimen, MNB R706, has an extremely reduced third chin shield on the right, with the second and fourth in contact on the midline. 
This variation in both labials and chin shields is reflected in the number of labials in contact with the first chin shield. Four specimens have such a contact with 4 labials, four others with 5 , and two have 3 on one side opposed by 4 on the other.

Five specimens have reductions in the number of dorsal scale rows. Four of these are reductions far posteriorly to 13 rows as a result of fusion of the vertebral row with the paravertebrals, and this is accompanied by a distinct widening of the vertebral row, often from moderately to broadly enlarged. In three of the four specimens the reduction occurs within 12 ventrals from the anus, but in the fourth (MNB R705) the reduction is as follows:

$$
\underline{15} \frac{\mathrm{V}+7(134)}{\mathrm{V}+7(134)} \underline{13}
$$

The fifth specimen has a reduction by fusion of the vertebral row with the paravertebral on the left for a short distance only, with a return to 15 , thereafter, continuing to the anus.

The caudodorsals reduce in the normal fashion on all except two individuals, one of which, MNB R705, retains a midvertebral row for a considerable distance on the tail, and has middorsal fusions rather than lateral ones as a result. The formula for this specimen is as follows:

$$
\underline{7} \frac{\mathrm{V}+3(6)}{\mathrm{V}+3(8)} \underline{5} \frac{\mathrm{V}+2(16)}{\mathrm{V}+2(16)} \underline{3} \mathrm{~V}<\frac{2(19)}{2(19)} \underline{4} \frac{1+2(41)}{1+2(41)} \underline{2}
$$

Divided ventrals were noted in only one specimen, MP 1549, which has a Type 1 division on the 25 th ventral. No fused subcaudals were noted.

REMARKS. - There can be little doubt that the relationship between this species and its congeners, mikani and turgidus, is extremely close, and there is probably sufficient basis to consider them all in a single subspecific chain. The diagnostic characters for ventrimaculatus are details in coloration and color pattern and the fact that its members possess only 6 upper labials. This latter character is directly derived from the situation that exists in both turgidus and mikani, which have 7 upper labials, with 3 posterior to the last one entering the orbit. Since ventrimaculatus has only 2 labials posterior to the last one entering the orbit, it is logical to look for a fusion of 2 of the postorbital labials. The 5th labial in ventrimaculatus is quite elongate, although it is not increased in height, and it is in contact with the postocular, the primary and the secondary temporals. While this character is typical of the species belonging to the genus Sibon, it is found normally only in the species ventrimaculatus in the rest of the subfamily. It is not to be interpreted as an indication of a relationship between Sibon and this species, however, because of the differences in the formation of the character. In Sibon the contact results from a fusion between a labial and the lower anterior temporal, with a large labial rising high above the labial row, while in ventrimaculatus the contact is a result of fusion of two adjoining labials and does not involve any scales in the temporal region. 
The original data for the cotypes of ventrimaculatus have been checked for me by Dr. H. W. Parker, at the British Museum (Natural History). It appears that Boulenger's $(1885: 85)$ statement that the cotypes formed part of a "collection made by Dr. von Ihering on the southern border of the Lagoa dos Patos" is not entirely accurate. Parker has located the original list sent by von Ihering, which says, in reference to the entire collection that included the cotypes, "Alles aus den auf der Serra dos Tapes gelegenen Colonie S. Lourenço am südlichen Ufer der Lagoa dos Patos.” Parker pointed out that on older maps the Colony of São Lourenço appears as a district in the mountains, quite distinct from the town of the same name on the coast. Dr. von Ihering obtained specimens of S. mikani mikani from the city itself.

Leptognathus intermedia was described by Steindachner in 1903 on the basis of a single specimen from Altos, Paraguay. Steindachner briefly compared it with both ventrimaculatus and turgidus, and Amaral (1929:199) saw fit to synonymize it with the latter species. I do not agree with this synonymy, because the locality is within the range of ventrimaculatus as defined by the specimens I have examined, and also because of the presence of only 5 labials in the type, of which the $2 \mathrm{~d}$ and $3 \mathrm{~d}$ enter the orbit. This leaves only 2 postorbital labials, as is typical of ventrimaculatus, and would indicate that a second fusion has taken place anterior to the eye on this particular specimen. This specimen, as well as the two specimens examined from Asuncion, Paraguay, which is only a short distance west of Altos, are from near the northern end of the range of ventrimaculatus and from that part of the range nearest to turgidus, and they might be considered indicative of the approach of the two species, although they cannot be justifiably called intergrades between them.

It seems likely that the specimen from Lagoa Santa, Minas Geraes, Brazil, identified as ventrimaculata by Hvirveldyr (Jensen, 1900:280), and transferred to mikani by Jensen (p. 280), belongs to mikani, as defined in this study. The specimens called Leptognathus turgida by Berg $(1898: 29)$ from Corrientes and Misiones, in Argentina, are without doubt members of the species ventrimaculatus. Boettger $(1885: 237)$ described a juvenile of this species from Paraguay, which he called Leptognathus mikanii, and Bertoni (1914:29) discussed several ventrimaculatus from Asunción, Paraguay under the name Cochliophagus turgidas.

SPECIMENS EXAMINED. -

ARGENTINA: Misiones; Iguazu Falls (CNHM 9257-59, 9375), Monte Carlo (CNHM 12354). BRAZIL: Río Grande do Sul; Santa Maria (MCZ 43316-18), São Lourenco (BMNH 1885.6.26.32, cotype). PARAGUAY: Asuncion (MNB R705-06), Encarnacion (MP 1549).

ADDITIONAL RECORDS. -

ARGENTINA: Resistencia (Peracca, 1895: 21). PARAGUAY: Altos (Steindachner, 1903: 16), Luque (Peracca, 1895: 21), Alto Parana (Bertoni, 1914: 29), Río Ara (Peracca, 1895: 21), Trinidad (Serié, 1915c: 580).

\section{GENUS SIBON FITZINGER}

Sibon Fitzinger, 1826: 31. Genotype: Coluber nebulatus Linnaeus.

Sibynon Fitzinger, 1843: 27. Genotype: Coluber nebulatus Linnaeus (a misprint for Sibon?). 
Petalognathus Duméril, 1853: 466. 463. Genotype: Coluber nebulatus Linnaeus (Duméril apparently did not recognize the validity of Fitzinger's earlier names, but he did not amplify his reasons for assigning it a new generic name).

Mesopeltis Cope, $1866 \mathrm{~b}$ : 318. Genotype: Mesopeltis sanniolus Cope.

Asthenognathus Bocourt, 1884: 141. Genotype: Petalognathus multifasciatus Bocourt (=Sibon dimidiata Günther).

DESCRIPTION OF GENUS. - Dorsum of head with full complement of colubrid head scales, that is, internasals, prefrontals, frontal, supraoculars, and parietals; nasal lies between semidivided scale or in suture between two scales (occasionally entire); loreal enters orbit (except in sanniola); preocular none (except in sanniola); postoculars 2; suboculars none, primary temporal 1 (exceptionally 2); secondary temporals 2 ; tertiary temporals none; temporal region very constant, showing little variation; upper labials 7, 8, or 9 (except in sanniola, with 8-10); penultimate labial enlarged, much higher than other labials, in contact with postocular, primary and secondary temporals (Fig. $3 a-b$ ). Lower labials 6 to 11, usually less than 10 , a single pair in contact behind the mental in two species, no contact of any labials behind the mental in six species, in which either the first chin shields are in contact with the mental, an unpaired postmental is present, or a tiny pair of scales of same size as postmental is present; one of posterior lower labials greatly enlarged, considerably wider than others, extending far beyond edge of labial row and usually coming in contact with chin shields; mental groove present but poorly defined in most species (fairly prominent in nebulata); paired chin shields usually three, with the first pair crescentic and longer than broad (Fig. $4 a-b$ ).

Body compressed laterally; head sharply distinct from neck. Dorsal scale rows smooth, without apical pits, 15 in all except one species (anthracops, with 13), no scale row reductions in any species; vertebral row not to moderately enlarged; caudodorsals reducing abruptly behind anus to six scale rows, and gradually thereafter to two, which is number at tip; points at which reductions take place variable. Ventrals rounded, occasionally split or divided into two parts; anal entire; subcaudals in two rows, with pairs fused into single scale only exceptionally.

Color pattern of large, well-marked dorsal blotches, which do not fuse across ventral midline (except in anthracops); blotches of ten with lighter centers; ontogenetic color change takes place in some species.

Hemipenis short, slightly capitate; sulcus spermaticus bifurcate; tip slightly bilobed, but not divided; proximal part spinose, spines slightly recurved, several enlarged basal spines; distal part calyculate, with fairly long papillae; constriction at border between spinose and calyculate parts rather prominent, causing capitate appearance.

Maxillary teeth subequal in size or gradually decreasing in length posteriorly; ectopterygoid present, anterior end expanded; palatine toothed throughout length; pterygoid toothed to point of divergence toward quadrate, posterior end either in contact with quadratomandibular joint or only slightly separated from it, if separated, a strong ligamentous attachment between pterygoid and joint present. Hypopophyses absent on posterior vertebrae.

Body compressed laterally; head distinct from neck, not shortened or blunt; eye large, with vertically elliptic pupil, tail elongate, slim. 
RANGE. - Mexico from Michoacan on the west and Veracruz on the east, excluding highlands, south to northern South America, including equatorial Brazil and Ecuador; also known from Trinidad and Tobago.

NOMENCLATURAL HISTORY. - The species upon which this genus is based was originally described by Linnaeus, and he unfortunately described it not once but twice, as Coluber sibon and as C. nebulatus. While Fitzinger's (1826) description of the genus Sibon was brief, and confined to a series of key characters (p. 29), it is true that he assigned a genotype (p. 31), and the genus is, therefore, valid and available under the rules of nomenclature. There is little justification, therefore, for the names Sibynon Fitzinger (1843) and Petalognathus Dumeril (1853), which were also based on Coluber nebulatus Linnaeus.

Fitzinger listed three species as belonging to his genus Sibon. The genotype still remains in the genus, of course, but it is the only one of the three that does, for the second is a Leptodeira (annulata Linnaeus), and the other, Coluber catenularis Daudin, has been placed in the synonymy of Dipsadomorphus trigonata Russell.

Schlegel (1837) synonymized the new genus and called nebulata a Dipsas, thereby adding it to one of the greatest generic composites since Linnaeus' original Coluber, for he included all arboreal serpents under the single generic name Dipsas, an arrangement that was followed by practically no one. Fitzinger (1843) used nebulatus as the type of a genus he called Sibynon, which quite possibly was a lapsus or typographical error, since the original Sibon designation was his own. The work in which this name appeared contained only names for genera and designations of genotypes, so it is not possible to check further to learn the reason for this change in orthography. Fitzinger named Sibynomorphus at the same time, so it is likely that the name refers to the similarity in body shape between it and Sibon. This indicates that the root he wished to use was sibyno- and suggests that the lapsus was made at the time of the designation of Sibon in 1826 . Whatever the actual situation, he pointed out no errors in orthography himself, and the generic name Sibon is legitimate.

Duméril (1853) published a series of names and an entirely new arrangement, but complications arise from the fact that this is merely a prodromus, and he used what appear to be common names in French orthography for approximately half of his genera. For example, he included in a family grouping called the "Leptognathiens" the following genera (listed in his original spelling): Pétalognathe, Dipsadomore, Leptognathe, Cochléophage, Hydrops, Rachiodon, Sténognathe, Ischognathe, Brachyorrhos, Streptophore, and Stremmatognathe. All of those ending in "e" were later called new genera, and described by Duméril, Bibron and Duméril, in their Erpétologie général (1854). The only change was in the ending, which was classisized by substituting "us" for "e." It is plain that Duméril, in his original paper (1853), was referring to the genera later properly spelled, but it is also true that each of his names is accompanied by a short description pointing out the outstanding characters as well as the names of species belonging to it. Hence, this is the first place in which Pétalognathe (=Petalognathus) is used, with nebulatus as the only species assigned.

Duméril, Bibron, and Duméril (1854) described Petalognathus in detail, 
but they gave no suggestion as to why they felt that the name Sibon (or Sibynon) was not available. Fitzinger's combination, Sibon nebulatus, is cited in the species synonymy. The genus was included in the family these authors called "les Leptognathiens" and perpetuated Schlegel's recognition of the relationship of Sibon to Leptognathus (=Dipsas). Gưnther (1858) recognized and used the new name Leptognathus Duméril, Bibron, and Duméril, but he placed Petalognathus in its synonymy. Furthermore, in his Biologia Centrali-Americana (1895:168), Günther said that “Fitzinger's definition of Sibon is extremely vague, and I prefer to retain the name which I chose for this genus in 1858," in reference to Leptodira. He therefore included Sibon in the synonymy of the latter genus and also mentioned (in the same footnote) that "Linnaeus named a snake Coluber sibon, which, however, does not seem to enter the present genus." He did not include this species in the synonymy of Petalognathus nebulatus (1895:139), nor did he mention Sibon under Petalognathus, although Fitzinger's designation of genotype was quite clear. It is apparent that Günther did not recognize the synonymy of sibon and nebulatus and that he did not understand what Fitzinger's genus Sibon was. He was not alone in the synonymization of Sibon with Leptodeira, however, for Boulenger included it under the heading "Leptodira" in his catalogues, and Cope used the name several times for what is now understood to be the genus Leptodeira. Their usage is apparently based upon the fact that Fitzinger assigned three species to the genus, as mentioned above, and the first listed on page 60 of his "neue Classification” (1826) was Coluber annulatus Linnaeus. Cope (1860:266) gave the genotype of Sibon as S. annulata (L.). This is the first known restriction of genotype, following publication of the name, and would fix the name with annulata as genotype and permit its use in place of, not synonymy within, the genus Leptodeira, were it not for the fact that Fitzinger (1826:31) himself actually made what can be considered an assignment of genotype when he stated "Daudin's Coluber Clelia repräsentirt die Gattung Clelia, und Linne's Coluber nebulatus meine Gattung Sibon." This is a clear statement of intent, and Cope's use of the name for Leptodeira was entirely unjustified. In addition, Fitzinger used Linnaeus' Coluber annulatus in 1843 as the type of his new genus Leptodeira, a rather obvious indication that he did not feel that it was typical of the genus Sibon. Cope $(1900: 1106)$ persisted in this usage, however, up to his death. Cope (1895:202) used the generic name Petalognathus in his "Classification of the Ophidia" for the species nebulatus. The same reasoning lies behind Boulenger's use of Petalognathus nebulatus (1896a:292), for he included Sibon under the generic synonymy of Leptodira. Cope placed the genus Petalognathus in his subfamily Leptognathinae, while Boulenger separated it entirely from the dipsadine snakes, and placed it in the Colubrinae. Werner $(1929: 158)$ continued the use of Petalognathus, but Amaral, in the same year $(1929: 194)$ returned to the use of Sibon. Amaral also used the specific name sibon in preference to nebulatus. Authors since Amaral have varied as to choice of specific name, but most have continued to call the genus Sibon. Notable exceptions have been Shreve $(1947 b: 531)$ and Dunn $(1947: 157)$, both of whom placed nebulata in Dipsas.

Since its inception the genus has been considered to be monotypic by 
practically all authors. This monotypy, in fact, provided a basis for a study on quantum evolution by E. R. Dunn (1952). I believe, however, that evidence, based upon the uniformity and continuity expressed by two series of species in Central America, is strongly indicative of a direct relationship with the species Sibon nebulata, and I have transferred the two series from their old position in the genus Dipsas (=Sibynomorphus) to the genus Sibon. I believe this arrangement will prove to be more natural and logical, and should be satisfactory to herpetologists concerned with Central American snakes.

\section{VARIATION WITHIN THE GENUS}

Sibon is considerably more consistent in its coloration and scutellation than Dipsas is, as will be readily seen by comparison of the discussions of variation within the two genera. To a degree, Sibon can be characterized by its uniformity, while Dipsas is characterized by its variability.

There are three fairly well marked species groups in Sibon, based primarily on color patterns, as in Dipsas. The annulata group is characterized by its regularly blotched or banded pattern. The argus group has an ocellate pattern that is unique in the dipsadines. The nebulata group is characterized primarily by irregularity in pattern, with small blotches, spots, stippling, and so on, all combining to make a highly disruptive pattern.

The head scales of Sibon are practically without variation from species to species. The dorsum of the head is completely uniform. The nasal is divided either entirely or in part in all species except annulata and dimidiata, both of which have individuals with entire nasals. The loreal enters the orbit in all except sanniola, which has 2 or 3 preoculars, the lower of which exclude the loreal from the orbit. The preoculars are absent in all the remaining forms. Suboculars are consistently missing. The secondary temporals are 2 in all species except carri, which has only 1 , and tertiary temporals are absent. S. carri lacks the primary temporals entirely, otherwise there is usually one. The type of costaricensis Taylor, synonymized with longifrenis in this paper, has 2 primary temporals on one side of the head. This situation obtains in specimens of annulata (in the type of pictiventris), anthracops, sanniola, and nebulata. Occasional fractionation of secondary temporals takes place, but has been observed only in those species represented by fairly adequate series, and in a very small percentage of individuals. The same is true of horizontal splitting, which produces 3 secondary temporals. The upper labials are most often 7 or 8. The species sanniola is again a most conspicuous exception, since the majority of its members have nine, with a range from 8 to 10 . The species carri and dunni typically have only 6 labials. The species nebulata, with its wide geographic range, also shows a greater variability in labial count, and has individuals with only 5 , while others may have as many as 9 . There are 2 labials entering the orbit in all species except sanniola, in which, in correlation with its increase in labial count, the greater percentage of its members have 3 labials that enter the orbit. While 2 is the usual number 
for nebulata, there are some individuals that have 3 and others only 1 in the orbit, which again is probably a reflection of the size of the sample available and the wide geographic area covered. The enlarged upper labial following those that enter the orbit is always present, and constitutes the best single method for generic identification (Fig. $3 a-b$ ). The deep entrance into the primary temporal row by this enlarged labial suggests that it has been formed by fusion of a labial and the lower primary temporal. This labial contacts the postocular, the entire lower border of the single remaining primary temporal, and the anterior edge of the lowest secondary temporal, precisely as the lower primary temporal does when it is present. The hypothesis that fusion has taken place between a labial and a temporal is strengthened by the fact that in carri the single primary temporal is gone, and the enlarged labial is in contact with the parietal. There is only a single labial posterior to this enlarged scale in all species except dunni, and the actual gape of the mouth is rather small. In dunni the enlarged labial occupies the entire lip posterior to the last labial in the orbit. The posteriormost labial is bordered above only by the secondary temporals, and the tertiary row is almost invariably posttemporal, and falls behind both the labials and the parietal.

The number of lower labials is much more consistent both within and between species in Sibon than in Dipsas. In keeping with the fact that one of the lower labials is greatly enlarged and extends to the paired chin shields, the number is quite low. In only one species, dimidiata, are there any individuals with more than 10 labials; a single specimen has 11 on one side and 10 on the other. Although several individuals of nebulata have 10, there are none with more. One individual of nebulata has only 6 on one side, but the majority of the specimens of that species examined have 8 or 9 , the normal number for the genus. One of the posterior lower labials is elongated in all species, and it is usually the first or second one posterior to those in contact with the first chin shield. It is, however, sometimes in contact with the first chin shield itself. In all species except argus the scale is not only elongated but enlarged, so that its inner edge is usually in contact with the chin shields, and in carri the two scales contact one another along the midline. In argus, however, the scale is only elongated, with its posterior edge flush with the edges of the other lower labials. Three species agree with nebulata in having a single pair of labials in contact behind the mental, including anthracops, carri, and dunni. Three different scale arrangements have been observed in the postmental region. The first type is a tiny pair of scales which appear to be split off the ends of the labials that normally lie in that position; it is found in most individuals of annulata. In the second type, the two small scales appear to have fused, to form a single, rather large scale, called the postmental in this study. This condition exists in sanniola, the two subspecies of dimidiata, and occasional specimens of annulata. The single specimen of dimidiata grandoculis that I have examined has two such postmentals in tandem before the paired chin shields begin. The third condition, found in argus, involves complete loss of scales between the mental and the paired chin shields, so that the normally enlarged first pair of the latter separate the labial pairs, and are in broad contact with the mental. The condition in 
longifrenis is probably like that found in argus, although the type of the species retains a minute single postmental scale. The type of costaricensis has the first pair of chin shields in contact with the mental. Since the closest relative of longifrenis is argus, I am inclined to think that the condition in the type of longifrenis is the anomaly, and that the normal condition is the complete absence of any small scales between the mental and the chin shields. The paired chin shields are usually 3 , with 4 pairs occurring occasionally in nebulata and dimidiata. Four is also the number recorded for annulata, but it must be remembered that the second pair in this species is equivalent to the first pair in the other species, since the first pair is formed by suturing off the end of the first labial on either side.

The dorsal scale rows are 15 throughout the genus, with the exception of anthracops and carri, which have only 13 rows. The vertebral row is moderately enlarged in nebulata, but in all the rest of the species either show no enlargement at all, or are only scarcely enlarged. There are occasional reductions from 15 to 13 in only one species, nebulata. Although anthracops and carri are similar to Dipsas indica in the low number of scale rows, they do not have broadly enlarged vertebrals. On the contrary, the vertebrals are not enlarged at all. In those species of Dipsas with the low scalerow counts, on the other hand, the broadest vertebral rows are found, and there seems to be a strong correlation between the two characteristics. The vertebral is widened at the expense of paravertebral rows in Dipsas, but this does not appear to be true also of Sibon.

The total range in ventral counts for the genus is from 136 in dunni to 201 in argus, or a total of 66 scales. Stuart (1941:17) commented on the total ranges of several genera, and made several statements that can bear further scrutiny at this time. He stated "In the ventral scutellation sexual dimorphism, genetically lethal characters, and the normally great variability of this character combine to make it the most unstable feature of the genus." He pointed out that Ortenburger (1928) gave a total range for ventral counts in the genus Masticophis as 31 (actually 32, from 183 in anthonyi to 214 in taeniatus), and in the genus Coluber as 35 (actually 41, from 154 in oaxacae to 194 in flaviventris). In addition, Blanchard (1921) gave the total range for ventrals for Lampropeltis as 102. Stuart himself found that the range for Dryadophis is 47 scales. From these facts he concluded that "...variation in the genus Dryadophis is not excessive. It is, in fact, considerably less than that in the wholly unrelated genus Lampropeltis ..." I cannot agree with the conclusions, or, at least, that they can be validly drawn from the data presented. In the first place, the use of a character which is considered, at best, of value only on the specific level, and is often used to define subspecific relationships, is of extremely doubtful validity in generic comparisons. I know of no two genera of snakes which are defined as different from one another purely on total ventral count. Not only is the comparison of two genera on the basis of that count unjustified, but also the comparison of variability of the genera concerned is invalid. If differences exist between the species contained in any one of the genera, then the character cannot be expressed on the generic level, except as a generality. In the genera concerned, the total range of ventrals is simply a reflection of the diversity of the species concerned and the degree of 
sexual dimorphism. The lowest count, 32 for Masticophis, is for a genus with twelve species representing two very compact groups. The next count, 41 , is found in the American representatives of Coluber, with only two species concerned. From Ortenburger's account, there is little or no sexual dimorphism in ventrals within the two genera. Dryadophis has nine species, but is divided into four, and possibly five groups. Lampropeltis, at the time of Blanchard's work, contained fourteen species, representing three or possibly four distinct groups, and a great number of subspecies. The range of variation of any single species of Lampropeltis is no greater than that of any single species of Masticophis. The range of ventrals in the several subspecies of Coluber constrictor, on the other hand, far exceeds that of any of the other species, just as does the range in Dryadophis boddaerti. In both, it is a direct corollary of the wide area geographically that is represented by the specimens examined, and no single population includes the entire range. In short, the variability has not been checked at all at the point where it is of basic importance. The calculation of the standard deviation is necessary to estimate dispersion, and gives an accurate method of determining the validity of the observed range as an indicator of the actual range for the entire population. Since this has not been checked for any of the groups concerned, statements concerning the comparative "variability" of the genera cannot be made. Therefore, the statement that the ventral count is the "most unstable feature of the genus" (Stuart, 1941:17) is unacceptable. Certainly it is no more unstable than the total number of vertebrae, body segments, or ribs, for the number of ventrals is directly correlated with these.

The subcaudals range from a minimum of 41 in carri to a maximum of 126 in dimidiata. There is some sexual dimorphism in practically all of the species in both subcaudals and the reduction of caudodorsals (see discussion under species heading for sanniola). The variations in point of reduction for the caudodorsals are given under the respective species headings.

Divided ventrals (Fig. 2) were noted in all species when samples were large. Type 1 is the most common, with Types 2 and 3 also observed. Fused subcaudals are very rarely present.

From the above discussion, it is obvious that sanniola is the poorest fit as far as the generic characterization is concerned. It is the most diminutive species, as well. It is a peripheral form, and must be of rather recent origin, since it is entirely confined to the Yucatán Peninsula, which was apparently flooded for the most part during the Pliocene and early Pleistocene.

\section{KEY TO SPECIES OF Sibon}

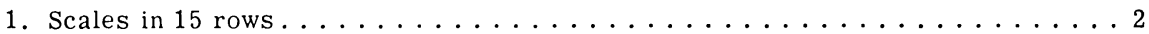

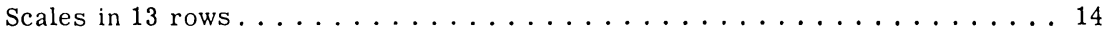

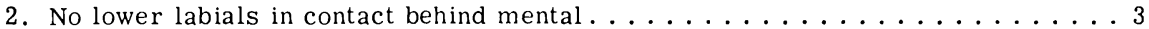
One pair of lower labials in contact behind mental . . . . . . . . . . . 10

3. An azygous chin shield between paired chin shields and mental . . . . . . . 4 No azygous chin shields, or an extremely tiny one ............. 


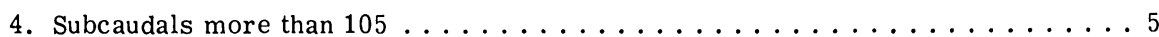

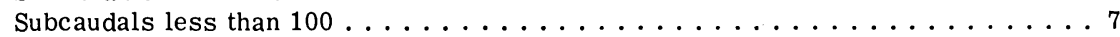

5. Centers of dorsal blotches in adults considerably lighter than outer parts

$(\mathrm{Pl} . \mathrm{VII} b) \ldots \ldots \ldots \ldots \ldots \ldots \ldots \ldots \ldots \ldots \ldots \ldots \ldots$ dimidiata dimidiata Dorsal blotches unicolor, not lighter toward centers (Pl. VII $a) \ldots \ldots \ldots \ldots \ldots$. . . . . .

6 . Ventrals 192 or less . . . . . . . . . . . . . . . . annulata

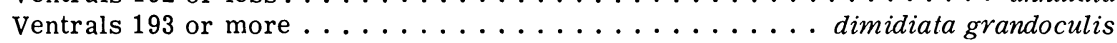

7. Dorsal pattern of a series of vertebral blotches, small and numerous . . . sanniola Dorsal pattern of large ocelli, which extend low on sides. . . . . . . longifrenis

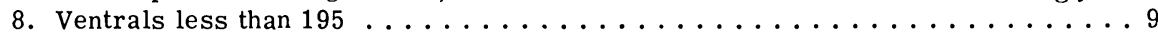
Ventrals more than 195, dorsal pattern of yellowish light-edged ocelli. . . . . argus

9. Extremely small pair of chin shields behind mental . . . . . . . . annulata First pair of chin shields larger than second pair ...........

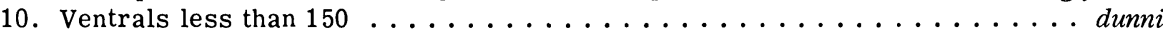

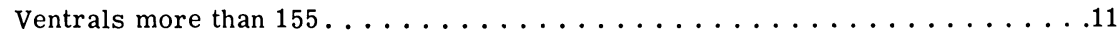

11. First dorsal blotches wide, well-marked (Pl. VIII $d-e) \ldots \ldots \ldots$ nebulata hartwegi First dorsal blotches not different from rest of body blotches . . . . . . . . 12

12. Dorsal pattern often obscured by heavy deposition of black pigment, belly heavily spotted with dark brown, or may be completely black (Pl. VIII $c$ ) . . . . . 13 Dorsal pattern of chocolate or reddish-brown blotches, contrasting strongly with the light-brown or grayish interblotch areas ........... nebulata nebulata

13. Ventrals less than 175 in both sexes, subcaudals less than 85 in males, less than

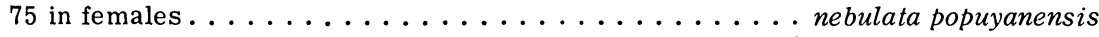
Ventrals more than 175 in both sexes, subcaudals more than 90 in males, more than 80 in females ............................... leucomelas

14. No primary temporal, fifth upper labial in contact with parietal . . . . . . . carri One primary temporal, no upper labial in contact with parietal. . . . . . anthracops

\section{THE ANNULATA GROUP}

\section{Sibon annulata Günther}

Leptognathus annulatus Günther, 1872: 30 . Leptognathus pictiventris Cope, 1876: 130.

S. [ibynomorphus] annulata, Barbour and Dunn, 1921: 158.

S. [ibynomorphus] pictiventris, Barbour and Dunn, 1921: 158.

S. [ibon] annulata, Dunn and Bailey, 1939: 9.

Dipsas annulata, Parker, 1926: 206 (by inf.); Taylor, 1951: 61.

HOLOTYPE. - BMNH 1871.11.22.14, "from the elevated country of Costa Rica, near Cartago."

RANGE. - Atlantic slopes of Costa Rica and Panamá (Map 11).

DESCRIPTION. - Rostral broader than deep, not visible from above; internasals half as long as prefrontals, which enter orbit; frontal longer than broad; nasal entire or semidivided; loreal enters orbit; preoculars none; postoculars 2; suboculars none; primary temporal 1; secondary temporals 2; tertiary temporals none; upper labials 7 or 8,4 th and 5 th or 5 th and 6 th enter orbit, 6th or 7th greatly enlarged and in contact with postocular, primary and secondary temporal. Lower labials 7 to 9 , no pairs in contact behind mental, 5th or 6th labial greatly enlarged and in contact with largest pair of chin shields; 2 to 4 pairs of chin shields, mental followed by a postmental or tiny pair of scales posterior to which are normal chin shields.

Ventrals 177-192 in males, (161) 168-186 in females; anal entire; subcaudals $118-124$ in males, 113-126 in females. Dorsal scale rows 15 


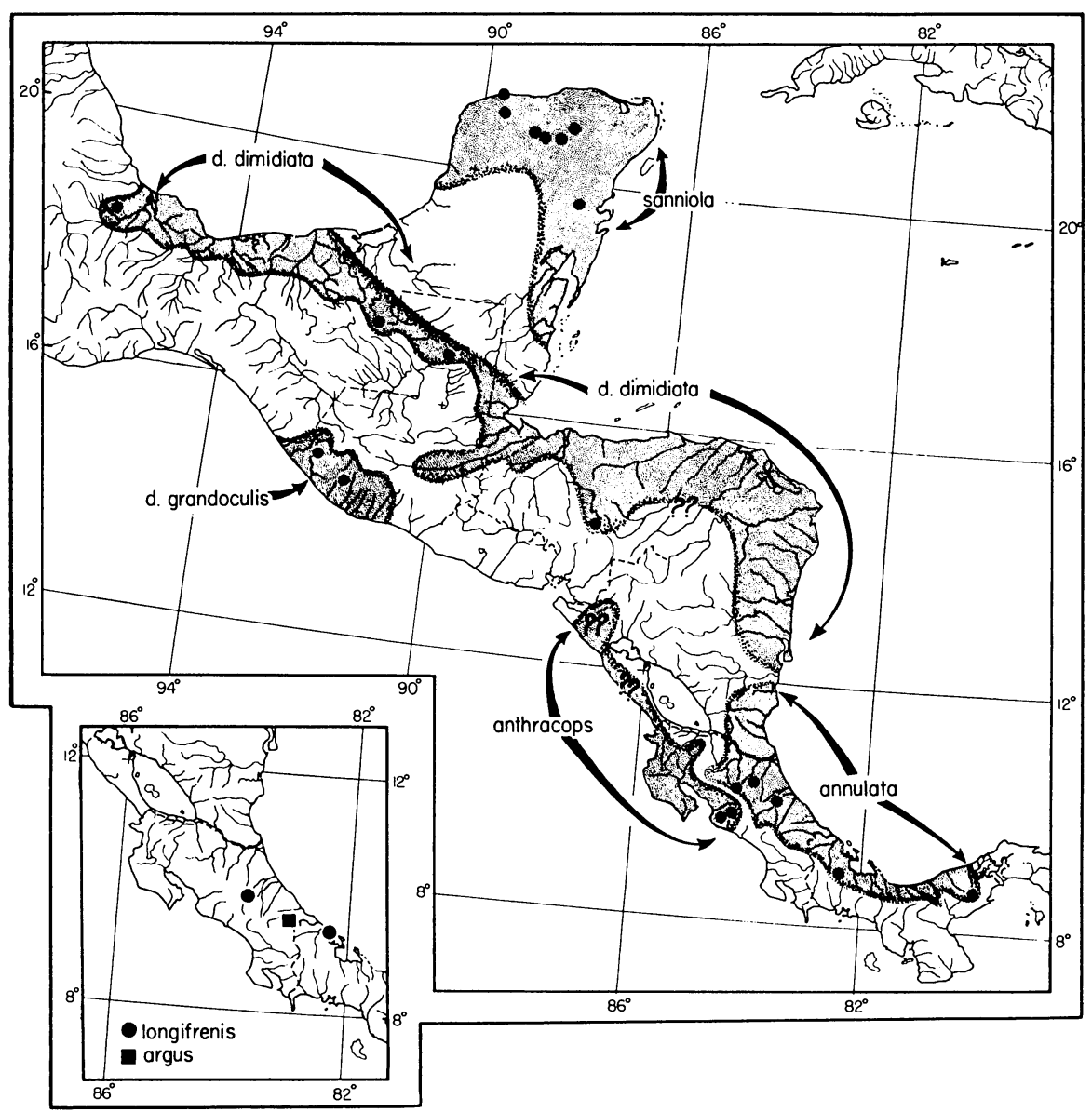

Map 11. Geographic distribution of the annulata and argus groups of Sibon.

throughout body, vertebral row scarcely to moderately enlarged, caudodorsals:

Males: $62+3(6-21) 41+2(44-71) 2(118-124)$

Females: $\underline{6} 2+3(6-7) \underline{4} 1+2(41-42) \underline{2}(113)$

Maxillary teeth 17; palatine teeth 11 (one individual).

Body length male $352 \mathrm{~mm}$., female $329 \mathrm{~mm}$., minimum $247 \mathrm{~mm}$. (no juveniles seen); tail length male $205 \mathrm{~mm}$., female $173 \mathrm{~mm}$., minimum 119 $\mathrm{mm}$.

Dorsal ground color of body brownish-cream (raspberry pink, Taylor, 1951:62), without spotting laterally, heavily stippled with darker brown dorsally; 26 to 35 reddish-brown dorsal annuli with irregular edges, darkbrown to black borders, somewhat lighter centers. Bands equal in length 
or slightly longer than interspaces; occasionally slightly widened laterally. Ventral ground color slightly yellowish, faint pinkish tinge in fresh specimen; ends of dorsal annuli narrow abruptly at first dorsal scale row; usually alternate along midventral line, occasionally directly in contact; that part of blotch on ventrals almost entirely dark brown to black, e.g., as border color. Tail colored as body with annuli much wider than interspaces dorsally, narrowed ventrally.

Dorsum of head light yellowish-brown, with large, irregular, often fused dark-brown spots on nape of neck, parietals, frontal, and prefrontals; poorly marked dark postocular bar to corner of mouth; dark bars on labials, one below eye and irregularly on other labials, which are predominantly yellowish. Chin yellow-white with scattered, dark-brown spots.

INDIVIDUAL VARIATION. - The upper labials are subject to somewhat more variation than is usual in this genus since, of the eight specimens for which data are available, only two have the usual 7-7 labial count, two have $7-8$, three have $8-8$, one has $8-9$, and one, the type of pictiventris, has 9-9. Cope counted only 8 labials in the type; the "suture" that is now present on the very elongate 7 th labial may have been the result of handling since Cope's time (see Remarks below). When 8 labials are present, the 5 th and 6th enter the orbit, and in the type of pictiventris (with 9) the 5th through 7th. Three specimens have the lower posterior corner of the loreal split off to form a subocular which does not enter the labial at all, a character duplicated in the type of annulata. Günther (1894:141; Pl. 49, Fig. C) shows the condition very clearly. An additional primary temporal on the right side of the head in the pictiventris type prevents the enlarged labial, which retains its contact with the upper primary temporal, from touching the secondary temporal. Divided secondary temporals are present in two other individuals.

The lower labials are 7-7 (two individuals), 7-8 (one, in addition to the holotype), 8-8 (two), 7-9 (one), and 9-9 (one). Three individuals, including both of the Panamanian specimens, have an undivided postmental; the other five have an extremely small pair of scales in place of it. Two individuals have 2 pairs of chin shields (both of them have postmentals, which eliminates the anteriormost pair), two others have 3 pairs, and four specimens have 4 pairs, as does the holotype.

The last ventral on the BMNH specimen examined is divided as in Type 2. AMNH 58819 has the 37-39th and the 55-56th pairs of subcaudals fused across the tail. All other specimens are uniform in the body and tail scalation.

Dunn sent me data concerning the holotype, which he has examined personally. He verified all of Günther's original counts. In addition, he reported that a specimen (a female) in the Cartago Museum, collected at Peralta, Costa Rica, has 161 ventrals, 90 subcaudals, 7 upper labials, and an azygous postmental. (This is an extremely low subcaudal count, due perhaps, to loss of a part of the tail.) Still another individual that he saw in the Costa Rica National Museum, from Siquirres, Costa Rica, has 175 ventrals and 7 upper labials; it resembles the type of pictiventris in that 3 labials, the 4 th, 5 th, and 6 th, enter the orbit.

REMARKS. - The condition of the type of pictiventris is so poor that 
complete confidence in my action in placing it as a synonym of annulata is unwarranted. All that remains of the specimen are two pieces, the head and 2 inches of the neck and the tail, and 2 inches of the body anterior to the anus; it is badly dried and shrunken; and the color pattern is completely gone, even that which Cope was able to describe. Boulenger $(1896 a: 459)$ placed the species near argus, probably as a result of Cope's statement in the type description that it belonged in the same group of Leptognathus as that species. Direct comparison of the types, both of which are in the United States National Museum, make it obvious that they are not the same. The similarities that exist in head scutellation merely reflect the uniformity of those scales throughout the genus. Synonymization of pictiventris with annulata, on the other hand, is justified on the basis of the characters that can be determined in the clastotype of pictiventris. The color, as far as described by Cope, is in agreement with that of specimens of annulata available to me; certain head scale aberrations of the same nature are found also in the type of annulata; and the head shape is the same. The mental scale of the clastotype is destroyed and with it apparently the first pair of labials; hence, it is difficult to say exactly what the condition of the postmental region is or was. It seemed clear, however, that either the first pair of labials were in contact, or that a tiny pair of chin shields occupied the area. When Cope examined the specimen, the mental apparently was still present; he called it wedge-shaped and stated that the elongate chin shields are in contact with it, emphasizing this character as a means of separating it fromargus. Actually, the mental is in contact with the first elongate chin shields in argus, however. Since Cope was trying to contrast his specimen with argus and as I am convinced from my examination that some sort of scale is (or was) present between the mental and the elongate chin shields of the clastotype, I feel certain that Cope was the victim of a typographical error, and that he originally wrote, "It differs [from argus] in the peculiarity that the front of the long genials is not in immediate contact with the wedge-shaped symphyseal." Since argus has the "genials" in contact with the "symphyseal," and Cope was contrasting pictiventris with it, it seems obvious that the all important "not" was lost in the type-setting. If this assumption is correct, then the last obstacle to synonymizing pictiventris with annulata is renoved, since the latter has the tiny pair of chin shields following the mental. This is one of the two probable conditions in the clastotype.

All in all, acceptance of the synonymy based upon the arguments presented above should prove satisfactory and practical. The species pictiventris has existed as incertae sedis since its inception and its proper allocation has been a thorn in the flesh of workers in Central American herpetology, who have been loath to discard it without justification. They have, however, continued to compare it only with argus, as Boulenger did; its transferal to an entirely different species will shed new light on the situation.

In the BMNH specimen examined the annuli are noticeably broadened laterally in a way that suggests the method of ocellus formation discussed in the remarks under longifrenis. The first few lateral scale rows are invaded by the ventral color, and this again is suggestive of the appearance 
of the lateral ocelli in longifrenis. The characters of this specimen are thus indicative of a direct relationship between the two species, and suggest that the argus group is derived from annulata or an annulata-like ancestor.

Considerable resemblance exists between annulata and the two subspecies of dimidiata. The primary difference in scutellation between them is the occurrence of a small pair of chin shields behind the mental in annulata, while in dimidiata the same area is occupied by an azygous postmental. Occasional individuals, however, of annulata from all parts of the range have the single postmental. The differences between annulata and dimidiata grandoculis are so minor that assignment of individuals with a single postmental is sometimes difficult. The similarities indicate a close relationship, and it is possible that annulata and dimidiata should be considered subspecies of a single species.

The name annulata, as used by Günther, is a secondary homonym in practically all of its many combinations of the annulatus of Linnaeus, now a Leptodeira. Cope used the generic name Dipsas for the species that are today considered to belong to Leptodeira. In addition, Cope has used the combination Sibon annulatum Linnaeus for specimens from Nicaragua, Peru, México, Costa Rica, and Brazil, never referring to specimens belonging to Sibon in the present sense. No previous author has seen fit to substitute a name for this secondary homonym, however, and as the International Rules require substitution only if the condition of homonymy still exists, it will not be necessary to change the name of this long recognized species.

SPECIMENS EXAMINED.-

COSTA RICA (AMNH 58819, 73235; USNM 30657, holotype of pictiventris), Cariblanco (MCZ 15307), Carillo (BMNH 1913.7.19.146), Isla Bonita, Volcan Poas, American Cinchona Plantation (KMNH 25702). PANAMÁ: La Loma Mts. (MCZ 19324), El Valle (HT 6337).

ADDITIONAL RECORDS. -

COSTA RICA: Peralta (Cartago Museum), Siquirres (National Museum of Costa Rica). (Both records ex Dunn, in litt.).

\section{Sibon anthracops Cope}

Leptognathus anthracops Cope, 1868: 136.

Tropidodipsas anthracops, Boulenger, 1894: 297.

Sibynomorphus ruthveni Barbour and Dunn, 1921: 158.

Sibynomorphus anthracops, Amaral, 1926a: 9 (by inf.); Amaral, 1929: 195.

Dipsas anthracops, Parker, 1926: 206 (by inf.); Dunn, 1942: 7.

HOLOTYPE. - ANSP 10135, female, from "Central America," collected by Robert Bridges (Pl. VII $c$ ).

RANGE. - Pacific Slope of Costa Rica and Nicaragua (Map 11).

DESCRIPTION. - Rostral broader than deep, visible from above; internasals slightly less than half to half as long as prefrontals, which enter the orbit; frontal longer than broad, considerably shorter than parietal; nasal divided; loreal enters orbit; preoculars none; postoculars 2; suboculars none; primary temporal 1; secondary temporals 2; tertiary temporals none; upper labials 7, 4th and 5th enter orbit, 6th greatly enlarged and in contact with postocular, primary and secondary temporal. Lower labials 
8 or 9 , first pair in contact behind mental, 5 labials in contact with first chin shield, 6th or 7th labial greatly enlarged, but fail to contact largest and most anterior chin shield; 3 pairs of chin shields.

Ventrals 184 in single male, 166-177 in females; anal entire; subcaudals 89 in male, 76-79 in females. Dorsal scale rows 13 throughout body, vertebral row not enlarged; caudodorsals:

$$
\begin{aligned}
& \text { Males: } \underline{6} 2+3(10-16) \underline{4} 1+2(52-54) \underline{2}(89) \\
& \text { Females: } \underline{6} 2+3(9-16) \underline{4} 1+2(48-66) \underline{2}(76-79)
\end{aligned}
$$

Maxillary teeth 14-15; palatine teeth 8-12, pterygoid teeth 16-18.

Body length male $325 \mathrm{~mm}$., female $371 \mathrm{~mm}$., no juveniles seen; tail length male $133 \mathrm{~mm}$., female $131 \mathrm{~mm}$.

Dorsal ground color yellowish-white, with 19-25 reddish-brown to brownish-black bands on body; interspaces horizontally streaked and dashed with band color, heaviest high on sides; bands two to three times as wide as interspaces anteriorly, about equal in width posteriorly; bands slightly narrowed on sides, abruptly narrowed on ventrals. Ventral ground color as dorsal; bands same color ventrally as dorsally, tend to angle across venter so that ends alternate; ventral ends of bands usually in contact anteriorly, separated posteriorly. Tail as in body, with 12-17 bands; considerably wider than interspaces, and continuous across ventral surface.

First dorsal band begins on occipital region, preceded by white collar which does not include parietals, but extends forward on sides of head below parietal to include all temporals, but not postoculars, and continues forward on labials below eye and loreal. Color of remainder of dorsum of head same as in dorsal bands, no mottling or spotting. Chin immaculate white, but mental, first labial, anterior end of first pair of chin shields and labials bordering it each have a small brown spot.

INDIVIDUAL VARIATION. - The head scales are uniform in the specimens examined. The scales on the lower jaw are somewhat variable, with four specimens having a labial count of 9-8, and one with 8-8; and three with 3 pairs of chin shields, one with 3 on the left and 2 on the right, and one with 4 on the left and 3 on the right. The 6 th lower labial is usually greatly enlarged, but in two specimens it is the 7th on one side.

The variation in color pattern from reddish-brown to almost blackbanded individuals is perhaps a matter of length of time in preservative, for the lighter colors seem to be associated with those preserved the longest time.

The dorsal scales seem to be rather uniform, with the exception of the type specimens. The type of anthracops has the following dorsal formula:

$$
\text { (5) } \underline{15} \frac{-3(7)}{-3(7)} \underline{13} \overline{+5(175)} \underline{14} \stackrel{+4(176)}{15} \text { (176) }
$$

The type of ruthveni has the following dorsal formula: 


$$
\begin{gathered}
\frac{15}{2+3(5)} \frac{13}{2+3(6)} \frac{6-7(76)}{6-7(78)} \frac{15}{\mathrm{~V}+7(104)} 14 \frac{\mathrm{V}-7(114)}{15} \frac{6+7(116)}{6+7(118)} \underline{13} \\
\underline{13} \frac{+3(165)}{+3(165)} \underline{15}(166)
\end{gathered}
$$

Neither of these formulae is a great departure from normal. All of the variation in the type of anthracops takes place only a few scales anterior to the anus, a region often subject to change due to the narrowing of the body. The irregular return to 15 dorsal scale rows for a distance of 40 ventrals on the type of ruthveni is somewhat more unusual.

Both type specimens show caudodorsal irregularities, and again they are the only specimens which differ from the normal condition. The type of anthracops has the following formula:

$$
\text { (6) } \underline{6} \frac{2+3(16)}{2+3(16)} \underline{4} 2+2(63) \underline{3} \frac{\mathrm{V}+1(65)}{\mathrm{V}+1(66)} \underline{1} \mathrm{~V}=\frac{1}{1}(70,76) \underline{2}(76)
$$

The type of ruthveni has a pattern similar to this, but lacks the reduction to a single scale row dorsally. The fusion of the lateral rows with the vertebral row at the level of the 65-66 caudals, so as to leave only a single scale above and a pair of subcaudals below on the tail, is unique for the subfamily.

REMARKS. - Sibynomorphus ruthveni was compared by the original authors with all the species known from Costa Rica at the time of its description. At that time anthracops had not yet been taken there, and the species was known only from several very vague localities. As soon as specimens from Costa Rica with accurate locality data were available to Dunn (1942:7), he synonymized ruthveni with anthracops. I have examined the type of ruthveni; it agrees quite closely in most respects with anthracops. Its only unique character is the irregular increase to 15 scale rows on a part of the body, but this is insufficient evidence of a specific difference, in view of its many similarities.

SPECIMENS EXAMINED.-

CENTRAL AMERICA: no additional data (ANSP 10135, type of anthracops), "West Coast" (USNM 32219). COSTA RICA: Aguacate Mountains (MCZ 15549, type of ruthveni), San Antonio de Belen (MCZ 32042). NICARAGUA: (USNM 16123, 25247).

ADDITIONAL RECORD. -

COSTA RICA: Barranca (National Museum of Costa Rica - ex Dunn, in litt.).

\section{Sibon dimidiata dimidiata Günther}

Leptognathus dimidiatus Günther, 1872: 31 .

Petalognathus multifasciatus Jan, in Bocourt, 1884: 139.

Mesopeltis multifasciatus, Cope, 1887b: 67.

Mesopeltis dimidiatus, Stejneger, 1909: 457.

Sibynomorphus dimidiatus, Amaral, 1926a: 9 (by inf.); Amaral, 1929: 196.

Sibon sibon, Stuart, 1935: 52.

Sibon dimidiatus, H. M. Smith, 1943: 470.

Dipsas dimidiatus, Parker, 1926: 206 (by inf.) Smith and Taylor, 1945: 50. 
HOLOTYPE. - BMNH, female, from México.

RANGE. - Atlantic coast of Central America from Veracruz to Nicaragua, excluding the Yucatán Peninsula (Map 11).

DESCRIPTION. - Rostral slightly broader than deep or as deep as broad, just visible from above; internasals less than half the length of prefrontals; frontal longer than broad, much shorter than parietal; nasal entire or semidivided; loreal enters orbit; preoculars none; postoculars 2; suboculars none; primary temporal 1 ; secondary temporals 2 ; tertiary temporals none; upper labials 7 or 8,5 th and 6 th enter orbit, first labial posterior to those entering orbit greatly enlarged and in contact with postoculars, primary and secondary temporals. Lower labials 9 or 10, no pairs in contact behind mental, five pairs in contact with first paired chin shield, 6th or 7th lower labial two or three times larger than others; mental followed by a postmental and 3 or 4 pairs of chin shields.

Ventrals 186-199 in males, 179-187 in females; anal entire; subcaudals 113-126 in males, 106-111 in females (98 in type). Dorsal scale rows 15 throughout length of body; vertebral row not enlarged anteriorly, increases to scarcely enlarged on posterior portion of body; caudodorsals:

Males: $62+3(8-36) 41+2(41-100) 2(113-126)$

Females: $\underline{6} 2+3(15-\overline{2} 4) \underline{4} 1+2(72-9 \overline{2}) \underline{2}(106-111)$

Maxillary teeth 14-17 (4 individuals); palatine teeth 11-13 (4); pterygoid teeth 15-20 (3).

Body length male $444 \mathrm{~mm}$., female $326 \mathrm{~mm}$., minimum $126 \mathrm{~mm}$.; tail length male $216 \mathrm{~mm}$., female $141 \mathrm{~mm}$., minimum $53 \mathrm{~mm}$.

Dorsal ground color dull rust to olive-brown, with light brown-centered, dark-brown to black-bordered dorsal blotches, central color lighter than interspaces, blotches slightly constricted both dorsally and ventrolaterally, wider than interspaces, occasionally alternating at vertebral line, 23 to 31 on body, 13 to 26 on tail; interspaces spotted, mottled, or occasionally lineolate with black and cream, dorsal ground color usually restricted to upper part of sides, lower parts invaded by ventral color, contact may be along sharply marked line or through gradual change (Pl. VII $b$ ). Ventral color dull cream to light brown, narrowed dorsal blotches extend in border color almost to midventer, but do not quite come in contact with opposite blotch. Interspaces wider than blotches, may be immaculate or lightly dusted with brown spots.

Dorsum of head dark brown with light brown or whitish vermiculations to labials, which are for most part cream to white with occasional brown bars on sutures. Chin uniform cream to white, meagerly spotted with light brown, a large brown spot centered at end of paired chin shields.

Juvenile coloration distinct from adult, in that dorsal blotches are unicolor black on a white ground color spotted and lined with black. Head color as in adult, except that white vermiculations occupy as great an area as does blackish brown color. Two half grown adults (AMNH 67890 and CNHM 34718) have brown rather than black blotches but the centers of the blotches have not begun to lighten. Smith $(1943: 470)$ has described the juvenile coloration from living specimens as follows: "All light areas of 
head dark orange (burnt sienna); lower sides of head white, dorsal areas of light body bands dark orange; these areas not so broad anteriorly (2 scales), broader posteriorly ( 5 to 7 scales); sides of light bands, belly and tail pure white."

INDIVIDUAL VARIATION (Table XVI). - The loreal, ocular, and temporal regions are all extremely uniform. Two juveniles of 15 specimens possess preoculars, one with 1-1 and one with 2-2; in both the loreal is excluded from the orbit. Three other specimens from the same locality as the two juveniles are normal in these characters. The postoculars are other than two in only one specimen: in MCZ 38666 they are fused into a single scale; in addition, in AMNH 70227 the lower postocular on the right is partly fused with the 5th labial. Suboculars are present in MCZ 53882, in which they are split off the lower corner of the loreal, and on one side of MCZ 38744. The primary temporals are 1-1 in all specimens examined; the secondary temporals are 2-2 in twelve specimens, with vertical splitting of a single temporal in two individuals and horizontal division to make 3 in one specimen. The frontal is partly sutured in two specimens, in one laterally, extending toward center, in the other, along median line.

TABLE XVI

INDIVIDUAL VARIATION IN Sibon dimidiata dimidiata

\begin{tabular}{|c|c|c|c|c|c|c|}
\hline \multicolumn{2}{|c|}{ Upper Labials } & \multicolumn{2}{|c|}{ Lower Labials } & \multicolumn{3}{|c|}{ Teeth } \\
\hline $\begin{array}{c}\text { Total } \\
\text { Number }\end{array}$ & $\begin{array}{c}\text { Entering } \\
\text { Orbit* }\end{array}$ & $\begin{array}{c}\text { Total } \\
\text { Number }\end{array}$ & $\begin{array}{c}\text { Touching } \\
\text { First } \\
\text { Chin Shield* }\end{array}$ & Maxillary & Palatine & Pterygoid \\
\hline $7-7(2)$ & $4-5(6)$ & $8-8(1)$ & $4(4)$ & $14(1)$ & $11(1)$ & $15(1)$ \\
\hline $7-8(2)$ & $5-6(20)$ & $8-9(1)$ & $5(24)$ & $17(2)$ & $12(1)$ & $18(1)$ \\
\hline $8-8(8)$ & $6-7(1)$ & $9-9(6)$ & & $18(1)$ & $13(2)$ & $20(1)$ \\
\hline $8-9(1)$ & & $9-10(2)$ & & & & \\
\hline & & $10-10(3)$ & & & & \\
\hline & & $11-11(1)$ & & & & \\
\hline
\end{tabular}

*Single sides.

Although the dorsal scale rows are 15 in all specimens, and the vertebral row not to scarcely enlarged, two have the paravertebral rows slightly larger than the vertebral. No divided ventrals were observed, but one individual (AMNH 70227) has subcaudals 109-111 fused across the tail.

SEXUAL DIMORPHISM. - It is obvious from the observed data that the sexes differ in both ventral and caudal count. Only one male has a lower ventral count than that of the highest in females, and there is no overlap in subcaudal counts.

GEOGRAPHIC VARIATION. - The wide range given for point of reduction (from 4 to 2 scales) on the tail in males has, perhaps, a geographical correlation, since the specimens from Guatemala have the reduction between subcaudals 55-74 (three individuals), and those from Honduras and Nicaragua have it between subcaudals 83-99 (three individuals). The reduction in the single specimen from Veracruz, a male, is at subcaudals 86 and 96 , however. 
REMARKS. - Petalognathus multifasciatus Jan was first described by Bocourt, who stated in a footnote that the name was applied by Jan in a manuscript at the Paris Museum. The type locality was "Vera-Paz (Guatemala)." Although Bocourt referred to three figures of the species in his description, there were no plates in the volume that was available to me. The two cotypes are not distinct in any way from the specimens described above, and the species is clearly untenable. That both of the cotypes are juveniles is clear from Bocourt's description of their coloration.

I was able to study the specimen from Nicaragua that was referred to dimidiata by Günther (1885-1902 [1894]:143) and by Boulenger (1896a:459). Since both authors had compared it with the type, I have followed their usage of that name for those specimens examined that agree with it satisfactorily. The unsatisfactory provenance of the type, a purchased specimen from "Mexico," and certain statements in the original description cast some doubt upon the proper assignment of the material I have examined. I have seen no individuals with less than 106 subcaudals (there are 98 in the type), and the type is unique in possessing narrow black transverse lines in the interspaces. It has a pair of large whitish spots on the neck which form a kind of collar; and this is duplicated only in AMNH 67890 from Veracruz. The Nicaraguan specimen, although smaller than the type $(271 \mathrm{~mm}$. to $305 \mathrm{~mm}$.), has an intermediate color pattern, while the type still retains the black blotches. It seems possible that additional collections from the east coast of México may demonstrate that the name dimidiata is assignable to a Veracruzian population. If this can be shown, then the southern segment of the subspecies described here should be known as dimidiata multifasciata.

\section{SPECIMENS EXAMINED. -}

GUATE MAla: Department unknown; Río San Pedro (MCZ 38592). Petén (MCZ 38666); La Libertad (UMMZ 74895-96), Piedras Negras (UIMNH 18753; USNM 109903-6). HONDURAS: Montanita (AMNH 70227), Portillo Grande (CNHM 34718, MCZ 38744). MEXICO: Chiapas; Laguna Ocotal (MCZ 53832). Veracruz; Naranjos (AMNH 67890). NICARAGUA: Hacienda Rosa de Jericho (BMNH 1894.7.26.45).

\section{Sibon dimidiata grandoculis Müller}

Leptognathus species, Müller, 1878: 612, 684.

Leplognathus (Asthenognathus) grandoculis Müller, 1890: 271.

Leplognathus dimidiata (part), Boulenger, 1896a: 459.

Dipsas dimidiala (part), Smith and Taylor, 1945: 50.

HOLOTYPE. - Basle Museum, sex not given, from Mazatenango, Guatemala, collected by G. Bernoulli.

RANGE. - Known only from the Pacific slope of Guatemala (Map 11).

DESCRIPTION. - Rostral somewhat broader than deep, visible from above; internasals less than half length of prefrontals; frontal longer than broad, considerably shorter than parietal; nasal semidivided; loreal enters orbit; preoculars none; postoculars 2; suboculars none; primary temporal 1 ; secondary temporals 2 ; tertiary temporals none; upper labials 7 or 8 , 4th to 7th may enter orbit (see below), 6th or 7th greatly enlarged and in contact with postocular, primary and secondary temporals. Lower labials 
7,8 , or 9 , no pairs in contact behind mental, five pairs in contact with first pair of chin shields, sixth pair enlarged; mental followed by a postmental and 3 pairs of chin shields.

Ventrals 193-197; anal entire; subcaudals (115-)-126. Dorsal scale rows 15 on body; vertebral row not to scarcely enlarged; caudodorsals (for single specimen for which they are known);

$$
\text { Male: } \underline{6} 2+3(26-27) \underline{4} 1+2(99-100) \underline{2}(115+)
$$

Maxillary teeth 13 (1 individual); palatine teeth 9 (1); pterygoid teeth 17 (1).

Body length of specimen seen $425 \mathrm{~mm}$., tail length $196+$.

Coloration and pattern as in dimidiata dimidiata, except as follows: 29-30 blotches on body, 19-21 on tail, which do not have centers that are lighter in color than interspaces, but are entirely unicolor, and are quite dark (Pl. VII $a$ ). Juvenile coloration unknown.

INDIVIDUAL VARIATION. - The most unusual variation in the two specimens known is that in CNHM 20351, which has 2 unpaired shields following the mental, rather than a single one as in the type of grandocu$l i s$ and all specimens of $d$. dimidiata. The edges of the first are flush with the edges of the first pair of labials, and those of the second with the second pair of labials.

Both available specimens have 7-8 upper labials. In the type the enlarged upper labial has apparently crowded the lower postocular upward, and enters the orbit below it, so that labials 4 to 6 are in the orbit on one side, and 4 to 7 on the other. This situation, similar to that in some specimens of longifrenis and argus, is not repeated in the other specimen, however, in which labials 4 and 5 on one side and 5 and 6 on the other enter the orbit. The type has 7-8 lower labials, CNHM 20351 has 9-8, and only 4 labials contact the first chin shield on the left side on the type.

The 11th ventral on CNHM 20351 is divided as in Type 1.

REMARKS. - The use of the name grandoculis as a subspecies of $d i$ midiata is based upon the difference in coloration of the centers of the dorsal blotches (Pl. VII $a-b$ ). Fortunately, the single specimen of grandoculis available is practically a topotype; hence, it may be assumed that the unicolor blotch is common to other specimens from the area. It is not known if the type has a unicolor blotch or not, but the presumption is that it has. The somewhat negative evidence offered by Müller's original description (1890), coupled with his earlier description (1878) of the same specimen, is sufficiently detailed to lead one to conclude that he would have mentioned coloration of the blotches had they been other than unicolor.

The entrance of the enlarged labial into the orbit in the type of this subspecies is unique among individuals of the species dimidiata, and the presence of two single chin shields in tandem behind the mental is unique for the genus Sibon. If either character is repeated in other specimens from the western coast of Guatemala, it would constitute additional verification of the validity of this race or of the desirability of raising it to specific status. 
Müller did not state the sex of his type, but I assume it to be a male. If so, the variations in the female are unknown, since the specimen I have seen is also a male.

Müller mentioned in his earlier description (1878:685) that apical pits are irregularly present but he did not repeat this in his type description of grandoculis. Throughout this study, apical pits have been observed in only one or two other dipsadines.

SPECIMENS EXAMINED.-

GUATEMALA: San Marcos; El Porvenir (CNHM 20351).

ADDITIONAL RECORDS. -

GUATEMALA: Mazatenango (Basle Museum, type).

\section{Sibon sanniola Cope}

Mesopeltis sanniolus Cope, $1866 b$ : 318.

Leplognathus sanniola, Boulenger, 1896a: 459.

Sibynomorphus sanniolus, Amaral, 1926a: 9 (by inf.); Amaral, 1929: 199.

Sibon sanniolus, H. M. Smith, 1943: 470.

Dipsas sanniolus, Parker, 1926: 206 (by inf.), Smith and Taylor, 1945: 51.

HOLOTYPE. - USNM 6564, male, from Yucatán. 11).

RANGE. - Northern and eastern parts of the Yucatán Peninsula (Map

DESCRIPTION. - Rostral broader than deep; internasals half the length of prefrontals; frontal much longer than broad; nasal divided; loreal does not enter orbit; preoculars 2 or 3 ; postoculars 2 ; primary temporal 1; secondary temporals 2 , tertiary temporals none; upper labials 8,9 , or 10 , 4 th, 5th, and 6 th enter orbit, 1st labial posterior to those in the orbit enlarged, seldom in contact with lower postocular, primary and secondary temporals. Lower labials 9 or 10, none in contact behind mental, 4 or 5 in contact with first pair of chin shields and followed by much enlarged labial, usually two to three times size of its neighbors; mental followed by single postmental and 3 pairs of chin shields, posterior ends of the third pair usually separated by an azygous genial.

Ventrals 143-158 in males, 148-170 in females (see remarks below); anal entire; subcaudals 65-81 in males, 59-79 in females. Dorsal scale rows 15 from 4th, 5 th or 6 th ventral to anus; vertebral row not enlarged; caudodorsals:

Males: $62+3(13-29) 441+2(40-66) 2(65-81)$

Females: $\underline{6} 2+3(8-18 \overline{)} \underline{4} 1+2(33-58) \underline{2}(59-79)$

Maxillary teeth $12-15$ (17 individuals); palatine teeth 7-11 (17); pterygoid teeth 15-22 (16).

Body length male $295 \mathrm{~mm}$., female $279 \mathrm{~mm}$., minimum $109 \mathrm{~mm}$.; tail length male $119 \mathrm{~mm}$., female $88 \mathrm{~mm}$., minimum $32 \mathrm{~mm}$.

Dorsal ground color light brown, single middorsal row of small darker brown, somewhat light-centered spots, 40-62 in males, 35-67 in females, confined to vertebral and paravertebral rows, occasionally to upper edge of 5 th or 6 th rows; spots often joined anteroposteriorly in zigzag fashion; 
often one or two less distinct rows of lighter brown spots on scale rows 4-5 and 1-2, with latter usually partly on ends of ventrals. All dorsal scales spotted or stippled with dark brown to some extent. Dorsum of tail as body, with 17-32 dark-brown spots.

Belly light cream, with heavy stippling and spotting along ends of ventrals, decreasing toward center, often sufficiently concentrated along margins to form irregular, broken stripe on either side; stripes do not extend onto tail, which is simply spotted irregularly with dark brown.

Nuchal spot differentiated into larger blotch, extending forward along inner margins of parietals to frontal and usually downward around posterior margin of head to tips of ventrals. All head scales stippled with dark brown, heavier along sutures; often a postocular bar to posterior supralabials. Chin often immaculate, usually with dark-brown stippling.

Juveniles as in adults described above, except that ground color is often gray, with spots almost black.

INDIVIDUAL VARIATION. (Table XVII). - The temporals are constant, with only 17 percent of the individuals possessing other than a single primary temporal on either side, and only 7 percent having other than 2 secondary temporals per side. The preoculars, on the other hand, are quite irregular, although 2 is obviously the normal number, since 86 percent

TABLE XVII

INDIVIDUAL VARIATION IN Sibon sanniola

\begin{tabular}{|c|c|c|c|c|c|c|c|c|c|}
\hline \multicolumn{2}{|c|}{ Upper Labials } & \multicolumn{2}{|c|}{ Lower Labials } & \multirow[b]{2}{*}{$\begin{array}{c}\text { Pre- } \\
\text { Oculars }\end{array}$} & \multicolumn{2}{|c|}{ Temporals } & \multicolumn{3}{|c|}{ Teeth } \\
\hline $\begin{array}{c}\text { Total } \\
\text { Number }\end{array}$ & $\begin{array}{c}\text { Entering } \\
\text { Orbit* }\end{array}$ & $\begin{array}{c}\text { Total } \\
\text { Number }\end{array}$ & $\begin{array}{c}\text { Touching } \\
\text { First } \\
\text { Chin Shield }\end{array}$ & & $\begin{array}{l}\text { Pri- } \\
\text { mary }\end{array}$ & $\begin{array}{c}\text { Second- } \\
\text { ary }\end{array}$ & $\begin{array}{l}\text { Max- } \\
\text { illary }\end{array}$ & $\begin{array}{l}\text { Pal- } \\
\text { atine }\end{array}$ & $\begin{array}{c}\text { Ptery - } \\
\text { goid }\end{array}$ \\
\hline $8-8 \quad(4)$ & $3,4,5 \quad(4)$ & $8-8 \quad(2)$ & $3-3 \quad(1)$ & $0-1 \quad(1)$ & $1-1(50)$ & $1-2 \quad(1)$ & $12(3)$ & $7(1)$ & $15(3)$ \\
\hline $8-9 \quad(7)$ & $3,4,5,6 \quad(2)$ & $8-10 \quad(1)$ & $3-4 \quad(2)$ & $0-2 \quad(2)$ & $1-2 \quad(7)$ & $2-2(45)$ & $13(5)$ & $8(7)$ & $17(3)$ \\
\hline $9-9 \quad(39)$ & $4,5 \quad(8)$ & $9-9 \quad(12)$ & $3-5 \quad(1)$ & $1-1 \quad(4)$ & $2-2 \quad(3)$ & $2-3 \quad(2)$ & $14(8)$ & $9(7)$ & $18(4)$ \\
\hline $9-10 \quad(6)$ & $4,5,6(95)$ & $9-10(14)$ & $4-4(17)$ & $1-2 \quad(8)$ & & $3-3 \quad(1)$ & $15(1)$ & $10(1)$ & $19(4)$ \\
\hline \multirow[t]{4}{*}{$10-10$} & $4,5,6,7 \quad(4)$ & $10-10(24)$ & $4-5 \quad(9)$ & $2-2(30)$ & & & & $11(1)$ & $22(1)$ \\
\hline & $5,6 \quad(2)$ & $11-11$ & $4-6 \quad(1)$ & $2-3 \quad(9)$ & & & & & \\
\hline & $5,6,7 \quad(1)$ & & $5-5(22)$ & $3-3 \quad(4)$ & & & & & \\
\hline & $6-7 \quad(2)$ & & $5-6 \quad(2)$ & & & & & & \\
\hline
\end{tabular}

*Single sides.

have 2 on at least one side. Suboculars are present in twelve of 60 individuals. The postoculars are other than 2 in seven of the sixty, all except one of which have 3 on one side, 2 on the other. The exception (CNHM 36263) has the upper postocular on the left side fused with the supraocular, and the 2 postoculars on the right side fused into a single scale.

The labials which may enter the orbit include the $3 \mathrm{~d}$ through 7 th. This range seems large when compared with a variation of only 8-10 for the upper labials, but it is explained by the fact that most of the variation in number takes place anterior to the eye. In only five of 57 individuals are there other than 3 labials posterior to the last one entering the orbit. In only 17 of 118 counts (based on the 2 counts to each animal) are there other than 3 labials in the orbit. Fusion and division of labials is most often observed in those scales anterior to the first in the orbit. In three of the four 
instances that the 4th labial is excluded from the orbit its place is taken by a subocular below the preoculars. In five specimens the 1st labial behind those in the orbit is in contact with the postoculars, primary and secondary temporals. Three specimens have the $2 \mathrm{~d}$ and 4 th upper labials in contact above the $3 \mathrm{~d}$, two on one side only.

The loreal enters the orbit in twelve individuals. It is partly fused with the nasal in one specimen and partly fused with the lower preocular in another. A small scale, split off from the loreal's upper edge, extends from the nasal to the preocular in UMMZ 68707.

Divided ventrals occur in five specimens; division in three is Type 1, in one is Type 2, and in one is Type 3; ventrals involved are the $2 \mathrm{~d}, 5$ th, 6 th, 7 th and last. The umbilical scar is on ventrals 120-122 in one specimen, on 121-123 in another. Undivided subcaudals were observed in only one specimen, CNHM 36287, in which the second and third pairs were fused across the tail.

SEXUAL DIMORPHISM. - The most conspicuous differences between the sexes are in the total number of subcaudal scales and the point where reduction from 6 to 4 scale rows on the tail takes place. Furthermore, there is a direct correlation between these two characters (Fig. 7). The females have a lower subcaudal count, and a more anterior reduction in caudodorsals. There is no apparent sexual difference in number of ventral scales.

REMARKS. - Enough has been said above concerning the variations in this species to demonstrate that the particular specimens discussed by Cole and Barbour (1906:151) were not as peculiar as they believed. They suggested that the low caudal count for the type, which was given as 55 by Cope, was possibly due to a broken tail, and I have verified this by examination of the type. Andrews $(1937: 356)$ listed sanniola as endemic to the Yucatecan Biotic Province. I have been unable to duplicate the dorsal count given by Schmidt and Andrews (1936:175) for CNHM 20609 as 13-1513. I found the specimen to have a constant count of 15 from the fourth ventral to the anal plate.

\section{SPECIMENS EXAMINED.-}

MEXICO: Quintana Roo: Felipe Carillo Puerto (IPM). Yucalán (USMN 24888); ChichénItzá (AMNH 73236; CNHM 20609, 20613, 26988, 36257-58, 36268, 36272, 36276, 36285, 36287, 36289, 36296; LMK 41132, MCZ 7241, 7246 [2], 26842; USNM 46568; UMMZ 68707, 73031-32, 83294, 83932), Kantunil (CNHM 36264, 26270, 362?6, 33288), Libre Unıón (CNHM 36259, 36262, 36266, 36273, 36278, 36280-83, 36290, 36294-95), Mérida (CNHM 19424), Progreso (CNHM 40734-35), Yokdzonot (CNHM 36261, 36263, 36265, 36267, 36269, 36271, 36274-75, 36277, $36279,36284,36291-93,36297)$.

\section{THE ARGUS GROUP}

\section{Sibon argus Cope}

Leptognathus argus Cope, 1876: 130.

S. [ibynomorphus| argus, Barbour and Dunn, 1921: 158.

Dipsas argus, Parker, 1926: 206 (by inf.); Taylor, 1951: 60.

HOLOTYPE. - USNM 30656, male, from Sipurio, Costa Rica, collected by Dr. Wm. Gabb. 


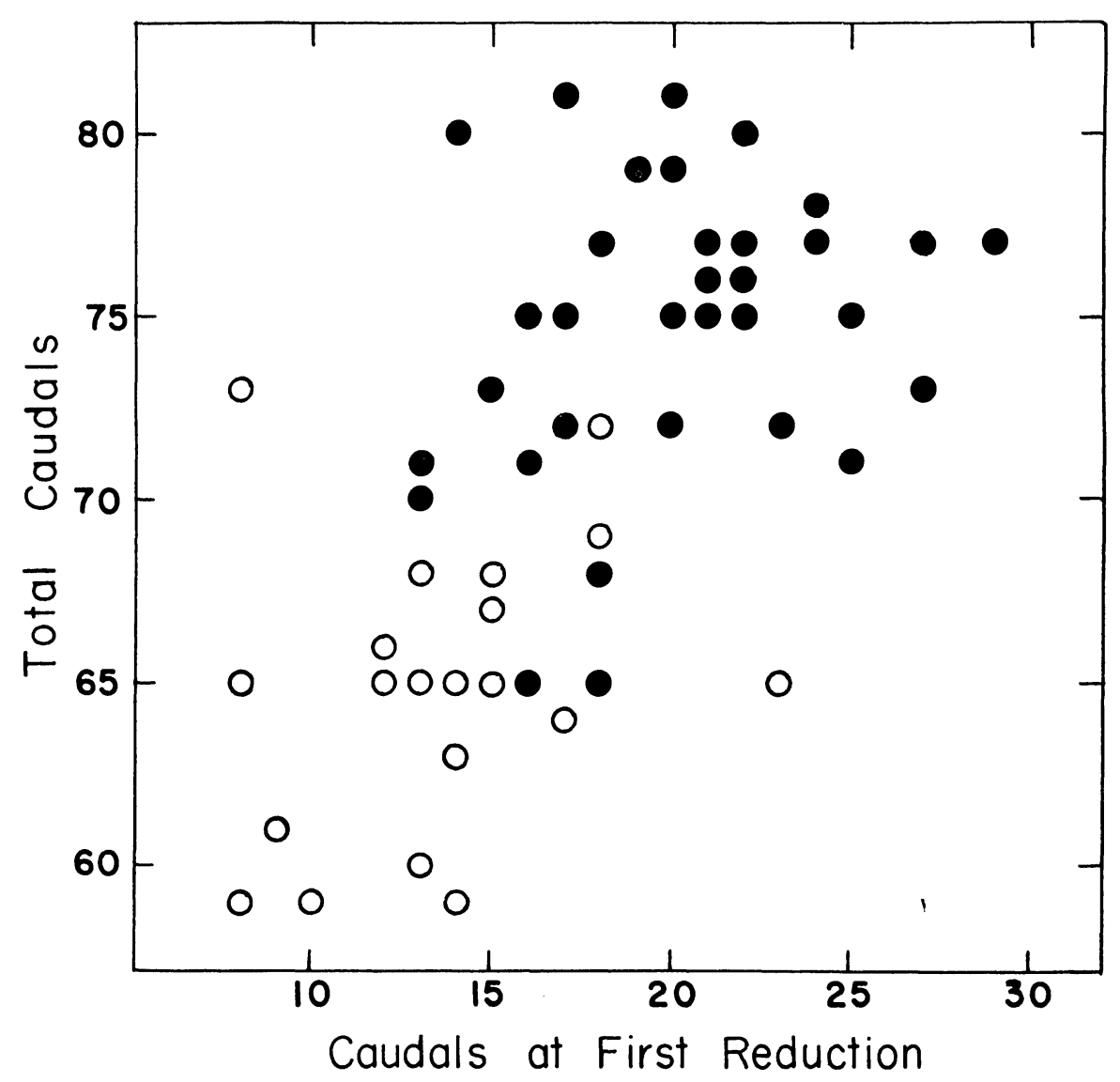

Fig. 7. Sexual dimorphism in number of subcaudals and point of reduction of caudodorsal scale rows from 3 to 4 in Sibon samiola. Circles refer to females, spots to males.

RANGE. - Known only from the type locality (Map 11).

DESCRIPTION. - Rostral as broad as deep, triangular, not visible from above; internasals less than one-half the length of prefrontals, which are quite large; frontal longer than broad; nasal appears divided; loreal enters orbit; preoculars none; postoculars 2; suboculars none; primary temporal 1 ; secondary temporals 2; tertiary temporals none; upper labials 7 , 4th to 6 th enter orbit; 6 th labial enters orbit, dips below the lower postocular, forming tiny fold, then enlarges to contact primary and secondary temporals. Lower labials 7, no pairs in contact behind mental, four pairs in contact with first paired chin shield, 5th labial elongated but not broadened, its inner edge even with that of other labials; mental followed directly by 3 pairs of chin shields, contact extremely narrow, with first pair of labials almost in contact; one unpaired gular between chin shield and mental.

Ventrals 201; anal entire; caudals 121. Dorsal scale-row formula: 
(3) $\underline{15}(201)$

Vertebral row not enlarged; caudodorsals:

$$
\underline{6} \frac{2+3(21)}{2+3(19)} \underline{4} \frac{1+2(?)}{1+2(?)} \underline{2}
$$

Body length of male holotype $248 \mathrm{~mm}$; tail length $98 \mathrm{~mm}$.

Dorsal ground color greenish-gray, with paravertebral series of light dark-bordered ocelli, usually alternating at vertebral line, and lateral series of yellowish, black-bordered ocelli on first three dorsal rows; those of lateral series more abundant than paravertebral, with one directly below each paravertebral ocellus and one between each such pair. Ventral color cream with much brown mottling which gives zigzag effect along margin and is correlated witl. :dges of lateral ocelli; dark-brown or blackish mottling heavier on posterior portion of body and on tail. Tail coloration entirely as body.

Dorsum of head heavily vermiculated with black and light areas; upper labials yellowish with dark spotting. Chin white with few dark spots.

INDIVIDUAL VARIATION. - The type, still unique, shows no bilateral asymmetry in scutellation.

REMARKS. - Although the similarities which exist between this species and longifrenis and its synonym, costaricensis, are striking, so also are the dissimilarities. The two species (argus and longifrenis) are the only ocellate forms in the genus, the scutellation of the head is identical in arrangement, if not in shape, including the unusual size of the 6th upper labial, which enters the orbit, and contacts the postocular, primary and secondary temporals. The postmental is absent in the type of costaricensis, and it is tiny in the type of longifrenis. The three localities from which the two species are known are all on the Costa Rica-Panamá border on the Atlantic Slope. The two specimens of longifrenis are females, the type of argus is a male, but the differences seem to be too great to charge to sexual dimorphism. While the subcaudals differ by only 23 scales, and the male has the higher count, the ventral counts are separated by 36 scales, a difference not equalled by the extremes of any other sexually dimorphic species in the group. The type of argus is extremely elongate and attenuate, its head is short and abruptly broader than the body, the snout is very short and abruptly rounded. The specimens of longifrenis have full, moderately compressed bodies, with the head gradually narrowing into a comparatively thick neck. On the basis of the material available, it is inconceivable that they can be considered as a single species, and they have, therefore, been treated as distinct entities here. Data on additional males are imperatively needed to determine the normality or aberrancy of the type of argus.

It is possible that argus actually more closely related to the genus Dipsas than to Sibon, and that the condition of the enlarged labial is an anomaly. The species has a pattern strongly reminiscent of that of Dipsas indica, in which there are brown bands with sloping sides and light spots at the ends of the ventrals, at the point of junction between adjoining 
bands. In argus this condition is extended by fusion of the bands dorsal to the spots. The head shape, body proportions, and head pattern are quite similar in both species. The enlarged vertebral row of scales and the crowding of the labials seen in indica and other dipsadine species are not repeated in argus. It has not been practical to examine the pterygoids or the temporal musculature of the unique specimen; hence any clues to relationships that they might furnish must await collection of added material.

SPECIMENS EXAMINED.-

COSTA RICA: Sipurio (USNM 30656, holotype).

\section{Sibon longifrenis Stejneger}

Mesopeltis longifrenis Stejneger, 1909: 457.

Leplognathus longifrenis, Werner, 1909a: 285.

Sibynomorphus longifrenis, Amaral, 1926a: 9 (by inf.); Amaral, 1929: 198.

Dipsas longifrenis, Parker, 1926: 206 (by inf.)

Dipsas coslaricensis Taylor, 1951: 63.

HOLOTYPE. - USNM 38750, female, Bocas del Toro, Panamá, collected by Frank E. Read.

RANGE. - Known from a single locality in both Panamá and Costa Rica; Atlantic Slope (Map 11).

DESCRIPTION. - Rostral as deep as broad, scarcely visible from above; internasals less than half the length of prefrontals; frontal longer than broad; shorter than parietal; nasal partly or completely divided; loreal enters orbit; preoculars none; postoculars 2; suboculars none; primary temporals 1 or 2 ; secondary temporals 2; tertiary temporals none; upper labials 7, 4th, 5th, and 6th enter orbit, 6th labial greatly enlarged, contacts orbit, postocular, primary and secondary temporals. Lower labials 6 to 9 , no pairs in contact behind mental, 4 or 5 pairs in contact with 1 st pair of chin shields, 5th lower labial greatly enlarged and elongated; mental with faint grooving which resembles labial suture; single extremely tiny postmental (present in type of longifrenis, absent in type of costaricensis) followed by 3 pairs of chin shields; 1 or 2 unpaired gulars between ventrals anù paired chin shields.

Ventrals 165 (161 in costaricensis) in females; anal entire; subcaudals 94-97 in females; no males known. Dorsal scale rows 15 throughout body; vertebral row not enlarged; paravertebrals as large as or larger than vertebrals; caudodorsals in the type (USNM 38750):

$$
\text { Female: } \underline{6} 2+3(5) \underline{4} 1+2(37) \underline{2}(97)
$$

Maxillary teeth 13 ; palatine teeth 9 ; pterygoid teeth $15 \pm$.

Body length of holotype $333 \mathrm{~mm}$.; tail length $153 \mathrm{~mm}$.

Dorsal ground color dull grayish-brown, a median series of 33-40 paler brown ocelli, which are confluent or alternating at vertebral row; series of similar spots low on sides and tips of ventrals; all ocelli edged with dark brown to black; dorsum variegated irregularly with brown or black throughout; in type last six median ocelli on body are fused with lateral spots so that banded pattern is evident. Tail with alternating 
variegated bands of pale brown and dark grayish-brown, 18 on left and 20 on right; grayish-brown bands with light or white spot in middle on sides.

Ventral color pale to white with brownish spotting and stippling, scanty anteriorly but increases to heavy posteriorly; spots may form irregular line or lines along midventer. Ventral surface of tail heavily colored with brown.

Head dark brown with indistinct marbling of pale brown; labials marked with whitish. Chin pale whitish, with scattered dark spots.

Taylor (1951:65) described the coloration of this species in life as follows: "Lichen-green, the color interrupted on the scale edges by a variegated brown or black; a dorsal series of 33 brownish yellow blotches, variegated with dark brown and dusky markings on body; on tail there are 15-16 but these are rather indefinite; low on the sides and encroaching on the ventrals is a series of cream white, dark edged ocellilike markings; chin whitish with a faint yellow wash; neck and anterior fourth of body nearly pure white with small greenish or black flecks forming an irregular, indistinct, median line; there is more yellow color on latter three fourths of body; there are similar dark markings becoming more dense under tail with some greenish and yellow flecks. On dorsal surface the head is nearly uniform black-brown with some indistinct reddish brown marks; a divided white blotch below eye; chin with a distinct pair of black spots on the fourth labials and a few other less distinct flecks of greenish black."

INDIVIDUAL VARIATION. - Since the type is the only specimen I have examined, I can say little about variation within the species. Taylor's description of costaricensis is excellently detailed, however, and provides a good basis for comparison with the type of longifrenis. The latter has three pairs of chin shields on the left side; on the right the $2 \mathrm{~d}$ and $3 \mathrm{~d}$ are fused into a single scale. Taylor's type of costaricensis has 3 pairs, and the fused condition is apparently the anomaly. The type has 9-8 lower labials, Taylor's specimen has 6-6. The left side of the head of the type of costaricensis has the postoculars fused into a single scale; there is an extra primary temporal, and apparently at least one labial fusion, since only 6 labials are present, and only the 4 th and 5 th enter the orbit.

All the color differences are probably due to the leaching effect of preservatives, for they involve losses of greens, yellows and reds.

REMARKS. - The color of this species is particularly striking in the formation of the ocelli. It is obviously a brown-blotched form, however, in which lateral connections between the blotches have developed, dividing the interspaces into upper and lower ocelli. At such points where these lateral connections are not present the blotched pattern, which approaches a banded condition, is evident. The greenish tinge, mentioned by Taylor, has been noted in several specimens of Dipsas dimidiata.

The figures and description of costaricensis have been compared with the type of longifrenis at the United States National Museum, and, except for one or two points, there is agreement. The type has a very tiny postmental and this scale is missing in Taylo:'s specimen; this lack is not surprising in view of the small scales posterior to the mental exhibited by other members of this genus. Taylor's specimen has somewhat less 
spotting on the ventral surface, and the spots are in a median line rather than doubled, as in longifrenis. The parallel rows in the type of longifrenis are present only on the middle third of the body, however, with scanty, scattered marking anteriorly and more abundant spotting posteriorly. In several other respects one of the specimens is different on one side of its head from the other individual, while on the other side they are the same. These points have been discussed above, and are considered to be individual differences.

SPECIMENS EXAMINED.-

PANAMA: Bocas del Toro (USNM 38750, type).

ADDITIONAL RECORDS. -

COSTA RICA: 5 miles southwest of Turrialba, Morehead Finca (UKMNH 25703, type of costaricensis).

\section{THE NEBULATA GROUP}

\section{Sibon carri Shreve}

Tropidodipsas carri Shreve, 1951: 52 .

HOLOTYPE. - MCZ 49797, male, from the Escuela Agricola Panamericana, near Tegucigalpa, Honduras, collected August 16, 1945, by A. F. Carr, Jr.

RANGE. - Pacific Slopes of Honduras; San Salvador.

DESCRIPTION. - Rostral broader than deep, scarcely visible from above; internasals less than half length of prefrontals; frontal longer than broad, shorter than parietals; nasal divided; loreal enters orbit; preocular none; postocular 1; suboculars none; primary temporals absent, secondary temporal 1; no tertiary temporals; upper labials $6,3 \mathrm{~d}$ and 4 th enter orbit, 5 th enlarged and in contact with parietal between postocular and secondary temporal. Lower labials 7, single pair in contact behind mental, 4 or 5 pairs in contact with first chin shields; first pair of chin shields elongate, crescentic, followed by contact on midline between greatly enlarged pair of lower labials, and then 2 additional pairs of chin shields.

Ventrals in males 164-168, in females (160-) 172; anal entire; subcaudals in males 48 (2 individuals), in females 41 (1). Dorsal scale rows 13, vertebral row very slightly enlarged; caudodorsals:

$$
\begin{aligned}
& \text { Males: } \underline{6} 2+3(15-19) 4 \frac{4}{1+2}(38-43) 2(48) \\
& \text { Females: } \underline{6} 2+3(13-15) \underline{4} 1+2(34-3 \overline{5}) \underline{2}(41)
\end{aligned}
$$

Body length male $340 \mathrm{~mm}$. (holotype, tail incomplete), female $344 \mathrm{~mm}$; tail length male $71 \mathrm{~mm}$., female $71 \mathrm{~mm}$.

Dorsal ground color light brown, with many very irregular, dark-brown blotches, which are equal in width to interspaces and often fused along vertebral line, forming zigzag to straight streak down back; interspaces heavily mottled and stippled with dark brown, particularly high on sides, and with single dark spot on first and second scale rows, between ends of adjacent blotches. Tail as body. Venter brownish-cream, with two irregular 
rows of spots and streaks, rows equidistant from each other and first scale rows.

Dorsum of head dark brown, irregularly vermiculated with brownishcream; vermiculations strongest and most abundant on sides of head, temporals, and edges of parietals; weakest or absent on dorsal head scales and inner parts of parietals. Chin brownish-cream, very sparsely spotted with dark brown.

INDIVIDUAL VARIATION. - The dorsal head scales are identical in all four specimens seen, including labials and temporal counts. The type has 6-7 lower labials, the others have 7-7. Three of the four specimens seen have the enlarged lower labials in contact between the first and second pairs of chin shields, while on the fourth, AMNH 70187, the contact is prevented by a small scale at the right side of the midline. The type and AMNH 70188 have 2 pairs of chin shields posterior to the contact of the labials, while AMNH 70186 has only unpaired gulars there.

Two specimens, the type and AMNH 70186, have 13 scale rows over the entire length of the body. AMNH 70187 has a reduction to 11 one or two ventrals anterior to the anus, while AMNH 70188 has the following formula:

$$
\underline{13} \mathrm{v}=\frac{8}{8}(83-84,87-89,92-94,99-101,157 \rightarrow) \underline{14}(164)
$$

There are no irregularities in caudodorsal reductions, nor are there any divided ventrals or fused subcaudals in the material examined. A divided ventral in a single specimen has been reported in the literature.

REMARKS. - This recently discovered species is remarkable in that it carries to the greatest extent possible the tendency in the genus Sibon to enlarge both a single upper and lower labial. S. carri has the enlarged upper labial in contact with the parietal, which indicates a fusion between it and the single anterior temporal typical of all other species of Sibon. The lower labials have enlarged to the extent of contacting each other along the midline of the chin. The postoculars have apparently fused, leaving only a single scale. In addition, the number of scale rows has been reduced to 13, a character duplicated only by Sibon anthracops, another species from the Pacific Slope of Central America. It has retained the general color pattern of Sibon nebulata, however.

Mertens $(1952 b: 76)$ described an individual from El Salvador that agrees in all respects with the specimens included in this description. It is a female, and establishes the lower limit of variation for that sex in ventrals (160). Mertens said the 159th ventral is divided. The tail of this specimen is incomplete.

SPECIMENS EXAMINED.-

HONDURAS: Escuela Agricola Panamericana, near Tegucigalpa (A MNH 70186-88; MCZ 49797, holotype).

ADDITIONAL RECORDS. -

EL SALVADOR: Between the Tropical Institute and San Carlos (Mertens, 1952b: 76). 


\section{Sibon dunni Peters}

Sibon dunni Peters, 1957: 110.

HOLOTYPE. - UMMZ 92068, male, from Pimanpiro, San Nicholas, Province of Imbabura, Ecuador, collected by Philip Hershkovitz (Pl. VII $d$ ).

RANGE. - Known only from the type locality.

DESCRIPTION. - Rostral broader than deep, visible from above; internasals three-fourths length of prefrontals, which enter orbit; frontal longer than wide, considerably shorter than parietals; nasal semidivided; loreal enters orbit; preoculars none; postoculars 2; suboculars none; primary temporal 1 ; secondary temporals 2 ; tertiary temporals absent; upper labials 6 , 4th and 5th enter orbit; 6th upper labial in broad contact with postocular, primary and secondary temporals. Lower labials 8 or 9 , one pair in contact behind mental, five pairs in contact with first pair of chin shields; 3 pairs of chin shields.

Ventrals 142-145 in males, 136-139 in females; anal entire; subcaudals 60-62 in males, 48-56 in females. Dorsal scale rows 15 from level of 4 th or 5 th ventral to anus; vertebral row moderately enlarged; caudodorsals:

Males: $62+3(16-23) \underline{4} 1+2(38-51) 2(60-62)$

Females: $6 \underline{2}+3(12-1 \overline{6}) \underline{4} 1+2(39-4 \overline{3}) \underline{2}(48-56)$

Maxillary teeth 14 ; palatine teeth 9 ; pterygoid teeth 18 (all from a single specimen).

Body length male $304 \mathrm{~mm}$., female $187 \mathrm{~mm}$., minimum $128 \mathrm{~mm}$.; tail length male $98 \mathrm{~mm}$., female $52 \mathrm{~mm}$., minimum $36 \mathrm{~mm}$. (All male measurements from holotype.)

Dorsal ground color light brownish-cream, with a vertebral series of small, irregular, ovate, chocolate-brown spots wider than long, confined for most part to vertebral and paravertebral scale rows, often broken and jagged in outline; all other dorsal scales with at least some trace of chocolate-brown or dark-brown markings on anterior edges, giving reticulate appearance where not spotted; occasional massing of dark color laterally produces small spots, usually directly below vertebral spot; amount of dark color on individual scales increases from ventrals to vertebral row. Belly cream, either immaculate or with very small, irregularly arranged, widely spaced, brownish spots, increasing in number posteriorly; tips of ventrals with brown edges, as on dorsal scales. Tail as body, with more pigment ventrally; zigzag line along midventral sutures of paired subcaudals more or less marked.

Dorsum of head chocolate-brown, strongly variegated with cream-white, most prominent on occiput and snout; frontal and parietals brown for most part; sides of head variegated with brown and cream, with labials entirely cream except for large, well marked brown spot on last labial. Chin, throat, and lower labials immaculate or with poorly defined small brown spots and occasionally with dark labial sutures.

INDIVIDUAL VARIATION. - There are no variations in the dorsal head scales, and little in the scales on the side of the head. The type is the only individual with a completely divided nasal, in all others it is 
semidivided. UMMZ 92071 has a tiny extra scale between the postoculars, primary temporals, and labials. UMMZ 92070 has 5 labials on the left side, with the $3 \mathrm{~d}$ and 4 th entering the orbit; UMMZ 92069 has 7-7 upper labials, although it is normal in that the 4th and 5th enter the orbit. It is the only specimen with other than a single labial posterior to those entering the orbit. The lower labials are 8-8 in two specimens, 9-9 in two, and 8-9 in one.

The type is the only specimen showing any dorsal reduction of scale rows, and this takes place at the anus. There are no irregularities in caudal reductions.

REMARKS. - This species apparently has a very restricted range in the highlands of Ecuador. It is peripheral in the range of the genus Sibon as a whole, a property it shares with Sibon sanniola. The two species are quite similar in many respects. Both show a great reduction in number of body segments as compared with all the other species in the genus, as shown by the ventral and subcaudal counts. Both are characterized by a reduction of the dorsal pattern to an indefinite number of vertebral spots. The Yucatecan species (sanniola) is, in addition, diminutive. The material of dunni is too scanty to give an indication of size, but all five specimens seen are quite small, and it is quite possible that the reduction in total body segments is accompanied by a decrease in absolute size as well.

SPECIMENS EXAMINED.-

ECUADOR: Imbabura; Pimanpiro (UMMZ 92068, holotype, 92069-72).

\section{Sibon nebulata Linnaeus}

Coluber nebulatus Linnaeus, 1758: 383.

RANGE. - From Michoacán and Campeche in México, including all of the Yucatán Peninsula, south to Ecuador and Brazil. Also known from Trinidad and Tobago (Map 12).

DESCRIPTION. - Rostral wider than or as wide as deep, not or scarcely visible from above; nasals divided; internasals slightly less than half to half as long as prefrontals, which enter orbit; frontal longer than broad or as broad as long, shorter than parietal; loreal enters orbit; preoculars none; postoculars 2; suboculars none; primary temporal 1; secondary temporals 2; upper labials 7 or 8 , 4th and 5 th or 5 th and 6 th enter orbit, 6 th or 7 th greatly enlarged and in contact with postocular, primary and secondary temporals (Fig. 3 ). Lower labials 8 to 10, a single pair in contact behind mental, four to six pairs in contact with first chin shields; 3 pairs of chin shields.

Dorsal scale rows 15 from level of 4 th-10th ventrals to anus, no reductions posteriorly; vertebral row moderately enlarged.

The species can be divided into four subspecies, primarily on the basis of ventral and subcaudal counts as well as on color and color pattern.

Andersson (1899:19) examined the type of Linnaeus' Coluber nebulatus, and gave the ventral count as 184 , the subcaudal count as 83 . The ventral count is much too high for the subspecies popayanensis, and the subcaudal count too low for leucomelas. This leaves hartwegi as a possibility, but 

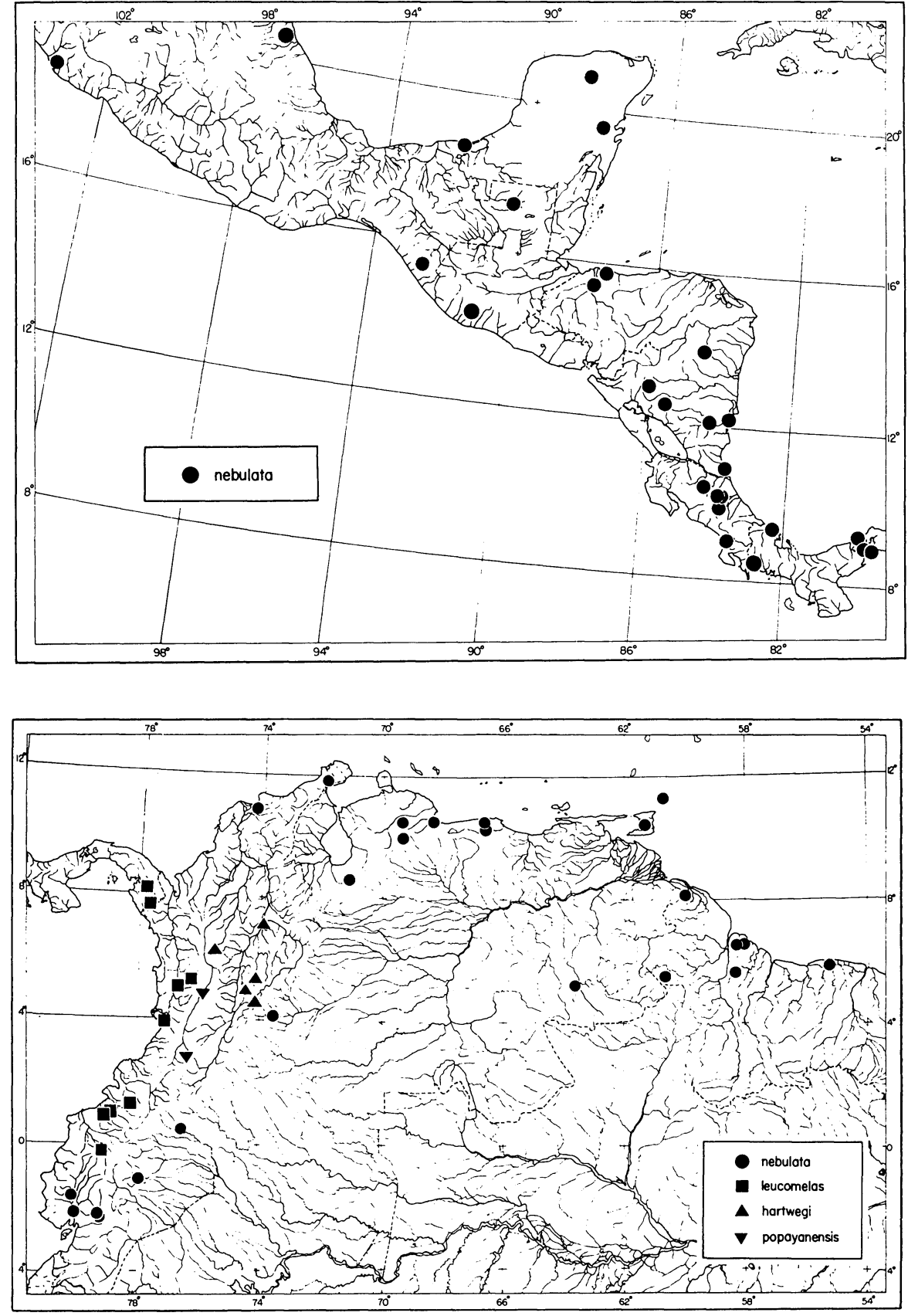

Map 12. Geographic distribution of subspecies of Sibon nebulala. 
the original figure of the type specimen of nebulata (Linnaeus, 1754: $\mathrm{Pl}$. 24, Fig. 1) shows that the broad bands characteristic of hartwegi are absent. Thus, the nominate subspecies is the wide-ranging form, found throughout all of Central America and most of the South American part of the range of the species.

Taylor $(1940: 473)$ pointed out that doubt as to the proper assignment of the name Coluber sibon Linnaeus still exists. Presumably, this doubt is a consequence of the fact that the type specimen has not been located, and since it seems unlikely that the type will ever be found, the name can be assigned only on the basis of the figure in Seba (1734: Pl. 14, Fig. 4). As he figured it the snake appears to have a light streak running along the vertebral and paravertebral rows, bordered below by a series of spots that are often fused with each other, giving the impression of parallel lines. I have seen no pattern comparable to this in any of the specimens examined. Because the type of Coluber nebulatus Linnaeus is extant, however, the validity of the use of that name can be established. Since the situation does not involve clear-cut priority, which can be invoked only when two names are probably synonymous, it seems advisable to use the name that is more likely to survive when applied to the taxon in question. This, to my mind, is nebulata, and I have used this name throughout.

\section{Sibon nebulata nebulata Linnaeus}

Coluber nebulatus Linnaeus, 1758: 383.

Coluber sibon Linnaeus, 1758: 383.

Cerastes nebulatus, Laurenti, 1768: 83.

Sibon nebulatus, Fitzinger, 1826: 31.

Leptognathus affinis Fischer, 1879: 78.

Petalognathus nebulatus, Fischer, 1879: 81.

?Dipsas leucomelas, Cope, 1887b: 68.

Leptognathus leucomelas, Beebe, 1919: 216.

Sibynomorphus mikanii, Ruthven, 1922: 69.

Sibon sibon, Amaral, 1929: 195.

Sibynon nebulatus, Amaral, 1031: 92.

Dipsas nebulatus, Dunn, 1947: 157.

HOLOTYPE. - One specimen in the Museum Regis Adolphi Friderici, Stockholm, from "America." Type found and designated as such by Andersson (1899:19).

RANGE. - Extreme northern South America, east and north of the Andean chain, as well as all of lowland Central America to Michoacán on the west and Veracruz on the east in México, including Yucatán Peninsula.

Also known from Trinidad and Tobago Islands; and from an isolated population in northwestern Ecuador below the range of leucomelas (Map 12).

DIAGNOSIS. - This subspecies can be recognized by the very irregular, disruptive dorsal pattern, with narrow dorsal blotches, which may be broken dorsolaterally, or be complete onto ventrals. The anterior dorsal blotches are not different from others on body, and the interspaces are not obscured by melanin deposits. The ground color is usually considerably lighter than the blotches, but may be heavily invaded by spots and streaks of blotch 
color. The ventrals in males are 159-193; in females, 162-193. The subcaudals are 75-114 in males, 70-98 in females.

Body length male $596 \mathrm{~mm}$., female $573 \mathrm{~mm}$., minimum $148 \mathrm{~mm}$.; tail length male $230 \mathrm{~mm}$., female $178 \mathrm{~mm}$., minimum $48 \mathrm{~mm}$.

VARIATION WITHIN SUBSPECIES. - There is considerable variation between populations of this subspecies, as would be expected from the wide geographical area covered in its range. This variation along with that found in the other subspecies is discussed in detail below.

\section{SPECIMENS EXAMINED.-}

LOCALITY UNKNOWN: (NYZS 31219, 31272, 31241); Central America (ANSP 10134, 14785; USNM 12460). BRAZIL (AMNH 3945, USNM 5443): Taparinha (MCZ 2940). Baía; Baía (MCZ 2948). BRITISH GUIANA: Demerara River (UMMZ 53902), Dunoon (UMMZ 47756), Kako River (UMMZ 85278), Lama Creek (AMNH 36092), McKenzie (UMMZ 84524), Santa Rosa Island (UMMZ 56463), Yarikita River (UMMZ 83747). COLOMBIA (AMNH 17476-77): La Concepcion (MCZ 6542; UMMZ 55682), Kuzo (ANSP 20889), Río Frío (MCZ 25047), San Lorenzo to Casa Vieja, Colombia-Ecuador Border (AMNH 20395), Villavicencio (MCZ 21980). COSTA RICA (AMNH 5918, 17359; USNM 30621-22): Boruca (CNHM 2523), Guápiles (MCZ 15328; KU 31936; UMMZ 83175), La Suiza (ANSP 22432), Santa Clara (AMNH 17385), Sarapiquí (A MNH 17341), Río Torres (AMNH 17311), Turrialba (AMNH 69713; MC Z 8340; KMNH 31937). DUTCH GUIANA (AMNH 3827-29; ANSP 19125, 10136-37; MP 163334; MCZ 4760; USNM 11146): Paramaribo (AMNH 8674). ECUADOR (SU 11875; USNM 14035, 14038): Bucay (AMNH 22092), Chanchan Valley (MCZ 17099), Daule River (MC Z, 3564), Guayquil (EPN 750), Napo (USNM 55762), Paramba (AMNH 13427). GUATEMALA: "Pacific Slope" (AMNH 38098), El Paso (MCZ 38564-55), Paso Caballos (MCZ 38593), Río Las Brisas, nr. Yepocapa (USNM 127967), Yepocapa (UMMZ 107314). HONDURAS (AMNH 46985): "Guaymas District" (MCZ 22022; UMMZ 63366), Portillo Grande (CNHM 21889, 35453; MCZ 38743), Progreso District (MCZ 21799-800), Tela (MCZ 20226). MEXICO: "Tierra Caliente" (USNM 7100), Jicaltepec [Veracruz?] (ANSP 11704). Campeche; Ciudad del Carmen (UMMZ 83542). Chiapas; Escuintla (UMMZ 87612). Guerrero; near Buena Vista (UIMNH 18704). Michoacán; $1 / 2$ mile south of Aquila (UMMZ 103658). Quintana Roo; Felipe Carillo Puerto (UMMZ 113558). Yucatán; Chichen-Itza (UMMZ 73026). NICARAGUA: Big Falls, Pis Pis District (AMNH 12682), Camp Machado (USNM 19558), Comoapa (MCZ 9517), Cukra (AMNH 12679-81), Greytown (USNM 5571, 62997), Matagalpa (MCZ 9560; UMMZ 46615), Rama (UMMZ 79778-80). PANAMA: Corozal (CNHM 16754), Bocas del Toro (USNM 38675), Chagres (MCZ 37099-100), Dos Bocas (ANSP 22477), Madden Dam (MCZ 38229), Panamá City (MCZ 17183, 28047, 32457-59), Pedro Miguel (MCZ 39758), Progreso (MCZ 26866), Sabanas-Pecora (MCZ 39758). TOBAGO ISLAND (MCZ 6332, 12076): Bacolet River (AMNH 7312'), Scarborough (A MNH 73126). TRINIDAD (AMNH 20588; MCZ 37158): Brickfield (CNHM 49960-61), Caura Sanitorium (AMNH 73125), Macqueripe Bay (MCZ 39684), Mt. St. Benedict (CM 6504, 6522), St. Augustine (MCZ 28575, 39683), San Rafael (CNHM 49959), Tucker Valley (CNHM 40441-42). VENE ZUE LA: Agua Blanca, Portuguesa (MCZ 51476), Los Canales, Naiguara (AMNH 59484-85), Caracas (ANSP 10130; MBUCV 1192-9, MBUCV unnumbered 2), Chama (AMNH 13578-79, 13581-82), Merida (AMNH 13570-73, 13416-17), Curupao (AMNH 59451), Naiguatá (CM 22778-79), Pauji (MCZ 48758, 49029-30), San Rafael (CM 7835, 7847, 7850, 7870, 7875), Santa Elena (UMMZ 57431), Urama (CNHM 29178), El Yaque (CM 7967, 7973).

\section{Sibon nebulata hartwegi, new subspecies}

Petalognathus nebulata, Cope, 1899: 14.

?Sibynomorphus leucomelas, Amaral, 1928: 8.

HOLOTYPE. - Chicago Natural History Museum, No. 27580, male, from Barrancabermeja, Santander Province, Colombia (Pl. VIII $d-e$ ).

RANGE. - Upper reaches of Rio Magdalena and its tributaries in Colombia, and the valley of the Rio Porce (Medellín) (Map 12). 
DIAGNOSIS. - The members of this subspecies have broad, regular, well-formed dorsal blotches on the neck, followed by blotches reduced in size and poorly marked, on rest of body. The ventrals in males are 171195 , in females $172-181$. The subcaudals in males are $85-103$, in females 75-82.

Body length male $496 \mathrm{~mm}$., female $439 \mathrm{~mm}$., minimum $189 \mathrm{~mm}$.; tail length male $173 \mathrm{~mm}$., female $139 \mathrm{~mm}$., minimum $52 \mathrm{~mm}$.

COLOR. - Dorsal ground color light brown or brownish-gray, first chocolate-brown body blotch well-formed, regular, wide, sharply set off from interspaces, second and third blotches often as well-formed as first but not as wide, with rounded edges and clearly defined light-cream borders; remaining body blotches irregular, with many secondary blotches in interspaces; primary blotches easily distinguished from secondary blotches on all parts of body by greater width, well-marked cream borders, and by extending onto ventrals; ground color darkens posteriorly, with heavy stippling of chocolate-brown, pattern of dorsal blotches somewhat obscured far posteriorly. Dorsum of tail as body, darkening considerably on posterior part. Venter creamy white, color as borders of dorsal blotches; blotches extend well onto ventrals on all parts of body, usually two or more ventrals in width and often in contact with blotch from opposite side, first blotch 3 to 8 ventrals wide and usually completely fused across midventer; interspaces spotted and stippled with dark brown, increasing posteriorly. Tail with more dark brown than cream ventrally, usually some indication of dorsal pattern left on all individuals.

Dorsum of head for most part unicolor chocolate-brown, with cream punctulations on outer edges of parietals, supraoculars, prefrontals and snout in some individuals; side of head slightly lighter brown, with increased creamy spotting; upper labials predominantly dark brown. Chin and lower labials and throat with fairly heavy brown spotting; no unicolor chins.

DESCRIPTION OF HOLOTYPE. - Head scales as described for species. Upper labials 8, 4th and 5th enter orbit, 6th rather small and apparently split off anterior edge of 7 th; lower labials 9 , with 6 in contact with the first of 3 pairs of chin shields. Pustules present on many head scales, but very small and difficult to distinguish.

Ventrals 184, with the 20th divided as in Type 3 and the 31 st as in Type 1 , both on right side. Vertebral row moderately enlarged; dorsal scale row formula:

$$
\text { (6) } \underline{17} \frac{\mathrm{V}+8(7)}{\mathrm{V}+8(9)} \underline{15} \mathrm{~V}=\frac{8}{8}(16-20,29-31,35-36) \underline{15} \text { (184) }
$$

Subcaudals $87+n$ with tip of tail missing, all double, caudodorsal reduction:

$$
6 \frac{2+3(29)}{2+3(35)} \underline{4} \frac{1+2(81)}{1+2(82)} \underline{2}(87+n)
$$

Maxillary teeth 17; palatine teeth 11 ; pterygoid teeth 20. 
Dorsal ground color brownish-gray; first two blotches twice as broad as interspaces between them, which is quite light, third and fourth slightly larger than interspaces between them, rest narrower than interspaces, and with prominent secondary blotches. All dorsal blotches, primary and secondary, extend across ventrals to fuse with mate, if opposed.

Body length 434 (all measurements in $\mathrm{mm}$.); tail length 132+ (tip missing); rostral width 3.5 , depth 2.6 ; internasal width 4.3 , length 1.5 ; prefrontal width 5.8, length 3.5 ; frontal width 3.8 , length 4.5 ; parietal length 6.3 .

VARIATION WITHIN SUBSPECIES. - There is individual variation in the extent and size of the anterior dorsal blotches, although they are consistent in their regularity and prominence. The specimens from higher elevations, that is, from the environs of Bogotá, have rather narrow blotches, and in none is the first blotch twice as wide as the first interspace. In most, the second blotch is narrower than the interspace following it.

USNM 95924-25 have secondary blotches between the anteriormost primary ones, a character not seen in either the type or the specimens from $\mathrm{Me}-$ dellín. UMMZ 78284 has a comparatively wide first blotch, but it is not followed by a light-cream interspace, as in the type, but by a normally grayish-brown area. The light-cream interspace between the anterior blotches, when present, seems to be a result of fusion between the lightcream borders of the enlarged blotches.

Variation in scutellation of this subspecies is described and analyzed in detail in the discussion below of the variation within the species.

SPECIMENS EXAMINED. -

COLOMBIA (AMNH 17475, 17623): Barrancabermeja (CNHM 27580, holotype), Bogotá (MCZ 19205; USNM 95924-25), Medellín (AMNH 37938, 35546-47), Paime (MCZ 21998), Sasaima (ANSP 22781; UMMZ 78284). (All of above are designated as paratypes, with the exception of AMNH 17475 and AMNH 17623, which are badly faded.)

\section{Sibon nebulata leucomelas Boulenger}

Leptognathus leucomelas Boulenger, 1896b: 18.

Sibynomorphus leucomelas, Amaral, 1927: 46.

Sibon sibon, Schmidt, 1933: 17; Dunn and Bailey, 1939: 10.

HOLOTYPE. - BMNH 1895.11.16.16, female, from Buenaventura, Colombia, collected by W. F. Rosenberg (Pl. VIII $c$ ).

RANGE. - From Panamá-Colombia border including all of Choco in Colombia to NW Ecuador (Map 12).

DIAGNOSIS. - This subspecies is primarily differentiated on the basis of its distinctive color, which is described in detail below. The ventrals are 183-200 in males, $178-192$ in females. The subcaudals are 90-111 in males, 84-100 in females.

Body length male $547 \mathrm{~mm}$., female $562 \mathrm{~mm}$., minimum $168 \mathrm{~mm}$.; tail length male $210 \mathrm{~mm}$., female $194 \mathrm{~mm}$., minimum $62 \mathrm{~mm}$.

COLOR. - Dorsal ground color grayish-brown, obscured for most part by heavy stippling and spotting with darker brown or black; dorsal blotches dark brown or black, very irregular in shape and size, often not clearly discernible; when recognizable, blotches on all parts of body narrower than interblotch areas, often with white border on single edge only; interspaces 
heavily invaded by blotch color and strongly stippled, spotted and mottled. Venter pale yellowish, with very prominent dark blotches two or three ventrals wide that are usually continuations of dorsal blotches and that meet at midline with their fellows of opposite side; ground color of venter between blotches of ten spotted with blotch color, and may be almost entirely obscured by blotch color in old adults. Tail as body dorsally, although with greater deposition of dark pigment; ventral side of tail unicolor dark brown or black or with widely scattered light-yellowish spots or stippling.

Dorsum of head either entirely unicolor dark brown or blackish-brown, or with stippling of silver along sutures, most prominently on snout, seldom on frontal or parietals; sides of head as dorsum, with stippling somewhat more prominent, confined for most part to edges of individual scales, stippling forms poorly defined line from upper posterior border of eye to posterior angle of head. Entire chin and first few ventrals on throat dark brown or black, with occasional widely scattered, irregular, yellowish spots or streaks along sutures.

SPECIMENS EXAMINED. -

COLOMBIA: Andagoya (MCZ 32732, 51498; USNM 12452), Buenaventura (BMNH 1895.11.16.16, holotype), Cole (AMNH 4468), Jimenez (AMNH 13565), Ricuarte (ANSP 25437), Playa del Oro, Río San Juan (CNHM 54945; USNM 72356), Santa Cecilia (CNHM 54910-11, 54941-44). ECUADOR: Carondelet (AMNH 13566-67), Esmeraldas Province, no other data (EPN 74-75), Pambelar (AMNH 13568) San Javier (AMNH 13569, 13574-77), Santo Domingo de los Colorados (EPN 738; SU 13313). PANAMA: Cana (USNM 50117), Minas de Cana (MCZ 42754), San Juan de Pequeni (MCZ 38228 [2] ), Yavisa (MCZ 39778 [2]).

Sibon nebulata popayanensis, new subspecies

HOLOTYPE. - Chicago Natural History Museum 54947, male, from Popayan, 1700 m., Cauca Province, Colombia; collected by Kjell von Sneidern, in January, 1947, (Pl. VIII $a-b$ ).

RANGE. - Known only from the upper reaches of the Río Cauca, in Colombia (Map 12).

DIAGNOSIS. - Members of this subspecies can be recognized by the low ventral counts, which are 161-170 in males and 161-173 in females, and the low subcaudal counts, which are 77-84 in males and 64-71 in females. This is another dark subspecies, with a heavy deposition of black pigment in interblotch areas, as in leucomelas, from which it is distinguished by scale counts.

Body length male $392 \mathrm{~mm}$., female $397 \mathrm{~mm}$., minimum $116 \mathrm{~mm}$.; tail length male $145 \mathrm{~mm}$., female $113 \mathrm{~mm}$., minimum $43 \mathrm{~mm}$.

COLOR. - Dorsal ground color brownish-gray to grayish-black, with poorly contrasted brownish-black dorsal blotches that are very irregular but generally maintain their integrity from vertebral to ventral scales; blotches irregularly and often unilaterally bordered with creamy white, primary and secondary blotches not distinguishable as such on posterior part of body, anteriormost blotches may be quite regular, with clearly defined interspaces, but first blotch, on nape of neck, does not extend onto ventrals at all or but slightly, leaving throat immaculate. Dorsum of tail as body, with more complete breakup of dorsal blotches. Venter creamy 
white, with dorsal black blotches often extending onto ventrals, particularly posteriorly, usually only one ventral or less in width, may reach clear across belly or only to tips of ventrals; usually much black pigment in interspaces, in the form of spotting, stippling or supernumerary rectangular black blotches (i.e., not related to a dorsal blotch), spotting and stippling often forming midventral stripe.

Dorsum of head grayish-black, with much mottling and vermiculation of grayish-white, increasing laterally to labials, which are usually whitish with occasional black sutures. Lower labials, chin, and throat usually white, with occasional black suturing on labials, and sometimes with irregular black spotting and stippling on chin shields and first ventrals.

DESCRIPTION OF HOLOTYPE. - Head scales as described above for species, with following exceptions: upper labials $6,3 \mathrm{~d}$ and 4 th enter orbit (partial suture on $3 \mathrm{~d}$ labial on left, showing point of fusion of $3 \mathrm{~d}$ and 4 th labials), lower labials 7 on left, 8 on right, 6 th lower labial on left extremely elongate, apparently as result of fusion of 6 th and 7th, 4 labials on left, 5 on right in contact with first pair of chin shields. Pustules present on rostral, internasals, nasals, prefrontals, supraoculars, upper and lower labials, and paired chin shields.

Ventrals 166 , dorsal scale rows 15 , with no reductions on any part of the body, vertebral row scarcely enlarged anteriorly, increasing to moderately enlarged posteriorly. Subcaudals 78, all double, caudodorsal reduction:

$$
\underline{6} \frac{2+3(15)}{2+3(18)} \underline{4} \frac{1+2(53)}{1+2(56)} \underline{2}
$$

Maxillary teeth 15; palatine teeth 9; pterygoid teeth 19.

Color as described for subspecies. Ground color grayish-black, first seven dorsal blotches regular, broader than interspaces, which are light between first two or three blotches and darken rapidly thereafter. Midventer line, formed by black spotting, fairly prominent, chin heavily stippled on rostral and first pair of chin shields, otherwise clear cream.

Body length 392 (all measurements in mm.); tail length 145; rostral width 3.3 , depth 2.9 ; internasal width 4.1 , length 1.3 ; prefrontal width 6.0 , length 3.1 ; frontal width 3.3 , length 3.8 ; parietal length 5.4 .

VARIATION WITHIN SUBSPECIES. - The analysis of variation of this subspecies is taken up in detail below, in the discussion of variation within the species.

REMARKS. - I doubt whether the material from Cartago, Colombia (AMNH 20404-05) actually belongs in this subspecies. Geographically, both Cartago and Popayan are in the same intermont basin, which is quite isolated except through the Cauca Valley. The two localities are not a great distance apart, but Popayan is in a forested region of the valley, while Cartago is in a belt of savanna. The two specimens from Cartago certainly do not fit the diagnosis of the subspecies very well. The male, No. 20405, has 103 subcaudals and 195 ventrals, both values far beyond the limit of variation as expressed by topotypical material; this individual is badly faded and its color pattern cannot be used in its determination. The second 
specimen, No. 20404, presumably a female, is very badly dried, and it is not possible to determine the sex or the ventral count with surety. I have recorded the subcaudal count to be 78 , which again is high for the subspecies, although my count may be somewhat inaccurate. The color pattern of this specimen is distinct; it has very narrow dorsal bands, quite regular, widely separated by much lighter interspaces, in which there is practically no deposition of blotch pigment. In view of these facts, I have only included these two specimens provisionally as members of this subspecies. Additional material is needed to solve the problem.

SPECIMENS EXAMINED. -

COLOMBIA: Moscopan (ANSP 25613); Popayan (ANSP 25612; CNHM 54900-02, 54909, $54912-18,54946-47$ ). (All of the preceeding, with the exception of the holotype, CNHM 54947 , are designated as paratypes of the subspecies Sibon nebulata popuyanensis.) Doubtfully included: COLOMBIA: Cartago (AMNH 20404-05).

\section{VARIATION WITHIN THE SPECIES Sibon nebulata Linnaeus}

INDIVIDUAL VARIATION. - As is true of all members of the genus Sibon, this species is characterized by the uniformity of its head scales. Although a wide geographic area is covered by the material included under this name, there are very few differences between populations insofar as head scales are concerned. The nasal is completely divided in somewhat more than 80 percent of the specimens and partly divided in the remainder. Only five specimens were noted as having an entire nasal. The loreal enters the orbit in every specimen except one. The preocular is absent in more than 95 percent of the specimens, the postoculars, although 2 in about 80 percent, are occasionally 3 , and both 1 and 4 have been observed; the subocular is absent in about 90 percent of the specimens but occasionally a single one is present, and one individual has 2 on one side of the head (AMNH 13579). The primary temporals are single, and there are 2 secondary temporals in over 90 percent of the specimens seen. The primary temporal is usually quite large, and occasionally divides, either horizontally or vertically. Fractionation of the temporals, either primaries or secondaries, was observed in seven specimens. The presence of 3 secondaries was noted in five individuals, on one side only in all, thus splitting on the secondary row is uncommon. The upper labials are 7 in about 70 percent of the specimens. There may be as few as 5 or as many as 9 labials, with 7 the modal class. When the labials are 7 , the 4 th and 5 th enter the orbit, when they are 8 , the 5 th and 6 th. The variation in labials appears to take place anterior to the eye for the most part, although there are four individuals that have only a single labial posterior to the last one entering the orbit on one side, and two with that condition on both sides of the head. Normally, there are 2 labials in that position, one of which is the greatly enlarged scale that appears to have resulted from a fusion of the lower anterior temporal with a labial, and which serves as a diagnostic character for the genus.

The lower labials are 8 or 9 in 82 percent of the specimens seen, and 9 percent more have 8 or 9 on one side of the head. The remaining 9 
percent have the following distribution: one has $6-7$, five have 7-7, and six have 10-10. Every individual seen has only a single pair of lower labials in contact behind the mental, and none of them have unpaired chin shields. While there are usually 5 or 6 labials in contact with the first chin shield, which is fairly elongate and crescentic, there may be as few as 4 or as many as 7 bordering it. The chin shields are usually 3 , with the first longer than broad, the second about equally as broad as long, and the third broader than long (with reference to each individual scale in the pair).

The dorsal scale rows are usually 15. Occasional individuals in all populations show either reductions or increases in row numbers. Thus, twenty-three specimens have at least one reduction to 13 rows, as a result of fusion of the vertebral and paravertebral rows. Thirteen specimens have short increases to 16 rows, which is invariably a result of a division of the scales in the vertebral row into two scales, forming an eighth row on either side. Divided ventrals were noted in individuals throughout the range of the species, with a total of 28 having at least one division. Five specimens have at least one pair of subcaudals fused across the tail.

VARIATION BETWEEN POPULATIONS. - As mentioned above, there is no correlation between the observed variations in the scutellation of the head and separate populations. This, however, is not equally true of the observed variations in the counts of the ventral and subcaudal scales, or in the colors and patterns. Unfortunately, the material available is insufficient for a completely satisfactory analysis. But it can be shown that trends in population differentiation do exist, and this evidence has been used to establish subspecies.

There has been no preconceived concept as to the maximum size of the area covered by the individual populations, but rather the data and their analysis has led to the establishment of what appear to be rather heterogeneous units. Thus, a group of individuals in Pacific Ecuador is geographically isolated from the subspecies nebulata nebulata, to which it belongs, by the subspecies leucomelas. As a consequence, this sample is treated as an individual population, although its small size precludes the calculation of any statistic other than the mean. On the other hand, analysis of the specimens from the whole of Central America has indicated that there are no independent units within that area between which gene flow might be restricted. I have, therefore, combined the data for all specimens from Central America into a single populational unit. There are no significant statistical differences between the populations occupying northern South America and the island of Trinidad, but I have maintained Trinidad, combined with its island neighbor Tobago, as a unit in my calculations, because sufficient specimens are available to permit calculation of a standard error. In addition to the populations represented by the subspecific names hartwegi and popayanensis, I have isolated a small segment of the material from northern South America, because it is strikingly different from the remaining material. This is the series from the region of Merida, Venezuela.

Although the species as a whole is rather uniform in respect to the usually quite variable character of the ventral scutellation, several of the 
populational units show marked divergence. When populations are compared directly (Fig. 8), there is no significant difference between any two of the series from the whole of Central America, northern South America, Trinidad and Tobago, or the subspecies hartwegi. It is likely that a sufficiently large sample from Pacific Ecuador would also not be significantly different from those four populations, as shown by the plotted range and mean. On the other hand, the subspecies leucomelas has a very high mean

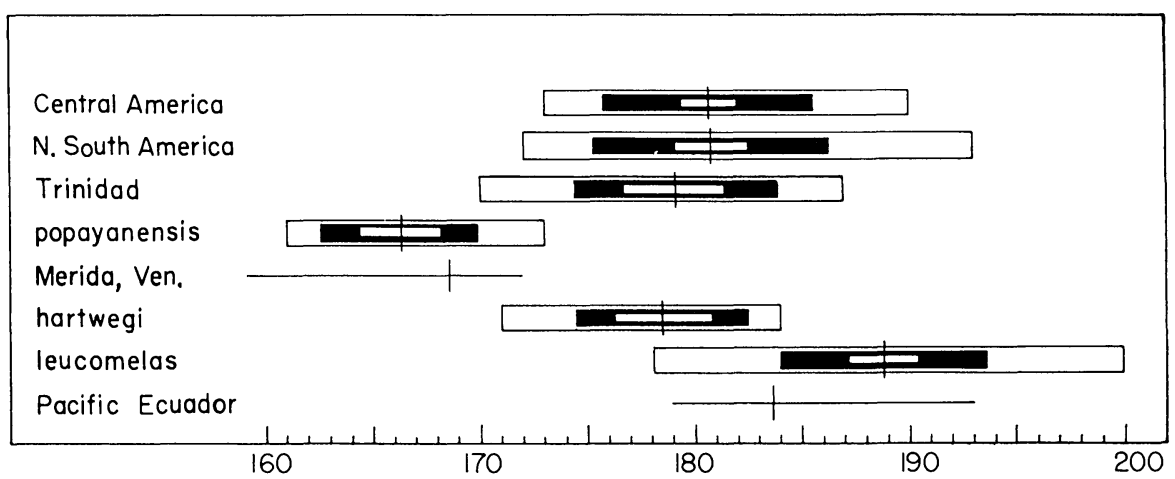

Fig. 8. Variation in number of ventral scales in Sibon nebulata. Vertical bar indicates the mean; small white rectangle, twice the standard error on either side of the mean; black rectangle, one standard deviation on either side of the mean; and large white rectangle, the observed variation. Data for sexes are combined.

value that is statistically different from all other populations, the only possible exception being the Pacific Ecuador series. The subspecies popayanensis and the unnamed series from the region of Merida, Venezuela, are markedly different in the low number of ventrals usually present. The popayanensis series is obviously statistically different, and it is quite likely that the same is true of the Merida series. The subspecies hartwegi, which is characterized primarily by its color pattern, is very similar to the nominate subspecies, and cannot be distinguished from it on the basis of ventral scutellation.

In view of the large area covered by the sample from Central America (from México to Panamá), it is quite possible that it does not comprise a completely homogeneous sample. No areas of distinctive differentiation could be found, however, when the samples were analyzed separately. Thus, when the population is broken down into somewhat smaller units, no statistically significant differences between means could be found (Fig. 9). The smaller units used were the individual countries except for México and Guatemala. These two were considered together in order to provide enough material for statistical treatment, and there are no observable trends of variation or clines within the area and the data seem to be completely random in their distribution. The uniformity of this Middle American sample as well as the absence of sexual dimorphism in ventral counts (see below) provide excellent data for comparative purposes. There is practically no difference between the material from northern South America and that from Middle America, and the two units might have been combined in the 


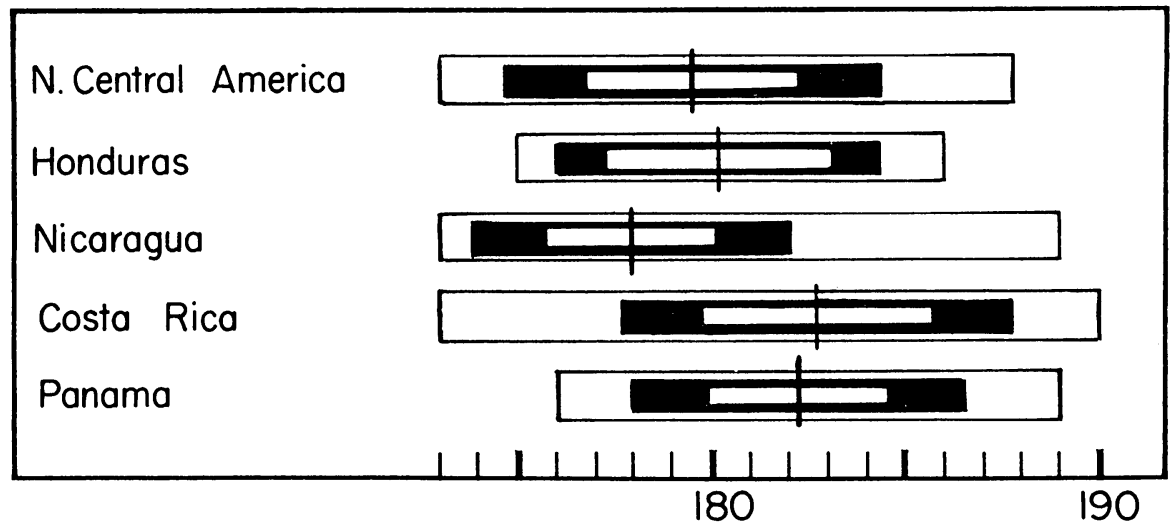

Fig. 9. Variation in number of ventral scales in Central American population of Sibon nebulata. Symbols as in Figure 8.

statistical analysis of the ventral counts. However, this was not done in recognition of the discontinuity between the two areas in the region of the Panamanian isthmus and northwestern Colombia.

There seems to be some correlation between the number of ventral scales and altitude. The snakes from higher altitudes tend to have lower ventral counts. Thus, the subspecies popayanensis, found only in the valley between the western and central cordilleras in Colombia, has the lowest mean of all populations, and the value for the Merida series is only slightly higher. These are the only areas in which the species occurs in upland situations to any extent, with the exception of the subspecies hartwegi, found in the valleys between the central and eastern cordilleras of Colombia. While the mean for this subspecies is lower than all others except the two just discussed, the difference is not statistically significant. The highest mean value is found in the subspecies leucomelas, which inhabits the humid, tropical lowlands of Pacific Colombia and Ecuador.

Since there is a difference between the sexes in subcaudal scales, it is necessary to analyze the differences between populations within sexes (Figs. 10 and 11). This is somewhat unfortunate, since it sometimes reduces the number in a sample, such as the Trinidad-Tobago one, to a point at which complete statistical analysis is no longer reliable.

Again, as was found in the ventral count, the subspecies popayanensis is obviously distinct from the remaining populations in the very low values for this character. The only series approaching it is that from Merida, but sufficient samples are not available to allow accurate determination of the significance of their differences.

The subspecies leucomelas is slightly anomalous in that, while the mean for the subcaudals of the females is at a significant distance from that of the other samples, with the possible exception of the inadequate one from Trinidad and Tobago, this is not true for the males. There is broad overlap between the doubled standard errors of the sample from northern 


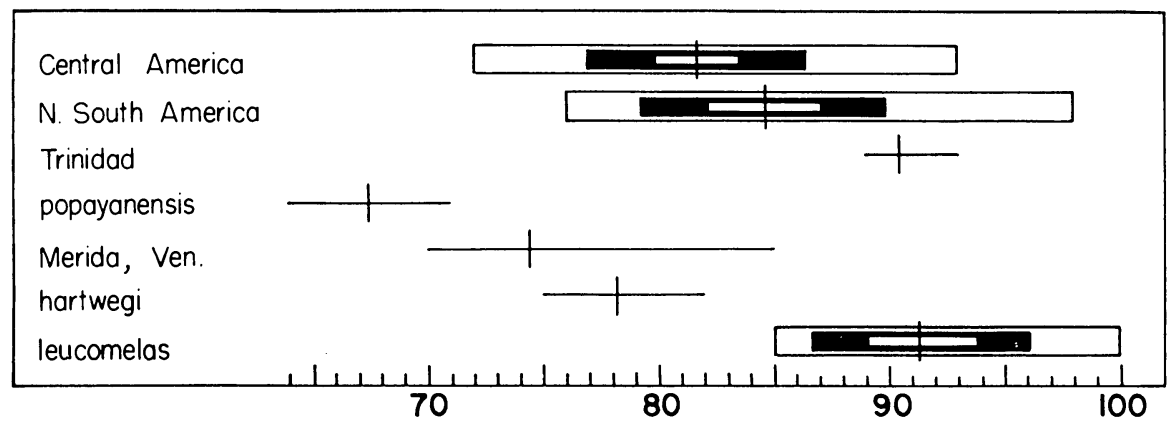

Fig. 10. Variation in number of subcaudal scales in females of Sibon nebulata. Symbols as in Figure 8.

South America and the leucomelas males, indicating no significant difference.

While the males fron Trinidad and Tobago, with a range of variation of 24 ventrals, and those from Merida, with a range of 26 , seem to have a greater span than any population except the possibly heterogeneous material from Central America, the data are somewhat misleading. Only one male from Trinidad has more than 105 ventrals, and that one has 114 . Similarly, a male from the Merida series with 101 ventrals is the only one with more than 83 . When both these very high counts are excluded, the spread is reduced to 15 in the Trinidad material, and to 8 in the Merida series.

As was noted for the ventral scutes, there appears to be a slight correlation between the number of subcaudals and the altitude whence the sample is taken. The lower counts are associated with the high altitudes. The subspecies hartwegi again shows its intermediacy, for it has lower mean values than the lowland populations, but at the same time there is an uncertainty as to whether the differences are significant. It is perhaps of greater value to note that the correlation of lower counts with higher

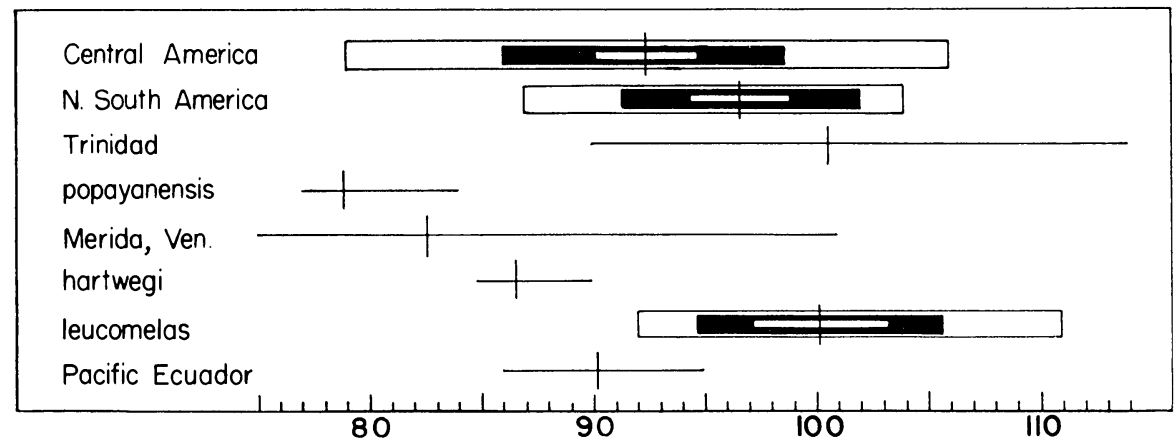

Fig. 11. Variation in number of subcaudal scales in males of Sibon nebulata. Symbols as in Figure 8. 
altitudes occurs in all three cases (i.e., for ventrals as well as male and female subcaudals). It might be hypothecated that the consistently lower values of the Middle American sample, both in the means and in the extremes of all tabulations, are attributable to the fact that it is not possible to segregate and analyze that group of specimens by altitudinal range because of lack of sufficient information. It is certainly true that this particular sample probably includes greater altitudinal differences than any of the others.

In addition to the variations between populations in scutellation, there are several distinct color patterns or color combinations that are mutually exclusive, either completely or partly. One of the recognized subspecies, hartwegi, is based almost entirely on the presence of the well-marked, broad dorsal bands on the anterior part of the body. This is in marked contrast with all other populations of the species, which show a consistent trend toward total breakup of blotches and interspaces, so that a very disruptive pattern is achieved. It is entirely possible that hartwegi is close to the ancestral prototype within the genus Sibon, for it is likely that the entire genus has its origin in the Andean area, and it can be hypothecated that two waves of invasion of Central America were produced during periods of closure of the Panamanian portal. Since the earlier invasion probably had its source in a banded stock, which spread throughout Central America and then developed into the several species of the annulata group, it is logical to call the remaining banded species in the Andean highlands the possible prototype.

The subspecies leucomelas is distinguished from all others by its strong development of melanism, and the invasion of the interblotch areas by the dark-brown to black pigments of the blotches themselves. The head is quite dark, with the loss of much or all of the light-spotting, stippling, or striping, and the chin is also very heavily darkened. There are intermediate individuals between this subspecies and the nominate form in the region of the Panama Canal. Since occasional melanic individuals, such as ANSP 22432, from La Suiza, Costa Rica, have been taken in various parts of Central America, it does not seem that this trait is peculiar to leucomelas.

The isolated population in western Ecuador, below the range of leucomelas, is not distinguishable from the nominate subspecies on the basis of color, and appears to be relict, indicating a former continuous range throughout the Choco for the parent form. This would indicate that leucomelas developed in situ, after the entire area it now occupies had been invaded at an earlier date by nebulata stock. Whether leucomelas is still actively extending its range and will eventually replace the relict population in Ecuador remains to be seen. It should be pointed out, however, that there is a fairly well-marked climatological break between extreme northwestern Ecuador, which is a continuum of the humid tropics of the Choco, and the region near Guayaquil, which, while still tropical, is considerably more arid. The presently recognized southern limit of the range of leucomelas is practically concurrent with the limit of the Humid Tropical Zone of Ecuador.

There are certain, fairly well-marked differences between the two 
large segments of the subspecies nebulata, analyzed above as the populations from Middle America and from northern South America, east of the Andes. Specimens from Middle America usually possess regular, clearly defined, dark-brown or black dorsal blotches, which are fairly sharply contrasted with the rich chocolate-brown of the interblotches and are continuous from the vertebral row to the ventrals, and often extend well onto two or more ventrals and fuse across the midventer. On the other hand, individuals from northern South America of ten have small, poorly defined dorsal blotches, occupying only the vertebral and paravertebral rows. The blotches seldom extend onto the belly, and are never fused with the opposite blotch across the ventrum. The blotches are a light brown, with the interspaces very light brown or grayish. These differences are not perfectly constant, however, and cannot be used alone to distinguish members of the two populations. Variations in each part of the color description given above for the Middle American material can be observed, so that no one point can be selected as a basis for taxonomic separation. Thus, in UMMZ 83175 from Guapiles, Costa Rica, the blotches show little contrast with the interspaces, but the general color is quite dark. USNM 19558, from Camp Machado, Nicaragua, shows more contrast than UMMZ 83175, but still has little differentiation between blotches and interspaces. AMNH 12679 has a very disrupted pattern, with almost all the blotches broken laterally, and the primary blotches scarcely distinguishable from the secondary; AMNH 12680 has a fairly regular, well-marked pattern of primary blotches, but they are still often broken on the sides; while AMNH 12681 has regular blotches. All three are from Cukra, Nicaragua. CNHM 35453 from Portillo Grande, Honduras, is typical, except that many of the black dorsal blotches are invaded by streaks of the white-blotch border color, rendering many of them incomplete on the sides. AMNH 38098, from the Pacific Slope of Guatemala, has a clearly contrasted pattern, but many blotches are confined to the vertebral and paravertebral rows.

The same kind of variation from the description given above for northern South American specimens can be demonstrated. In the MBUCV material from Caracas, Venezuela, the two adults are fairly typical, but a single juvenile has a very strongly contrasted pattern, with almost black dorsal blotches. UMMZ 83747, from the Yarakita River, British Guiana, is another juvenile, with contrasting blotches and interspaces, but the blotches are confined to the vertebral and paravertebral rows. UMMZ 47756, from Dunoon, British Guiana, is an adult, with well-marked dorsal blotches many of which extend well onto the ventrals. In addition to these individuals that possess characters of coloration more similar to the Central American material, three specimens, AMNH 59451, AMNH 59484, and UMMZ 55682, have wide, well-marked dorsal blotches, very similar to those of the subspecies hartwegi. AMNH 59485, which comes from the same locality as 59484, "Los Canales," Naiguata, Venezuela, however, is entirely typical of northern South America.

The Trinidad-Tobago series is for the most part very similar to the mainland population in general coloration, but there are a few variations. There is a tendency among these specimens to have a white spot or blotch alternate with the dark blotch along the middorsal line. The lateral 
blotches extend well onto the ventral scales, where they are often two ventrals wide, and may fuse across the belly. One specimen, AMNH 20588, is quite outstanding, in that it possesses the regular banding of the hartwegi type.

The series from Merida, Venezuela, is quite similar in all respects to the northern South American material, with only one specimen, AMNH 13578 , at all unusual. This individual has a very heavy deposition of darkbrown pigment ventrally, in contrast to the usual clear light-cream venter.

VARIATION BETWEEN SEXES. - The only scale character in which sexual dimorphism is statistically demonstrable is the number of subcaudals (Fig. 10 and 11). It is likely that correlated with this difference is a similar one in relative tail length, and perhaps also in the points of reduction of scale rows on the tail (see discussion of variation in Sibon sanniola), but these two characters have not been analyzed.

In addition to the above, pustules have been noted on the head scales of many of the males of this species. It has been suggested (Smith, 1946:106) that such tubercles might be of use in recognition of the sexes in courtship.

\section{INCERTAE SEDIS}

The species discussed in the following section are for one reason or another not definitely assignable to a place in my generic or specific groupings. This is usually due to inadequate description and unavailability of the type specimen. Those unassigned due to the present unavailability of the type will almost certainly find their proper places eventually, but those lacking a type, adequate description, and provenance are the lost souls of herpetology, doomed to spend the rest of their existence in the murky depths of appendices called "incertae sedis." Fortunately, the International Commission on Zoological Nomenclature now has the power to declare unavailable the names of forms that are totally unassignable due to lack of sufficient information. This is perhaps the only way in which future generations of taxonomists are to be spared repetition of hours of work, trying to name the unnamable, and assign the unassignable.

\section{Leptognathus andrei Sauvage}

Leptognathus Andrei Sauvage, 1884: 146.

Leptognathus mikani (part), Boulenger, 1896a: 453.

HOLOTYPE. - Paris Museum, type No. 6285, female, from "NouvelleGrenade," collected by "Andre."

RANGE. - Unknown.

ORIGINAL DESCRIPTION. - "Tête grosse. Museau court, tronqué, rétréci au-devant des yeux. Rostrale étroite; pas de preoculaires; deux postoculaires, 7 supéro-labiales, les $3 e, 4 e, 5 e$ touchant l'oeil, les antérieures étroites; une seule temporale. Écailles au nombre de 15 dans une rangée. Corps jaune brunâtre, avec de larges taches irrégulières d'un brun rougeâtre. Longueur, Om800." 
Prefrontal enters orbit. Lower labials 10 , 1st through 6 th narrow. 180 ventrals; 78 subcaudals.

REMARKS. - Added information about the type was furnished by J. Guibé, of the Paris Museum, who examined it for me. When Boulenger $(1896 a: 453)$ placed this species in the synonymy of mikani, he stated in a footnote that the type had been examined by M. Bocourt at his request. The information he received was sufficient to enable him to combine the two names. Boulenger did not regard mikani in the same light as I have in this study, however. In Boulenger's estimation, the range of that species covered the major part of northern South America whereas I restrict it to eastern and southern Brazil. Another of the species synonymized with mikani by Boulenger, Leptognathus oreas Cope, I consider belongs in an entirely different genus. I do not accept Boulenger's synonymy, therefore, because of the composite nature of his form.

While the type of Leptognathus andrei is still available and was examined for me, current information is still insufficient to assign the name properly. The only statement in the original description that indicates an incorrect generic assignment, however, is to the effect that there is only a single temporal. There are no dipsadine species known which do not have at least two rows of temporals.

\section{Leptognathus brevis Duméril, Bibron, and Duméril}

Leptognathus brevis, Duméril, Bibron, and Duméril, 1854: 476.

Leptognathus viguieri, Boulenger, 1896a: 457 (in part).

[Sibynomorphus] brevis, Amaral, 1926a: 9 (by inf.).

Dipsas brevis, Smith and Taylor, 1945: 50.

HOLOTYPE. - Formerly in Paris Museum, disappeared from that collection as early as 1862 (Boulenger, 1896a:457), from "Mexique."

RANGE. - Unknown.

ORIGINAL DESCRIPTION. - "Caractères. Corps alternativement cerclé de blanchâtre et de blanc marron et non de taches arrondies sur le dos.

"Deux plaques pré-oculaires; la première paire des sous-labiales réunies et non celles de la seconde.

\section{“DESCRIPTION.}

“Formes. Comme le corps est beaucoup plus court que dans l'espece précédente, le monbre des gastrostèges et des urostèges est considerablement diminué. Le mode de coloration est aussi fort différent.

"Dimensions. Le tronc relativement á sa largeur ne la dépasse que de 65 fois seulement et la queue forme un peu moins du tiers de la longueur total chez l'unique exemplaire que nous possédons, cette longueur totale est de Om,592. La Tête a Om,016. Le Tronc, Om,272. La Queue, Om, 116.

“Ecaillure. Il y a 15 rangs d'ecailles sur la longueur du tronc et 4 à la queue seulement. En dessous, on complete trois gulaires, 190 gastrostèges, une anale entiere et 103 urostèges divisées.

"Coloration. Les principaux caractères tirés de la couleur sont donnés 
par la trentaine de larges anneaux d'un brun marron que sépare les uns des autres une zône blanchâtre ou d'un blanc fauve généralement plus étroite sous le ventre que sur le dos ou l'on n'observe pas les taches isolées que existent de long du tronc.

"Patrie. Ce Leptognathe provient du Mexique."

REMARKS. - When the authors refer to two preoculars, they are actually including the loreal, which, in their generic definition, they state is lacking. It is likely that the "blanc marron" which appears in the paragraph headed "Caracteres" is a misprint for "brun marron," the words used for the same region in the paragraph headed "Coloration." Thus brevis probably has a single preocular and reddish-brown dorsal bands, which are apparently complete across the ventral surface. The first lower labials meet behind the mental, the ventral-subcaudal count is 190-103, and the scale rows are 15. In addition, those characters assigned to the genus Leptognathus by the authors can be considered as part of the specific definition, e.g.: nasal undivided, 10 or 11 upper labials, 3 or 4 entering eye, 2 or 3 postoculars, enlarged vertebral scale row. All of these, however, are scarcely sufficient to definitively isolate brevis from all other banded species in the genera possibly concerned. A strong possibility exists that it is close to, and perhaps the same as brevifacies. All of the characters mentioned except the number of labials meeting behind the mental and the number of ventrals and caudals are within the normal variations of brevifacies, also a Mexican species. Even those characters in which it differs from brevifacies are satisfied by the variation in viguieri, the species with which Boulenger synonymized it. Since viguieri is a Panamanian species, geographic consideration alone prevents the synonymization of brevis with it, and this is the basis for Smith and Taylor's revival of the name. Amaral in his list of neotropical species of snakes (1929) omitted brevis. Obviously, the act of synonymizing the species with the form it most resembles is insufficient to lay completely the specter.

\section{Dipsas infrenalis Rosén}

Dipsas infrenalis Rosén, 1905: 180.

HOLOTYPE. - Museum of Lund, no additional data.

RANGE. - Unknown.

ORIGINAL DESCRIPTION. - "Maxillary with 12 teeth. Rostral as deep as broad. Internasals broader than long. Praefrontals much longer than the internasals, entering the eye. Nasal entire. One praeocular. Two postoculars. No loreal. Frontal small, broad anteriorly, much shorter than the parietals. Temporals 1-2, very small. Nine upper labials, third, fourth, and fifth entering the eye. First lower labial in contact with its fellow behind the symphysial. Two pairs of chin shields, the posterior largest. Five lower labials in contact with the anterior chin-shields. Scales smooth, in 15 rows, vertebral row enlarged. Ventrals 193. Anal entire. Subcaudals 99, in two rows. Colour? (in spirit), with dark crossbands, extending on the ventrals.

"Total length $390 \mathrm{~mm}$. , tail 100." 
REMARKS. - The original description is inadequate, and it is obvious that this species cannot be properly placed in the dipsadine heirarchy on the basis of present information. From Boulenger's remarks (1905b:283), it seems likely that Rosén was not well grounded in ophidian taxonomy. Boulenger stated "I have done my best to supply a guide to the determination of snakes ('Catalogue to Snakes in the British Museum,' 1893-1896), and that it does not work in the hands of some students, as evidenced by Mr. Rosén's paper published in the last number of these 'Annals,' I deeply regret." He also adds "... beginners ... should not be encouraged to publish descriptions of so-called new species, which only go to swell the synonymy." He then proceeded to place in their proper synonymy all of the species Rosén had described and figured well enough to be recognizable. Whether his comments and multiple synonymies should be allowed to influence any decision concerning the status of infrenalis or not is a moot point, but I find it impossible to list it as other than incertae sedis at this time. Since Rosén stated that he followed Boulenger's systematic classification and nomenclature, and, since Boulenger had restricted the name Dipsas to a single species from South America (indica), it is probable that the type at least answers Boulenger's description of that genus, and is likely neotropical.

\section{SUMMARY AND CONCLUSIONS}

The snakes of the genera Dipsas, Sibon, and Sibynomorphus are members of a group of nocturnal snakes some of which are highly specialized arboreal, monophagous forms. They form a subfamilial unit, the Dipsadinae, within the Colubridae. Although the genera and species included in this grouping are for the most part easily recognized, there is no single character used in its definition the possession of which holds for all of the taxa. I attribute this to survival of many of the intermediate stages in the evolution of the most specialized members of the genera. Most taxonomists will agree that extinction of intermediate stages is what makes possible the establishment of categorical taxonomy. When many of the intermediate forms exist, as in the dipsadine snakes, then the boundaries of some taxonomic units become arbitrary.

Evolution within the Dipsadinae has progressed in two main directions, one toward monophagy and the other toward an arboreal existence, but the three genera seem to be at different levels in the sequence. Dipsas is the most specialized of the three, and certain of its species combine all of the modifications observed for both monophagy and arboreal life. Sibon has developed, to a high degree, most of the modifications for arboreal existence but many of the monophagic changes in bone and tooth structure in the mouth are not present. Sibynomorphus, on the other hand, although it has nearly all of the monophagous adaptations, retains the cylindrical body and nonenlarged vertebral row typical of nonarboreal snakes.

Dipsas ranges from Southern Brazil and Argentina through the Andes north to México. There are seven distinct species groups; groups which, 
for the most part, are based on coloration. Thirty-seven forms are recognized.

Sibynomorphus is restricted to the South American continent, and is found in southern Brazil, Argentina, Paraguay, Uraguay, Bolivia, and Peru. Seven forms are recognized.

Sibon ranges from México in the lowlands south through Central America into extreme northern South America, to Ecuador in the Andes and northern Brazil on the east. The genus is composed of three species groups, and there are 13 forms, many of which have been previously considered as members of Dipsas.

The principal food for all the species is molluscan. Most of the species are entirely monophagous, but it has not been proven that all are. In the approximately 100 stomachs that I examined only slugs and deshelled snails were found. It has been reported in the literature that these snakes also consume soft-bodied insect larvae.

A distinct ontogenetic color change has been detected in several species of Sibon and Dipsas. The pratti group of Dipsas seems to be characterized by this, and many of the names applied to the various species within that group have been based on different stages of pattern development and change. Juveniles of most of the species of the group have distinct, contrasting blotch and interspace colors. This contrast is less in the adults, because of an invasion of the interspaces by darker color, so that they come to resemble the blotches; in old adults most of the pattern is lost. Completely unicolor animals are exceptional, however, since most of the species retain a white or yellow line marking the border of each individual blotch.

Sibon has a fairly uniform arrangement of scales on the side of the head. Variability in that region is, however, characteristic of the other two genera. The number of temporals and oculars can be extremely variable within a single species, and various types of fusion and division are common. This pronounced variability in Dipsas and Sibynomorphus seems to be correlated with shortening of the head, one of the end results of evolution within the subfamily. In many species this shortening has created a compression both anterior and posterior to the eye, and has resulted in complete loss of preoculars and tertiary temporals. The upper labials are also affected by this shortening, and they are either compressed and narrowed, or fused.

\section{LITERATURE CITED}

Amaral, Afranio do

1923 New genera and species of snakes. Proc. New Eng. Zool. Club, 8: 85-105.

1925 South American snakes in the collection of the United States National Museum. Proc. U. S. Nat. Mus., 67 (24): 1-30.

$1926 a$ 2nd nota de nomenclature Ophiologica. Sobre o emprego do nome generico Sibynomorphus em vez de "Leptognathus," "Stremmatognathus," "Anholodon," etc. Rev. Mus. Paulista, 14: 7-9.

$1926 b$ Novos generos e especies de ophidios brasileiros. Arch. Mus. Nac. Brasil, 26: $1-27$. 
1926 c Ophidios de Matto Grosso. Comm. Linh. Telegr. Estrat. Matto Grosso ao Amazonas S. Paulo 84, Annex. 5, Hist. Nat. Zool. Pp. 1-29.

1926 d Albinismo em “Dorme-dorme," Sibynomorphus turgidus (Cope, 1868). Rev. Mus. Paulista, 15: 61-62.

1927 Studies on neotropical Ophidia. VII. An interesting collection of snakes from West Colombia. Bull. Antivenin Inst. Amer., 1 (2): 44-47.

1928 Studies on neotropical Ophidia. XI. Snakes from the Santa Marta region, Colombia. Ibid., 2 (1): 7-8.

1929 Estudos sobre ophidios neotropicos. XVIII.-Lista remissiva dos ophidios da regiao neotropica. Mem. Inst. Butantan, 4: 129-271.

1930 Studies on neotropical Ophidia. XVI. Two new snakes from Central Colombia. Bull. Antivenin Inst. Amer., 4 (2): 27-28.

1931 Studies on neotropical Ophidia. XXVI. Ophidia of Colombia. Ibid., 4 (4): 89-94.

1932 Studies of neotropical Ophidia. XXVII. On two small collections of snakes from central Colombia. Ibid., 5 (3): 66-68.

Andersson, Lars G.

1899 Catalogue of Linnean type-specimens of snakes in the Royal Museum in Stockholm. Bih. K. Svenska Vet.-Akad. Hand., Band 24, Afd. 4, No. 6: 1-35.

1901 Some New species of Snakes from Cameroon and South America, Belonging to the Collections of the Royal Museum in Stockholm. Ibid., Band 27, Afd. 4: 1-26.

Andrews, E. Wyllys

1937 Notes on snakes from the Yucatan Peninsula. Zool. Ser. Field Mus. Nat. Hist., 20 (25): 355-59.

Barbour, Thomas, and Emmett R. Dunn

1921 Herpetological novelties. Proc. Biol. Soc. Wash., 34: 157-62.

Barbour, Thomas, and G. K. Noble

1920 Amphibians and reptiles from southern Peru collected by the Peruvian Expedition of 1914-1915 under the auspices of Yale University and the National Geographic Society. Proc. U. S. Nat. Mus., 58: 609-720.

Beebe, William

1919 The higher vertebrates of British Guiana with special reference to the fauna of Bartica District, No. 7. List of Amphibia, Reptilia and Mammalia. Zoologica, $2(7-9): 205-27$.

1946 Field notes on the snakes of Kartabo, British Guiana, and Caripito, Venezuela. Ibid., 31 (1): 11-52.

Berg, Carlos

1898 Contribuciones al conocimiento de la Fauna erpetologica Argentina y de los paises limitrofes. Anal. Mus. Nac. Buenos Aires, 6: 1-35.

1901 Herpetological notes. Comun. Mus. Nac. Buenos Aires, 8: 289-91.

Bertoni, A. de Winkelried

1914 Fauna Paraguaya. Catalogos sistematicos de los vertebrados del Paraguay. Desc. Fis. y Econ. del Paraguay, 59 (1): 1-86.

Blanchard, Frank N.

1921 A Revision of the king Snakes: Genus Lampropeltis. Bull. U. S. Nat. Mus., 114: $1-260$.

Bocourt, M. F.

1884 Note sur quelques ophidiens nouveaux, provenant de l'Amerique inter-tropicale. Bull. Soc. Philomet. Paris, Ser. 7, 8: 133-42.

Boettger, Oskar

1885 Liste von Reptilien und Batrachiern aus Paraguay. Zeitsch. fur Naturwiss. (Naturw. Ver für Sachsen und Thüringen), 58: 213-48.

1898 Katalog der Reptilien-Sammlung im Museum der Senckenbergischen Naturforschenden Gesellschaft im Frankfurt am Main. II. Teil (Schlangen). Frankfort: Gebrüder Knauer. Pp. i-ix +1-160.

Boie, Friedrich

1827 Bemerkungen über Merrem's Versuch einen Systems der Amphibien. Isis, 20: 508-66.

Boulenger, George A.

1885 Second list of reptiles and batrachians from the Province of Rio Grande do Sul, 
Brazil, sent to the Natural History Museum by Dr. H. von Thering. Ann. Mag. Nat. Hist., Ser. 5, 16: 85-88.

1890 The fauna of British India, including Ceylon and Burma. London: Taylor and Francis. Pp. i-xviii $+1-541$.

1893 Catalogue of the snakes in the British Museum (Natural History). London, Brit. Mus., 1, i-xiii, 1-448, 28 pls.

1894 (Same title.) Vol. 2. Pp. i-xi + 1-382, 20 pls.

$1896 a$ (Same title.) Vol. 3. Pp. i-xiv $+1-727,25$ pls.

$1896 b$ Description of new reptiles and batrachians from Colombia. Ann. Mag. Nat. Hist., Ser. 6, 17: 16-21.

1897 Description of a new snake from the Andes of Colombia. Ibid., 20: 523.

1898 a An account of the reptiles and batrachians collected by Mr. W. F. H. Rosenberg in Western Ecuador. Proc. Zool. Soc. London, pp. 107-26, 9 pls.

$1898 \mathrm{~b}$ A list of reptiles, batrachians and fishes collected by Cav. Guido Boggiani in the Northern Chaco. Ann. Mus. Genova, Ser. 2, 19: 125-27.

1902 Descriptions of new batrachians and reptiles from northwestern Ecuador. Ann. Mag. Nat. Hist., Ser. 7, 9: 51-57.

$1905 a$ Description of a new snake from Venezuela. Ibid., 15: 561.

$1905 b$ Remarks on Mr. N. Rosén's list of the snakes in the zoological museums of Lund and Malmö. Ibid., pp. 283-84.

1908 Descriptions of new South American reptiles. Ibid., Ser. 8, 1: 111-15.

1911 Descriptions of new reptiles from the Andes of South America, preserved in the British Museum. Ibid., 7: 19-25.

1912 Descriptions of new reptiles from the Andes of South America, preserved in the British Museum. Ibid., 10: 420-24.

$1913 a$ A collection of batrachians and reptiles made by Dr. H. G. F. Spurrell, FZS, in the Choco, Colombia. Proc. Zool. Soc. London, pp. 1019-38.

$1913 b$ Description of a new snake discovered by Mr. A. E. Pratt in Eastern Peru. Ann. Mag. Nat. Hist., Ser. 8, 12: 72.

1920 Descriptions of four new snakes in the collections of the British Museum. Ibid., Ser. 9, 6: 108-11.

Brattstrom, Bayard H., and Thomas R. Howell

1954 Notes on some collections of reptiles and amphibians from Nicaragua. Herpetologica, 10: 114-23.

Cabrera, Angel, and Jose Yepes

1940 Mamiferos Sud-Americanos. Buenos Aires: Hist. Nat. Ediar. Pp. 1-370, 78 pls.

Chapman, Frank M.

1917 The distribution of bird-life in Colombia: A contributicn to a biological survey of South America. Bull. Amer. Mus. Nat. Hist., 36: i-x +1-729, 41 pls.

1926 The distribution of bird-life in Ecuador: A contribution to a study of the origin of Andean bird-life. Ibid., 55: i-xiii + 1-144, 24 pls.

Cole, Leon J., and Thomas Barbour

1906 Vertebrata from Yucatan. Reptilia; Amphibia; Pisces. Bull. Mus. Comp. Zool. , 50 (5): $146-59$.

Cope, Edward D.

1860 Catalogue of the colubridae in the Museum of the Academy of Natural Sciences of Philadelphia, with notes and descriptions of new species. Part 2. Proc. Acad. Nat. Sci. Phila., pp. 241-66.

1862 Catalogues of the reptiles obtained during the explorations of the Parana, Paraguay, Vermejo and Uruaguay rivers, by Capt. Thos. J. Page, U. S. N.; and of those procured by Lieut. N. Michler, U. S. Top. Eng., Commander of the expedition conducting the survey of the Atrato River. Ibid., pp. 346-59.

$1866 a$ Fourth contribution to the herpetology of Tropical America. Ibid., pp. 123-32.

$1866 b$ Fifth contribution to the herpetology of Tropical America. Ibid., pp. 317-23.

1868 An examination of the Reptilia and Batrachia obtained by the Orton Expedition to Ecuador; and the Upper Amazon; with notes on other species. Ibid., pp. 96-138.

1874 Description of some species of reptiles obtained by Dr. John F. Bransford, Assistant Surgeon United States Navy, while attached to the Nicaraguan Surveying Expedition in 1873. Ibid., 1873 (1874): 64-72. 
1876 On the batrachia and reptilia of Costa Rica. Jour. Acad. Nat. Sci. Phila., New Ser., 8 (2): $93-154$.

1885 Twelfth contribution to the herpetology of Tropical America. Proc. Amer. Philos. Soc., 22: 167-94, 1 pl.

1886 An analytical table of the genera of snakes. Ibid., 23: 479-99.

1887 a Appendix on a Leptognathus from San Paulo. Ibid., 24: 60.

$1887 \mathrm{~b}$ Catalogue of batrachians and reptiles of Central America and Mexico. Bull. U. S. Nat. Mus., 32: 1-98.

$1887 \mathrm{c}$ Synopsis of the batrachia and reptilia obtained by H. H. Smith, in the Province of Mato Grosso, Brazil. Proc. Amer. Philos. Soc. 24: 44-60.

1893 Prodromus of a new system of the non-venomous snakes. Amer. Nat., 27: 477-83.

1895 The classification of the Ophidia. Trans. Amer. Philos. Soc., 18: 186-219, 20 pls.

1899 Contributions to the herpetology of New Grenada and Argentina, with description of new forms. Phila. Mus. Sci. Bull., 1: 1-22, 4 pls.

1900 The crocodilian, lizards and snakes of North America. Ann. Rept. U. S. Nat. Mus., 1898 (1900): 151-1294.

Cranwell, Jorge A.

1943 Para la herpetologia de Misiones. Rev. Argentina Zoog., 3 (1-2): 65-66.

Daniel, Hermano

1939 Apuntes Ofiologicos. Rev. Acad. Col. Cienc. Exact., Fis. y Nat., 2 (8): 594$98,1 \mathrm{pl}$.

1949 Los serpientes en Colombia. Rev. Fac. nacion. Agron. Medellin, 10 (36): 301-33. Dowling, Herndon G.

$1951 a$ A proposed method of expressing scale reductions in snakes. Copeia, No. 2: 131-34.

$1951 b$ A proposed standard system of counting ventrals in snakes. Brit. Journ. Herpetol., 1 (5): 97-99.

Duméril, Andre M. C.

1853 Prodrome de la classification des reptiles ophidiens. Mem. l'Acad. Sci., 23: $399-536,2$ pls.

Duméril, Andre M. C., G. Bibron, and A. Duméril

1854 Erpétologie général ou histoire naturelle complète des reptiles. Paris. Vol. 7 (Pts. 1-2): 1-1536.

Dunn, Emmett Reid

1923 Some snakes from Northwestern Peru. Proc. Biol. Soc. Wash., 36: 185-88.

1928 A tentative key and arrangement of the American genera of Colubridae. Bull. Antivenin Inst. Amer., 2 (1): 18-24.

1933 A new snake from Panama. Copeia, No. 4: 193-94.

1940 New and noteworthy herpetological material from Panama. Proc. Acad. Nat. Sci. Phila., 92: 105-22.

1942 New or noteworthy snakes from Panama. Notulae Nat., No. 108: 1-8.

1946 A small herpetological collection from eastern Peru. Proc. Biol. Soc. Wash., 59: 17-19.

1947 Snakes of the Lérida Farm (Chiriqui Volcano, Western Panamá). Copeia, No. 3: 153-57.

1952 The status of the snake genera Dipsas and Sibon, a problem for "Quantum Evolution, 5, 1951 (1952): 355-59.

Dunn, Emmett Reid, and Joseph R. Bailey

1939 Snakes from the uplands of the Canal Zone and of Darien. Bull. Mus. Comp.

Fischer, J. G. Zool., 86 (1): 1-22.

1879 Neue oder wenig bekannte Reptilien, Verh. Naturw. Ver. Hamburg, Ser. 2, 3: $76-102,5$ pls.

1885 Herpetologische Bemerkungen. Jahrb. Wiss. Anst. Hamburg, 2: 82-119, 2 pls. Fitzinger, Leopoldo J. F. J.

1826 Neue Classification der Reptilien nach ihren natürlichen Verwandtschaften. Vienna. Pp. i-viii $+1-66$. 
1843 Systema reptilium. Vol. 1. Vienna. Pp. i-xi $+1-106$.

Gans, Carl

1952 The functional morphology of the egg-eating adaptations in the snake genus Dasypeltis. Zoologica, 37 (4): 209-44, 4 pls.

Gloyd, Howard K.

1940 The rattlesnakes, genera Sistrurus and Crotalus. A study in zoogeography and evolution. Chicago Acad. Sci. Spec. Publ., 4: i-vii +1-270, 31 pls.

Gomes. J. Florencio

1918 Contribucao para o conhecimento dos ophidios do Brazil. II. Ophidios do Museu Rocha (Ceará). Rev. Mus. Paulista, 10: 503-27.

\section{Gray, John}

1825 A synopsis of the genera of reptiles and amphibia, with a description of some new species. Ann. Philos., New Ser., 10: 193-217.

\section{Griffin, Lawrence E.}

1915 A catalog of the ophidia from South America at present (June, 1916) contained in the Carnegie Museum with descriptions of some new species. Mem. Carnegie Mus., 7 (3): 163-229.

Günther, Albert

1858 Catalogue of the colubrine snakes in the collection of the British Museum. London: British Museum (Natural History). Pp. i-xvi +1-281.

1864 The reptiles of British India. Ray Soc. Publ., No. 35. Pp. i-xxvii +1-452, 26 pls.

1872 Seventh account of new species of snakes in the collection of the British Museum. Ann. Mag. Nat. Hist., Ser. 4, 9: 15-37.

1885-1902 Biologia Centrali-Americana. Reptilia and batrachia. London. Pp. i-xx +1-326, 76 pls.

Haas, G.

1931 Über die Morphologie der Kiefermuskalatur und die Schadelmechanik einiger

Schlangen. Zool. Jahrb. (Anat.), 54: 333-416.

1938 A note on the origin of solenoglyph snakes. Copeia, No. 2: 73-78.

Hoge, A. R.

1950 Notas Erpetológicas 7. Fauna erpetológica da Tha da Queimada Grande. Mem. Inst. Butantan, 22: 151-72.

Thering, von, Rodolpho

1910 As Cobras do Brazil. Rev. Mus. Paulista, 8: 273-379.

Jan, Georges

1863 Elenco sistematico degli ofidi, descritti e disegnati per l'iconografia generale. Milan: Lombardi. Pp. i-vii + 1-143.

Jan, Georges, and Ferdinand Sordelli

1860 - Iconographie general des ophidiens. Milan and Paris. Pp. 100 (in 2 vols.), Atlas 1881 (3 vols.).

Jensen, Adolf $\mathrm{S}$.

1900 Lagoa Santa Egnens Slanger. Et Bidrag til det indre Brasiliens Herpetologi. Vid. Meddel. Naturhist. for Kjob., pp. 99-111.

Jijon y Caamano, J.

1943 Mapa de las zonal bioticas del Ecuador, accompanying El Ecuador Interandino y Occidental antes de la Conquista Castellana, Part 1. Quito, Ecuador. Vol. 3., Map 1 .

Koslowsky, Julio

1898a Enumeracion sistematica y distribucion geografica de los reptiles Argentinos.

Rev. Mus. La Plata, 8: 161-200, 7 pls.

$1898 b$ Ofidios de Matto-Grosso (Brasil). Ibid., 8: 25-32.

Lacépède, Bernard G. E. (le Comte de)

1789 Histoire naturelle des quadrupedes ovipares et des serpens. Paris. Vol. 2, pp. i-xx + 1-527, 22 pls.

Lampe, Eduard

1902 Catalog der reptilien- und amphibien-sammlung (Schlangen; frosch-, schwanzund schleichenlurche) des Naturhistorischen Museums zu Wiesbaden. Jahrb. Nassauischen Ver. Naturk., 55: 1-66. 
Laurent, Raymond

1949 Notes sur quelques reptiles appartenant a la collection de l'Institut Royal des Sciences Naturelles de Belgique. III.-Formes américaines. Bull. Inst. roy. Sci. nat. Belg., 25 (9): 1-20.

Laurenti, Josephi Nichlai

1768 Specimen medicum, exhibens synopsin reptilium emendatum cum experimentis circa venena et antidota reptilium Austriacorum. Vienna: Joan Thom. Pp. 1214,5 pls.

Linnaeus, Carolus

1754 Museum S. R. M. Adolphi Friderici Regis... in quo Animalium rariora imprimis, ex exotica ... describuntur .... H. M. Adolf Frederiks ... Naturaliae Samling, etc. (fol. Holmiae.) Pp. i-xxx $+1-96,33$ pls.

1758 Systema naturae per regna tria naturae, secundum classes, ordines, genera, species cum characteribus, differentiis, synonymis, locis. 10th ed.; Stockholm, Vol. 1. Pp. i-ii $+1-824$.

Lönnberg, Einar

1902 On a collection of snakes from north-western Argentina and Bolivia containing new species. Ann. Mag. Nat. Hist., Ser. 7, 10: 457-62.

Lubosch, W.

1933 Untersuchungen über die Visceralmuskulatur der Sauropsiden. (Der Untersuchungen über die Kaumuskulatur der Wirbeltiere 3. Teil). Jahrb. Morph. und Mikros. Anat., 72 (4): 584-666.

Mahendra, Beni C.

1938 Some remarks on the phylogeny of the Ophidia. Anat. Anz., 86: 321-68.

Maria, Bro. Nicéforo

1942 Los ofidios de Colombia. Rev. Acad. Colombiana Cienc. Exactas, Fis. y Nat., 5: 84-101.

Mello-Leitão, Candido de

1942 Los alacranes y la Zoogeografia de Sudamerica. Rev. Argentina Zoog., 2 (3): 125-31, 2 pls.

Mertens, Robert

1952a On snail-eating snakes. Copeia, No. 4: 279.

$1952 b$ Die Amphibien und Reptilien von El Salvador, auf Grund der Reisen von R. Mertens und A. Zilch. Abhand. Senckenb. Naturf. Gesell., 487: 1-120, 16 pls.

Mocquard, F.

1908 Reptiles. In: Duméril et Bocourt Mission scientific au Mexique et dans l'Amérique Central, Pt. 3. Vol. 2. Pp. 863-98, Pls. 70-73.

Müller, F.

1878 Katalog der im Museum und Universitatskabinet zu Basel aufgestellten Amphibien und Reptilien nebst Anmerkungen. Verhand. Naturf. Gesell. Basel, 6: 551-709.

1890 Fumfter Nachtrag zum Katalog der herpetologischen Sammlung des Basler Museums. Ibid., 8: 249-96, Pls. 1-3.

Müller, Lorenz

1923 Neue oder seltene Reptilien und Batrachier der Zoologischen Sammlung des bayrischen Staates. Zool. Anz., 57: 145-56.

1924 Ueber neue oder selten mittel- und südamerikanische Amphibien und Reptilien. Mitt. Zool. Mus. Berlin, 11 (1): 75-93.

Oliver, James A.

1937 Notes on a collection of amphibians and reptiles from the state of Colima, Mexico. Occ. Papers Mus. Zool. Univ. Mich., No. 360: 1-28.

1948 The relationships and zoogeography of the Genus Thalerophis Oliver. Bull. Amer. Mus. Nat. Hist., 92 (4): 161-280.

Oppel, Mich.

1810 Suite du Ier. Memoire sur la classification des reptiles. Ann. Mus. d'Hist. Nat. , Paris, 16: 376-95.

Ortenburger, Arthur I.

1928 The whip snakes and racers: Genera Masticophis and Coluber. Mem. Univ. Mich. Mus., 1: 1-247. 
Parker, H. W.

1926 Description of a new snake from Trinidad. Ann. Mag. Nat. Hist., Ser. 9, 18: 205-07.

1934 Reptiles and Amphibians from Southern Ecuador. Ibid., Ser. 10, 14: 264-73.

1935 The frogs, lizards and snakes of British Guiana. Proc. Zool. Soc. London, pp. 505-30.

Peracca, M. G.

1895 Viaggio dell dott. Alfredo Borelli nelle Repubblica Argentina e nel Paraguay. Rettili et Amphibi. Boll. Mus. Zool. Torino, 10 (195): 1-32.

1897 Viaggio dell Dott. Alfredo Borelli nel Chaco boliviano e nella Repubblica Argentina II. Rettili et Anfibi. Ibid., 12 (274): 1-19.

$1904 a$ Viaggio del Dr. Enrico Festa nell 'Ecuador e regioni vicine. Ibid., 19 (465): 1-41.

$1904 b$ Viaggio del Dr. A. Borelli nel Matto Grosso brasiliano e nel Paraguay, 1899. Ibid., 19 (460): 1-15.

Peters, James A.

1955 Herpetological type localities in Ecuador. Rev. Ecuator. de Entom. y Parasit., $2(3-4)$ : $335-52$.

1956 An analysis of variation in a South American snake, Catesby's snailsuicker (Dipsas catesbyi Sentzen). Amer. Mus. Novit., No. 1783: 1-41.

1957 A New Snake of the Genus Sibon from Ecuador. Copeia, No. 2: 109-11.

Peters, W.

1871 Mittheilung über eine von Hrn. Dr. Robert Abendroth in dem Hochlande von Peru gemachte Sammlung von Amphibien. Monats. Akad. Wiss. Berlin, pp. 398-404.

Prado, Alcides

$1940 a$ Notas Ofiologicas. 5. Observacoes sobre serpentes de Colombia. Mem. Inst. Butantan, 14: 1-11.

$1940 b$ Notas ofiologicas 6 . Uma nova especie de Colubrideo aglifo da Colombia. Ibid., pp. 13-15.

1941 Algumas serpentes Colombianas, com a descricao de uma nove especie do genero Dipsas. Ciencia $2(10-12): 345$.

Prado, Alcides, and Alphonse R. Hoge

1947 Observacoes sobre serpentes do Peru, com a descriçao de uma nova especie. Ciencia, 8 (6-9): 180, 1 fig.

Rendahl, Hjalmar, and Greta Vestergren

1941 Notes on Colombian snakes. Ark. Zool., 33A (1): 1-16.

Rosén, Nils

1905 List of the snakes in the zoological museums of Lund and Malmö, with description of new species and a new genus. Ann. Mag. Nat. Hist., Ser. 7, 15: 168-81.

Ruthven, Alexander G.

1908 Variations and genetic relationships of the garter-snakes. Bull. U. S. Nat. Mus., 61: 1-201.

1922 The amphibians and reptiles of the Sierra Nevada de Santa Marta, Colombia. Misc. Publ. Univ. Mich. Mus. Zool., No. 8: 1-69.

Sauvage, M. H.-E.

1884 Sur quelques Reptiles de la collection du Museum d'histoire naturelle. Bull. Soc. Philomet. Paris, (7) 8: 142-147.

Schinz, H. R.

1822 In: Cuvier, Das Thierreich, 2: 117 (not seen).

Schlegel, H.

1837 Essai sur la physionomie des serpens. Amsterdam. Vol. 2, pp. 1-606.

Schmidt, Karl P.

1933 Amphibians and reptiles collected by the Smithsonian Biological Survey of the Panama Canal Zone. Smithsonian Misc. Coll., 89 (1): 1-20.

1950 Modes of evolution discernible in the taxonomy of snakes. Evolution, 4 (1): 79-86.

Schmidt, Karl P., and E. Wyllys Andrews

1936 Notes on snakes from Yucatan. Zool. Ser. Field Mus. Nat. Hist., 20 (18): 167-87. 
Schmidt, Karl P., and Robert Inger

1951 Amphibians and reptiles of the Hopkins-Branner Expedition to Brazil. FieldianaZoology, 31 (42): 439-65.

Schmidt, Karl P., and Warren F. Walker

1943 Peruvian snakes from the University of Arequipa. Zool. Ser. Field Mus. Nat. Hist., 24 (26): 279-96.

Seba, A.

1734 Locupletissimi rerum naturalium thesauri accurata descriptio, et iconibus artificiosissimis expressio, per universam physices historiam, Amsterdam. Vol. I. P. 1734.

Sentzen, U. J.

1796 Ophiologische Fragmente No. 6. Beschreibung des Coluber Catesbeji. Meyer's Serié, Pedro Zool. Arch., 2: 66-74

$1915 a$ Notas sobre la erpetología del Paraguay. II. Addenda a los ofidios de la "Fauna Paraguaya" de W. Bertoni. Physis, 1: 581-82.

$1915 \mathrm{~b}$ Suplemento a la fauna erpetológica Argentina. Anales Mus. Nac. Hist. Nat. Buenos Aires, 27: 93-109.

1915 c Notas sobre la erpetología del Paraguay. I. Colección de ofidios del Dr. Fiebrig. Physis, 1: 573-81.

Shaw, George

1802 General zoology or systematic natural history. London. Vol. 3, Pt. 2. Pp. i-viii + 313-615.

Shreve, Benjamin

$1947 a$ On Colombian reptiles and amphibians collected by Dr. R. E. Schultes. Caldasia, 4 (19): 311-16.

$1947 b$ On Venezuelan reptiles and amphibians collected by Dr. H. C. Kugler. Bull. Mus. Comp. Zool., 99 (5): 519-37.

1951 A new snake of the genus Tropidodipsas from Honduras. Copeia, No. 1: 52 .

Smith, Albert G.

1946 Notes on the secondary sex characters of Thamnophis ruthveni. Copeia, No. 2: 106. Smith, Hobart M.

1943 Summary of the collections of snakes and crocodilians made in Mexico under the Walter R. Bacon Traveling Scholarship. Proc. U. S. Nat. Mus., 93 (3169): 393-504.

Smith, Hobart M., and Edward H. Taylor

1945 An annotated checklist and key to the snakes of Mexico. Bull. U. S. Nat. Mus., 187. Pp. i-iv + 1-239.

Steindachner, Franz

1901 Herpetologische und Ichthyologische ergebnisse einer Reise nach Sudamerika. Ann. Akad. Wiss. Wien, pp. 89-148, 5 pls.

1903 Ueber einige neue Reptilien- und Fischarten de Hofmuseums in Wien. Sitzb. Akad. Wien, 112: 15-21.

Stejneger, Leonhard

1909 Description of a new snake from Panama. Proc. U. S. Nat. Mus., 36 (1681): 457-58.

Stuart, Laurence C

1935 A contribution to a knowledge of the herpetology of a portion of the Savanna region of central Peten, Guatemala. Misc. Publ. Mus. Zool. Univ. Mich., No. 29: $1-56,4$ pls.

1941 Studies of neotropical Colubrinae, VIII. A revision of the genus Dryadophis Stuart, 1939. Ibid., No. 49: 1-106, 4 pls.

Taylor, Edward $\mathrm{H}$.

1940 Some Mexican serpents. Univ. Kans. Sci. Bull., 26 (14): 445-87.

1951 A brief review of the snakes of Costa Rica. Ibid., 34 (1): $1-188$.

1954 Further studies on the serpents of Costa Rica. Ibid., 36 (2): 673-801.

Vanzolini, Paulo E.

1948 Notas sôbre os ofídios e lagartos da Cachoeira de Emas, no Município de Pirassununga, Estado de São Paulo. Rev. Brasil. Biol., 8 (3): 377-400. 
1953 On the type locality of some Brazilian reptiles and amphibians collected by H. H. Smith and described by E. D. Cope. Copeia, No. 2: 124-25. Werner, Franz

1896 Beitrage zur Kenntniss der Reptilien und Batrachier von Centralamerika und Chile, sowie einiger seltenerer Schlangenarten. Verh. k. k. zool.-bot. Gesell Wien, pp. 344-65.

1901 Reptilien und Batrachier aus Peru und Bolivien. Abh. und. Ber. d. K. Zool. und Antr.-Ethn. Mus. Dresden, 1900/01, 9 (2): 1-14.

$1909 a$ Neue oder seltene Reptilien des Musee Royal d'Histoire Naturelle de Belgique in Brüssel. Zool. Jahrb., Abt. für Syst., Geog., und Biol., 28: 263-85.

$1909 b$ Ueber neue oder seltene Reptilien des Naturhistorischen Museums in Hamburg. Mitt. Naturh. Mus. Hamburg, 26: 206-44.

1916 Bemerkungen über einige niedere Wirbeltiere der Anden von Kolombien mit Beschreibungen neuer Arten. Zool. Anz., 47 (10): 301-10.

1922 Synopsis der Schlangenfamilien der Amblycephaliden und Viperiden nebst Übersicht über die kleineren Familien und die Colubriden der Acrochordinengruppe. Auf Grund des Boulengerschen Schlangenkatalogs (1893-1896). Arch. fur Naturg., Abt. A, heft 8: 185-244.

1929 Ubersicht der Gattungen und Arten der Schlangen aus der Familie Colubridae. III. Teil (Colubrinae, Mit einem Nachtrag zu den übrigen Familien). Zool. Jahrb., Abt. Syst., 57: 1-196. 


P LATES 


\section{PLATE I}

Color pattern in articulata group. a: Dipsas brevifacies, noar midbody. b: D. gracilis, posterior body. $c:$ D. gracilis, posterior body and anterior tail. d: D. gaigeae, holotype. 


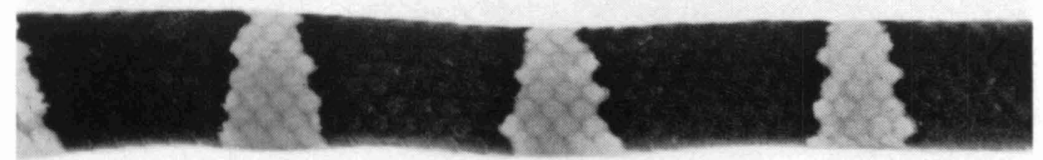

a

UMMZ 73030
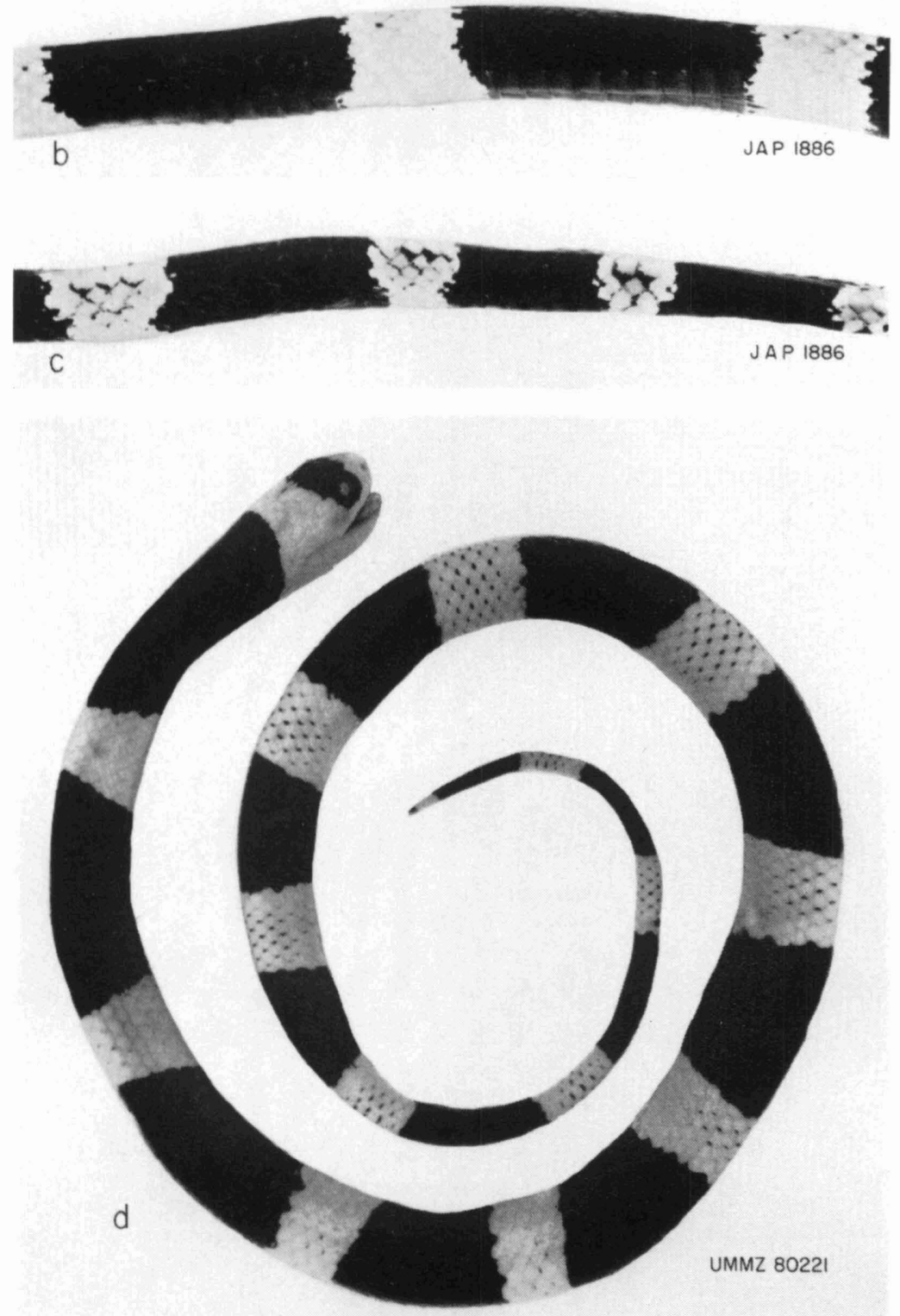
PLATE II

Color pattern in calesbyi group. a: Dipsas calesbyi, near midbody.

$b: D$. vermiculata, new species, head of holotype. $c: D$. vermiculala, holotype. 

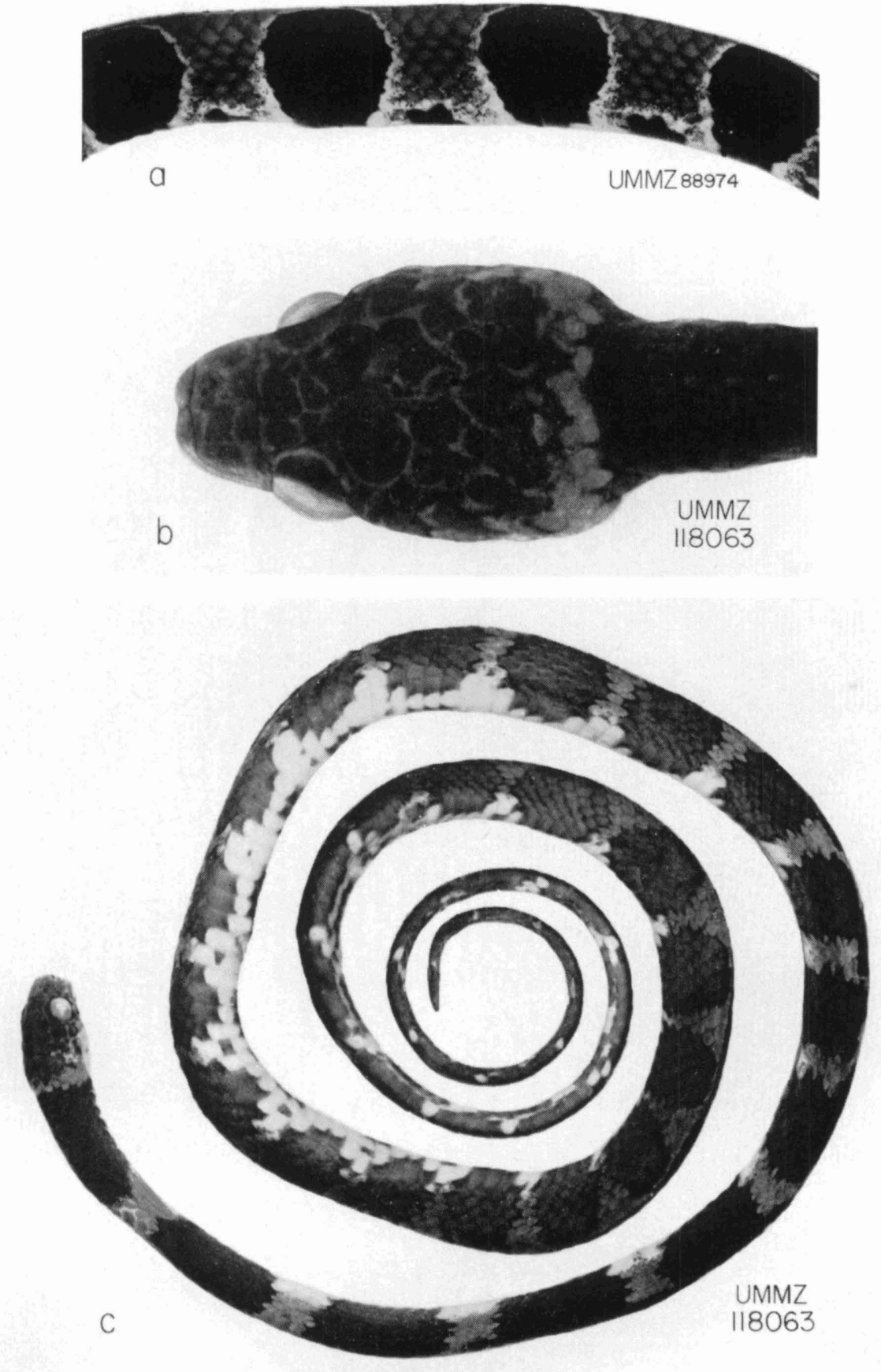
PLATE III

Color pattern in indica group. a: Dipas indica bucephala. b: D. i. cisticeps. $c$ : D. i. ecuadorensis, holotype. $d$ : Dorsal surface of head of ecuadorensis. $e$ : Ventral surface of head of ecuadorensis. 

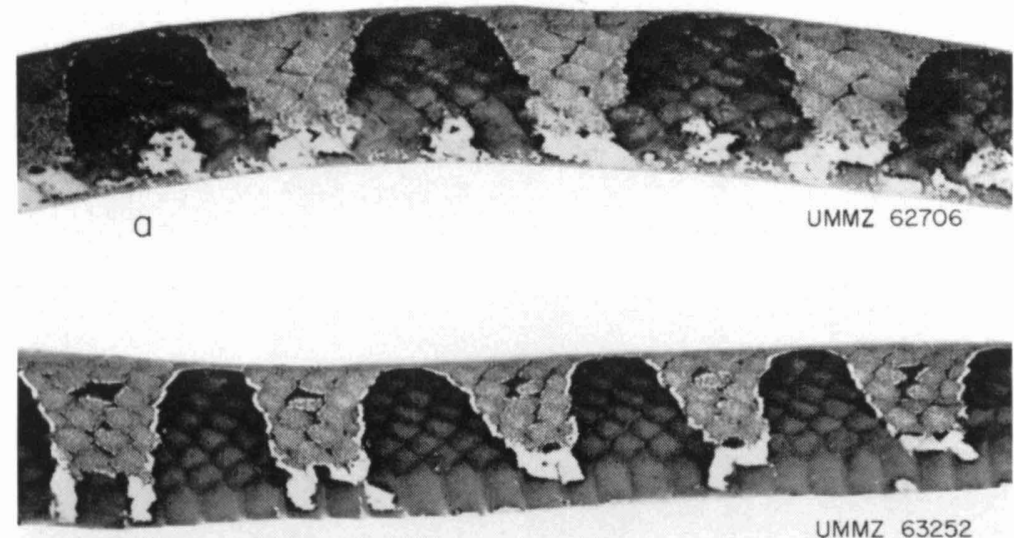

b
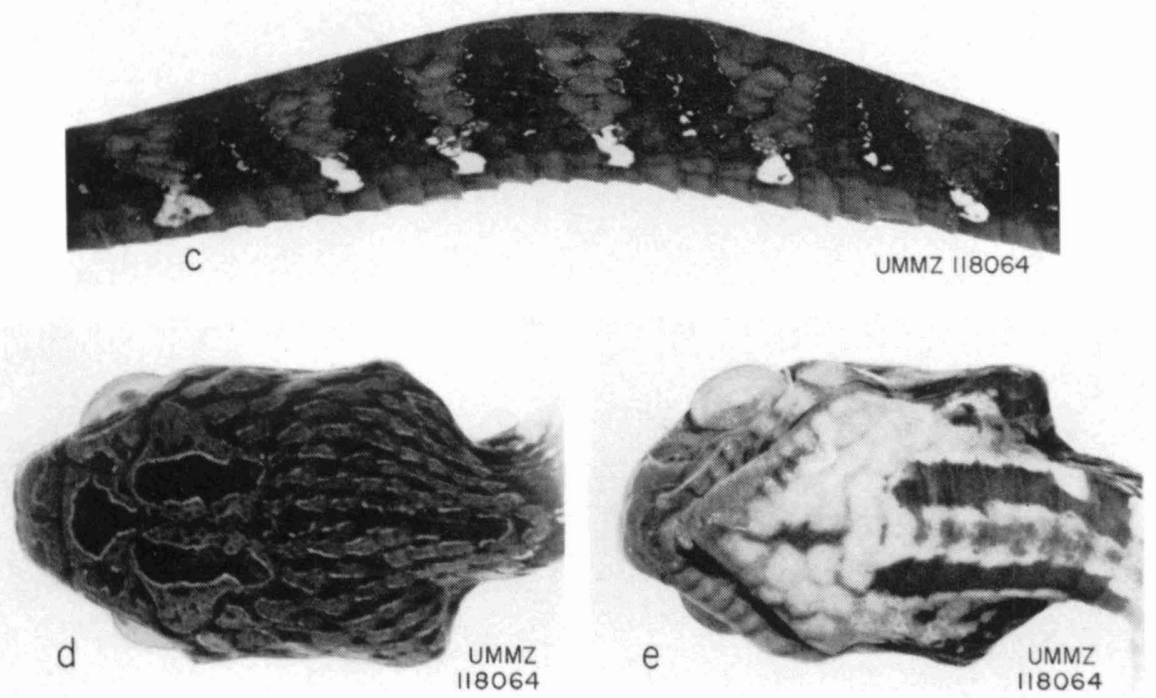
PLATE IV

Color pattern in oreas group. a: Dipsas ellipsifera.

Color pattern in the pratti group. b: D. schunkei. c. D. lalifasciala. d: D. latifrontalis. e: D. schunkei. $f$ : D. Ialifasciala. 

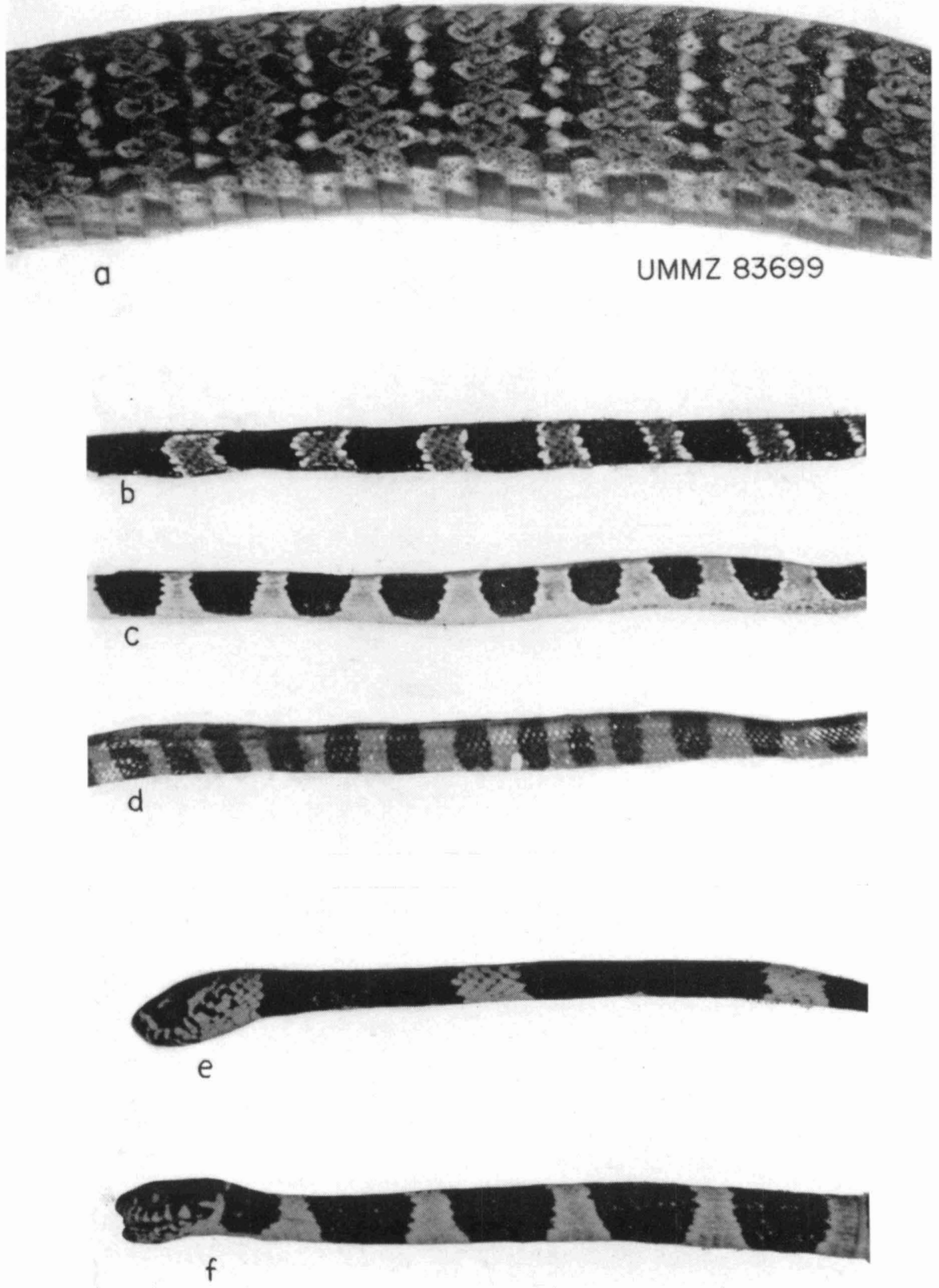


\section{PLATE V}

a: Dipsas peruana, holotype. Lateral view of head. b: $\mathrm{D}$. peruana, holotype.

Color pattern in variegata group. $c: D$. \%. nicholsi. $d: D$. albifrons. e: D. v. variegata. 

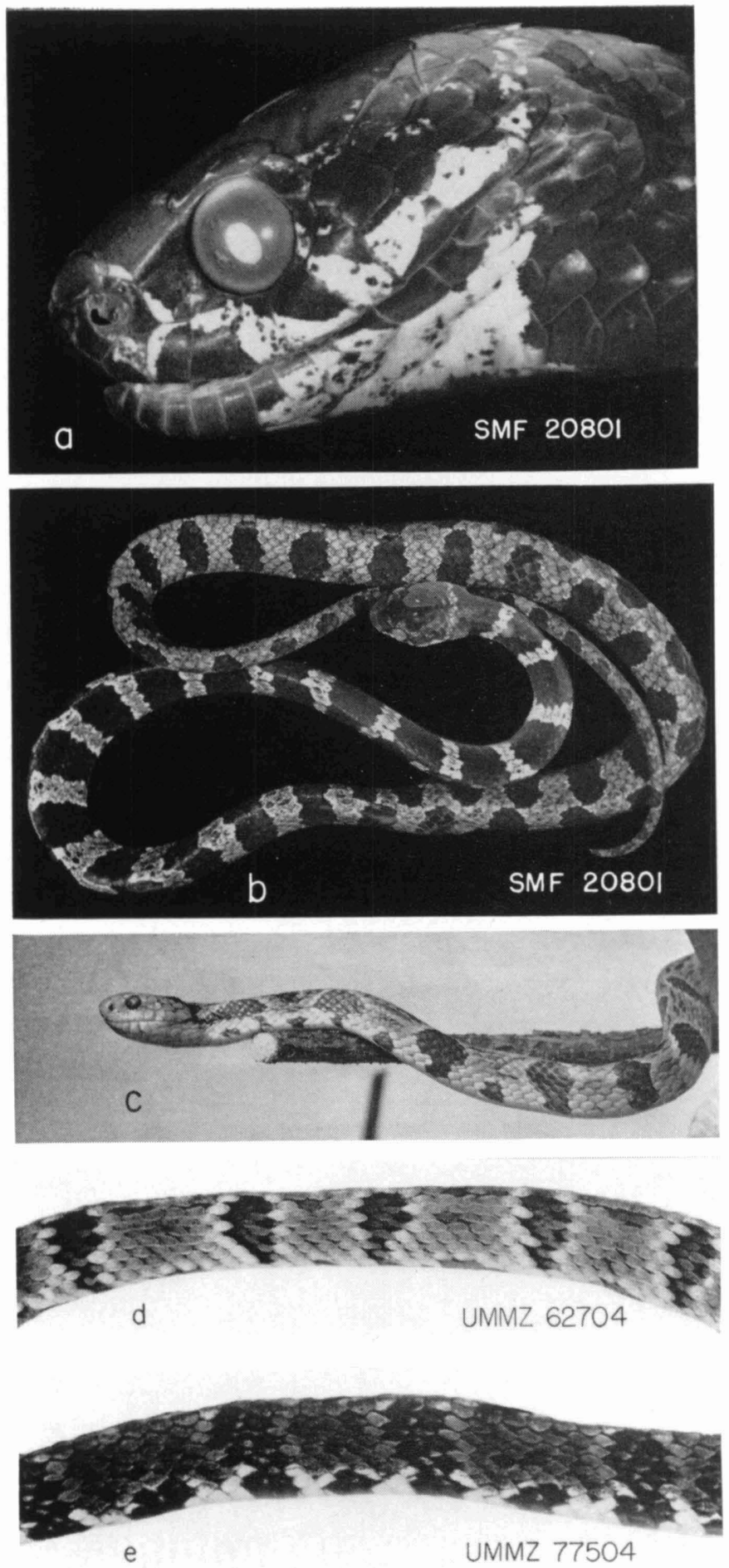


\section{PLATE VI}

Color pattern in Sibynomorphus. a: Sibynomorphus turgidus. b: S. mikani mikani. c: S. m. neuwiedi. d: S. ventrimaculatus. e: S. vagrans, paratype. 

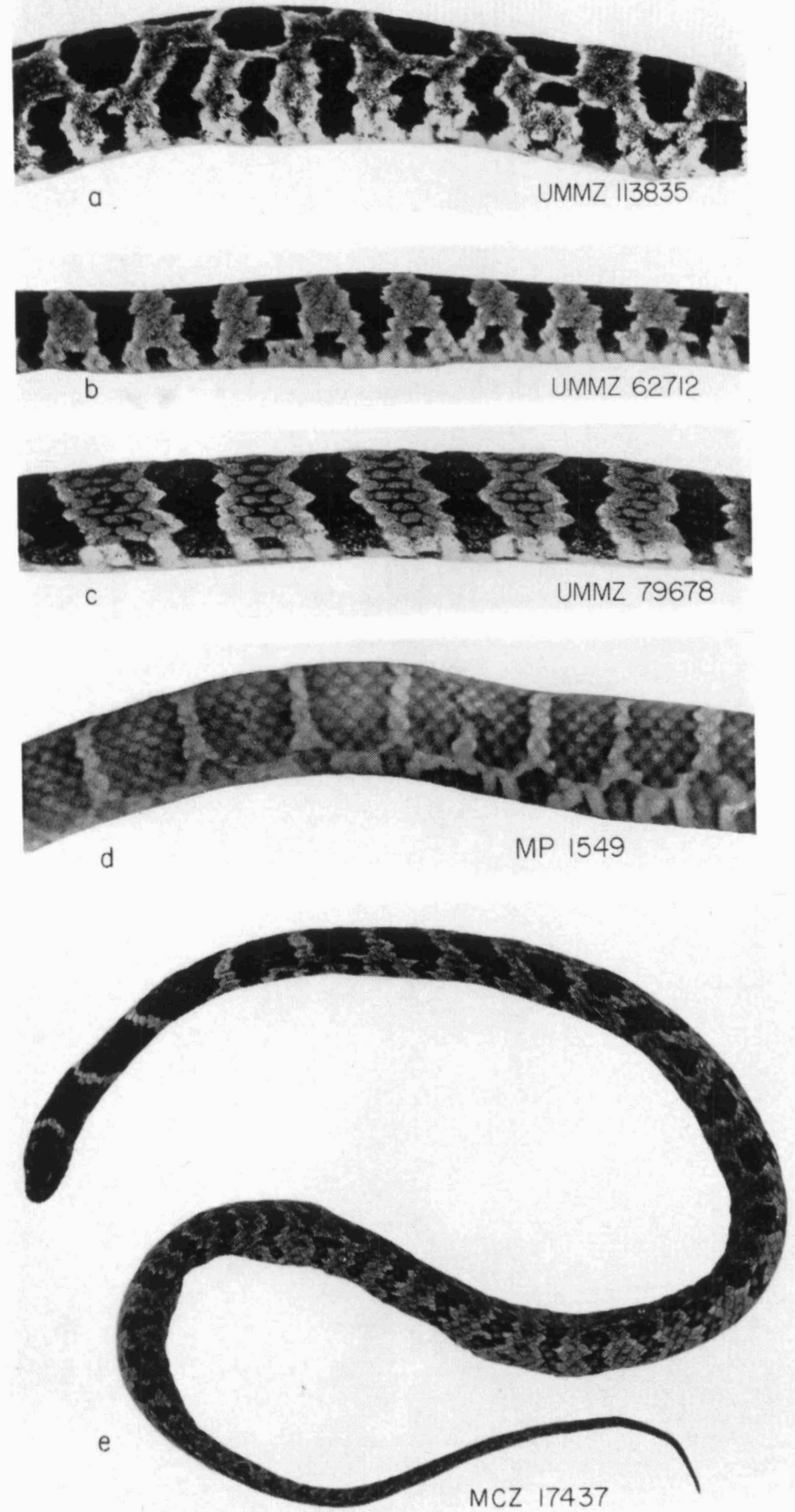


\section{PLATE VII}

Color pattern in annulata group. a: Sibon dimidiata grandoculis. b: s. d. dimidiala. c: S. anthracops, holotype.

Color pattern in nebulala group. d: S. dunni, holotype. 

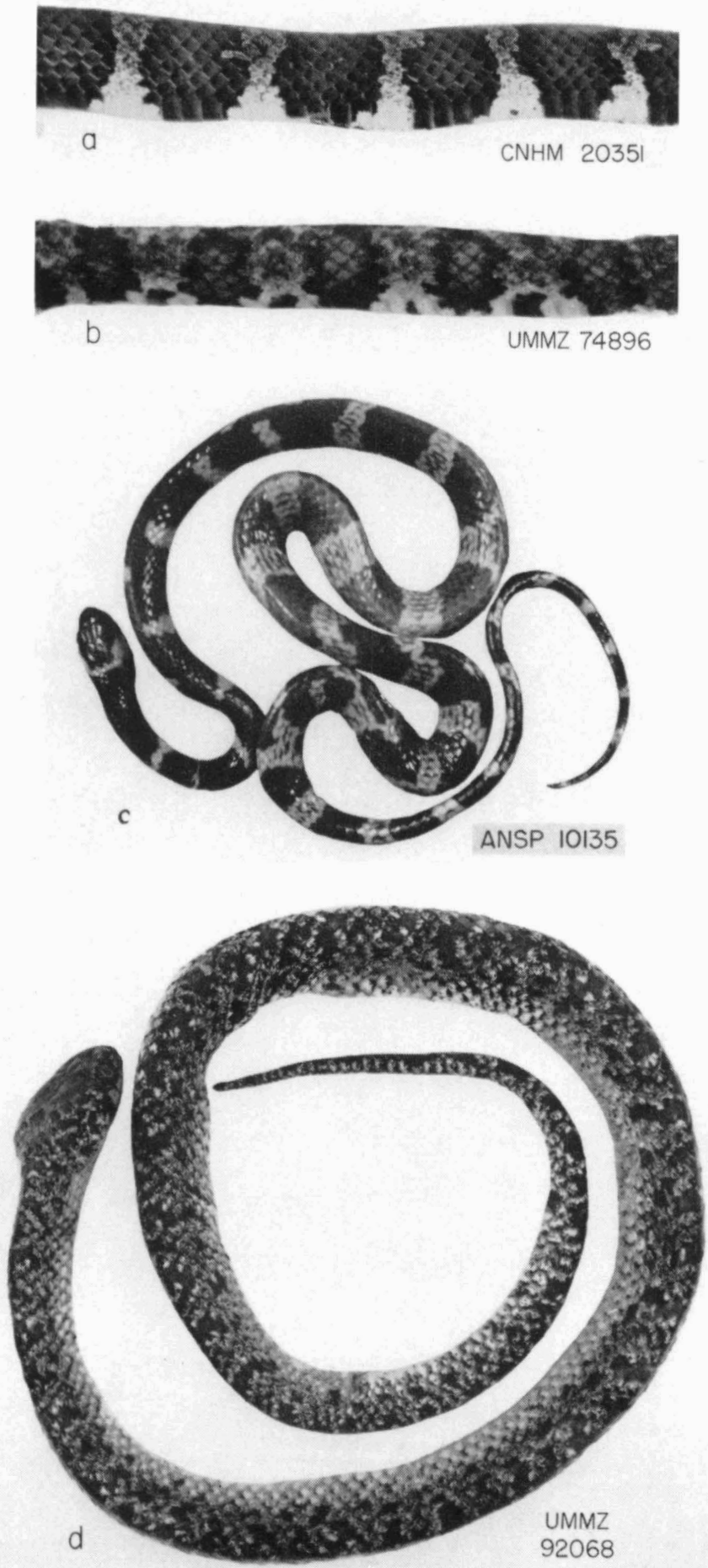


\section{PLATE VIII}

Color patern in nebulata group. a-b: Sibon nebulata popay anensis, holotype. $c: S$. n. leucomelas, holotype. d-e: S. n. harlwegi, holotype. 


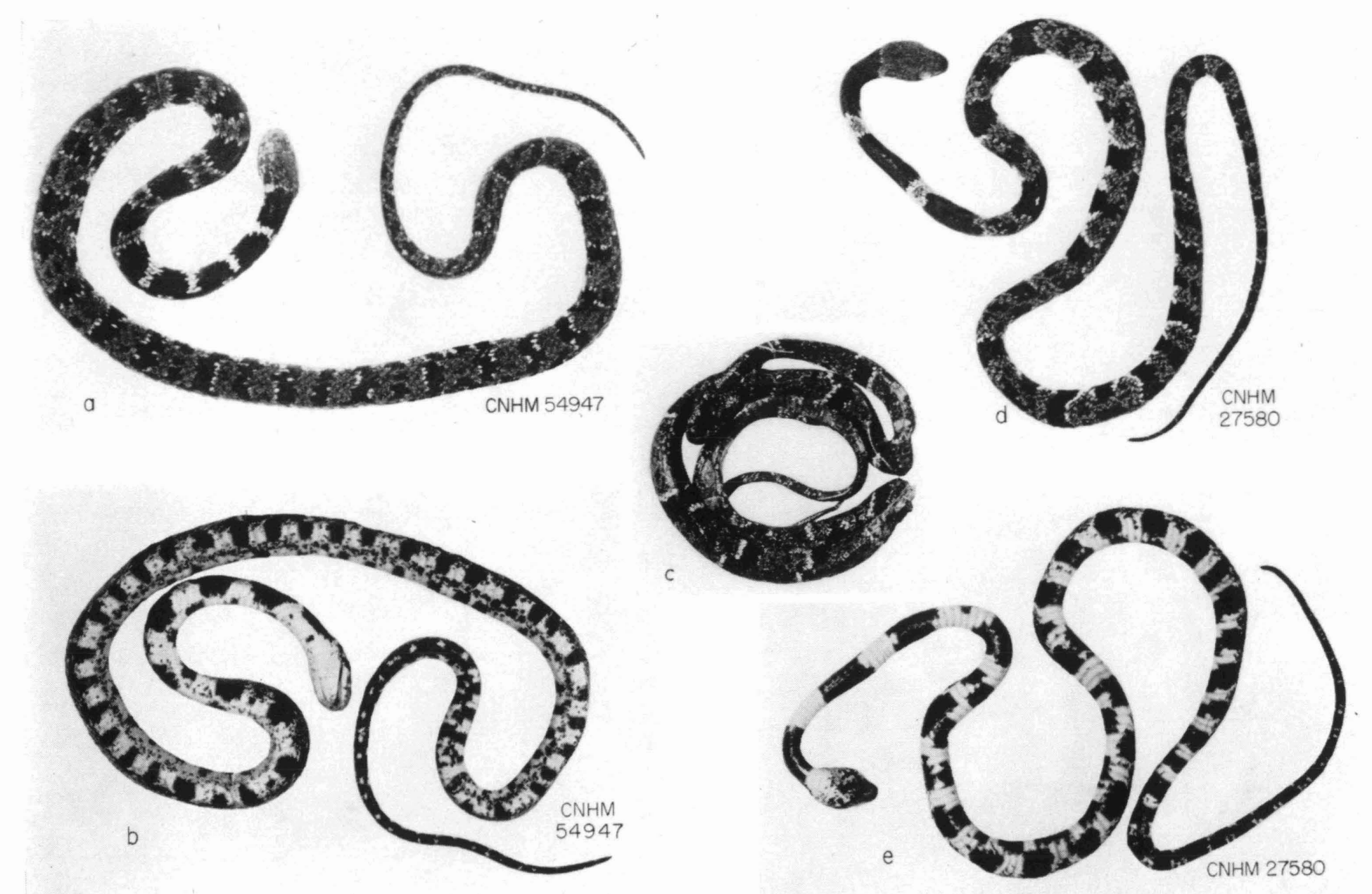




